NEW GENERA AND SPECIES OF MYRTACEAE-FEEDING PHYLINAE FROM AUSTRALIA, AND THE DESCRIPTION OF A NEW SPECIES OF RESTIOPHYLUS (INSECTA: HETEROPTERA: MIRIDAE)

MICHAEL D. SCHWARTZ, CHRISTIANE WEIRAUCH, AND RANDALL T. SCHUH

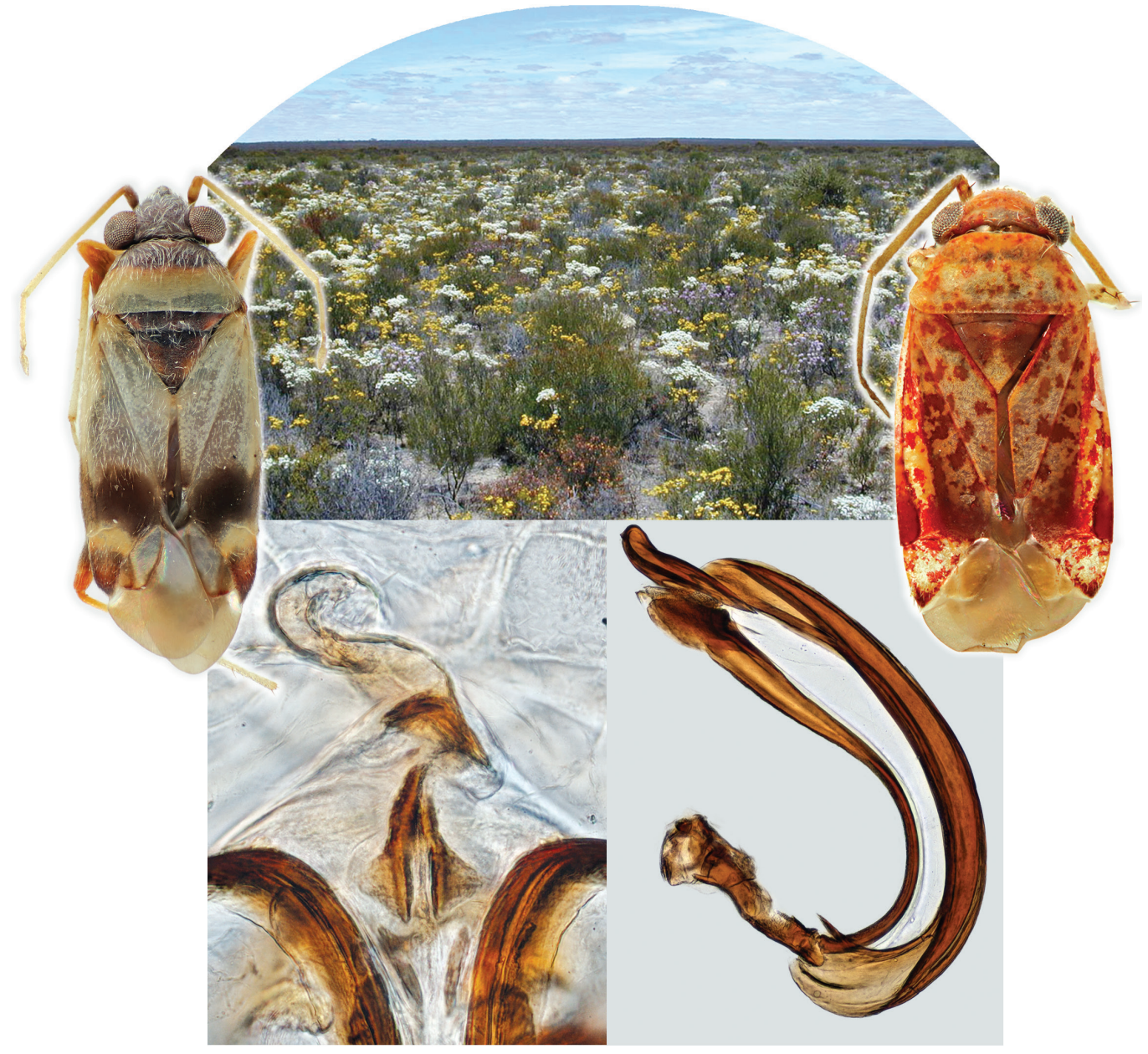

BULLETIN OF THE AMERICAN MUSEUM OF NATURAL HISTORY 


\title{
NEW GENERA AND SPECIES OF MYRTACEAE-FEEDING PHYLINAE FROM AUSTRALIA, AND THE DESCRIPTION OF A NEW SPECIES OF RESTIOPHYLUS (INSECTA: HETEROPTERA: MIRIDAE)
}

\author{
MICHAEL D. SCHWARTZ \\ Division of Invertebrate Zoology \\ American Museum of Natural History
}

\section{CHRISTIANE WEIRAUCH}

Department of Entomology

University of California, Riverside

\author{
RANDALL T. SCHUH \\ Division of Invertebrate Zoology \\ American Museum of Natural History
}

BULLETIN OF THE AMERICAN MUSEUM OF NATURAL HISTORY

Number 424, 157 pp., 22 figures, 41 plates, 6 maps, 5 tables

Issued October 31, 2018 


\section{CONTENTS}

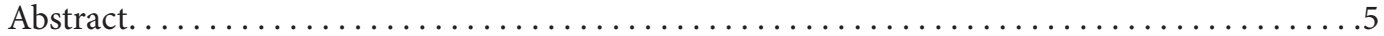

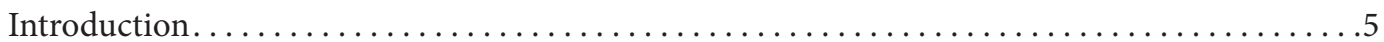

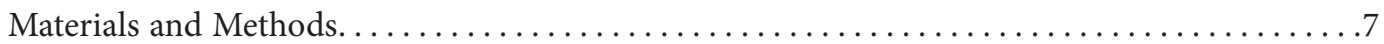

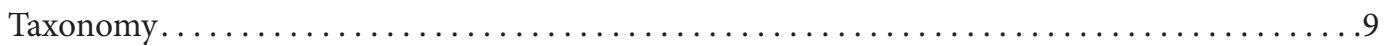

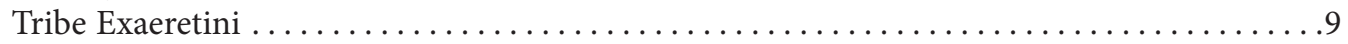

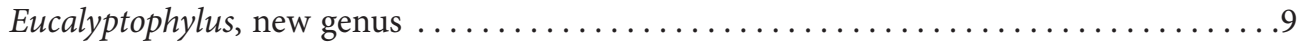

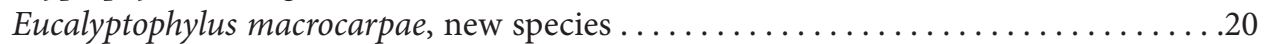

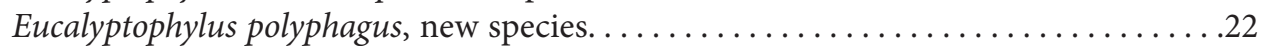

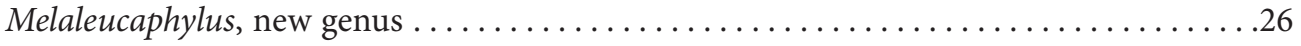

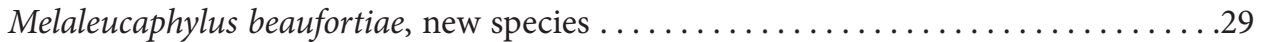

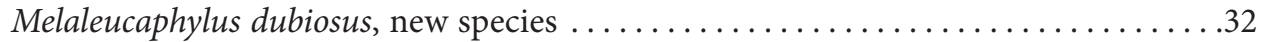

Melaleucaphylus eremaeae, new species............................

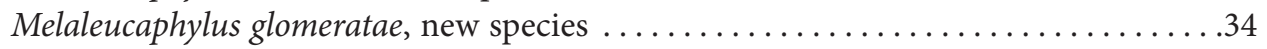

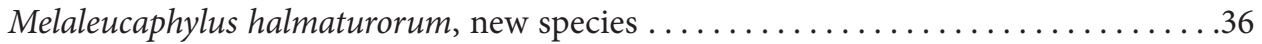

Melaleucaphylus kaputar, new species .............................. 39

Melaleucaphylus kunzeae, new species............................ 40

Melaleucaphylus micranthae, new species . . . . . . . . . . . . . . . . 42

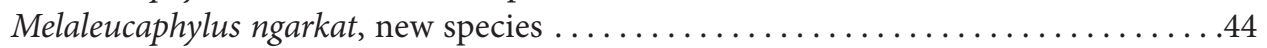

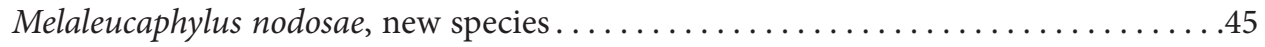

Melaleucaphylus omnivorus, new species...........................

Melaleucaphylus pauperiflorae, new species ....................... 50

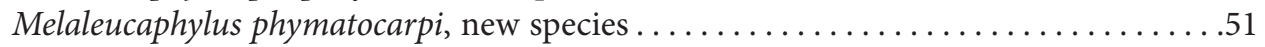

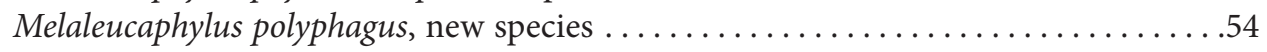

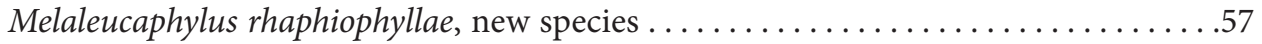

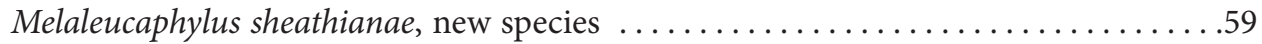

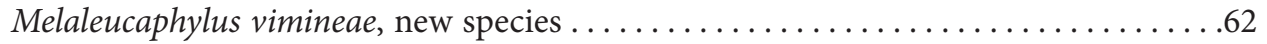

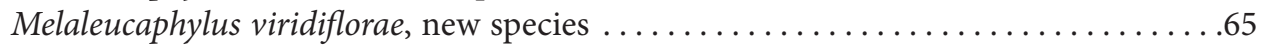

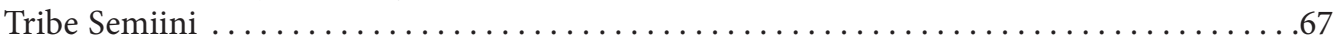

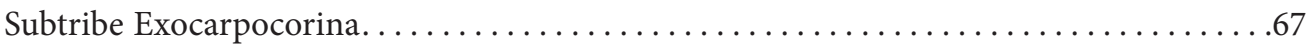

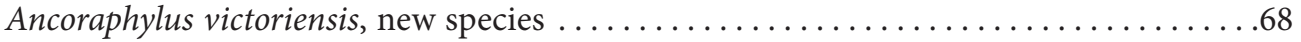

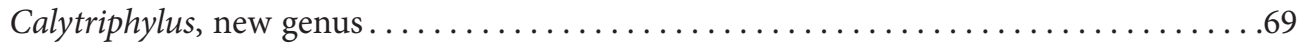

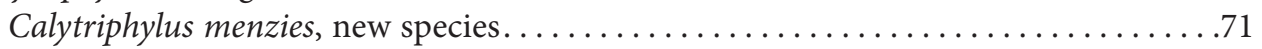

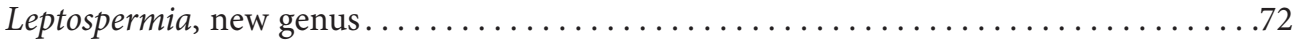

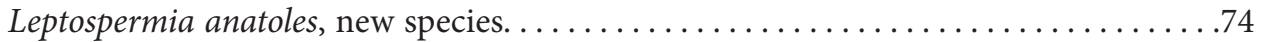

Leptospermia cassisi, new species .............................

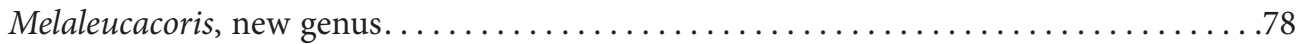

Melaleucacoris glomeratae, new species . . . . . . . . . . . . . . . . 80

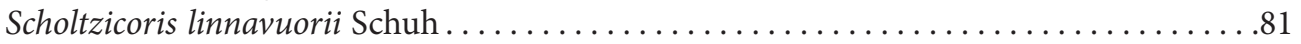

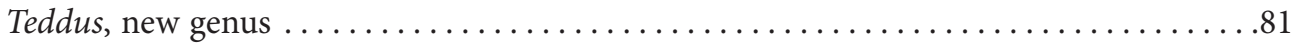

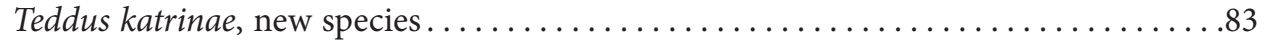

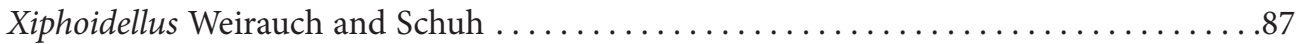

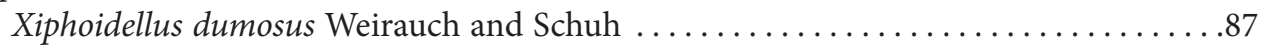




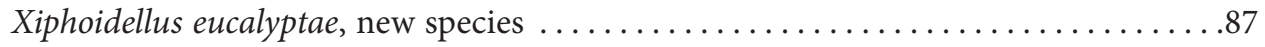

Xiphoides Eyles and Schuh . . . . . . . . . . . . . . . . . . . . . . . . . . . . 90

Xiphoides anangu, new species ................................. 90

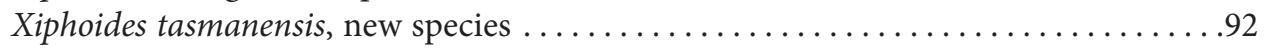

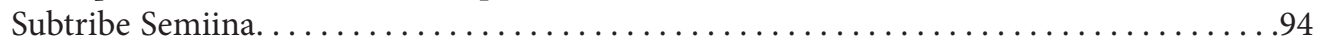

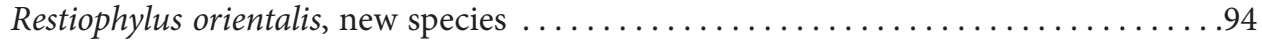

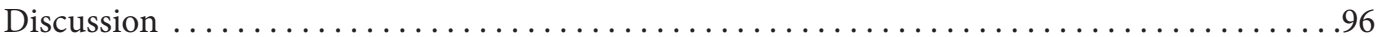

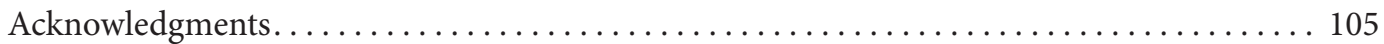

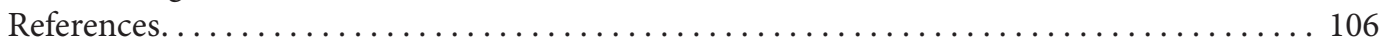

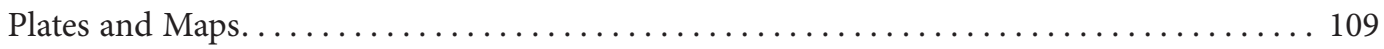





\section{ABSTRACT}

Six new genera of Australian Phylinae are described on the basis of existing collections. The tribe Exaeretini-represented by the two new genera Eucalyptophylus (two new species) and Melaleucaphylus (18 new species) - is recognized for the first time as occurring in Australia. Nine new taxa of Semiini, subtribe Exocarpocorina, are proposed: Four new genera, Calytriphylus, Melaleucacoris, Teddus (each monotypic), and Leptospermia (two new species), and four new species placed in Ancoraphylus Weirauch, 2007 (one species), Xiphoidellus Weirauch and Schuh, 2011 (one species), and Xiphoides Eyles and Schuh, 2003 (two species). Based on specimen data almost all the new taxa are associated with Myrtaceae plant hosts in the tribes Chamelaucieae, Eucalypteae, Leptospermeae, and Melaleuceae. A new species of Restiophylus Leon and Weirauch, 2016, taken in coastal New South Wales and perhaps associated with Leptocarpus tenax (Restionaceae), represents the first record for this genus beyond the southwest coast of Western Australia. Documentation is provided in the form of diagnoses and descriptions of all genera and species, color habitus images of males (and females when available) of all species, distributional maps, color images of male genitalic structures of all species, female genitalic structures in most species, and scanning electron micrographs of representative morphology of some taxa. Host-plant information is provided for most species, along with representative images of hosts and habitats. New distribution records for Xiphoidellus dumosus Weirauch and Schuh, 2011, and scanning micrographs of the pretarsus for Scholtzicoris linnavuorii Schuh, 2016 are provided.

\section{INTRODUCTION}

The Myrtaceae, a mostly tropical plant family that comprises two subfamilies, 17 tribes with about 142 genera, and 5550 species worldwide, are a dominant landscape element in Australia (Wilson et al., 2001; Wilson, 2011). Across tropical and warm-temperate regions of the world many genera contain species of economic importance, including Eucalyptus (lumber), Eugenia (fruit), Psidium (guava), Melaleuca (tea tree oil), Syzygium (cloves), Pimenta (allspice), as well as many ornamentals. The Myrtaceae in Australia are represented by nearly all tribal-level groupings (Wilson, 2011). Nonetheless, most Miridae host records from Australian Myrtaceae come from a limited number of genera, all with capsular-as opposed to fleshy-fruits, belonging to the tribes Chamelaucieae and Melaleuceae (Schuh and Weirauch, 2010; Cheng et al., 2012), the relationships of which can be seen in figure 1 (Wilson et al., 2005).

Schuh and Weirauch (2010) described three new genera and 26 new species of Myrtaceaefeeding Phylinae which belong to the tribe Semiini, subtribe Exocarpocorina; Schuh (2016) described the new genus Scholtzicoris, also placed in the Exocarpocorina, as feeding on the genera Scholtzia and Melaleuca; and Schuh and Schwartz (2016) described three species in the new genus Myrtophylus, which they assigned to the tribe Cremnorrhinini, subtribe Cremnorrhinina. All of those taxa were documented as breeding on members of the tribes Chamelaucieae and Melaleuceae. In the present paper we describe six new genera and 24 new species of Myrtaceae feeders, including taxa documented for the first time to feed on the tribes Eucalypteae and Leptospermeae (fig. 1). We discuss the tribal assignments for each of these phyline taxa.

Among the Myrtaceae-feeding taxa are: two new species in the genus Xiphoides Eyles and Schuh (2003); one new species of Xiphoidellus Weirauch and Schuh (2011); and one new species of Ancoraphylus Weirauch (2007), providing new information on species diversity, distributional ranges, and host associations in each of these groups. We also describe the new genus and species Teddus katrinae, a taxon of unclear host associations, which we assign to the Semiini, Exocarpocorina. We provide scanning micrographs of the pretarsus and color photographs of the female genitalia for Scholtzicoris linnavuorii. Finally, we describe a new species of 


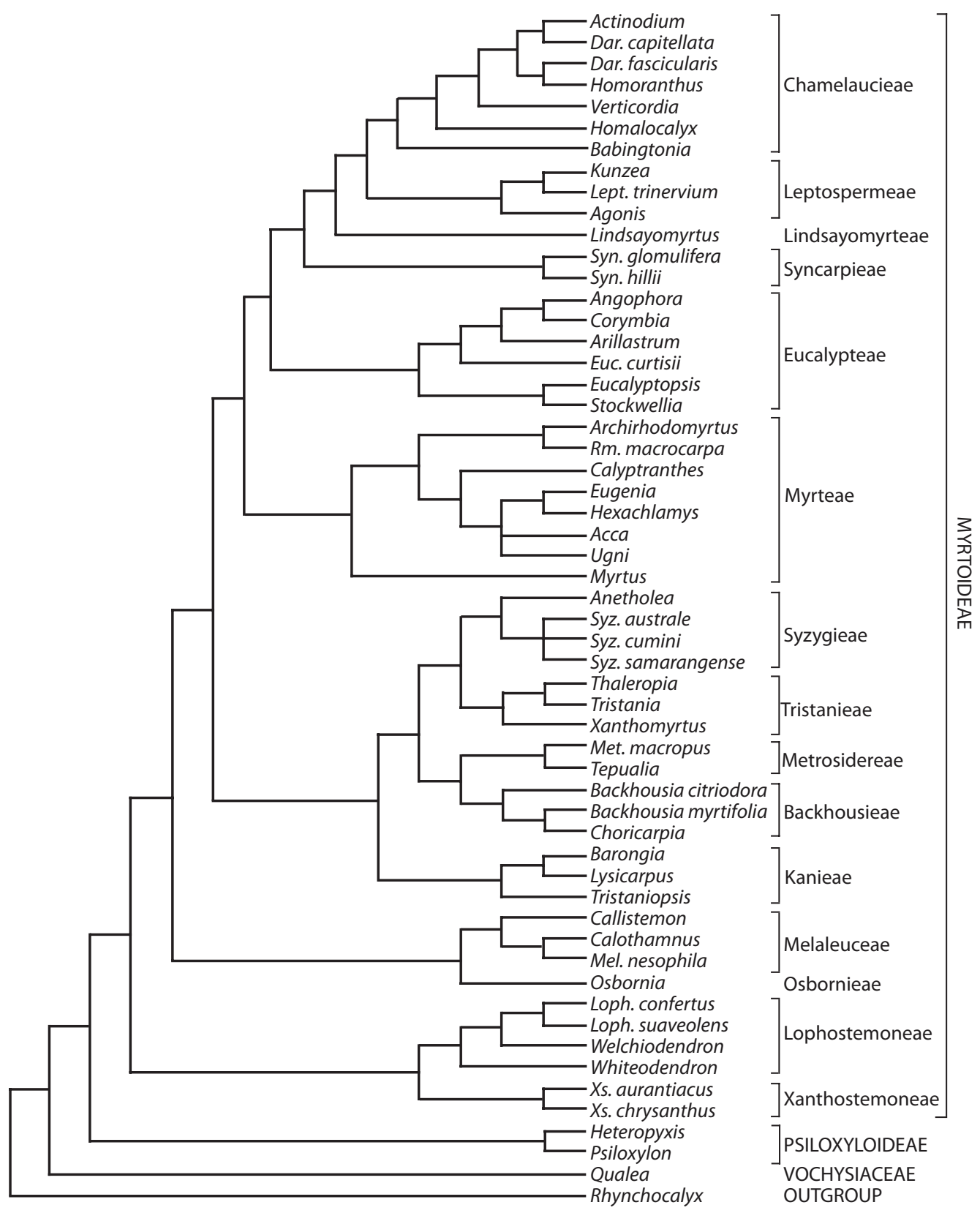

FIG. 1. Relationships within the Myrtaceae (after Wilson et al., 2005). 
Restiophylus Leon and Weirauch (2016), Semiini, Semiina, from coastal Eastern Australia.

Modern revisionary works have placed Australian Phylinae in the following tribes: Cremnorrhinini (Cremnorrhinina) (Schuh and Schwartz, 2016), Semiini (Semiina, Exocarpocorina) (Weirauch, 2007; Schuh and Weirauch, 2010; Weirauch and Schuh, 2011; Leon and Weirauch, 2016; Russell and Weirauch, 2017), Leucophoropterini (Menard and Schuh, 2011), and Pilophorini (Schuh and Menard, 2011), in addition to the widespread genus Campylomma Reuter (Schuh, 1984; Malipatil, 1992; Yasunaga et al., 2015), which was recovered in the Nasocorini by Menard et al. (2013) and Schuh and Menard (2013). For the first time we place members of the Phylinae from Australia in the tribe Exaeretini, on the basis of morphology.

\section{MATERIALS AND METHODS}

Taxa within the present paper are arranged in alphabetical order by tribe, genus, and species. The tribal and generic diagnoses and discussions provide comments on how to distinguish the various taxa. All these elements are based on males, and then compared with females where there are significant differences.

Our male genitalic terminology follows that of Cassis (2008) in the use of the term endosoma rather than vesica as had been the practice in much of the literature on Miridae. Remaining terminology is similar to that used by Schuh (2006) and Weirauch (2007) when referring to the orientation of structural features of the endosoma, parameres, and phallotheca (see figure and plate legends for explanation). Terminology for the bursa copulatrix and genital chamber is adapted from Schuh (2006), Schuh and Pedraza (2010), Schuh and Weirauch (2010), and Schuh and Schwartz (2016). We use the term paracuneus (Knight, 1968: fig. 14), the distal region of the endocorium medial of the cuneal fracture, adjacent to the base of the hemelytral membrane, which frequently has distinctive coloration. The abbreviations of morpho- logical terms included on the scanning electron micrographs (also in the figure legends) and on genitalic color plates are listed below as Anatomical Abbreviations.

Data for the 3421 specimens examined for this study have been captured using the American Museum of Natural History's Arthropod Easy Capture database, which was originally developed with funding from a U.S. National Science Foundation (NSF) Planetary Biodiversity Inventories award for plant bugs, with Randall T. Schuh and Gerasimos Cassis as principal investigators. The database application was further enhanced with funding from an NSF ADBC-TCN award to the American Museum of Natural History. All specimens bear a unique specimen identifier (USI) in the form AMNH_PBI 00123456; this alphanumeric is included on the USI label also in the form of a matrix code. Specimen data can be viewed online (through Discoverlife.org, research.amnh. org/pbi/heteropteraspeciespage/), and through the iDigBio web portal (https://www.idigbio.org/portal). Reference is made in the distribution section of each species treatment to the terrestrial phytogeographic subregions of González-Orozco et al. (2014) and Ebach et al. (2015).

Because USI information for the majority of specimens contains the institutional string AMNH_PBI we have abbreviated the information in the sections on Specimens Examined to just the numerical portion of the USI, except in the cases of holotype specimens where the entire USI is listed and for specimens of Melaleucaphylus viridiflorae with the institutional string UNSW_ENT. The entire USI is listed in the figure and genitalia plate captions.

Habitus images were prepared using a Microptics/Visionary Digital photomicrographic system as developed by Roy Larimer (http://duninc.com). Multiple layers were stacked using Helicon Focus ${ }^{\odot}$ (Kozub et al., 2008) to produce the final high-depth-of-field image. Photographic images of genitalic structures temporarily placed under a coverslip in shallow well-slides containing $85 \%$ lactic acid were taken with a $10 \times$ or $20 \times$ objective lens 
using a Nikon E800 compound microscope, photomicrographic attachment, and software. As many as 50 layers were stacked to produce a composite high-depth-of-field image. Scanning electron micrographs were prepared using Hitachi 4300 and FEI Quanta 600 digital microscopes.

Measurements were prepared using digital micrometers attached to a movable stage, the data being recorded directly to a spreadsheet in the form of calculated distances. All measurement data are in millimeters. The data are presented in summary form in table 1 with the numbers of specimens measured, means, and standard deviations. In the descriptions the length of antennal segment 2 is given as a value and also compared to the width of the head in order to give an indication of both absolute and relative length; these values and calculations are based on the means of the specimen-measurement sample rather than the measurements for a single specimen.

Host data presented in this paper are based on authoritatively identified herbarium-quality plant voucher specimens collected concurrently with insect specimens in the field. Host information is available for $93 \%$ of the collected specimens. Authors of all the plant taxa are provided in a comprehensive list in table 2 and are not included in the text and plate legends. Host-plant associations for the bug species described herein are presented in tables 2 and 3 . The number of insect specimens collected and number of collecting events for each plant species are provided to indicate a measure of confidence in the hostspecificity data (see Weirauch et al., 2017, which provides a rationale for confidence in host associations). Table 2 is organized by plant family (tribe for Myrtaceae) and includes distribution by state or territory; table 3 is organized by plantbug species. Table 4 reports the distribution of each described plant-bug species by phytogeographical subregion (Ebach et al., 2015; see maps for locations of each subregion), state, or territory as well as the number of collection events and specimens. Table 5 lists the shared Myrta- ceae host plants utilized by Melaleucaphylus and Melaleucoides species. Tables 2-5 do not repeat the names of the organizing taxa, so that the limits of specificity per host and bug species can be visualized directly from the table.

\section{Institutional AbBREviations}

Specimens examined during this study came from the following collections or are deposited in them; the institutional abbreviations used in the Specimens Examined sections precede the institutional name and the names of individuals who assisted with the loan of specimens:

AM Australian Museum, Sydney; Gerasimos Cassis, David Britton, and Derek Smith

AMNH American Museum of Natural History, New York; Randall T. Schuh

ANIC Australian National Insect Collection, Canberra; Beth Mantle and Federica Turco

BMNH Natural History Museum, London; Mick Webb

CAS California Academy of Sciences, San Francisco; Christopher C. Grinter

CNC Canadian National Collection of Insects and Arachnids; Robert G. Foottit

MAGNT Museum and Art Galley of the Northern Territory, Darwin; Gavin Dally

MVMA Museums Victoria, Melbourne; Richard Marchant

SAMA South Australian Museum, Adelaide; the late Gordon Gross, Peter Hudson

TMAG Tasmanian Museum and Art Gallery, Hobart; Kirrily Moore

UNSW University of New South Wales, Sydney; Gerasimos Cassis

USNM United States National Museum of Natural History, Smithsonian Institution, Washington, DC; Thomas J. Henry

WAMP Western Australian Museum, Perth; Terry Houston, Nikolai Tatarnic

ZISP Zoological Institute, Russian Academy of Sciences, St. Petersburg; Fedor Konstantinov, Dimitry A. Gapon 


\section{Anatomical Abbreviations}

Terms in Legends of Scanning Electron Micrograph Figures: ap, anterior process; endo, endosoma; lp, left paramere; mttsp, metathoracic spiracle; pe, parempodium; phl, phallotheca; pp, posterior process; pul, pulvillus; rp, right paramere; sgaur, scent gland auricle; sgev, scent gland evaporatory area.

Terms for Female Genitalia in Color Plates: acgl, accessory (vermiform) gland; bsfg, basal sclerite of first gonapophyses; dlp, dorsal labiate plate; gc, genital chamber; irl, interramal lobe; irscl, interramal sclerites (lateral and medial); isstr, intersegmental structure; latov, lateral oviduct; latscl, lateral interramal sclerite; lsclr, left sclerotized ring; mdext, medioventral extension of ventral labiate plate; mdscl, medial interramal sclerite; mppw, midline out-pocket on interramal sclerite of posterior wall; pmr, posteromedial region of dorsal labiate plate; prmdlb, paramedial lobes on posterodorsal portion of posterior wall; pvm, posteroventral margin of dorsal labiate plate; pw, posterior wall; ramfg, ramus of first gonapophysis; rsclr, right sclerotized ring; sclr, sclerotized ring; smrcpt, seminal receptacle; v, vestibulum; vlp, ventral labiate plate; vs, vestibular sclerites.

Terms for Male Genitalic Features in Color Plates: ap, anterior process of left paramere; asdst, apical spine(s) of dorsal strap (anterior ant and posterior pos); asvst, anterior surface of ventral strap; crest, crest, carina, or ridge on surface of phallotheca; desg, distal edge of secondary gonopore; dst, dorsal strap; flg, flange of phallotheca; intrstm, interstrap membrane; ldaps, large discrete apical sclerite of ventral strap; otpk, out-pocket of phallotheca; pesg, proximal edge of secondary gonopore; pp, posterior process of posterior paramere; ppsg, proximal process of secondary gonopore; prong, from subapical surface on posterior surface of ventral strap; psvst, posterior surface or edge of ventral strap; tub, tubercle of phallotheca tusk, from posterior surface of ventral strap; sbaps, subapical spine on posterior surface of ventral strap sg, secondary gonopore; sgs, secondary gonopore sclerite; shldr, shoulder of left paramere; spur, from posterior surface of ventral strap; vst, ventral strap.

\section{TAXONOMY}

\section{Tribe Exaeretini}

Rediagnosis: Claws usually elongate with pulvilli ranging from small to absent; endosoma usually relatively short, stout, twisted, S-shaped, composed of two straps united by a membrane often with serrations, castellations, or spicules and with distinct large, twisted secondary gonopore; sometimes posterior lobe of left paramere elevated; labium relatively long extending past hind coxae; most members with dark or sericeous setae on hemelytron; female gentialia variable, posterior wall usually sclerotized and anterior surface microspiculate, without large anterior projections into genital chamber.

Discussion: We place the following genera in the Exaeretini because the parempodia show inflation to the same degree as observed in the genus Moissonia Reuter, 1894 (see also discussion below under Melaleucaphylus); the endosoma is short, stout, and shows ornamentation on the apical portion of the ventral strap in a comparable position to that seen in Moissonia; and the pulvilli are small and in some taxa the claws are elongate.

Placement of the new genera Eucalyptophylus and Melaleucaphylus in the Exeraetini provides another biogeographical connection for the Australian Phylinae to other continental areas. We call attention in particular to the potential relationship between Australia and tropical Southeast Asia and the Malay Archipelago, which have an extensive Moissonia fauna, as documented by Schuh (1984 [under the generic names Ellenia Reuter and Ragmus Distant]), Yasunaga (2010), and Yasunaga and Duwal (2015).

\section{Eucalyptophylus, new genus}

Type Species: Eucalyptophylus macrocarpae, new species. 
DiAgnosis: Recognized by angulate head and large eyes of both sexes and endosoma of male formed of two distinct straps with sclerotized apical plate of ventral strap subtended by obvious, weakly sclerotized subapical region. Dorsum of one species with bold contrasting markings of dark mahogany and pale gray and predominately uniformly pale gray coloration with dusky orange to brown markings of other included species combined with unique head and endosmal structure is currently unknown in other exaeretine phylines.

Description: Male: Macropterous, total length 2.87-3.50, pronotum width 0.82-0.99. COLORATION (pl. 1): Either practically uniform pale yellow to yellow gray, including all appendages, slightly darker on head, calli, mesoscutum, and apex of endocorium-or dark mahogany with pale gray on posterior lobe of pronotum, clavus, corium proximal of distal angle of clavus, proximal one half of cuneus, and appendages except femora; tibiae without dark spots at spine bases. SURFACE AND VESTITURE: Dorsum weakly rugulose, matte to weakly shining; dorsal vestiture with extensive silvery shining, somewhat sericeous setae and brown sericeous setae or black simple setae over dark colored areas of hemelytron; tibial spines pale. STRUCTURE: Head: Moderately broad, sometimes transverse and separated from, or closely conforming to, anterior margin of pronotum; eyes large, sometimes reaching to buccula in lateral view. Antenna: Segment 2 either thick with length longer than width of pronotum or narrow and length approximately equal to width of pronotum. Labium: Reaching from base of mesocoxa to apex of metacoxa. Thorax: Pronotum: Either subconical or subquadrate, lateral margins nearly straight, calli weakly demarcated, posterior lobe nearly flat, posterior margin straight to weakly excavated; mesoscutum broadly exposed; metathoracic spiracle and scent-gland system typically phyline (figs. 2D, 3D). Pretarsus: Claw small, delicate, gently curved; parempodia straight, setiform; pulvilli present or absent (figs. 2E, 3E). Hemelytron: Costal margin straight, sometimes elongate. GENITALIA (figs. 2F, 3F, pls. 6A-H, 7A-J): Pygophore: Large, broadly conical or cylindrical; ventral posterior region and dorsoanteriad of paramere insertions without tubercles or discrete patches of bristles. Endosoma: Formed by two distinct straps, either C-shaped, sturdy, and apically blunt or sigmoid, narrow and apically pointed; ventral strap with obvious, weakly sclerotized subapical region subtending a sclerotized apical plate of variable size. Secondary gonopore: Subapical with variable size and definition. Phallotheca: Variable. Parameres: Left paramere: Typical phyline shape; posterior region between posterior and anterior processes not produced; length of anterior process subequal to, or about one-half length of, posterior process. Right paramere: Variable.

Female (pl. 1): Coloration and structure similar to male; total length 2.92-3.29, pronotum width $0.76-1.01$. Costal margin slightly more convex than in male; antennal segment 2 more slender and tapering proximally. GENITALIA (pls. 6I, J, 7K-M): Posterior margin of sternite 7: Medially either concave or with posteriorly directed projection. Vestibular sclerites: Small, not projecting beyond anterior edge of dorsal labiate plate. First gonapophyses: Small, basal, quadrate blocks. Ventral labiate plate: Platelike, medial, anteroventral extension variable, covering anterior surface of basal structures. Dorsal labiate plate: Small, variable longitudinally. Sclerotized rings: Medium sized, widely separated, subquadrate, thin walled, medial angle curved. Posteromedial region: Surface without apparent microstructure, sometimes with concentric ribbing. Anterolateral region: Variably projecting anteriad of sclerotized rings. Posterior wall: Variable. Without anteriorly projecting structure. Interramal sclerites: Wellsclerotized, lateral sclerites wedge shaped, medial sclerite obscure.

Eтymology: Named for the occurrence of known species on the genus Eucalyptus, in combination with the generic name Phylus; masculine.

Discussion: The two species included in Eucalyptophylus are divergent in coloration, shape, antennal length, and details of the endo- 
TABLE 1

Measurements of described plant bug taxa

\begin{tabular}{|c|c|c|c|c|c|c|c|c|c|c|c|c|}
\hline \multirow[b]{2}{*}{ Species } & & \multicolumn{6}{|c|}{ Length } & \multicolumn{3}{|c|}{ Width } & \multicolumn{2}{|c|}{ Ratio } \\
\hline & & Body & $\begin{array}{l}\text { Cun- } \\
\text { Clyp }\end{array}$ & Head & Prono & Scut & Cun & Head & Prono & Scut & IntOcDi & AntSeg2 \\
\hline \multicolumn{13}{|c|}{ Eucalyptophylus } \\
\hline \multicolumn{13}{|c|}{ E. macrocarpae } \\
\hline \multirow[t]{5}{*}{$\widehat{\delta}(N=5)$} & Mean & 2.96 & 2.12 & 0.29 & 0.44 & 0.38 & 0.44 & 0.76 & 0.94 & 0.49 & 0.33 & 0.95 \\
\hline & SD & 0.09 & 0.08 & 0.04 & 0.02 & 0.02 & 0.01 & 0.01 & 0.02 & 0.01 & 0.01 & 0.03 \\
\hline & Range & 0.22 & 0.19 & 0.11 & 0.06 & 0.03 & 0.02 & 0.03 & 0.04 & 0.03 & 0.03 & 0.08 \\
\hline & Min & 2.87 & 2.02 & 0.23 & 0.41 & 0.36 & 0.44 & 0.75 & 0.93 & 0.47 & 0.32 & 0.93 \\
\hline & Max & 3.08 & 2.21 & 0.34 & 0.46 & 0.40 & 0.45 & 0.78 & 0.96 & 0.50 & 0.35 & 1.00 \\
\hline \multirow[t]{5}{*}{$q(N=5)$} & Mean & 3.01 & 2.16 & 0.31 & 0.44 & 0.39 & 0.44 & 0.77 & 0.96 & 0.50 & 0.35 & 0.92 \\
\hline & $\mathrm{SD}$ & 0.06 & 0.02 & 0.02 & 0.02 & 0.00 & 0.03 & 0.01 & 0.03 & 0.01 & 0.01 & 0.02 \\
\hline & Range & 0.16 & 0.05 & 0.06 & 0.05 & 0.01 & 0.08 & 0.02 & 0.09 & 0.03 & 0.02 & 0.04 \\
\hline & Min & 2.92 & 2.15 & 0.28 & 0.41 & 0.38 & 0.39 & 0.76 & 0.92 & 0.48 & 0.34 & 0.91 \\
\hline & Max & 3.07 & 2.20 & 0.34 & 0.46 & 0.39 & 0.48 & 0.78 & 1.00 & 0.51 & 0.37 & 0.95 \\
\hline \multicolumn{13}{|c|}{ E. polyphagus } \\
\hline \multirow[t]{5}{*}{$\widehat{o}(N=5)$} & Mean & 3.36 & 2.28 & 0.26 & 0.39 & 0.41 & 0.54 & 0.71 & 0.92 & 0.46 & 0.25 & 1.05 \\
\hline & $\mathrm{SD}$ & 0.18 & 0.14 & 0.03 & 0.02 & 0.03 & 0.02 & 0.03 & 0.07 & 0.03 & 0.01 & 0.02 \\
\hline & Range & 0.44 & 0.36 & 0.07 & 0.04 & 0.08 & 0.05 & 0.08 & 0.18 & 0.09 & 0.01 & 0.05 \\
\hline & Min & 3.06 & 2.05 & 0.23 & 0.37 & 0.37 & 0.52 & 0.66 & 0.82 & 0.42 & 0.24 & 1.04 \\
\hline & Max & 3.50 & 2.42 & 0.29 & 0.41 & 0.44 & 0.56 & 0.74 & 0.99 & 0.51 & 0.26 & 1.09 \\
\hline \multirow[t]{5}{*}{$q(N=5)$} & Mean & 3.16 & 2.23 & 0.28 & 0.39 & 0.39 & 0.49 & 0.69 & 0.93 & 0.47 & 0.30 & 0.95 \\
\hline & SD & 0.11 & 0.13 & 0.04 & 0.01 & 0.03 & 0.01 & 0.03 & 0.10 & 0.05 & 0.01 & 0.03 \\
\hline & Range & 0.24 & 0.30 & 0.09 & 0.03 & 0.09 & 0.04 & 0.08 & 0.26 & 0.12 & 0.03 & 0.08 \\
\hline & Min & 3.05 & 2.07 & 0.24 & 0.38 & 0.34 & 0.47 & 0.63 & 0.76 & 0.39 & 0.28 & 0.91 \\
\hline & $\operatorname{Max}$ & 3.29 & 2.37 & 0.33 & 0.40 & 0.43 & 0.50 & 0.71 & 1.01 & 0.51 & 0.32 & 0.99 \\
\hline \multicolumn{13}{|c|}{ Melaleucaphylus } \\
\hline \multicolumn{13}{|c|}{ M. beaufortiae } \\
\hline \multirow[t]{5}{*}{$\widehat{o}(N=4)$} & Mean & 3.16 & 2.25 & 0.20 & 0.50 & 0.42 & 0.48 & 0.76 & 1.12 & 0.57 & 0.37 & 0.73 \\
\hline & SD & 0.06 & 0.06 & 0.01 & 0.01 & 0.02 & 0.03 & 0.02 & 0.05 & 0.03 & 0.02 & 0.02 \\
\hline & Range & 0.12 & 0.10 & 0.01 & 0.02 & 0.04 & 0.06 & 0.05 & 0.13 & 0.07 & 0.03 & 0.04 \\
\hline & Min & 3.08 & 2.20 & 0.19 & 0.49 & 0.40 & 0.45 & 0.73 & 1.05 & 0.53 & 0.35 & 0.71 \\
\hline & Max & 3.20 & 2.30 & 0.20 & 0.51 & 0.44 & 0.51 & 0.78 & 1.18 & 0.60 & 0.38 & 0.75 \\
\hline \multirow[t]{5}{*}{ 우 $(N=5)$} & Mean & 3.51 & 2.40 & 0.25 & 0.51 & 0.46 & 0.54 & 0.81 & 1.21 & 0.61 & 0.38 & 0.79 \\
\hline & $\mathrm{SD}$ & 0.13 & 0.12 & 0.03 & 0.02 & 0.02 & 0.02 & 0.02 & 0.05 & 0.03 & 0.02 & 0.04 \\
\hline & Range & 0.35 & 0.31 & 0.08 & 0.05 & 0.04 & 0.06 & 0.06 & 0.11 & 0.07 & 0.05 & 0.11 \\
\hline & Min & 3.35 & 2.24 & 0.21 & 0.48 & 0.44 & 0.51 & 0.78 & 1.14 & 0.56 & 0.35 & 0.74 \\
\hline & Max & 3.70 & 2.55 & 0.29 & 0.53 & 0.48 & 0.58 & 0.84 & 1.25 & 0.63 & 0.40 & 0.85 \\
\hline
\end{tabular}




\begin{tabular}{|c|c|c|c|c|c|c|c|c|c|c|c|c|}
\hline \multirow{2}{*}{ Species } & & \multicolumn{6}{|c|}{ Length } & \multicolumn{3}{|c|}{ Width } & \multicolumn{2}{|c|}{ Ratio } \\
\hline & & Body & $\begin{array}{l}\text { Cun- } \\
\text { Clyp }\end{array}$ & Head & Prono & Scut & Cun & Head & Prono & Scut & IntOcDi & AntSeg2 \\
\hline \multicolumn{13}{|l|}{ M. dubiosus } \\
\hline$\delta(N=1)$ & & 3.34 & 2.24 & 0.20 & 0.45 & 0.44 & 0.51 & 0.74 & 1.13 & 0.57 & 0.31 & 0.96 \\
\hline 우 $(N=1)$ & & 3.29 & 2.31 & 0.20 & 0.46 & 0.45 & 0.47 & 0.75 & 1.20 & 0.60 & 0.38 & 0.83 \\
\hline \multicolumn{13}{|c|}{ M. eremaeae } \\
\hline \multirow[t]{5}{*}{$\hat{\jmath}(N=7)$} & Mean & 3.00 & 2.11 & 0.18 & 0.49 & 0.39 & 0.42 & 0.72 & 1.08 & 0.51 & 0.38 & 0.72 \\
\hline & $\mathrm{SD}$ & 0.10 & 0.06 & 0.02 & 0.02 & 0.01 & 0.01 & 0.01 & 0.03 & 0.02 & 0.01 & 0.03 \\
\hline & Range & 0.30 & 0.20 & 0.05 & 0.05 & 0.02 & 0.04 & 0.04 & 0.10 & 0.04 & 0.03 & 0.07 \\
\hline & Min & 2.85 & 2.00 & 0.15 & 0.46 & 0.38 & 0.40 & 0.70 & 1.03 & 0.49 & 0.36 & 0.68 \\
\hline & Max & 3.15 & 2.20 & 0.20 & 0.51 & 0.40 & 0.44 & 0.74 & 1.13 & 0.53 & 0.39 & 0.75 \\
\hline \multirow[t]{5}{*}{ 우 $(N=2)$} & Mean & 3.55 & 2.48 & 0.19 & 0.50 & 0.46 & 0.53 & 0.79 & 1.21 & 0.59 & 0.43 & 0.76 \\
\hline & $\mathrm{SD}$ & 0.14 & 0.04 & 0.01 & 0.01 & 0.01 & 0.04 & 0.01 & 0.12 & 0.01 & 0.01 & 0.03 \\
\hline & Range & 0.20 & 0.05 & 0.02 & 0.02 & 0.01 & 0.05 & 0.01 & 0.17 & 0.02 & 0.01 & 0.04 \\
\hline & Min & 3.45 & 2.45 & 0.18 & 0.49 & 0.45 & 0.50 & 0.78 & 1.12 & 0.58 & 0.42 & 0.74 \\
\hline & $\operatorname{Max}$ & 3.65 & 2.50 & 0.20 & 0.51 & 0.46 & 0.55 & 0.79 & 1.29 & 0.60 & 0.43 & 0.78 \\
\hline \multicolumn{13}{|c|}{ M. glomeratae } \\
\hline \multirow[t]{5}{*}{$\widehat{o}(N=6)$} & Mean & 3.83 & 2.60 & 0.22 & 0.53 & 0.56 & 0.58 & 0.86 & 1.31 & 0.68 & 0.36 & 1.02 \\
\hline & $\mathrm{SD}$ & 0.08 & 0.07 & 0.01 & 0.02 & 0.02 & 0.03 & 0.02 & 0.05 & 0.03 & 0.01 & 0.03 \\
\hline & Range & 0.19 & 0.20 & 0.03 & 0.05 & 0.06 & 0.06 & 0.06 & 0.13 & 0.07 & 0.02 & 0.08 \\
\hline & Min & 3.74 & 2.51 & 0.20 & 0.50 & 0.54 & 0.55 & 0.85 & 1.25 & 0.64 & 0.35 & 0.98 \\
\hline & $\operatorname{Max}$ & 3.93 & 2.71 & 0.23 & 0.55 & 0.60 & 0.61 & 0.90 & 1.38 & 0.71 & 0.37 & 1.06 \\
\hline \multirow{5}{*}{ 우 $(N=4)$} & Mean & 3.80 & 2.62 & 0.22 & 0.56 & 0.55 & 0.55 & 0.86 & 1.32 & 0.69 & 0.40 & 1.00 \\
\hline & $\mathrm{SD}$ & 0.10 & 0.10 & 0.02 & 0.03 & 0.04 & 0.01 & 0.02 & 0.06 & 0.03 & 0.02 & 0.03 \\
\hline & Range & 0.23 & 0.21 & 0.03 & 0.07 & 0.09 & 0.02 & 0.05 & 0.14 & 0.07 & 0.03 & 0.07 \\
\hline & Min & 3.69 & 2.48 & 0.20 & 0.52 & 0.50 & 0.54 & 0.84 & 1.24 & 0.65 & 0.38 & 0.97 \\
\hline & $\operatorname{Max}$ & 3.92 & 2.68 & 0.23 & 0.59 & 0.59 & 0.56 & 0.89 & 1.38 & 0.72 & 0.41 & 1.04 \\
\hline \multicolumn{13}{|c|}{ M. halmaturorum } \\
\hline \multirow[t]{5}{*}{$\widehat{o}(N=6)$} & Mean & 4.10 & 2.79 & 0.32 & 0.60 & 0.56 & 0.62 & 0.87 & 1.40 & 0.71 & 0.39 & 0.94 \\
\hline & $\mathrm{SD}$ & 0.12 & 0.08 & 0.05 & 0.04 & 0.01 & 0.03 & 0.01 & 0.03 & 0.01 & 0.01 & 0.03 \\
\hline & Range & 0.28 & 0.18 & 0.11 & 0.10 & 0.03 & 0.07 & 0.03 & 0.08 & 0.03 & 0.03 & 0.08 \\
\hline & Min & 3.91 & 2.69 & 0.26 & 0.53 & 0.55 & 0.58 & 0.87 & 1.37 & 0.70 & 0.38 & 0.90 \\
\hline & $\operatorname{Max}$ & 4.19 & 2.87 & 0.37 & 0.64 & 0.58 & 0.65 & 0.89 & 1.45 & 0.73 & 0.41 & 0.98 \\
\hline \multirow[t]{5}{*}{ 우 $(N=4)$} & Mean & 4.36 & 2.99 & 0.34 & 0.64 & 0.59 & 0.64 & 0.90 & 1.58 & 0.80 & 0.44 & 0.96 \\
\hline & $\mathrm{SD}$ & 0.19 & 0.17 & 0.03 & 0.03 & 0.04 & 0.04 & 0.03 & 0.11 & 0.05 & 0.03 & 0.04 \\
\hline & Range & 0.54 & 0.46 & 0.07 & 0.08 & 0.09 & 0.09 & 0.09 & 0.26 & 0.13 & 0.08 & 0.10 \\
\hline & Min & 4.04 & 2.72 & 0.30 & 0.59 & 0.55 & 0.60 & 0.83 & 1.35 & 0.70 & 0.38 & 0.89 \\
\hline & Max & 4.58 & 3.18 & 0.37 & 0.67 & 0.64 & 0.70 & 0.92 & 1.61 & 0.84 & 0.46 & 0.99 \\
\hline
\end{tabular}




\begin{tabular}{|c|c|c|c|c|c|c|c|c|c|c|c|c|}
\hline \multirow{2}{*}{ Species } & & \multicolumn{6}{|c|}{ Length } & \multicolumn{3}{|c|}{ Width } & \multicolumn{2}{|c|}{ Ratio } \\
\hline & & Body & $\begin{array}{l}\text { Cun- } \\
\text { Clyp }\end{array}$ & Head & Prono & Scut & Cun & Head & Prono & Scut & IntOcDi & AntSeg2 \\
\hline \multicolumn{13}{|l|}{ M. kaputar } \\
\hline \multirow[t]{5}{*}{$\widehat{o}(N=5)$} & Mean & 3.32 & 2.41 & 0.24 & 0.60 & 0.51 & 0.56 & 0.80 & 1.32 & 0.55 & 0.40 & 0.88 \\
\hline & $\mathrm{SD}$ & 0.12 & 0.07 & 0.02 & 0.01 & 0.02 & 0.02 & 0.01 & 0.02 & 0.02 & 0.01 & 0.01 \\
\hline & Range & 0.26 & 0.15 & 0.05 & 0.03 & 0.05 & 0.04 & 0.03 & 0.04 & 0.05 & 0.02 & 0.04 \\
\hline & Min & 3.23 & 2.34 & 0.22 & 0.58 & 0.50 & 0.55 & 0.79 & 1.30 & 0.53 & 0.39 & 0.86 \\
\hline & Max & 3.49 & 2.49 & 0.26 & 0.61 & 0.54 & 0.59 & 0.81 & 1.34 & 0.58 & 0.41 & 0.89 \\
\hline$\stackrel{q}{(N=1)}$ & & 3.32 & 2.42 & 0.22 & 0.57 & 0.54 & 0.54 & 0.83 & 1.38 & 0.68 & 0.43 & 0.86 \\
\hline \multicolumn{13}{|l|}{ M. kunzeae } \\
\hline \multirow[t]{5}{*}{$\widehat{\jmath}(N=5)$} & Mean & 3.36 & 2.28 & 0.24 & 0.49 & 0.44 & 0.49 & 0.75 & 1.07 & 0.52 & 0.34 & 0.84 \\
\hline & SD & 0.11 & 0.07 & 0.02 & 0.01 & 0.01 & 0.01 & 0.01 & 0.03 & 0.01 & 0.01 & 0.02 \\
\hline & Range & 0.29 & 0.17 & 0.04 & 0.03 & 0.02 & 0.03 & 0.02 & 0.07 & 0.04 & 0.02 & 0.05 \\
\hline & Min & 3.20 & 2.19 & 0.23 & 0.47 & 0.43 & 0.48 & 0.74 & 1.03 & 0.50 & 0.33 & 0.82 \\
\hline & Max & 3.48 & 2.36 & 0.26 & 0.50 & 0.44 & 0.51 & 0.76 & 1.10 & 0.53 & 0.35 & 0.86 \\
\hline \multirow[t]{5}{*}{ 우 $(N=5)$} & Mean & 3.29 & 2.30 & 0.24 & 0.50 & 0.45 & 0.46 & 0.76 & 1.15 & 0.57 & 0.38 & 0.74 \\
\hline & SD & 0.17 & 0.07 & 0.02 & 0.03 & 0.02 & 0.04 & 0.02 & 0.05 & 0.02 & 0.01 & 0.01 \\
\hline & Range & 0.46 & 0.18 & 0.05 & 0.07 & 0.04 & 0.09 & 0.05 & 0.13 & 0.05 & 0.02 & 0.01 \\
\hline & Min & 3.01 & 2.19 & 0.22 & 0.47 & 0.43 & 0.40 & 0.74 & 1.07 & 0.54 & 0.37 & 0.74 \\
\hline & Max & 3.47 & 2.37 & 0.26 & 0.54 & 0.47 & 0.49 & 0.78 & 1.20 & 0.59 & 0.39 & 0.75 \\
\hline \multicolumn{13}{|c|}{ M. micranthae } \\
\hline \multirow[t]{5}{*}{$\widehat{\delta}(N=7)$} & Mean & 2.87 & 1.96 & 0.23 & 0.45 & 0.38 & 0.42 & 0.70 & 1.01 & 0.49 & 0.33 & 0.63 \\
\hline & SD & 0.12 & 0.09 & 0.03 & 0.02 & 0.01 & 0.02 & 0.02 & 0.04 & 0.02 & 0.01 & 0.04 \\
\hline & Range & 0.30 & 0.23 & 0.09 & 0.06 & 0.03 & 0.06 & 0.06 & 0.11 & 0.06 & 0.04 & 0.11 \\
\hline & Min & 2.74 & 1.87 & 0.21 & 0.42 & 0.37 & 0.40 & 0.69 & 0.97 & 0.47 & 0.31 & 0.60 \\
\hline & Max & 3.04 & 2.10 & 0.30 & 0.48 & 0.40 & 0.46 & 0.74 & 1.09 & 0.53 & 0.35 & 0.71 \\
\hline q $(N=1)$ & & 2.94 & 2.02 & 0.25 & 0.48 & 0.40 & 0.44 & 0.72 & 1.03 & 0.49 & 0.34 & 0.65 \\
\hline \multicolumn{13}{|l|}{ M. ngarkat } \\
\hline \multirow[t]{5}{*}{$\widehat{o}(N=2)$} & Mean & 2.99 & 2.03 & 0.20 & 0.51 & 0.42 & 0.39 & 0.80 & 1.09 & 0.56 & 0.38 & 0.70 \\
\hline & SD & 0.02 & 0.05 & 0.00 & 0.02 & 0.02 & 0.00 & 0.01 & 0.02 & 0.00 & 0.01 & 0.01 \\
\hline & Range & 0.02 & 0.06 & 0.01 & 0.03 & 0.02 & 0.01 & 0.01 & 0.02 & 0.01 & 0.01 & 0.02 \\
\hline & Min & 2.98 & 2.00 & 0.20 & 0.50 & 0.41 & 0.38 & 0.79 & 1.08 & 0.55 & 0.37 & 0.70 \\
\hline & Max & 3.00 & 2.06 & 0.21 & 0.53 & 0.43 & 0.39 & 0.80 & 1.11 & 0.56 & 0.38 & 0.71 \\
\hline \multicolumn{13}{|l|}{ M. nodosae } \\
\hline \multirow[t]{5}{*}{ ठิ $(N=5)$} & Mean & 3.10 & 2.12 & 0.21 & 0.47 & 0.43 & 0.44 & 0.71 & 1.10 & 0.54 & 0.31 & 0.77 \\
\hline & SD & 0.06 & 0.05 & 0.02 & 0.02 & 0.01 & 0.03 & 0.01 & 0.01 & 0.01 & 0.01 & 0.04 \\
\hline & Range & 0.16 & 0.13 & 0.04 & 0.05 & 0.02 & 0.07 & 0.02 & 0.03 & 0.04 & 0.03 & 0.10 \\
\hline & Min & 3.04 & 2.06 & 0.19 & 0.44 & 0.42 & 0.40 & 0.70 & 1.07 & 0.53 & 0.30 & 0.72 \\
\hline & Max & 3.19 & 2.19 & 0.23 & 0.49 & 0.43 & 0.47 & 0.73 & 1.11 & 0.56 & 0.33 & 0.82 \\
\hline
\end{tabular}




\begin{tabular}{|c|c|c|c|c|c|c|c|c|c|c|c|c|}
\hline \multirow[b]{2}{*}{ Species } & & \multicolumn{6}{|c|}{ Length } & \multicolumn{3}{|c|}{ Width } & \multicolumn{2}{|c|}{ Ratio } \\
\hline & & Body & $\begin{array}{l}\text { Cun- } \\
\text { Clyp }\end{array}$ & Head & Prono & Scut & Cun & Head & Prono & Scut & IntOcDi & AntSeg2 \\
\hline \multicolumn{13}{|l|}{ M. nodosae } \\
\hline \multirow[t]{5}{*}{ ㅇ $(N=5)$} & Mean & 3.13 & 2.23 & 0.22 & 0.49 & 0.46 & 0.43 & 0.72 & 1.17 & 0.59 & 0.35 & 0.75 \\
\hline & $\mathrm{SD}$ & 0.06 & 0.03 & 0.02 & 0.02 & 0.01 & 0.03 & 0.01 & 0.03 & 0.02 & 0.01 & 0.02 \\
\hline & Range & 0.13 & 0.08 & 0.04 & 0.06 & 0.03 & 0.06 & 0.02 & 0.06 & 0.04 & 0.02 & 0.05 \\
\hline & Min & 3.09 & 2.20 & 0.20 & 0.47 & 0.45 & 0.40 & 0.70 & 1.15 & 0.57 & 0.33 & 0.72 \\
\hline & Max & 3.22 & 2.28 & 0.24 & 0.53 & 0.48 & 0.47 & 0.73 & 1.20 & 0.61 & 0.36 & 0.77 \\
\hline \multicolumn{13}{|c|}{ M. omnivorus } \\
\hline \multirow{5}{*}{$\widehat{\delta}(N=5)$} & Mean & 3.34 & 2.28 & 0.23 & 0.51 & 0.47 & 0.46 & 0.75 & 1.23 & 0.60 & 0.37 & 0.75 \\
\hline & $\mathrm{SD}$ & 0.14 & 0.09 & 0.03 & 0.02 & 0.01 & 0.03 & 0.02 & 0.05 & 0.02 & 0.02 & 0.02 \\
\hline & Range & 0.38 & 0.25 & 0.07 & 0.05 & 0.03 & 0.06 & 0.06 & 0.12 & 0.03 & 0.04 & 0.05 \\
\hline & Min & 3.19 & 2.15 & 0.20 & 0.48 & 0.46 & 0.44 & 0.73 & 1.16 & 0.58 & 0.35 & 0.73 \\
\hline & $\operatorname{Max}$ & 3.57 & 2.39 & 0.27 & 0.54 & 0.49 & 0.50 & 0.79 & 1.28 & 0.61 & 0.39 & 0.77 \\
\hline \multirow{5}{*}{ q $(N=5)$} & Mean & 3.58 & 2.45 & 0.26 & 0.55 & 0.49 & 0.50 & 0.78 & 1.31 & 0.66 & 0.41 & 0.76 \\
\hline & SD & 0.08 & 0.07 & 0.02 & 0.02 & 0.02 & 0.03 & 0.01 & 0.03 & 0.02 & 0.01 & 0.03 \\
\hline & Range & 0.15 & 0.18 & 0.06 & 0.04 & 0.06 & 0.08 & 0.02 & 0.07 & 0.04 & 0.03 & 0.07 \\
\hline & Min & 3.49 & 2.38 & 0.23 & 0.54 & 0.46 & 0.46 & 0.78 & 1.27 & 0.64 & 0.39 & 0.72 \\
\hline & Max & 3.64 & 2.56 & 0.28 & 0.58 & 0.52 & 0.54 & 0.80 & 1.34 & 0.68 & 0.42 & 0.79 \\
\hline \multicolumn{13}{|c|}{ M. pauperiflorae } \\
\hline$\widehat{o}(N=1)$ & & 3.50 & 2.30 & 0.19 & 0.50 & 0.38 & 0.50 & 0.68 & 1.15 & 0.55 & 0.33 & 0.83 \\
\hline \multicolumn{13}{|c|}{ M. phymatocarpi } \\
\hline \multirow[t]{5}{*}{$\widehat{\delta}(N=7)$} & Mean & 3.21 & 2.23 & 0.25 & 0.48 & 0.44 & 0.45 & 0.77 & 1.15 & 0.58 & 0.35 & 0.75 \\
\hline & SD & 0.09 & 0.02 & 0.03 & 0.02 & 0.02 & 0.02 & 0.01 & 0.06 & 0.02 & 0.01 & 0.02 \\
\hline & Range & 0.21 & 0.07 & 0.08 & 0.05 & 0.05 & 0.07 & 0.04 & 0.20 & 0.07 & 0.04 & 0.07 \\
\hline & Min & 3.09 & 2.20 & 0.22 & 0.45 & 0.41 & 0.42 & 0.75 & 1.07 & 0.55 & 0.32 & 0.72 \\
\hline & $\operatorname{Max}$ & 3.31 & 2.27 & 0.30 & 0.50 & 0.46 & 0.48 & 0.79 & 1.26 & 0.62 & 0.36 & 0.79 \\
\hline \multirow[t]{5}{*}{$q(N=10)$} & Mean & 3.59 & 2.45 & 0.22 & 0.50 & 0.49 & 0.51 & 0.81 & 1.30 & 0.65 & 0.42 & 0.79 \\
\hline & $\mathrm{SD}$ & 0.14 & 0.07 & 0.03 & 0.04 & 0.02 & 0.04 & 0.02 & 0.08 & 0.03 & 0.03 & 0.04 \\
\hline & Range & 0.48 & 0.25 & 0.07 & 0.12 & 0.08 & 0.12 & 0.05 & 0.29 & 0.10 & 0.08 & 0.11 \\
\hline & Min & 3.40 & 2.35 & 0.18 & 0.43 & 0.45 & 0.46 & 0.78 & 1.21 & 0.60 & 0.40 & 0.73 \\
\hline & Max & 3.88 & 2.60 & 0.25 & 0.55 & 0.53 & 0.58 & 0.83 & 1.50 & 0.70 & 0.48 & 0.84 \\
\hline \multicolumn{13}{|c|}{ M. polyphagus } \\
\hline \multirow[t]{5}{*}{$\hat{\delta}(N=10)$} & Mean & 3.20 & 2.20 & 0.23 & 0.46 & 0.43 & 0.48 & 0.76 & 1.13 & 0.57 & 0.34 & 0.77 \\
\hline & SD & 0.11 & 0.10 & 0.03 & 0.05 & 0.02 & 0.02 & 0.02 & 0.04 & 0.02 & 0.01 & 0.04 \\
\hline & Range & 0.44 & 0.36 & 0.08 & 0.14 & 0.06 & 0.06 & 0.06 & 0.12 & 0.06 & 0.03 & 0.11 \\
\hline & Min & 2.95 & 2.01 & 0.19 & 0.38 & 0.40 & 0.45 & 0.73 & 1.06 & 0.56 & 0.32 & 0.71 \\
\hline & $\operatorname{Max}$ & 3.39 & 2.37 & 0.27 & 0.52 & 0.46 & 0.51 & 0.79 & 1.19 & 0.62 & 0.35 & 0.81 \\
\hline
\end{tabular}




\begin{tabular}{|c|c|c|c|c|c|c|c|c|c|c|c|c|}
\hline \multirow[b]{2}{*}{ Species } & & \multicolumn{6}{|c|}{ Length } & \multicolumn{3}{|c|}{ Width } & \multicolumn{2}{|c|}{ Ratio } \\
\hline & & Body & $\begin{array}{l}\text { Cun- } \\
\text { Clyp }\end{array}$ & Head & Prono & Scut & Cun & Head & Prono & Scut & IntOcDi & AntSeg2 \\
\hline \multicolumn{13}{|c|}{ M. polyphagus } \\
\hline \multirow[t]{5}{*}{$q(N=10)$} & Mean & 3.37 & 2.30 & 0.24 & 0.50 & 0.46 & 0.50 & 0.77 & 1.22 & 0.62 & 0.37 & 0.76 \\
\hline & SD & 0.15 & 0.07 & 0.02 & 0.02 & 0.02 & 0.04 & 0.01 & 0.04 & 0.03 & 0.01 & 0.03 \\
\hline & Range & 0.49 & 0.23 & 0.06 & 0.07 & 0.05 & 0.11 & 0.03 & 0.12 & 0.09 & 0.02 & 0.09 \\
\hline & Min & 3.09 & 2.17 & 0.22 & 0.47 & 0.44 & 0.44 & 0.76 & 1.17 & 0.58 & 0.36 & 0.73 \\
\hline & Max & 3.58 & 2.41 & 0.28 & 0.54 & 0.48 & 0.55 & 0.79 & 1.29 & 0.67 & 0.38 & 0.81 \\
\hline \multicolumn{13}{|c|}{ M. rhaphiophyllae } \\
\hline \multirow[t]{5}{*}{$\widehat{\partial}(N=5)$} & Mean & 3.87 & 2.72 & 0.26 & 0.59 & 0.56 & 0.60 & 0.84 & 1.39 & 0.72 & 0.37 & 0.87 \\
\hline & $\mathrm{SD}$ & 0.12 & 0.14 & 0.02 & 0.04 & 0.03 & 0.03 & 0.01 & 0.06 & 0.03 & 0.01 & 0.03 \\
\hline & Range & 0.28 & 0.38 & 0.05 & 0.10 & 0.07 & 0.07 & 0.03 & 0.15 & 0.08 & 0.03 & 0.08 \\
\hline & Min & 3.73 & 2.54 & 0.24 & 0.54 & 0.52 & 0.57 & 0.83 & 1.30 & 0.67 & 0.36 & 0.82 \\
\hline & $\operatorname{Max}$ & 4.01 & 2.92 & 0.29 & 0.64 & 0.59 & 0.63 & 0.86 & 1.45 & 0.75 & 0.39 & 0.90 \\
\hline \multirow[t]{5}{*}{ 우 $(N=5)$} & Mean & 4.21 & 2.89 & 0.28 & 0.63 & 0.61 & 0.64 & 0.88 & 1.53 & 0.78 & 0.42 & 0.92 \\
\hline & $\mathrm{SD}$ & 0.18 & 0.10 & 0.04 & 0.03 & 0.02 & 0.03 & 0.02 & 0.06 & 0.03 & 0.01 & 0.02 \\
\hline & Range & 0.44 & 0.25 & 0.11 & 0.06 & 0.04 & 0.07 & 0.05 & 0.16 & 0.08 & 0.02 & 0.06 \\
\hline & Min & 4.02 & 2.79 & 0.22 & 0.61 & 0.59 & 0.60 & 0.85 & 1.48 & 0.75 & 0.41 & 0.89 \\
\hline & $\operatorname{Max}$ & 4.46 & 3.04 & 0.33 & 0.67 & 0.63 & 0.68 & 0.91 & 1.64 & 0.83 & 0.43 & 0.95 \\
\hline \multicolumn{13}{|c|}{ M. sheathianae } \\
\hline \multirow[t]{5}{*}{$\widehat{\delta}(N=5)$} & Mean & 3.96 & 2.84 & 0.25 & 0.62 & 0.62 & 0.61 & 0.90 & 1.48 & 0.74 & 0.43 & 1.02 \\
\hline & $\mathrm{SD}$ & 0.34 & 0.16 & 0.03 & 0.08 & 0.03 & 0.05 & 0.03 & 0.07 & 0.06 & 0.02 & 0.08 \\
\hline & Range & 0.74 & 0.36 & 0.06 & 0.18 & 0.08 & 0.14 & 0.06 & 0.18 & 0.14 & 0.04 & 0.21 \\
\hline & Min & 3.56 & 2.65 & 0.22 & 0.53 & 0.58 & 0.57 & 0.86 & 1.38 & 0.68 & 0.41 & 0.92 \\
\hline & $\operatorname{Max}$ & 4.30 & 3.01 & 0.27 & 0.71 & 0.66 & 0.70 & 0.92 & 1.57 & 0.82 & 0.45 & 1.12 \\
\hline \multirow[t]{5}{*}{ ㅇ $(N=5)$} & Mean & 4.49 & 3.15 & 0.34 & 0.67 & 0.65 & 0.63 & 0.94 & 1.61 & 0.83 & 0.46 & 1.11 \\
\hline & $\mathrm{SD}$ & 0.38 & 0.22 & 0.07 & 0.05 & 0.06 & 0.05 & 0.03 & 0.09 & 0.07 & 0.01 & 0.09 \\
\hline & Range & 0.80 & 0.47 & 0.16 & 0.13 & 0.15 & 0.13 & 0.06 & 0.19 & 0.16 & 0.03 & 0.21 \\
\hline & Min & 4.03 & 2.86 & 0.29 & 0.61 & 0.57 & 0.57 & 0.91 & 1.51 & 0.73 & 0.45 & 1.00 \\
\hline & $\operatorname{Max}$ & 4.83 & 3.33 & 0.45 & 0.74 & 0.72 & 0.69 & 0.97 & 1.71 & 0.90 & 0.48 & 1.21 \\
\hline \multicolumn{13}{|l|}{ M. vimineae } \\
\hline \multirow[t]{5}{*}{$\widehat{\partial}(N=5)$} & Mean & 3.37 & 2.34 & 0.26 & 0.52 & 0.45 & 0.52 & 0.75 & 1.16 & 0.57 & 0.32 & 0.91 \\
\hline & SD & 0.18 & 0.16 & 0.05 & 0.05 & 0.03 & 0.01 & 0.03 & 0.07 & 0.03 & 0.01 & 0.05 \\
\hline & Range & 0.43 & 0.37 & 0.13 & 0.10 & 0.07 & 0.03 & 0.07 & 0.16 & 0.08 & 0.04 & 0.10 \\
\hline & Min & 3.17 & 2.16 & 0.19 & 0.46 & 0.42 & 0.50 & 0.72 & 1.07 & 0.52 & 0.31 & 0.87 \\
\hline & Max & 3.60 & 2.53 & 0.32 & 0.56 & 0.49 & 0.53 & 0.78 & 1.23 & 0.60 & 0.34 & 0.96 \\
\hline
\end{tabular}




\begin{tabular}{|c|c|c|c|c|c|c|c|c|c|c|c|c|}
\hline \multirow[b]{2}{*}{ Species } & & \multicolumn{6}{|c|}{ Length } & \multicolumn{3}{|c|}{ Width } & \multicolumn{2}{|c|}{ Ratio } \\
\hline & & Body & $\begin{array}{l}\text { Cun- } \\
\text { Clyp }\end{array}$ & Head & Prono & Scut & Cun & Head & Prono & Scut & IntOcDi & AntSeg2 \\
\hline \multicolumn{13}{|c|}{ M. vimineae } \\
\hline \multirow[t]{5}{*}{$q(N=5)$} & Mean & 3.58 & 2.51 & 0.28 & 0.54 & 0.48 & 0.54 & 0.76 & 1.26 & 0.63 & 0.39 & 0.92 \\
\hline & $\mathrm{SD}$ & 0.07 & 0.06 & 0.02 & 0.02 & 0.01 & 0.02 & 0.01 & 0.05 & 0.02 & 0.02 & 0.06 \\
\hline & Range & 0.15 & 0.18 & 0.05 & 0.06 & 0.03 & 0.04 & 0.04 & 0.13 & 0.06 & 0.05 & 0.16 \\
\hline & Min & 3.50 & 2.44 & 0.25 & 0.50 & 0.47 & 0.53 & 0.75 & 1.18 & 0.60 & 0.36 & 0.84 \\
\hline & $\operatorname{Max}$ & 3.65 & 2.61 & 0.30 & 0.56 & 0.50 & 0.56 & 0.79 & 1.31 & 0.66 & 0.41 & 0.99 \\
\hline \multicolumn{13}{|c|}{ M. viridiflorae } \\
\hline \multirow[t]{5}{*}{$\widehat{\sigma}(N=3)$} & Mean & 3.27 & 2.42 & 0.24 & 0.53 & 0.51 & 0.37 & 0.87 & 1.18 & 0.62 & 0.34 & 0.94 \\
\hline & $\mathrm{SD}$ & 0.08 & 0.04 & 0.01 & 0.02 & 0.01 & 0.02 & 0.01 & 0.03 & 0.01 & 0.01 & 0.01 \\
\hline & Range & 0.15 & 0.07 & 0.02 & 0.04 & 0.02 & 0.03 & 0.02 & 0.05 & 0.02 & 0.01 & 0.02 \\
\hline & Min & 3.20 & 2.38 & 0.23 & 0.51 & 0.50 & 0.36 & 0.86 & 1.15 & 0.61 & 0.33 & 0.93 \\
\hline & $\operatorname{Max}$ & 3.35 & 2.45 & 0.25 & 0.55 & 0.52 & 0.39 & 0.88 & 1.20 & 0.63 & 0.34 & 0.95 \\
\hline \multirow[t]{5}{*}{ ㅇ $(N=3)$} & Mean & 3.82 & 2.80 & 0.36 & 0.62 & 0.56 & 0.48 & 0.90 & 1.41 & 0.71 & 0.40 & 1.03 \\
\hline & $\mathrm{SD}$ & 0.16 & 0.10 & 0.02 & 0.03 & 0.03 & 0.04 & 0.01 & 0.02 & 0.03 & 0.01 & 0.00 \\
\hline & Range & 0.30 & 0.20 & 0.03 & 0.05 & 0.05 & 0.07 & 0.02 & 0.04 & 0.05 & 0.01 & 0.00 \\
\hline & Min & 3.70 & 2.70 & 0.35 & 0.59 & 0.53 & 0.46 & 0.89 & 1.39 & 0.69 & 0.40 & 1.03 \\
\hline & Max & 4.00 & 2.90 & 0.38 & 0.64 & 0.58 & 0.53 & 0.91 & 1.43 & 0.74 & 0.41 & 1.03 \\
\hline \multicolumn{13}{|c|}{ Ancoraphylus } \\
\hline \multicolumn{13}{|c|}{ A. victoriensis } \\
\hline \multirow[t]{5}{*}{$\widehat{\delta}(N=2)$} & Mean & 2.99 & 1.84 & 0.20 & 0.37 & 0.38 & 0.53 & 0.63 & 0.89 & 0.43 & 0.30 & 0.78 \\
\hline & SD & 0.08 & 0.06 & 0.01 & 0.02 & 0.03 & 0.01 & 0.01 & 0.04 & 0.01 & 0.01 & 0.00 \\
\hline & Range & 0.11 & 0.09 & 0.01 & 0.03 & 0.06 & 0.02 & 0.01 & 0.08 & 0.01 & 0.01 & 0.00 \\
\hline & Min & 2.94 & 1.80 & 0.20 & 0.35 & 0.35 & 0.52 & 0.63 & 0.85 & 0.42 & 0.30 & 0.77 \\
\hline & $\operatorname{Max}$ & 3.05 & 1.89 & 0.21 & 0.38 & 0.40 & 0.53 & 0.64 & 0.93 & 0.44 & 0.31 & 0.78 \\
\hline \multicolumn{13}{|c|}{ Calytriphylus } \\
\hline \multicolumn{13}{|l|}{ C. menzies } \\
\hline \multirow[t]{5}{*}{$\widehat{\delta}(N=5)$} & Mean & 2.98 & 1.91 & 0.18 & 0.36 & 0.36 & 0.50 & 0.59 & 0.89 & 0.43 & 0.28 & 0.82 \\
\hline & $\mathrm{SD}$ & 0.11 & 0.05 & 0.01 & 0.03 & 0.01 & 0.04 & 0.01 & 0.04 & 0.04 & 0.01 & 0.04 \\
\hline & Range & 0.23 & 0.10 & 0.01 & 0.07 & 0.02 & 0.09 & 0.02 & 0.12 & 0.09 & 0.02 & 0.10 \\
\hline & Min & 2.83 & 1.85 & 0.17 & 0.32 & 0.35 & 0.45 & 0.59 & 0.83 & 0.39 & 0.27 & 0.76 \\
\hline & $\operatorname{Max}$ & 3.06 & 1.95 & 0.18 & 0.39 & 0.36 & 0.54 & 0.61 & 0.95 & 0.48 & 0.29 & 0.86 \\
\hline \multirow[t]{5}{*}{$q(N=3)$} & Mean & 2.63 & 1.75 & 0.16 & 0.36 & 0.32 & 0.44 & 0.60 & 0.89 & 0.44 & 0.34 & 0.83 \\
\hline & $\mathrm{SD}$ & 0.11 & 0.13 & 0.03 & 0.02 & 0.01 & 0.01 & 0.02 & 0.01 & 0.04 & 0.01 & 0.08 \\
\hline & Range & 0.21 & 0.24 & 0.06 & 0.04 & 0.02 & 0.02 & 0.04 & 0.02 & 0.08 & 0.03 & 0.15 \\
\hline & Min & 2.54 & 1.66 & 0.14 & 0.34 & 0.31 & 0.43 & 0.59 & 0.88 & 0.39 & 0.33 & 0.75 \\
\hline & Max & 2.75 & 1.90 & 0.20 & 0.38 & 0.33 & 0.45 & 0.63 & 0.90 & 0.47 & 0.36 & 0.90 \\
\hline
\end{tabular}




\begin{tabular}{|c|c|c|c|c|c|c|c|c|c|c|c|c|}
\hline \multirow[b]{2}{*}{ Species } & & \multicolumn{6}{|c|}{ Length } & \multicolumn{3}{|c|}{ Width } & \multicolumn{2}{|c|}{ Ratio } \\
\hline & & Body & $\begin{array}{l}\text { Cun- } \\
\text { Clyp }\end{array}$ & Head & Prono & Scut & Cun & Head & Prono & Scut & IntOcDi & AntSe \\
\hline \multicolumn{13}{|c|}{ Leptospermia } \\
\hline \multicolumn{13}{|l|}{ L. anatoles } \\
\hline \multirow[t]{5}{*}{$\hat{o}(N=9)$} & Mean & 3.66 & 2.53 & 0.27 & 0.54 & 0.46 & 0.60 & 0.80 & 1.24 & 0.61 & 0.41 & 1.02 \\
\hline & SD & 0.22 & 0.11 & 0.02 & 0.03 & 0.02 & 0.04 & 0.02 & 0.03 & 0.03 & 0.02 & 0.04 \\
\hline & Range & 0.66 & 0.34 & 0.05 & 0.09 & 0.05 & 0.10 & 0.05 & 0.11 & 0.08 & 0.06 & 0.13 \\
\hline & Min & 3.49 & 2.41 & 0.25 & 0.49 & 0.44 & 0.56 & 0.77 & 1.17 & 0.58 & 0.38 & 0.98 \\
\hline & Max & 4.15 & 2.75 & 0.30 & 0.58 & 0.49 & 0.66 & 0.83 & 1.28 & 0.66 & 0.44 & 1.10 \\
\hline \multirow[t]{5}{*}{ 우 $(N=10)$} & Mean & 3.75 & 2.59 & 0.29 & 0.55 & 0.47 & 0.59 & 0.80 & 1.23 & 0.61 & 0.44 & 1.02 \\
\hline & $\mathrm{SD}$ & 0.14 & 0.10 & 0.01 & 0.03 & 0.02 & 0.04 & 0.03 & 0.04 & 0.02 & 0.02 & 0.05 \\
\hline & Range & 0.52 & 0.35 & 0.04 & 0.08 & 0.06 & 0.13 & 0.10 & 0.13 & 0.05 & 0.08 & 0.15 \\
\hline & Min & 3.49 & 2.40 & 0.28 & 0.51 & 0.44 & 0.52 & 0.75 & 1.15 & 0.58 & 0.40 & 0.96 \\
\hline & Max & 4.00 & 2.75 & 0.31 & 0.59 & 0.50 & 0.65 & 0.85 & 1.27 & 0.63 & 0.48 & 1.11 \\
\hline \multicolumn{13}{|l|}{ L. cassisi } \\
\hline \multirow[t]{5}{*}{ ô $(N=8)$} & Mean & 3.88 & 2.53 & 0.22 & 0.49 & 0.49 & 0.67 & 0.79 & 1.23 & 0.62 & 0.40 & 1.07 \\
\hline & SD & 0.21 & 0.13 & 0.02 & 0.02 & 0.03 & 0.06 & 0.03 & 0.07 & 0.03 & 0.02 & 0.15 \\
\hline & Range & 0.73 & 0.44 & 0.06 & 0.07 & 0.09 & 0.18 & 0.10 & 0.21 & 0.10 & 0.06 & 0.48 \\
\hline & Min & 3.62 & 2.39 & 0.20 & 0.46 & 0.46 & 0.60 & 0.75 & 1.14 & 0.58 & 0.36 & 0.93 \\
\hline & Max & 4.35 & 2.83 & 0.26 & 0.52 & 0.54 & 0.78 & 0.85 & 1.35 & 0.67 & 0.42 & 1.42 \\
\hline \multirow[t]{5}{*}{ ㅇ $(N=9)$} & Mean & 3.47 & 2.39 & 0.22 & 0.49 & 0.45 & 0.54 & 0.78 & 1.19 & 0.60 & 0.42 & 0.88 \\
\hline & $\mathrm{SD}$ & 0.19 & 0.13 & 0.02 & 0.02 & 0.04 & 0.03 & 0.04 & 0.07 & 0.03 & 0.02 & 0.09 \\
\hline & Range & 0.67 & 0.43 & 0.07 & 0.05 & 0.12 & 0.10 & 0.10 & 0.21 & 0.10 & 0.05 & 0.28 \\
\hline & Min & 3.20 & 2.20 & 0.19 & 0.46 & 0.40 & 0.49 & 0.72 & 1.08 & 0.54 & 0.39 & 0.80 \\
\hline & Max & 3.87 & 2.63 & 0.26 & 0.51 & 0.52 & 0.59 & 0.82 & 1.29 & 0.64 & 0.44 & 1.08 \\
\hline
\end{tabular}

Melaleucacoris

M. glomeratae

\begin{tabular}{lllllllllllll}
\hline$(N=5)$ & Mean & $\mathbf{2 . 4 3}$ & $\mathbf{1 . 7 2}$ & $\mathbf{0 . 1 9}$ & $\mathbf{0 . 3 7}$ & $\mathbf{0 . 3 5}$ & $\mathbf{0 . 3 7}$ & $\mathbf{0 . 6 7}$ & $\mathbf{0 . 8 7}$ & $\mathbf{0 . 4 3}$ & $\mathbf{0 . 3 3}$ & $\mathbf{0 . 7 5}$ \\
& SD & 0.06 & 0.02 & 0.01 & 0.02 & 0.01 & 0.03 & 0.01 & 0.01 & 0.01 & 0.01 & 0.01 \\
& Range & 0.16 & 0.04 & 0.04 & 0.06 & 0.02 & 0.07 & 0.03 & 0.02 & 0.03 & 0.02 & 0.03 \\
은 $(N=5)$ & Min & 2.35 & 1.70 & 0.17 & 0.34 & 0.34 & 0.34 & 0.66 & 0.86 & 0.42 & 0.32 & 0.73 \\
& Max & 2.51 & 1.74 & 0.21 & 0.40 & 0.36 & 0.41 & 0.68 & 0.88 & 0.45 & 0.34 & 0.76 \\
& Mean & $\mathbf{2 . 6 2}$ & $\mathbf{1 . 8 4}$ & $\mathbf{0 . 1 9}$ & $\mathbf{0 . 3 7}$ & $\mathbf{0 . 3 7}$ & $\mathbf{0 . 4 0}$ & $\mathbf{0 . 6 8}$ & $\mathbf{0 . 9 1}$ & $\mathbf{0 . 4 5}$ & $\mathbf{0 . 3 7}$ & $\mathbf{0 . 7 9}$ \\
& SD & 0.07 & 0.03 & 0.02 & 0.01 & 0.01 & 0.02 & 0.02 & 0.03 & 0.01 & 0.02 & 0.02 \\
& Range & 0.18 & 0.07 & 0.05 & 0.03 & 0.02 & 0.05 & 0.04 & 0.07 & 0.04 & 0.04 & 0.06 \\
& Min & 2.51 & 1.81 & 0.16 & 0.35 & 0.35 & 0.37 & 0.66 & 0.87 & 0.44 & 0.35 & 0.77 \\
& Max & 2.70 & 1.88 & 0.22 & 0.38 & 0.37 & 0.42 & 0.70 & 0.94 & 0.48 & 0.39 & 0.83
\end{tabular}




\begin{tabular}{|c|c|c|c|c|c|c|c|c|c|c|c|c|}
\hline \multirow[b]{2}{*}{ Species } & & \multicolumn{6}{|c|}{ Length } & \multicolumn{3}{|c|}{ Width } & \multicolumn{2}{|c|}{ Ratio } \\
\hline & & Body & $\begin{array}{l}\text { Cun- } \\
\text { Clyp }\end{array}$ & Head & Prono & Scut & Cun & Head & Prono & Scut & IntOcDi & AntSe \\
\hline \multicolumn{13}{|l|}{ Teddus } \\
\hline \multicolumn{13}{|l|}{ T. katrinae } \\
\hline \multirow[t]{5}{*}{$\widehat{o}(N=6)$} & Mean & 2.87 & 1.96 & 0.20 & 0.47 & 0.41 & 0.41 & 0.93 & 0.97 & 0.47 & 0.40 & 0.79 \\
\hline & SD & 0.07 & 0.04 & 0.02 & 0.01 & 0.01 & 0.03 & 0.02 & 0.01 & 0.02 & 0.01 & 0.02 \\
\hline & Range & 0.19 & 0.10 & 0.05 & 0.04 & 0.02 & 0.06 & 0.05 & 0.03 & 0.04 & 0.02 & 0.06 \\
\hline & Min & 2.79 & 1.90 & 0.18 & 0.46 & 0.39 & 0.38 & 0.91 & 0.95 & 0.46 & 0.39 & 0.76 \\
\hline & Max & 2.97 & 2.00 & 0.23 & 0.50 & 0.42 & 0.44 & 0.96 & 0.98 & 0.50 & 0.41 & 0.82 \\
\hline \multirow[t]{5}{*}{$q(N=6)$} & Mean & 2.91 & 2.03 & 0.23 & 0.49 & 0.41 & 0.43 & 0.93 & 1.03 & 0.49 & 0.50 & 0.65 \\
\hline & SD & 0.10 & 0.04 & 0.02 & 0.01 & 0.02 & 0.02 & 0.02 & 0.03 & 0.02 & 0.01 & 0.01 \\
\hline & Range & 0.27 & 0.11 & 0.04 & 0.03 & 0.05 & 0.06 & 0.05 & 0.08 & 0.04 & 0.03 & 0.04 \\
\hline & Min & 2.72 & 1.97 & 0.21 & 0.47 & 0.38 & 0.40 & 0.92 & 0.99 & 0.47 & 0.48 & 0.63 \\
\hline & Max & 2.99 & 2.08 & 0.25 & 0.51 & 0.43 & 0.46 & 0.96 & 1.07 & 0.51 & 0.51 & 0.67 \\
\hline
\end{tabular}

\section{Xiphoidellus}

$X$. eucalyptae

\begin{tabular}{lllllllllllll}
\multirow{0}{*}{$(N=3)$} & Mean & $\mathbf{3 . 0 1}$ & $\mathbf{2 . 0 7}$ & $\mathbf{0 . 2 6}$ & $\mathbf{0 . 3 9}$ & $\mathbf{0 . 4 1}$ & $\mathbf{0 . 4 7}$ & $\mathbf{0 . 7 9}$ & $\mathbf{0 . 9 8}$ & $\mathbf{0 . 4 9}$ & $\mathbf{0 . 2 3}$ & $\mathbf{0 . 9 2}$ \\
& SD & 0.13 & 0.08 & 0.03 & 0.03 & 0.00 & 0.03 & 0.02 & 0.03 & 0.01 & 0.01 & 0.02 \\
& Range & 0.24 & 0.14 & 0.06 & 0.05 & 0.01 & 0.06 & 0.04 & 0.06 & 0.02 & 0.03 & 0.04 \\
& Min & 2.92 & 2.02 & 0.24 & 0.37 & 0.41 & 0.44 & 0.77 & 0.96 & 0.49 & 0.22 & 0.90 \\
& Max & 3.16 & 2.16 & 0.29 & 0.41 & 0.42 & 0.50 & 0.81 & 1.02 & 0.50 & 0.24 & 0.94 \\
& Mean & $\mathbf{3 . 1 5}$ & $\mathbf{2 . 1 9}$ & $\mathbf{0 . 2 8}$ & $\mathbf{0 . 4 1}$ & $\mathbf{0 . 4 3}$ & $\mathbf{0 . 4 8}$ & $\mathbf{0 . 7 6}$ & $\mathbf{1 . 0 6}$ & $\mathbf{0 . 5 3}$ & $\mathbf{0 . 3 2}$ & $\mathbf{0 . 9 3}$ \\
& SD & 0.13 & 0.07 & 0.02 & 0.01 & 0.01 & 0.02 & 0.02 & 0.02 & 0.02 & 0.01 & 0.02 \\
& Range & 0.36 & 0.20 & 0.06 & 0.03 & 0.03 & 0.05 & 0.04 & 0.07 & 0.07 & 0.02 & 0.06 \\
& Min & 2.89 & 2.08 & 0.26 & 0.40 & 0.41 & 0.46 & 0.75 & 1.02 & 0.48 & 0.31 & 0.90 \\
& Max & 3.25 & 2.28 & 0.32 & 0.43 & 0.44 & 0.51 & 0.78 & 1.09 & 0.55 & 0.34 & 0.96
\end{tabular}

\section{Xiphoides}

$X$. anangu

\begin{tabular}{lllllllllllll}
\multirow{0}{*}{$(N=2)$} & Mean & $\mathbf{3 . 8 3}$ & $\mathbf{2 . 7 3}$ & $\mathbf{0 . 2 2}$ & $\mathbf{0 . 5 9}$ & $\mathbf{0 . 6 1}$ & $\mathbf{0 . 6 1}$ & $\mathbf{1 . 0 3}$ & $\mathbf{1 . 5 1}$ & $\mathbf{0 . 7 0}$ & $\mathbf{0 . 4 6}$ & $\mathbf{1 . 3 6}$ \\
& SD & 0.12 & 0.11 & 0.01 & 0.01 & 0.01 & 0.03 & 0.01 & 0.00 & 0.05 & 0.01 & 0.05 \\
& Range & 0.17 & 0.15 & 0.01 & 0.01 & 0.01 & 0.04 & 0.02 & 0.00 & 0.07 & 0.01 & 0.08 \\
& Min & 3.75 & 2.65 & 0.22 & 0.59 & 0.61 & 0.59 & 1.02 & 1.51 & 0.66 & 0.46 & 1.32 \\
& Max & 3.92 & 2.80 & 0.22 & 0.60 & 0.61 & 0.63 & 1.04 & 1.51 & 0.73 & 0.47 & 1.39 \\
& Mean & $\mathbf{3 . 7 1}$ & $\mathbf{2 . 6 9}$ & $\mathbf{0 . 1 7}$ & $\mathbf{0 . 6 1}$ & $\mathbf{0 . 5 9}$ & $\mathbf{0 . 6 4}$ & $\mathbf{1 . 0 8}$ & $\mathbf{1 . 6 3}$ & $\mathbf{0 . 7 1}$ & $\mathbf{0 . 5 4}$ & $\mathbf{1 . 3 9}$ \\
& SD & 0.08 & 0.02 & 0.02 & 0.02 & 0.05 & 0.03 & 0.05 & 0.09 & 0.07 & 0.03 & 0.00 \\
& Range & 0.11 & 0.03 & 0.03 & 0.03 & 0.06 & 0.04 & 0.07 & 0.13 & 0.10 & 0.05 & 0.00 \\
& Min & 3.66 & 2.67 & 0.16 & 0.59 & 0.56 & 0.62 & 1.04 & 1.57 & 0.66 & 0.52 & 1.39 \\
& Max & 3.77 & 2.70 & 0.18 & 0.62 & 0.62 & 0.66 & 1.12 & 1.69 & 0.76 & 0.57 & 1.39
\end{tabular}


TABLE 1 Continued

\begin{tabular}{|c|c|c|c|c|c|c|c|c|c|c|c|c|}
\hline \multirow[b]{2}{*}{ Species } & & \multicolumn{6}{|c|}{ Length } & \multicolumn{3}{|c|}{ Width } & \multicolumn{2}{|c|}{ Ratio } \\
\hline & & Body & $\begin{array}{l}\text { Cun- } \\
\text { Clyp }\end{array}$ & Head & Prono & Scut & Cun & Head & Prono & Scut & IntOcDi & AntSeg2 \\
\hline \multicolumn{13}{|c|}{ X. tasmanensis } \\
\hline \multirow[t]{5}{*}{$\hat{o}(N=5)$} & Mean & 2.74 & 1.82 & 0.20 & 0.43 & 0.36 & 0.45 & 0.74 & 1.01 & 0.46 & 0.36 & 0.63 \\
\hline & SD & 0.07 & 0.02 & 0.04 & 0.02 & 0.01 & 0.02 & 0.01 & 0.02 & 0.02 & 0.01 & 0.01 \\
\hline & Range & 0.19 & 0.06 & 0.09 & 0.06 & 0.02 & 0.04 & 0.02 & 0.06 & 0.05 & 0.02 & 0.04 \\
\hline & Min & 2.65 & 1.79 & 0.16 & 0.40 & 0.35 & 0.42 & 0.73 & 0.98 & 0.44 & 0.35 & 0.62 \\
\hline & Max & 2.83 & 1.85 & 0.25 & 0.45 & 0.37 & 0.46 & 0.75 & 1.04 & 0.48 & 0.36 & 0.65 \\
\hline \multirow[t]{5}{*}{ ㅇ $(N=5)$} & Mean & 2.84 & 1.90 & 0.20 & 0.46 & 0.38 & 0.48 & 0.76 & 1.07 & 0.48 & 0.38 & 0.63 \\
\hline & SD & 0.06 & 0.03 & 0.03 & 0.02 & 0.01 & 0.02 & 0.01 & 0.01 & 0.02 & 0.01 & 0.01 \\
\hline & Range & 0.15 & 0.07 & 0.08 & 0.06 & 0.02 & 0.05 & 0.01 & 0.04 & 0.05 & 0.02 & 0.04 \\
\hline & Min & 2.76 & 1.87 & 0.16 & 0.43 & 0.37 & 0.46 & 0.76 & 1.06 & 0.45 & 0.37 & 0.61 \\
\hline & Max & 2.91 & 1.94 & 0.24 & 0.49 & 0.39 & 0.51 & 0.77 & 1.10 & 0.50 & 0.38 & 0.64 \\
\hline \multicolumn{13}{|c|}{ Restiophylus } \\
\hline \multicolumn{13}{|l|}{ R. orientalis } \\
\hline \multirow[t]{5}{*}{$\widehat{\delta}(N=5)$} & Mean & 3.97 & 2.73 & 0.46 & 0.48 & 0.44 & 0.57 & 0.71 & 1.03 & 0.53 & 0.36 & 1.22 \\
\hline & SD & 0.18 & 0.12 & 0.04 & 0.01 & 0.03 & 0.03 & 0.02 & 0.05 & 0.03 & 0.02 & 0.07 \\
\hline & Range & 0.46 & 0.33 & 0.10 & 0.03 & 0.07 & 0.09 & 0.04 & 0.12 & 0.08 & 0.05 & 0.17 \\
\hline & Min & 3.65 & 2.54 & 0.40 & 0.47 & 0.40 & 0.52 & 0.69 & 0.99 & 0.51 & 0.35 & 1.15 \\
\hline & Max & 4.11 & 2.88 & 0.50 & 0.50 & 0.47 & 0.61 & 0.74 & 1.11 & 0.59 & 0.39 & 1.32 \\
\hline \multirow[t]{5}{*}{ 우 $(N=8)$} & Mean & 3.98 & 2.86 & 0.50 & 0.49 & 0.47 & 0.55 & 0.73 & 1.11 & 0.56 & 0.40 & 1.21 \\
\hline & SD & 0.14 & 0.07 & 0.02 & 0.02 & 0.02 & 0.03 & 0.01 & 0.05 & 0.03 & 0.01 & 0.03 \\
\hline & Range & 0.44 & 0.23 & 0.08 & 0.07 & 0.04 & 0.08 & 0.03 & 0.13 & 0.09 & 0.02 & 0.10 \\
\hline & Min & 3.75 & 2.73 & 0.45 & 0.45 & 0.45 & 0.51 & 0.72 & 1.06 & 0.53 & 0.39 & 1.17 \\
\hline & Max & 4.20 & 2.96 & 0.53 & 0.52 & 0.49 & 0.59 & 0.75 & 1.18 & 0.62 & 0.41 & 1.27 \\
\hline
\end{tabular}


soma. We consider them congeneric based on the overall form of the endosoma. The ventral and dorsal endosomal straps in each species are separated by obvious membranes along their length and the aperture of the secondary gonopore opens caudally adjacent to a discrete apical sclerite of the ventral strap. The dorsal surface of both species is densely covered with wooly trichomes (figs. 2C, 3C).

Currently Eucalyptophylus spp. were taken only on Eucalyptus (Eucalypteae) (see tables 2, 3). For both species of Eucalyptophylus, three out of four of their known host plants and all but one of 12 of their collecting events occur in the southwestern phytogeographic subregion of Western Australia. Eucalyptophylus polyphagus is also found in the eastern desert phytogeographic subregion of South Australia on the widely distributed Eucalyptus camaldulensis, currently making this plant-bug species the only member of the genus with a distribution east and west of the Nullarbor Plain( see table 4).

\section{Eucalyptophylus macrocarpae, new species}

Figure 2, map 1, plates 1, 6, table 1

Diagnosis: Recognized by bold contrasting markings of dark mahogany and pale gray, and endosoma C-shaped, sturdy, expanded apically; dorsal and ventral straps separated by wide area of membrane; dorsal strap terminating in large, well-formed subapical secondary gonopore.

Description: Male: Mean total length 2.96, mean pronotum width 0.94 . COLORATION (pl. 1): Contrasting bold markings of dark mahogany on head, calli, mesoscutum, scutellum, wide distal margin of corium and cuneus, femora, and venter and with contrasting pale gray on posterior lobe of pronotum, clavus, corium anteriad of posterior angle of claval commissure, base of cuneus, and legs distad of femoral apices; hemelytral membrane darkly fuscous, small areole mahogany, large areole and region near cuneus translucent. SURFACE AND VESTITURE (figs. 2A, C, pl. 1): Dorsal vestiture mixed, with silvery shining, somewhat sericeous setae covering paler colored areas and golden sericeous setae or brown simple setae over darker colored areas of hemelytron; narrow row of black setae on distal edge of corium; dorsum covered with dense, curved microtrichia and minute bumps (fig. 2C). STRUCTURE: Head (figs. 2A, B, pl. 1): Closely conforming to anterior margin of pronotum, eyes moderately large, occupying three-quarters height of head in lateral view; antenna inserted level with ventral margin of eye, eyes weakly emarginate at fossa; antennal segment 2 moderately long (0.95), 1.25 times width of head; labium reaching to apex of metacoxa. Thorax (pl. 1): Pronotum subquadrate, posterior margin weakly excavated. Pretarsus: Pulvilli present (fig. 2E). Hemelytron: Not elongate. GENITALIA (fig. 2F, pl. 6A-H): Pygophore: Conical, posteroventral surface not prominent. Endosoma: C-shaped, sturdy, with two distinct strongly sclerotized straps, separated by wide area of membrane or nonsclerotized cuticle; dorsal strap thin proximally, expanded to $2 \times$ proximal diameter distally; ventral strap wide, gradually tapered distally, terminating in large, discrete apical sclerite, separated from body of ventral strap by thin membrane. Secondary gonopore: Wellformed and ringlike, subapical; aperture apparently open on caudal surface abutting large, smooth, distally blunt sclerite situated between apices of dorsal and ventral straps. Phallotheca: Truncate apically with short tapered apex, aperture narrow on anterodistal surface gradually expanded posteriorly; anterior margin long, practically reaching anterior margin of pygophore. Parameres: Left paramere: Diameter of posterior process evenly thick; anterior process subequal in length to posterior process, with rounded apex and single apical bristle. Right paramere: Relatively large, slightly longer than left paramere; gradually tapered distally with small apical spine.

Female (pl. 1): Coloration as in male; differing from male as in generic description; mean total length 3.01 , mean pronotum width 0.96 . GENiTALIA (pl. 6I, J): Posterior margin of 

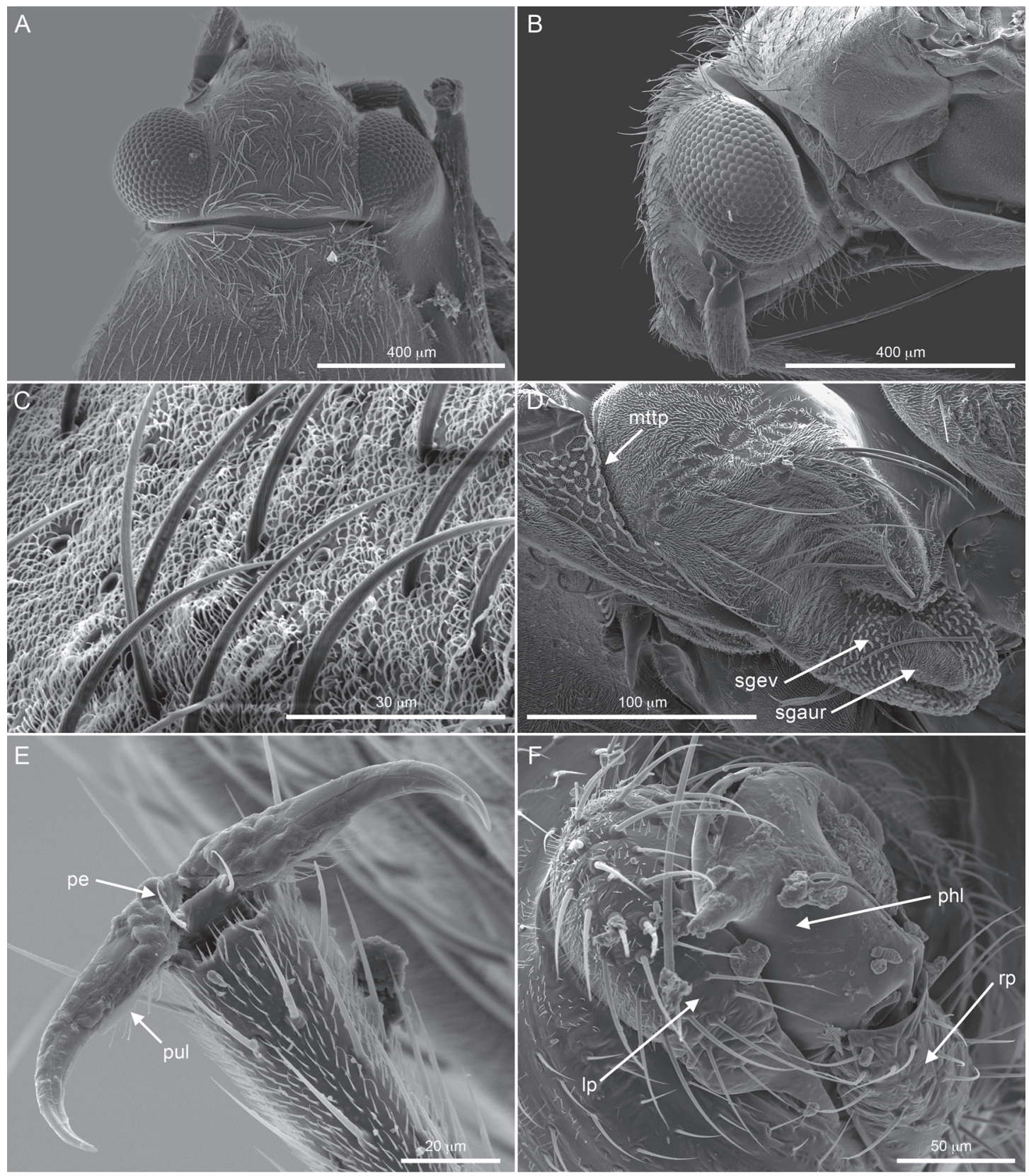

FIG. 2. Eucalyptophylus macrocarpae. Scanning electron micrographs. A. Head and pronotum, dorsal view. B. Head, lateral view. C. Detail of pronotal setae, lateral view. D. Thoracic pleuron, lateral view, showing metathoracic spiracle opening, metathoracic scent-gland auricle, and evaporatory area. E. Pretarsus, frontoventral view. F. Pygophore, left paramere, phallotheca, and right paramere, lateral view. AMNH_PBI 00414723: A, E, F; AMNH_PBI 00390308: B-D. Abbreviations: lp, left paramere; mttsp, metathoracic spiracle; pe, parempodium; phl, phallotheca; pul, pulvillus; rp, right paramere; sgaur, scent gland auricle; sgev, scent gland evaporatory area. 
sternite 7: With posteriorly directed medial subtriangular projection. Vestibular sclerites: Ventral labiate plate: With obvious sclerotized platelike anteroventral extension just right of midline. Dorsal labiate plate: Extending longitudinally subequal to width of ring. Posteromedial region: With pair of pocketlike depressions and faint concentric ribbing, with a few minute raised tubercles on midline. Anterolateral region: Projecting anteriad of sclerotized rings by length of ring. Posterior wall: Interramal sclerite: Thickened dorsoposteriad to posterior wall.

EтумоLоgy: Named for its host, Eucalyptus macrocarpa.

Hosts: Recorded from Eucalyptus macrocarpa and E. macrocarpa subsp. elachanta (pl. 38A, B) (Myrtaceae: Eucalypteae).

Distribution (map 1): Known from two collecting events on the west coast of Western Australia: one north of Perth, and one on the grounds of the Western Australian Herbarium. Both sites are in the southwestern phytogeographic subregion.

Holotype: AUSTRALIA: Western Australia: Perth, Western Australian Herbarium, 31.95002 ${ }^{\circ} \mathrm{S}$ $115.8667^{\circ} \mathrm{E}, 10 \mathrm{~m}, 18 \mathrm{Dec} 1997$, Schuh and Cassis, Eucalyptus macrocarpa Hook. (Myrtaceae), 10 (AMNH_PBI 00390295) (WAMP).

PARATYPes: AUSTRALIA: Western Australia: Brand Hiway, $18.8 \mathrm{~km} \mathrm{~S}$ of jct with Cervantes Rd, $30.47125^{\circ} \mathrm{S} 115.36406^{\circ} \mathrm{E}, 203 \mathrm{~m}, 07$ Nov 2004, Cassis, Weirauch, Tatarnic, Symonds, Eucalyptus macrocarpa Hook. subsp. elachanta (Myrtaceae), det. PERTH staff PERTH 6988164, 2 đo (00390868, 00390869), 4 ㅇ (00390872-00390875) (AM), 10 ๙ (00414719-00414728), 3 우 (00414729-00414731) $(\mathrm{AMNH}), 2$ 우 (00390870, 00390871), 6 우 (00414732-00414734, 00390876-00390878) (WAMP). Perth, Western Australian Herbarium, $31.95002^{\circ} \mathrm{S} 115.8667^{\circ} \mathrm{E}, 10 \mathrm{~m}, 18 \mathrm{Dec} 1997$, Schuh and Cassis, Eucalyptus macrocarpa Hook. (Myrtaceae), 30 우 (00390247-00390275, 00087134), 24 ðત (00390281-00390294, 00390296-00390302, 00390308, 00087133, 00087436) (AM), 21 ๙ (00195631, 00195632, 00414164-00414178, 00414187-00414190), 36 (00414199-00414226,
00414191-00414198) (AMNH), 1 đ (00414179), 1 우 (00414227) (ANIC), 1 우 (00390244), 1 추 (00390303) (CNC), 10 (00414181), 1 우 (00414229) (UCR), 1 के (00414180), 1 ㅇ (00414228) (UNSW), 19 (00390246), 1 ㅊ (00390305) (USNM), 11 đ (00414182-00414186, 00390306, 00390307, 00390309-00390312), 8 우 (00414230-00414237) (WAMP), 1 ㅇ (00390245), 1 ô (00390304) (ZISP).

Additional Specimens Examined: AUSTRALIA: Western Australia: Brand Hiway, 18.8 $\mathrm{km} \mathrm{S}$ of jct with Cervantes Rd, $30.47125^{\circ} \mathrm{S}$ 115.36406 ${ }^{\circ}$ E, 203 m, 07 Nov 2004, Cassis, Weirauch, Tatarnic, Symonds, Eucalyptus macrocarpa Hook. subsp. elachanta (Myrtaceae), det. PERTH staff PERTH 6988164, 6 nymphs (0039087900390884) (AM), 15 nymphs (0041473500414749) (AMNH). Perth, Western Australian Herbarium, $31.95002^{\circ} \mathrm{S} 115.8667^{\circ} \mathrm{E}, 10 \mathrm{~m}, 18$ Dec 1997, Schuh and Cassis, Eucalyptus macrocarpa Hook. (Myrtaceae), 5 nymphs (0039027600390280) (AM).

\section{Eucalyptophylus polyphagus, new species}

Figure 3, map 1, plates 1, 7, table 1

DiAgnosis: Recognized by predominately uniformly pale gray coloration with dusky orange to brown markings and strongly S-shaped endosoma with two straps separated by membrane, dorsal strap thin and terminating in small, subapical secondary gonopore; apex of ventral strap with slightly notched.

Description: Male: Mean total length 3.36, mean pronotum width 0.92. COLORATION (pl. 1): Predominately pale gray with diffuse dusky pale orange to brown on head, antenna, calli, mesoscutum, base of scutellum in middle, legs, and pygophore with discrete markings on apex of clavus, distal medial border of corium, and distal edge of cuneus. SURFACE AND VESTITURE (fig. 3A, C, pl. 1): Dorsal vestiture mixed, with silvery shining, somewhat sericeous setae and brown or golden recumbent simple setae on hemelytron and cuneus. STRUCTURE: Head 

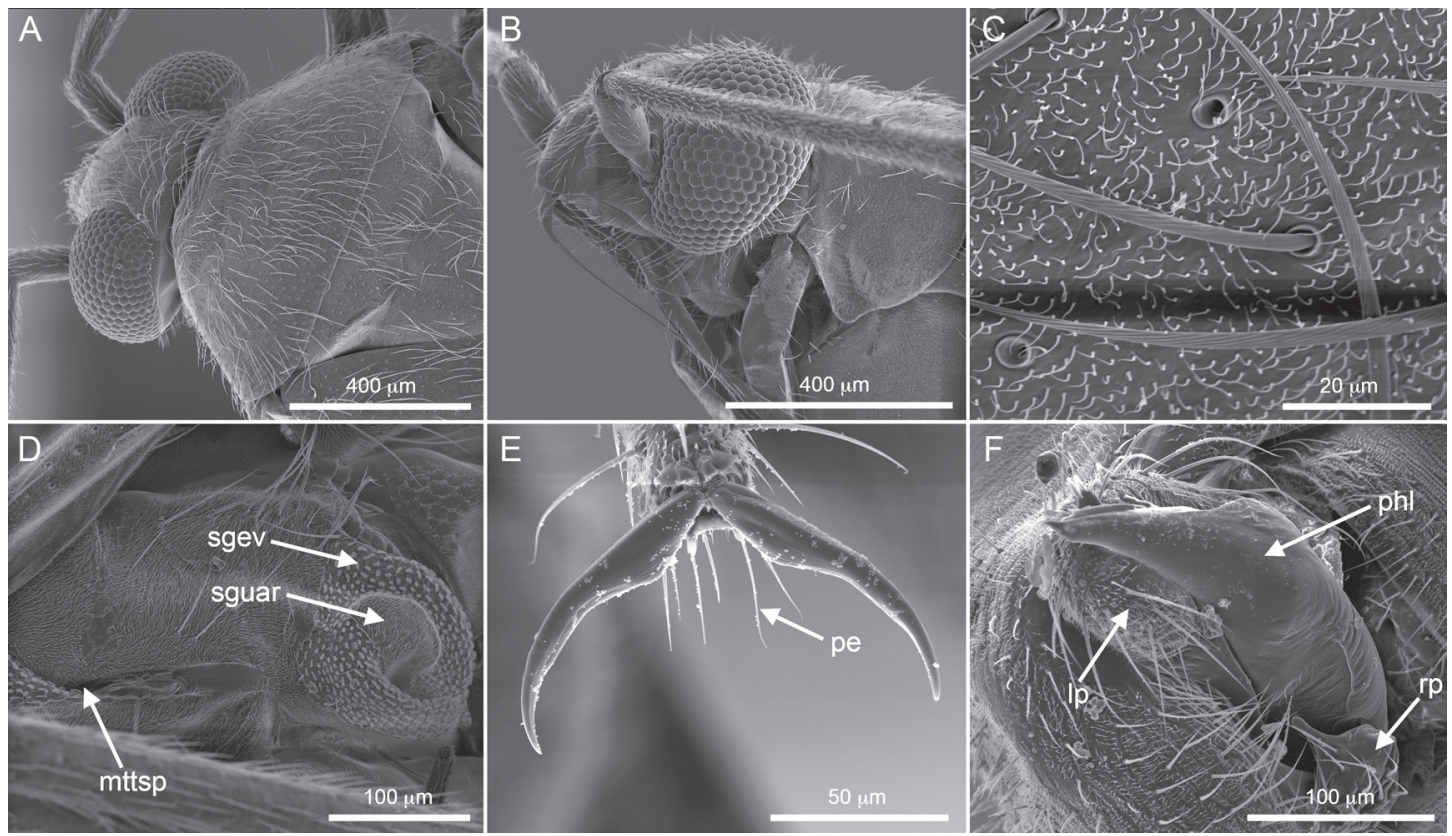

FIG. 3. Eucalyptophylus polyphagus, AMNH_PBI 00390393. Scanning electron micrographs. A. Head and pronotum, dorsal view. B. Head, lateral view. C. Detail of pronotal setae, dorsal view. D. Thoracic pleuron, lateral view, showing metathoracic spiracle opening, metathoracic scent-gland auricle, and evaporatory area. E. Pretarsus, frontoventral view. F. Pygophore, left paramere, phallotheca, and right paramere, caudal view. Abbreviations: lp, left paramere; $\mathbf{m t t s p}$, metathoracic spiracle; pe, parempodium; phl, phallotheca; rp, right paramere; sgaur, scent gland auricle; sgev, scent gland evaporatory area.

(figs. 3A, B, pl. 1): Transverse, separated from anterior margin of pronotum; eyes large, occupying practically entire head in lateral view; antenna inserted below ventral margin of eye by diameter of antennal segment 1 , eyes strongly emarginate at fossa, antennal segment 2 long (1.05), approximately 1.50 times width of head; labium reaching base of mesocoxa. Thorax: Pronotum subconical, posterior margin straight. Pretarsus: Pulvilli absent (fig. 3E). Hemelytron: Elongate. GENITALIA (fig. 3F, pl. 7A-J): Pygophore: Cylindrical with ventroposterior surface slightly prominent; one or two long separated bristles ventrad of left paramere insertion. Endosoma: Strongly S-shaped, with two straps; dorsal strap very thin, terminates at secondary gonopore; ventral strap divided in middle by hyaline seam, apical region of strap large, elongate, and extending distad of secondary gonopore, apex of apical sclerite slightly notched with serrate and smooth sides. Secondary gonopore: Small, ringlike, subapical; aperture teardrop shaped, open caudally, adjacent to discrete distal sclerite of ventral strap. Phallotheca: Elongate, gradually attenuate to posterior apex, aperture relatively short; anterior margin short, reaching to middle of pygophore. Parameres: Left paramere: Diameter of posterior process strongly tapered with pointed apex; anterior process short, pointed, with a few long apical bristles. Right paramere: Very small, rounded, with small apical spine.

Female (pl. 1): Coloration as in male; differing from male as in generic description; mean total length 3.16, mean pronotum width 0.93 . GENITALIA (pl. 7K-M): Posterior margin of sternite 7: Concave medially. Ventral labiate plate: With faint platelike anteroventral extension just right of midline. Dorsal labiate plate: Nar- 
row longitudinally. Posteromedial region: With obvious concentric ribbing. Anterolateral region: Even with anterior margin of sclerotized rings. Posterior wall: Interramal sclerite: Not differentiated from connecting membrane.

EтумоLOGY: Named for its multiple recorded hosts, all in the genus Eucalyptus. From the Greek polys, "many," and phagein, "to eat."

Hosts: Recorded from the following Eucalyptus species: Eucalyptus camaldulensis, E. gamophylla, E. macrocarpa (pl. 38A, B), E. pleurocarpa (pl. 38C), E. sp., and E. tetragona (Myrtaceae: Eucalypteae).

Distribution (map 1): Apparently widespread in desertic areas of central, southern, and western Australia. In Western Australia known from several collection events near Ravensthorpe on the southern coast of Western Australia, grounds of the Western Australian Herbarium, and Wheatbelt and Pilbara regions. Also found in Gammon Ranges of South Australia and central desert region of Northern Territory. Found in the widely separated southwestern, southwest interzone, Pilbara, and eastern desert phytogeographic subregions.

Holotype: AUSTRALIA: Western Australia: Pallarup Nature Reserve, $2.5 \mathrm{~km}$ W of Lake King-Ravensthorpe Road, $33.24958^{\circ} \mathrm{S}$ 119.7181º, 390 m, 05 Dec 1997, Schuh, Cassis, Brailovsky, Asquith, Eucalyptus pleurocarpa Schauer (Myrtaceae), det. PERTH staff PERTH 05055512, $10^{\widehat{ }}$ (AMNH_PBI 00131377) (WAMP).

PARATYPES: AUSTRALIA: Northern Territory: $143.3 \mathrm{~km} \mathrm{NW}$ of Bond Springs on Tanami $\mathrm{Rd}, 23.03333^{\circ} \mathrm{S} 132.722^{\circ} \mathrm{E}, 573 \mathrm{~m}, 22$ Oct 2001 , Cassis, Schuh, Schwartz, Silveira, Wall, Eucalyptus gamophylla F. Muell. (Myrtaceae), det. NSW staff NSW 658304, 2 ơ (00099086, 00413067), 10 우 (00099088-00099092, 00098889-00098893) (AMNH), 2 (00099093, 00099094) (WAMP). South Australia: $12 \mathrm{~km}$ E of Nepabunna, Gammon Ranges National Park, $30.60057^{\circ} \mathrm{S}$ 139.092 ${ }^{\circ}$ E, 440 m, 07 Nov 1998, Schuh, Cassis, Silveira, Eucalyptus camaldulensis Dehnh.

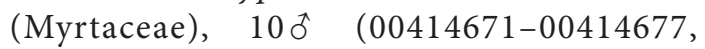
00414684-00414686), 7 우 (00414690-00414694,
00414700, 00414701) (AMNH), 60 (0041467800414683), $5 q$ (00414695-00414699) (SAMA). Western Australia: $8.6 \mathrm{~km} \mathrm{~S}$ of Ravensthorpe on Hopetoun Road, $33.61625^{\circ} \mathrm{S} 120.1345^{\circ} \mathrm{E}, 500 \mathrm{~m}$, 06 Dec 1997, Schuh, Cassis, Brailovsky, Asquith, Eucalyptus pleurocarpa Schauer (Myrtaceae), det. PERTH staff PERTH 05055512, 2 (00390456, 00390457), 2 đ (00390458, 00390459) (AM). 9.5 $\mathrm{km} \mathrm{E}$ of White Wells (SW of Paynes Find), $29.57676^{\circ} \mathrm{S} 117.066^{\circ} \mathrm{E}, 250 \mathrm{~m}, 11 \mathrm{Dec} 1997$, Schuh, Brailovsky, Eucalyptus sp. (Myrtaceae), det. PERTH staff PERTH 05879213, 3 क (00130020, 00130021, 00130019), 4 우 (0013002500130028) (AMNH). $39 \mathrm{~km}$ E of Lake King, $33.07796^{\circ} \mathrm{S} 120.0936^{\circ} \mathrm{E}, 400 \mathrm{~m}, 21$ Nov 1999, R.T. Schuh, G. Cassis, and R. Silveira, Eucalyptus pleurocarpa Schauer (Myrtaceae), det. PERTH staff PERTH 05672279, $14 \hat{0}$ (0039037500390385, 00390391-00390393), 5 ㅇ (0039040000390404) (AM), 5 ๙ (00390386-00390390) (WAMP). $39.7 \mathrm{~km}$ N of Ravensthorpe, $33.32199^{\circ} \mathrm{S}$ $119.82^{\circ} \mathrm{E}, 500 \mathrm{~m}, 06 \mathrm{Dec}$ 1997, Schuh, Cassis, Brailovsky, Asquith, Eucalyptus pleurocarpa Schauer (Myrtaceae), det. PERTH staff PERTH 05055512, 6 ô (00390335-00390339, 00390455), 3 우 (00390340, 00390341, 00390454) (AM). Fitzgerald River National Park, Hammersley Road, $33.90674^{\circ} \mathrm{S} 119.9567^{\circ} \mathrm{E}, 280 \mathrm{~m}, 06 \mathrm{Dec}$ 1997, Schuh, Cassis, Brailovsky, Asquith, Eucalyptus pleurocarpa Schauer (Myrtaceae), det. PERTH staff PERTH 05055512, 2 đิ (00390460, 00390461) (AM). Frank Hann National Park, 37 $\mathrm{km}$ E of Lake King, $33.07753^{\circ} \mathrm{S} 120.0918^{\circ} \mathrm{E}, 400$ m, 05 Nov 1996, Schuh and Cassis, Eucalyptus tetragona (R. Br.) F. Muell. (Myrtaceae), det. PERTH staff PERTH 05236762, 2 đ (00390327, 00390328), 3 ㅇ (00390330-00390332) (AM). Nangarup, Jct. of Doyle Road and Springdale Road, $33.82061^{\circ} \mathrm{S} 120.8682^{\circ} \mathrm{E}, 60 \mathrm{~m}, 27 \mathrm{Nov}$ 1999, R.T. Schuh, G. Cassis, and R. Silveira, Eucalyptus pleurocarpa Schauer (Myrtaceae), det. PERTH staff PERTH 05613213, 60 (0039031500390317, 00390356-00390358), 3 ㅇ (00390313, 00390364, 00390365) (AM), 2 ㅇ (00390314, 00390366) (WAMP). Pallarup Nature Reserve, $2.5 \mathrm{~km} \mathrm{~W}$ of Lake King-Ravensthorpe Road, 
$33.24958^{\circ} \mathrm{S} 119.7181^{\circ} \mathrm{E}, 390 \mathrm{~m}, 05$ Dec 1997 , Schuh, Cassis, Brailovsky, Asquith, Eucalyptus pleurocarpa Schauer (Myrtaceae), det. PERTH staff PERTH 05055512, 21 0 (00390405, 00390406, 00390408-00390421, 00390428$00390430, \quad 00087142, \quad 00087439), \quad 14$ 우 (00390435-00390447, 00087143) (AM), 29 (00128740-00128743, 00131378-00131392, 00131394-00131401, 00130903, 00131393), 22 우 (00128744-00128746, 00130904-00130920, 00130929, 00130930) (AMNH), 1 đ (00130898), 1 우 (00130923) (ANIC), 1 후 (00131407), 1 우 (00130927) (CNC), 1 후 (00130931), 1 우 (00130925) (UCR), 1 के (00130899), 1 우 (00130924) (UNSW), 1 † (00131406), 1 우 (00130926) (USNM), 10 ○े (00390422-00390427, 00131402-00131405), 8 우 (00390448-00390453, 00130921, 00130922) (WAMP), 1 đ (00131408), 1 우 (00130928) (ZISP). Perth, Western Australian Herbarium, $31.95002^{\circ} \mathrm{S} 115.8667^{\circ} \mathrm{E}, 10 \mathrm{~m}, 18$ Dec 1997, Schuh and Cassis, Eucalyptus macrocarpa Hook. (Myrtaceae), 10 (00390333), 1 우 (00390334) (AM). Pilbara Dist., Karijini NP, Dales Gorge Lookout, $22.4774^{\circ} \mathrm{S} 118.5599^{\circ} \mathrm{E}, 730$ m, 31 May 1999, G. Cassis, R. Silveira, Eucalyptus sp. (Myrtaceae), det. PERTH staff PERTH 5636663, 1 하 (00390325), 4 우 (0039032100390324) (AM), $1 \delta^{\star}$ (00390326) (WAMP). West Beach, Fitzgerald River National Park, $33.95175^{\circ} \mathrm{S}$ $119.9769^{\circ} \mathrm{E}, 20$ m, 28 Nov 1999, R.T. Schuh, G. Cassis, and R. Silveira, Eucalyptus pleurocarpa Schauer (Myrtaceae), det. Perth staff PERTH 05613213, 6 oิ (00390342-00390347), 4 우 (00390348, 00390349, 00390352, 00390353) (AM), 2 ㅇ (00390350, 00390351) (WAMP). adjacent to $\mathrm{N}$ boundary of Lake Shaster Nature Reserve, $33.83958^{\circ} \mathrm{S} 120.9291^{\circ} \mathrm{E}, 40 \mathrm{~m}, 27 \mathrm{Nov}$ 1999, R.T. Schuh, G. Cassis, and R. Silveira, Eucalyptus pleurocarpa Schauer (Myrtaceae), det. PERTH staff PERTH 05613213, 2 đ (00390367, 00390368), 3 우 (00390371-00390373) (AM), 1 우 (00390374) (WAMP).

Additional Specimens Examined: AUSTRALIA: Northern Territory: $143.3 \mathrm{~km} \mathrm{NW}$ of Bond Springs on Tanami Rd, $23.03333^{\circ} \mathrm{S}$ $132.722^{\circ} \mathrm{E}, 573 \mathrm{~m}, 22$ Oct 2001, Cassis, Schuh,
Schwartz, Silveira, Wall, Eucalyptus gamophylla F. Muell. (Myrtaceae), det. NSW staff NSW 658304, 1 nymph (00099087) (AMNH). South Australia: $12 \mathrm{~km}$ E of Nepabunna, Gammon Ranges National Park, $30.60057^{\circ} \mathrm{S} 139.092^{\circ} \mathrm{E}, 440 \mathrm{~m}, 07$ Nov 1998, Schuh, Cassis, Silveira, Eucalyptus camaldulensis Dehnh. (Myrtaceae), 3 nymphs (00414687-00414689) (AMNH). Western Australia: $9.5 \mathrm{~km}$ E of White Wells (SW of Paynes Find), $29.57676^{\circ} \mathrm{S} 117.066^{\circ} \mathrm{E}, 250 \mathrm{~m}, 11 \mathrm{Dec} 1997$, Schuh, Brailovsky, Eucalyptus sp. (Myrtaceae), det. PERTH staff PERTH 05879213, 3 nymphs (00130022-00130024) (AMNH). $39 \mathrm{~km}$ E of Lake King, $33.07796^{\circ} \mathrm{S} 120.0936^{\circ} \mathrm{E}, 400 \mathrm{~m}, 21 \mathrm{Nov}$ 1999, R.T. Schuh, G. Cassis, and R. Silveira, Eucalyptus pleurocarpa Schauer (Myrtaceae), det. PERTH staff PERTH 05672279, 6 nymphs (00390394-00390399) (AM). Frank Hann National Park, $37 \mathrm{~km}$ E of Lake King, $33.07753^{\circ} \mathrm{S}$ $120.0918^{\circ} \mathrm{E}, 400 \mathrm{~m}, 05$ Nov 1996, Schuh and Cassis, Eucalyptus tetragona (R. Br.) F. Muell. (Myrtaceae), det. PERTH staff PERTH 05236762, 1 nymph (00390329) (AM). Nangarup, Jct. of Doyle Road and Springdale Road, $33.82061^{\circ} \mathrm{S}$ $120.8682^{\circ} \mathrm{E}, 60 \mathrm{~m}, 27$ Nov 1999, R.T. Schuh, G. Cassis, and R. Silveira, Eucalyptus pleurocarpa Schauer (Myrtaceae), det. Pert staff PERTH 05613213, 5 nymphs (00390359-00390363) (AM). Pallarup Nature Reserve, $2.5 \mathrm{~km} \mathrm{~W}$ of Lake King-Ravensthorpe Road, $33.24958^{\circ} \mathrm{S}$ 119.7181º, 390 m, 05 Dec 1997, Schuh, Cassis, Brailovsky, Asquith, Eucalyptus pleurocarpa Schauer (Myrtaceae), det. PERTH staff PERTH 05055512, 4 nymphs (00390431-00390434) (AM), 3 nymphs (00130900-00130902) (AMNH). West Beach, Fitzgerald River National Park, $33.95175^{\circ} \mathrm{S} 119.9769^{\circ} \mathrm{E}, 20 \mathrm{~m}, 28 \mathrm{Nov} 1999$, R.T. Schuh, G. Cassis, and R. Silveira, Eucalyptus pleurocarpa Schauer (Myrtaceae), det. Perth staff PERTH 05613213, 2 nymphs (00390354, 00390355) (AM). adjacent to N boundary of Lake Shaster Nature Reserve, $33.83958^{\circ} \mathrm{S} 120.9291^{\circ} \mathrm{E}$, 40 m, 27 Nov 1999, R.T. Schuh, G. Cassis, and R. Silveira, Eucalyptus pleurocarpa Schauer (Myrtaceae), det. PERTH staff PERTH 05613213, 2 nymphs (00390369, 00390370) (AM). 


\section{Melaleucaphylus, new genus}

Type Species: Melaleucaphylus sheathianae, new species.

Diagnosis: Similar in general appearance to Moissonia spp. in ovoid, somewhat flattened body form; but distinguished from members of that genus by endosoma with distal portion of ventral strap usually bifurcate with flat rounded or truncate anterior apex situated adjacent to proximal edge of secondary gonopore and diverse posterior apex terminating in variablelength pointed spur, small variably curved subapical spine, or long hollow spine; dorsal strap usually bifurcate with narrow elongate spine(s); secondary gonopore usually with distinctive distally narrow proximal sclerite; sometimes distal end of secondary gonopore with large, serrate, mostly membranous lobe produced on left side. Overall appearance and occasionally fleshy parempodia also similar to species of Melaleucoides Schuh and Weirauch (Semiini, Exocarpocorina), but distinguished from members of that group by subtribal level differences in structure of endosoma and left paramere.

Description: MAle: Macropterous, total length 2.74-4.30, pronotum width 0.97-1.57. COLORATION (pls. 1-4): Variable; ranging from pale or dirty yellow to black, lighter specimens usually with small darker regions on various portions of head, pronotum, hemelytron, and appendages; sometimes dorsum with overall orange red cast, or with relatively discrete portions of bright orange red on mesoscutum, scutellum medially, and cuneus. SURFACE AND VESTITURE (figs. 5B, 6B, 7B, 8B, 10B, 11B, 12B, $14 \mathrm{~A}$, pls. 1-4): Dorsal vestiture variable, sometimes with uniformly distributed yellow, golden, or black setae; often a mixture of pale and dark setae covering similarly colored portions of dorsum; dorsum rarely with silvery sericeous setae; ventral vestiture usually longer than on dorsum; coxae sometimes with erect black setae. STRUCTURE: Head: Barely projecting; interocular space ranging from $1.5-2 \times$ as wide as dorsal width of an eye; eyes leaving gena narrowly exposed in lateral view (figs. 5A, 6A, 7A, 8A, 10A, 11A, 12A). Antenna: Segment 2 weakly tapering, more slender at base; length ranging from subequal to head width to approximately one-quarter longer; ventral margin of eye reaching ventrad of antennal fossa by width of fossa. Labium: Length variable, reaching from apex of meso- to metacoxa. Thorax: Pronotum: Subquadrate, lateral margins nearly straight, calli weakly demarcated, posterior lobe flat, posterior margin straight; mesoscutum broadly exposed; metathoracic spiracle and scent-gland system typically phyline (figs. 5C, 6C, 7C, 10C, 11C, 12C). Pretarsus: Claws of variable size, curvature, and basal thickness; parempodia variablestraight or curved setiform with apices pointed, clipped, or lamelliform, gradually widening, truncate or rounded; pulvilli of variable size and conformation on ventral surface of claw (figs. 4 , 9, 13, 14B). Hemelytron: Sublinear, gently curved at base and apex. GENITALIA (figs. 5D, 6D, 7D, 11D, 12D, pls. $8 \mathrm{~A}-\mathrm{K}, 9,10,11 \mathrm{~A}-\mathrm{J}, 12 \mathrm{~A}-\mathrm{K}, 13$, 14A-J, 15A-J, 16, 17A-J, 18A-J, 19, 20A-J, 21AI, 22A-J, 23A-J, 24A-J, 25A-L): Pygophore: Moderate to large in size, broadly conical, with slight prominence on each side subbasally on dorsal surface; caudal surface usually not extending perpendicular to genital aperture in lateral view; paramere insertions without tubercles, sometimes with obscure patches of bristles. Endosoma: Sigmoid, composed of dorsal and ventral straps, portion with torsion and extent twisting left or caudal variable; sometimes straps divergent in middle and separated by membrane. Ventral strap: Emanating from dorsal side of endosomal base, distal portion entire or bifurcate at variable distance from apex; if strap entire, then anterior surface dominant with length and apical conformation variable; usually posterior surface or edge with subapical spine of variable length and conformation protruding beyond curvature of ventral strap; sometimes subapical spine a large hollow elongate prong; if strap bifurcate, posterior surface or edge with variablelength spur, not protruding beyond curvature of ventral strap. Dorsal strap: Emanating from ven- 
tral side of endosomal base, entire or bifurcate with variable length and orientation, apically pointed. Sometimes dorsal strap notched, or ventral strap offset at level of proximal edge of secondary gonopore. Secondary gonopore: Well sclerotized, located medially or just distad of middle of endosoma, aperture open on ventroanterior surface; almost always with prominent proximal process of various size and conformation, usually adhered to proximal margin of secondary gonopore, projecting distad, terminating with variable apex; distal edge of secondary gonopore with microspiculate membranous patch of variable size on lateral surface; sometimes membranous sac emanating from proximal edge of secondary gonopore; sometimes interstrap membrane with very thin sclerite reaching from secondary gonopore to base of endosoma. Phallotheca: Large, variously attenuate apical region with undulate margins and posterior and anterior crest shaped flanges on dorsal aspect, sometimes posterior surface with small spine; aperture on anteroventral surface, long, narrow more broadly open at apex; right anterior margin gently curved-without long narrow spine. Long strut on right margin internally and a curved strongly sclerotized plate on posterior surface; sometimes ventroposterior surface of apical region with outpocket. Parameres: Left paramere: Posterior margin and shoulder region between posterior and anterior processes at most slightly elongate, sometimes with small short protuberance, otherwise typically phyline; posterior process with moderate length, gently attenuate, straight or slightly bent ventrad distally, apex small, rounded, base at most slightly expanded. Right paramere: Subrectangular, moderately elongate, usually with short distal region and small rounded apex; sometimes distal region and apex slightly longer.

FEMALE: Coloration and structure similar to male, except costal margin slightly more convex, frons more produced anteriorly, antennal segment 2 more slender and strongly tapering proximally than in male; total length $2.94-4.83$, pronotum width 1.03-1.71. GENITALIA (pls. 8L-O, 11K-
$\mathrm{M}, 12 \mathrm{~L}-\mathrm{O}, 14 \mathrm{~K}-\mathrm{N}, 15 \mathrm{~K}-\mathrm{N}, 17 \mathrm{~K}-\mathrm{M}, 18 \mathrm{~K}-\mathrm{M}$, 20K-M, 21J-L, 22K-O, 23K-O, 24K-Q, 25M-Q): Posterior margin of sternite 7: Bearing elongate or broadly triangular posteriorly directed projection; sometimes broad proximally and narrow apically. Vestibular sclerites: Size variable, large to moderately large, J-shaped, coiled tube, projecting from right paramedial side of ventral labiate plate or comprising a small shieldlike medioventral extension of ventral labiate plate; in posterior view forming convoluted tube stretching continuously from proximal region of first gonapophyses to strongly microspiculate surface on posterior edge of ventral labiate plate; in dorsal view placed medially between sclerotized rings and sometimes extending to border of right sclerotized ring, to middle of, or to just beyond anterolateral ring margin. First gonapophyses: Symmetrical subtriangular or asymmetrical subrectangular sclerites abutting proximal portion of right vestibular sclerite; with pair of small elongate sclerites distal to base of vestibulum. Ventral labiate plate: Variously sclerotized portion of vestibular base; surface ventral to sclerotized rings microspiculate. Dorsal labiate plate: Relatively large, subhexagonal, transverse, wider than long, lateral margin indented and slightly infolded. Sclerotized rings: Usually large, subovoid, ovoid, or subrectangular, broadly concave, separated by one-half width or width of ring; perimeter narrow, lateral margin sometimes angled and reaching lateral margin of dorsal labiate plate. Posteroventral margin of dorsal labiate plate notched on midline, usually bilateral regions folded on narrow crease, sometimes strongly symmetrically or asymmetrically tumid. Posteromedial region: Ventral surface facing genital chamber forming pair of concave, microspiculate invaginated plates, divided on midline, sometimes medial edges overlap; posterior margins slightly tumid, curved dorsad, forming pocket under base of lateral oviducts and spermathecal gland; sometimes plates strongly sclerotized and spiculate. Anterolateral region: Broad microspiculate region anterior of rings. Intersegmental membrane: With variable invaginated process projecting anteroventrad into genital chamber; shape 
and size variable, usually large subtriangular, membranous with anterior margin microspiculate; sometimes apically notched or posterior margin sclerotized and combined with dorsoposterior plate of posterior wall. Posterior wall: Variably sclerotized, not divided on midline, without paramedial anterior projections; anterior surface microspiculate; usually anterior one-half strongly sclerotized, posterior portion membranous. Interramal sclerites: Widely separated, wedge shaped anteroventrad; midline variably invaginated or depressed with posterior surface abutting bulb of ovipositor; usually knoblike or broadly longitudinal. Interramal lobes: Usually dorsoposterior region with widely separated, gently rounded, and somewhat tumid lateral swellings; when anteromedial region of interramal sclerite broadly invaginated and protuberant posteriad, adjacent paramedial membranous regions somewhat narrowly protuberant.

ETyMology: Named for the occurrence of many of the known species on the genus Melaleuca (Myrtaceae: Melaleuceae). The known hosts for Melaleucaphylus spp. also include members of genera in the Myrtaceae tribes Chamelaucieae, Leptospermeae, and additional genera in the Melaleuceae.

Discussion: Members of this taxon bear an uncanny resemblance to many species that Schuh and Weirauch (2010) placed in the genus Melaleucoides and often share the same host plants (see table 5 and Discussion, p. 96). Examination of both the male and female genitalia, however, indicates that these two genera do not belong to the same tribe within the Phylinae. Schuh and Weirauch (2010) placed considerable emphasis on the weakly fleshy structure of the parempodia in the recognition of the Melaleucoides group of genera (Harpagophylus, Melaleucoides, Thryptomenomiris; see following discussion in Exocarpocorina). Scanning micrographs for species of Melaleucaphylus indicate that fleshy parempodia are more widespread and with a greater diversity of form than previously recognized (see figs. 4, 9, 13, 14B).

The diagnosis of this genus is based primarily on the unique features of the endosoma. In particular, we point to the presence of a prominently thick, twisted proximal extension or process of the secondary gonopore, a variable projection emanating from the ventral strap located apically or subapically on the posterior surface, and the usually bifurcated apical spine of the dorsal strap. The female genitalia do not have the array of diverse paramedial structures projecting anteriad into the genital chamber from the mostly membranous, medially divided posterior wall as documented by Schuh and Weirauch (2010) for multiple species of Melaleucoides (Semiini, Exocarpocorina). In contrast, Melaleucaphylus spp. have a medially undivided, well-sclerotized posterior wall with an obvious pair of lateral subquadrate interramal sclerites on the anterior portion: one, a variably sclerotized invagination of the medial portion that projects posteriad and abuts the base of the ovipositor and the other a medial invagination or process of the intersegmental membrane situated between the posterior margin of the dorsal labiate plate and the posterodorsal margin of the posterior wall that projects ventrad into the genital chamber. The ventral surface of the intersegmental invagination is usually microspiculate and variably notched apically. In those species where the vestibulum is appreciably developed the vestibular sclerites are either arranged medially or slightly bent to the right. The sclerotized rings of Melaleucaphylus are consistently large, thin walled, and usually subovoid. The dorsal labiate plate in some species of Melaleucaphylus has a pair of thin, tumid, membranous lobes on the posterior edge, a feature of the female genitalia not previously documented in phylines.

The endosoma in Melaleucaphylus can be organized into several groups. Some of the species united by endosomal structure also share features of the female genitalia. Almost all the species in which the posterior surface of the ventral strap has a small subapical spine also haveto a varying degree-a paired billowy membrane on the posterior edge of the dorsal labiate plate, a longitudinal deep invagination of the medial 
portion of the posterior wall, flat intersegmental process with an entire apical margin, and an angulate lateral edge of the sclerotized rings.

Host-plant Associations: Of the Melaleucaphylus spp. with known hosts, there is strong evidence that all these plants belong to three tribes of Myrtaceae (subfamily Myrtoideae); only $2 \%$ of Melaleucaphylus specimens collected were not taken from myrtaceous plants (see tables 1 and 2). For $M$. nodosae, M. omnivorus and $M$. vimineae, three species with many well-documented myrtaceous host plants, non-Myrtaceae records were considered to be commingling of specimens in the field. Host associations for $M$. dubiosus, M. kaputar, and M. ngarkat, are unknown and will be determined only through additional field work. Melaleucaphylus spp. were found on 5 genera of Chamelaucieae (17\% of host spp.), 2 genera of Leptospermeae (6\% of host spp.), and 4 genera of Myrtaceae (78\% of host spp.). Melaleuca and Beaufortia (Melaleuceae) are the most utilized of the 11 genera of myrtaceous hosts $(74 \%$ and $12 \%$ of individual host associations respectively). Baeckea is the most utilized Chamelaucieae with $7 \%$ of the individual host associations; Calytrix, Pileanthus, Scholtzia, and Verticordia are known from singleinstance host associations. For the Leptospermeae single-instance host associations are documented for Kunzea and Leptospermum.

Of the 15 spp. of Melaleucaphylus with known hosts $83 \%$ of the individual host associations are known by a single collecting event, $12 \%$ by two collecting events, and $5 \%$ by 4 collecting events. Almost one-half of Melaleucaphylus spp. are apparently restricted to a single host-plant species (M. eremaeae, M. glomeratae, M. halmaturorum, M. kunzeae, M. pauperiflorae, $M$. rhaphiophyllae, and M. viridiflorae), 3 spp. ( $M$. beaufortiae, $M$. micranthae, $M$. sheathianae) have 2 hosts, 2 spp. (M. nodosae, M. phymatocarpi) have 3 hosts. Three Melaleucaphylus spp. have more numerous hosts: $M$. omnivorus (8 spp.), $M$. polyphagus (6 spp.), and M. vimineae (9 spp.). Five Melaleucaphylus spp. (M. nodosae, $M$. omnivorus, M. phymatocarpi, M. polyphagus, and
M. vimineae) are found on hosts of more than one Myrtaceae tribe.

Geographical Distribution: As presented in table 4, eight of the 18 Melaleucaphylus spp. are known solely from a limited region in southwestern Western Australia of high botanical endemism; two of these species are also found in desertic habitats of the Northern Territory, South Australia, and Victoria. The remaining species of Melaleucaphylus are known from New South Wales (4 spp.), Northern Territory (2 spp.), South Australia (1 sp.), and Victoria (1 sp.). The southwestern portion of Western Australia comprises all of the southwestern and southwest interzone subregions of the phytogeographical classification of Australia (González-Orozco et al., 2014; Ebach et al., 2015) as well as the western borders of the western and eastern desert subregions. For Melaleucaphylus $58 \%$ of the species and $60 \%$ of the collection events and specimens occurred in these 4 subregions of Western Australia. The southeastern subregion in New South Wales supports the next highest number of species (12\%), collection events (20\%), and specimens (15\%). Two species, $M$. polyphagus and $M$. vimineae are shared by more than one state and subregion; only the former is known east and west of the Nullarbor Plain with the latter occurring in southwestern Western Australia and the central desert region of Northern Territory.

\section{Melaleucaphylus beaufortiae, new species}

Figure 4A, B, map 2, plates 1, 8, table 1

Diagnosis: Distinguished among those congeners having an endosoma with a small subapical spine on posterior surface of ventral strap, and by dark brown to black dorsal coloration confined to frons and vertex medially and posterior margins of head and pronotum. Melaleucaphylus halmaturorum with most of frons and calli dark; M. micranthae with only frons medially dark-vertex and pronotum pale; $M$. nodosae is entirely dark; $M$. pauperiflorae with coloration as in M. halmaturorum; M. phymato- 

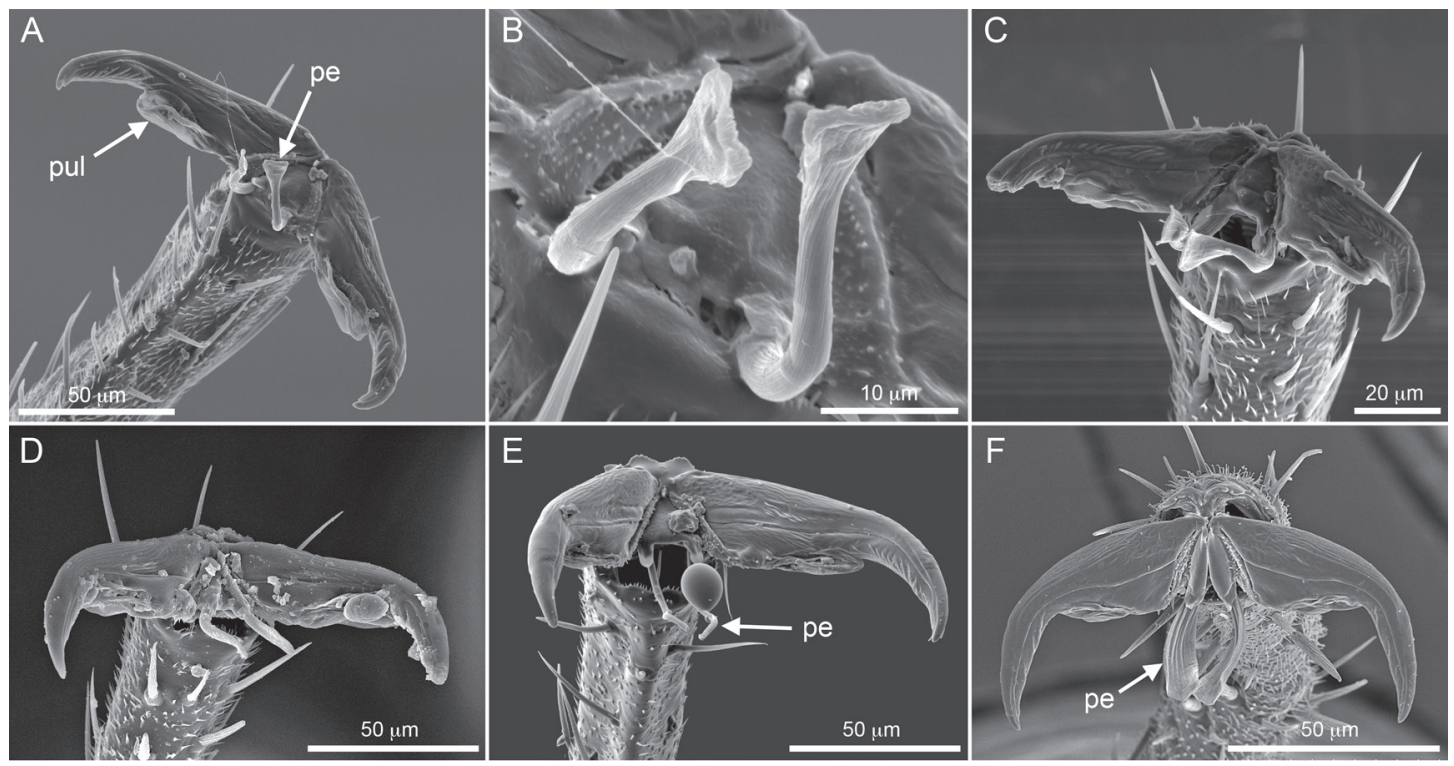

FIG. 4. Melaleucaphylus spp. Scanning electron micrographs of pretarsus. A, B. M. beaufortiae, AMNH_PBI 00087288. A. Frontoventral view. B. Detail of parempodia, ventral view. C. M. eremaeae, AMNH_PBI 00136216, frontoventral view. D. M. glomeratae, AMNH_PBI 00418691, frontoventral view. E. M. halmaturorum, AMNH_PBI 00371542, frontoventral view. F. M. kunzeae, AMNH_PBI 00128299, frontal view. Abbreviations: pe, parempodium; pul, pulvillus.

carpi generally dusky with dark frons and calli and endosoma with distal portion of dorsal strap bent; $M$. rhaphiophyllae with contrasting pale and dark coloration on hemelytron, sometimes hemelytron in $M$. rhaphiophyllae predominately pale but larger body (length 3.73-4.01 in males and 4.02-4.46 in females) and fine differences in endosomal structure unequivocally separate these two species. In M. beaufortiae apical spines of dorsal strap are shorter and with slightly thicker diameter than in M. rhaphiophyllae and distal region of dorsal strap is bent ventrad with apices separated by a variable distance, sometimes rather wide, and apices never contiguous over entire length of spine as in M. rhaphiophyllae. General coloration of $M$. viridiflorae similar to $M$. beaufortiae, but endosoma of former species unique among Melaleucaphylus spp.

Description: Male: Mean total length 3.16, mean pronotum width 1.12. COLORATION (pl. 1): Dusky yellow, black medial stripe extending dorsad from labrum, clypeus, to frons as some- what narrow band with convex lateral margins, reaching vertex, then expanding laterally to cover posterior margin of head; antenna with segment 2 yellowish red with distal one-third dark, segments 3 and 4 dark; pronotum including calli pale; posterior margin and humeral angles variably darkened, sometimes almost one-half of posterior lobe brownish black or dark coloration narrow, restricted to humeral angles and edge of posterior margin, anterior margin of variable dark pronotal marking always diffuse; tibia without dark spots at bases of spines. SURFACE AND VESTITURE (pl. 1): Subshining; dorsum with moderately dense, curved, reclining black simple setae; tibia with black spines. STRUCTURE: Labium reaching to base of metacoxa. Pretarsus: Claws relatively small, gently curved; parempodia relatively long, somewhat lamelliform, parallel for most part, terminating in converging, expanded and truncate apices; pulvilli with medium size and height, proximad of angle of claw (fig. 4A). GENITALIA (pl. 8A-K): Pygo- 
phore: As in generic description. Endosoma: Distal one-third with torsion, twisted to left side; ventral strap entire reaching to proximal end of secondary gonopore, apex formed by anterior surface broadly curved; posterior surface with small, narrow, smooth margined, distally hooked, pointed subapical spine, protruding beyond curvature of ventral strap with length as long as width of secondary gonopore; dorsal strap bifurcate at base of secondary gonopore, divided into pair of equal-length, sharply pointed spines, length of spines equal to $2.5 \times$ length of secondary gonopore, spines slightly diverging near apex of secondary gonopore, then parallel for remaining length, terminating with gradually tapering pointed apices, distance between apices variable, sometimes wide or apices practically contiguous. Secondary gonopore: Well-sclerotized, deep, located just distad of middle of endosoma, surface of aperture convoluted, proximal edge with large, well-sclerotized, irregularly shaped process ringing and projecting proximal to aperture, distal edge with small microspiculate membranous patch on lateral surface. Phallotheca: As in generic description. Parameres: Left paramere: Posterior margin and shoulder region between posterior and anterior processes with small protuberance not elongate; posterior process slightly bent ventrad, otherwise like generic description. Right paramere: As in generic description.

Female (pl. 1): Coloration as in male; differing from male as in generic description; mean total length 3.51 , mean pronotum width 1.21 . GENITALIA (pl. 8L-O): Posterior margin of sternite 7: With broadly triangular projection. Vestibular sclerites: Moderately large, J-shaped, convoluted, lateral margin curved, extending to right side, anterior edge reaching anterior border of ring and reaching within medial margin of right ring in dorsal view; tube weakly sclerotized near ventral labiate plate and enlarged, triangular basal sclerites of first gonapophyses; strongly sclerotized on medioventral extension of ventral labiate plate. Dorsal labiate plate: Moderately large, ovoid; posteroventral edge strongly tumid, asymmetrical. Sclerotized rings:
Large, subovoid, medial rounded, borders narrow, separated by one-half width of ring, lateral margin of ring angled, reaching lateral margin of dorsal labiate plate. Intersegmental process: Large, broad, bracket shaped, weakly sclerotized, and microspiculate, apical margin entire, slightly pointed. Posterior wall: Medium sized, anterior one-half sclerotized. Interramal sclerites: With broad, vertical, somewhat shallow, posteriorly directed, medial prominence abutting ovipositor bulb; ventrolateral region with strongly sclerotized subrectangular extension. Interramal lobes: Dorsolateral region hyaline, lateral regions without microspicules; region on either side of medial prominence not tumid or produced into genital chamber.

ЕтумоLоgy: Named for its occurrence on the plant genus Beaufortia.

Hosts: Recorded from Beaufortia elegans (pl. 37A) and B. sprengelioides (pl. 37C) (Myrtaceae: Melaleuceae).

Distribution (map 2): Known from three collecting events in Kalbarri National Park and Shark Bay region of Mid-West Gascoyne, Western Australia; the extreme northwest part of the southwestern phytogeographic subregion.

Discussion: Some specimens are almost uniformly pale; these can be distinguished from $M$. rhaphiophyllae by smaller body size and endosomal structure (see Diagnosis).

Holotype: AUSTRALIA: Western Australia: Kalbarri National Park, Z-Bend Road, $26.61238^{\circ} \mathrm{S} 114.4386^{\circ} \mathrm{E}, 500 \mathrm{~m}, 28$ Oct 1996 , Schuh and Cassis, Beaufortia elegans Schauer (Myrtaceae), det. PERTH staff PERTH 05120535, 10 (AMNH_PBI 00087287) (WAMP).

PARATYPES: AUSTRALIA: Western Australia: Kalbarri National Park, Z-Bend Road, 27.61971 $114.3864^{\circ} \mathrm{E}, 500 \mathrm{~m}, 28$ Oct 1996, Schuh and Cassis, Beaufortia elegans Schauer (Myrtaceae), det. PERTH staff PERTH 05120535, 1 † (00372146), 2 우 (00372149, 00372151) (AM), 1 우 (00372150) (AMNH), 2 ㅇ (00372147, 00372148) (WAMP). Kalbarri National Park, Z-Bend Road, $26.61238^{\circ} \mathrm{S}$ $114.4386^{\circ} \mathrm{E}, 500 \mathrm{~m}, 28$ Oct 1996, Schuh and Cassis, Beaufortia elegans Schauer (Myrtaceae), det. 
PERTH staff PERTH 05120535, 1 (00087288), $10^{\text {Tे }}$ (00087491) (AM). Useless Loop Rd ca. $20 \mathrm{~km}$ $\mathrm{W}$ of jct with Shark Bay Rd, $26.56331^{\circ} \mathrm{S} 113.9338^{\circ} \mathrm{E}$, $30 \mathrm{~m}, 25$ Oct 2004, Cassis, Wall, Weirauch, Symonds, Beaufortia sprengelioides (DC.) Craven (Myrtaceae), det. PERTH staff PERTH 6987729, 1 †ิ (00412912), 1 ㅇ (00412913) (AMNH).

\section{Melaleucaphylus dubiosus, new species}

$$
\text { Map 2, plates 1, 9, table } 1
$$

Diagnosis: Distinguished from congeners by pale yellow general coloration with diffuse pale brown centrally on scutellum, clavus, and endocorium, and striking dark infuscate hemelytral membrane. Male genitalia unique within genus by very large, pointed, tusklike spine projecting dorsad from ventral strap of endosoma and distinct prominence on posterodorsal surface of phallotheca.

Description: Male: Total length 3.34, pronotum width 1.13. COLORATION (pl. 1): Pale yellow to yellow with antennal segments 3 and 4, scutellum, clavus, and endocorium darker tan to brown; membrane infuscate, veins pale; tibia without dark spots at bases of spines. SURFACE AND VESTITURE (pl. 1): Shining; dorsum with moderately dense, curved, reclining, shining, tan or golden simple setae; tibia with tan spines. STRUCTURE: Labium reaching to middle of mesocoxa. Pretarsus: Claws small, gently curved, with slightly expanded bases; parempodia setiform, relatively long parallel, with apparently sharp apices; pulvilli minute, short, on proximal edge of claw base. GENITAliA (pl. 9): Pygophore: As in generic description. Endosoma: Distal one-third with torsion, twisted slightly to left side; well sclerotized from base to proximal portion of basal curve then bifurcate with sharp split, medially divergent with wide interstrap membrane; ventral strap bifurcate proximal of secondary gonopore with short anterior portion of strap terminating in broad flat surface at proximal margin of secondary gonopore and with long posterior portion of strap forming large tusklike spine $1.5 \times$ length of secondary gono- pore with pointed apex; dorsal strap undivided, narrow over entire length, portion distal to secondary gonopore slightly curving to right, apex pointed. Secondary gonopore: Well sclerotized, deep, with proximalmost margin thin and with well-sclerotized process, distal portion of proximal process short, not expanded caudally (as in other species); distal margin with small, membranous, constricted bag with microspiculate surface. Phallotheca: Narrow, with small tubercle on posterior surface, otherwise as in generic description. Parameres: Left paramere: Posterior margin and shoulder region between posterior and anterior processes slightly raised; posterior process slightly bent ventrad, otherwise as in generic description. Right paramere: Somewhat narrowed apically, otherwise as in generic description.

Female (pl. 1): Coloration as in male; differing from male as in generic description; total length 3.29, pronotum width 1.20. GENITALIA: Not examined.

Eтymology: From the Latin dubius, "doubtful" for the weak host association of the only plant record.

Host: Recorded from Notelaea microcarpa (Oleaceae). In light of the fact that nearly all other members of Melaleucaphylus are recorded from the family Myrtaceae and that only three specimens of this taxon are available, corroboration of the actual breeding host of this taxon will require additional fieldwork.

Distribution (map 2): Known only from the type locality near Warrabah National Park, west of Retreat, New South Wales, in the southeastern phytogeographic subregion.

Holotype: AUSTRALIA: New South Wales: $37 \mathrm{~km} \mathrm{~W}$ of Retreat (20 km E of Manilla), $30.66667^{\circ} \mathrm{S} 150.8^{\circ} \mathrm{E}, 450 \mathrm{~m}, 24$ Oct 1995 , Schuh and Cassis, Notelaea microcarpa R. Br. (Oleaceae), det. Field ID, 10 (AMNH_PBI 00087293) (AM).

PARATyPes: AUSTRALIA: New South Wales: $37 \mathrm{~km} \mathrm{~W}$ of Retreat (20 km E of Manilla), $30.66667^{\circ} \mathrm{S} 150.8^{\circ} \mathrm{E}, 450 \mathrm{~m}, 24$ Oct 1995 , Schuh and Cassis, Notelaea microcarpa R. Br. (Oleaceae), det. Field ID, 19 (00087294) (AM), 10 (00087494) (AMNH). 


\section{Melaleucaphylus eremaeae, new species}

Figure $4 \mathrm{C}$, map 2, plates 1, 10, table 1

Diagnosis: Distinguished by the smaller body, short, somewhat thickened antennal segment 2; overall dull olive gray to olive orange coloration, cuneus concolorous with hemelytron; and ventral strap of endosoma without projection from posterior edge. Other features discriminating $M$. eremaeae from $M$. omnivorus are apically dark antennal segment 2 in female, lamelliform lyrelike parempodia, and length and curvature of anterior and posterior spines of endosomal dorsal strap (former species with confluent apical spines and posterior spine shorter than anterior spine, latter species with diverging apical spines and posterior spine longer than anterior spine, in dorsal view).

Description: Male: Mean total length 3.00, mean pronotum width 1.08. COLORATION (pl. 1): General coloration dark dull olive gray to slightly paler olive orange, cuneus concolorous with hemelytron, not shades of red; narrow apical band of antennal segment 2 diffusely black; clypeus, central portion of frons, antennal segments 3 and 4, calli, tibia distally, and phallotheca dusky; wide periphery of hemelytral membrane fumose, hyaline near veins and cuneus, veins dusky yellow; tibia without dark spots at bases of black spines, tarsus black; abdomen concolorous with dorsum. SURFACE AND VESTITURE (pl. 1): Shining; dorsum with moderately dense, curved, reclining, black, simple setae; ventral surface of thorax and distal and lateral surfaces of all coxae with black bristlelike setae. STRUCTURE: Antennal segment 2 relatively short; labium reaching apex of mesocoxa. Pretarsus: Claws relatively small, slightly curved, bases not enlarged; parempodia lamelliform, lyrelike, apices expanded, truncate; pulvilli moderate sized, proximad of angle of claw (fig. 4C). GENITAliA (pl. 10): Pygophore: Relatively broad in dorsal view, dorsal surface with only a few longer bristles near both paramere insertions. Endosoma: Ventral strap entire, terminating level with middle of secondary gonopore, anterior surface with smooth margin reaching to posterior edge; posterior edge without process; dorsal strap bifurcate level with apex of secondary gonopore, divided into pair of narrow, approximately equal-length, gently curved parallel sharp spines, both spines projecting over left side of endosoma, reaching approximately $2 \times$ length of secondary gonopore; only apex of posterior spine diverging from apex of anterior spine, otherwise proximal length of both spines gently curving together; posterior spine shorter than anterior spine by $2 \times$ diameter of apex of spine. Secondary gonopore: Well-sclerotized, proximal edge with indistinct microspiculate membrane and well-sclerotized process wrapped around proximal margin of secondary gonopore, then expanded into small triangular apex, proximal edge of apex not narrowed. Phallotheca: Moderately sized, relatively narrowed apical region with short, low prominence on posterior surface; elongate ovoid aperture on anterior surface. Parameres: Left paramere: Compressed, triangular, in dorsal view, posterior processes with expanded base, abruptly narrowed, longer than anterior process; anterior process short, apex small, smoothly rounded; posterior surface of paramere without protuberance. Right paramere: Moderate length, margins smoothly rounded; apex short slightly notched.

Female (pl. 1): Coloration as in male; differing from male as in generic description; mean total length 3.55 , mean pronotum width 1.21 . GENITALIA: Not examined.

ETyMology: Named for its occurrence on the genus Eremaea.

Host: Recorded from Eremaea beaufortioides var. beaufortioides (Myrtaceae: Melaleuceae) (pl. 37F).

Distribution (map 2): Known only from the type locality on the west coast of Western Australia north of Perth in the southwestern phytogeographic subregion.

Holotype: AUSTRALIA: Western Australia: Eneabba on Brand Hiway, $29.80735^{\circ} \mathrm{S}$ $115.2699^{\circ} \mathrm{E}, 100 \mathrm{~m}, 31$ Oct 1996 , Schuh and Cassis, Eremaea beaufortioides Benth. var. beauforti- 
oides (Myrtaceae), det. PERTH staff PERTH 05120187, 10 (AMNH_PBI 00136216) (WAMP).

Paratypes: AUSTRALIA: Western Australia: Eneabba on Brand Hiway, $29.80735^{\circ} \mathrm{S}$ $115.2699^{\circ} \mathrm{E}, 100 \mathrm{~m}, 31$ Oct 1996, Schuh and Cassis, Eremaea beaufortioides Benth. var. beaufortioides (Myrtaceae), det. PERTH staff PERTH 05120187, 4ठ (00136212, 00136215, 00136218, 00136220) (AM), 3 đ (00136213, 00136217, $00136219), 1$ 우 $(00136221)(\mathrm{AMNH}), 1$ 우 (00136222) (WAMP).

\section{Melaleucaphylus glomeratae, new species}

Figures 4D, 5, map 2, plates 1, 11, table 1

DiAgnosis: Distinguished by generally yellow coloration, on vertex near eyes, calli, and mesoscutum without occasional orange blotches as seen in M. vimineae (see Discussion); pale dorsal setae and pale or pale brown tibial spines; parempodia uniformly but weakly thickened; endosoma with single long narrow apical spine of dorsal strap and distal surface of secondary gonopore with pair of strongly spiculate relatively tumid membranes. Endosoma of $M$. ngarkat also with apical spine of dorsal strap undivided and strongly spiculate distal portion of secondary gonopore, but body uniformly castaneous to dark brown, dorsal setae silvery, tibial spines black, and parempodia setiform.

Description: Male: Mean total length 3.83, mean pronotum width 1.31. COLORATION (pl. 1): Uniformly yellow; apex of cuneus with indistinct dark marking; hemelytral membrane weakly hyaline with barely perceptible, small, diffuse, black markings medial to anal vein; more strongly infuscate at apex of large cell, middle of small cell, and adjacent to apex of cuneus; tibia without dark spots at bases of spines. SURFACE AND VESTITURE (fig. 5B, pl. 1): Weakly shining; dorsum with moderately dense, curved, reclining, entirely pale, subshining, simple setae; tibial spines pale. STRUCTURE: Labium reaching apex of mesocoxa. Pretarsus: Claws moderately sized, abruptly bent; parempodia evenly thick, lamelliform; pulvilli short, situated from angle to base of claw (fig. 4D). GENITALIA (fig. 5D, pl. 11A-J): Pygophore: Conical in dorsal view, dorsal surface with small clump of bristles ventrad of left paramere insertion. Endosoma: Region just proximal to apex with torsion to left side; ventral strap entire, wide, terminating at base of secondary gonopore with smooth concave anterior edge, posterior edge without process, but with hollow margin; dorsal strap narrow, not bifurcate, strap narrowing over length to pointed apex, surpassing distal margin of secondary gonopore by length of secondary gonopore, moderately curved to left side of endosoma. Secondary gonopore: Large, well differentiated, and sclerotized; distal edge large, tumid, sinuate, with strong spicules on surface and rolled under apex; proximal edge of gonopore aperture strongly associated with relatively long, mostly sclerotized microspiculate lateral membrane, strongest spicules on entire edge nearest aperture; opposite surface of secondary gonopore wide, somewhat tumid, as a thickened microspiculate membrane; proximal portion of secondary gonopore with overlapped edge extending caudally as wellsclerotized expanded process; thin gonopore sclerite absent. Phallotheca: Large, attenuate apical region with weakly undulate anterior surface and weak crest along dorsal edge; ventroposterior surface with obvious outpocket; aperture on anteroventral surface with medium length and moderately open. Parameres: Left paramere: Triangular in dorsal view, posterior process relatively short; anterior process very short, weakly extending beyond base, apex poorly differentiated; posteromedial region of paramere body not raised dorsal to posterior and anterior lobes. Right paramere: Moderate size with smoothly rounded margins; gradually narrowed to small blunt apex.

Female (pl. 1): Coloration as in male; differing from male as in generic description; mean total length 3.80 , mean pronotum width 1.32 . 

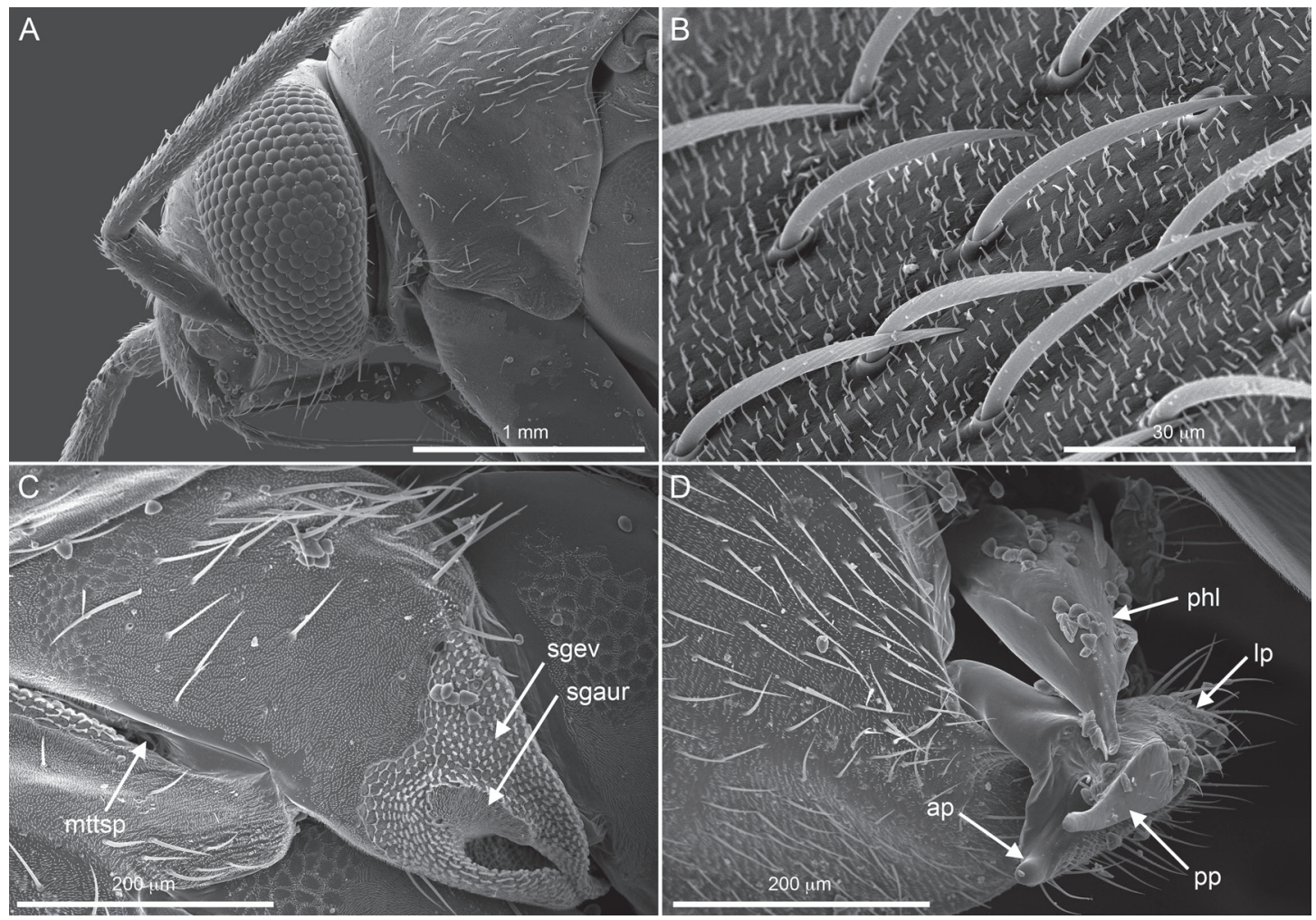

FIG. 5. Melaleucaphylus glomeratae, AMNH_PBI 00418691. Scanning electron micrographs. A. Head and pronotum, lateral view. B. Detail of pronotal setae, dorsal view. C. Thoracic pleuron, lateral view, showing metathoracic spiracle opening, metathoracic scent-gland auricle, and evaporatory area. D. Pygophore, left paramere, and phallotheca, lateral view. Abbreviations: ap, anterior process; lp, left paramere; $\mathbf{m t t s p}$, metathoracic spiracle; $\mathbf{p h l}$, phallotheca; pp, posterior process; sgaur, scent gland auricle; sgev, scent gland evaporatory area.

GENITALIA (pl. 11K-M): Subgenital plate: With elongate, relatively narrow projection. Vestibular sclerites: Moderately large, convoluted, situated medially, bent slightly to right side, predominately extending anteriad, anterior margin almost reaching to anterior and medial border of right sclerotized ring and occupying interring region in dorsal view. Dorsal labiate plate: Sclerotized rings large with narrow border, subovoid and separated by onehalf width of ring, lateral margin of ring rounded, reaching lateral margin of dorsal labiate plate; posteroventral margin folded, not tumid. Intersegmental process: Membrane strongly invaginated, forming relatively short, heavily microspiculate, apically bifurcate, medial prominence. Posterior wall: Mostly membranous. Interramal sclerites: Well sclerotized, wedge shaped, widely separated, and placed on ventrolateral margins; midline of wall with large invagination abutting ovipositor bulb, projecting posteriad to form a pointed prominence. Interramal lobes: Posterodorsal portion of wall membranous, with pair of large, widely separated, tumid, microspiculate lobes projecting anteriorly into genital chamber.

EтумоLogy: Named for its occurrence on Melaleuca glomerata.

Host: Recorded from Melaleuca glomerata (Myrtaceae: Melaleuceae) (pl. 39B).

Distribution (map 2): Known from two collecting events from south central Northern Territory in the eastern desert phytogeographic subregion. 
Discussion: Collected concurrently and apparently on the same host plant with $M$. vimineae near Alice Springs and Finke Gorge National Park of Northern Territory. Both species with almost identical dorsal coloration, however, $M$. vimineae usually has orange blotches on the vertex, calli, and mesoscutum, dark dorsal setae on cuneus and posterior portion of clavus and corium, black tibial spines, wider parempodia, smaller endosoma with shorter distal portion of dorsal strap, and much less spiculate region distal to secondary gonopore.

Holotype: AUSTRALIA: Northern Territory: $11 \mathrm{mi} \mathrm{N}$ of Alice Springs, $23.53956^{\circ} \mathrm{S}$ $133.8807^{\circ} \mathrm{E}, 625 \mathrm{~m}, 28$ Oct 1962, Ross and Cavagnaro, $10^{\widehat{ }}$ (AMNH_PBI 00418698) (MAGNT).

PARATYPES: AUSTRALIA: Northern Territory: $11 \mathrm{mi} \mathrm{N}$ of Alice Springs, $23.53956^{\circ} \mathrm{S} 133.8807^{\circ} \mathrm{E}$, $625 \mathrm{~m}, 28$ Oct 1962, Ross and Cavagnaro, $60^{\star}$ (00418689, 00418692, 00418697, 00418703, 00418712, 00418725), 1 우 (00418732) (AMNH), 22 ○ิ (00418688, 00418690, 00418691, 0041869300418696, 00418699-00418702, 0041870400418711, 00418713, 00418714, 00418716), 6 우 (00418727, 00418728, 00418731, 0041873300418735) (CAS), 8 주 (00418717-00418724), 3 우 (00418726, 00418729, 00418730) (MAGNT). Finke Gorge National Park, Palm Valley, $24.03333^{\circ} \mathrm{S}$ $132.7101^{\circ} \mathrm{E}, 586 \mathrm{~m}, 04$ Nov 2001, Cassis, Schuh, Schwartz, Silveira, Wall, Melaleuca glomerata F. Muell. (Myrtaceae), det. NSW staff NSW 666320, 1 đ (00097887), 1 우 (00097904) (AM), 15 ๙ (00097875-00097886, 00097889, 00414797, 00414796), 18 ㅇ (00097890-00097892, 0009789400097901, 00097906, 00097908, 0041479800414801, 00414880) (AMNH), 1 đ (00097888), $1+$ (00097905) (ANIC), $7 ㅇ$ (00097902, 00097903, 00097907, 00097909-00097912) (MAGNT).

\section{Melaleucaphylus halmaturorum, new species}

Figures 4E, 6, map 2, plates 2, 12, table 1

DiAgnosis: Recognized by coloration with bright orange red on discrete central portion of cuneus, black antenna, frons, calli, and middle of mesoscutum, and bright orange lateral shoulders of mesoscutum and medial base of scutellum. Endosoma very similar to $M$. beaufortiae, $M$. micranthae, M. nodosae, M. pauperiflorae, and M. rhaphiophyllae-all having a small subapical spine on posterior edge of ventral strap protruding beyond the curvature of strap in lateral view. Endosoma in M. halmaturorum most similar to that in $M$. pauperiflorae, but endosoma in $M$. halmaturorum larger, with longer apical spines of dorsal strap that are also divergent; in $M$. pauperiflorae endosoma smaller and the shorter apical spines of dorsal strap are convergent and contiguous over entire length.

Description: Male: Mean total length 4.10, mean pronotum width 1.40 . COLORATION (pl. 2): General coloration pale to dark olive yellow with variable dark brown to black areas on clypeus, frons, antenna, labium, calli, humeral angles of pronotum, mesoscutum, claval commissure, exocorium, femora, third tarsal segment, ventral aspect of thorax, venter, and pygophore; orange on mesoscutum sublaterally, base and midline of scutellum, cuneus centrally and on posterior margin of adjacent hemelytral membrane, as well as sometimes on paracuneus; white or cream color on mesepimeron dorsally and metepisternal scent gland evaporative area and auricle; hemelytral membrane slightly fumose; veins pale brown; tibial spines black, without dark spots at bases. SURFACE AND VESTITURE (pl. 2): Shining; dorsum predominantly with moderately dense, curved reclining golden simple setae; some black simple setae on pronotum and cuneus. STRUCTURE: Labium reaching base of metacoxa. Pretarsus: Claws moderately large, slightly curved, bases slightly enlarged; parempodia setiform, relatively long, apices apparently clipped and converging; pulvilli, length medium, height low, proximad of angle of claw (fig. 4E). GENITALIA (fig. 6D, pl. 12A-K): Pygophore: As in generic description. Endosoma: Distal one-third with torsion, twisted to left side; ventral strap entire, anterior surface with truncate apical margin, reaching level to base of second- 

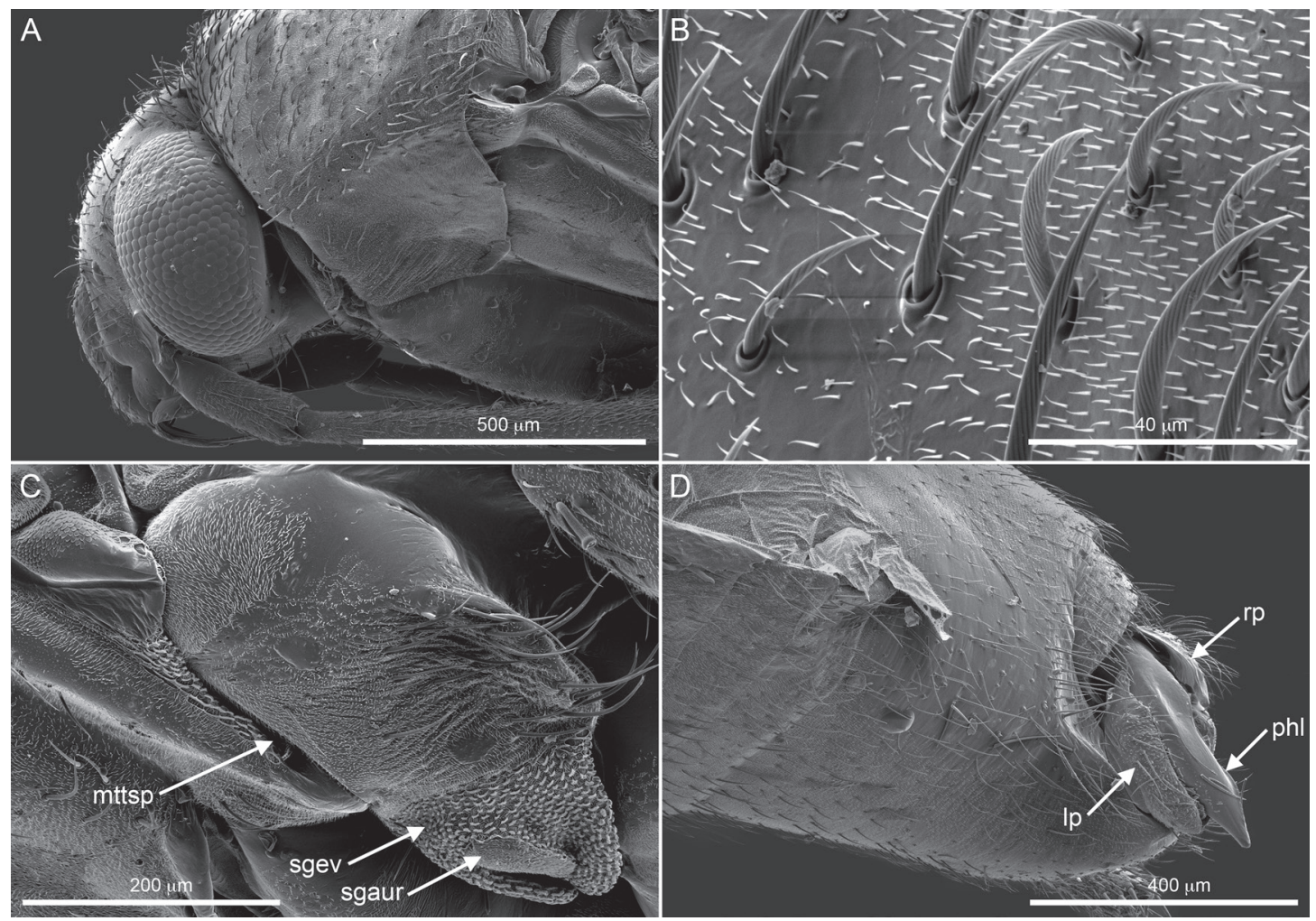

FIG. 6. Melaleucaphylus halmaturorum, AMNH_PBI 00371542. Scanning electron micrographs. A. Head and pronotum, lateral view. B. Detail of pronotal setae, dorsal view. C. Thoracic pleuron, lateral view, showing metathoracic spiracle opening, metathoracic scent-gland auricle, and evaporatory area. D. Pygophore, left paramere, phallotheca, and right paramere, lateral view. Abbreviations: lp, left paramere; mttsp, metathoracic spiracle; phl, phallotheca; rp, right paramere; sgaur, scent gland auricle; sgev, scent gland evaporatory area.

ary gonopore; posterior edge with hooked, hornshaped, pointed subapical spine, protruding beyond curvature of ventral strap; subapical process originating level to proximal end of secondary gonopore process with length subequal to anterior apical margin of ventral strap; dorsal strap bifurcate at level of distal end of secondary gonopore, divided into pair of sharply pointed mostly adjacent apical spines-large anterior spine extending distad of secondary gonopore $2.25 \times$ length of secondary gonopore ring; small posterior spine slightly fusiform at base, diverging from anterior apex at base, adjacent for most of length, and converging at apex. Secondary gonopore: Well sclerotized, located medially; aperture open on ventroanterior surface, proximal edge with large, well-sclerotized, lanceolate process, lateral surface with microspiculate membrane; interstrap region with extremely thin, gently curved gonopore sclerite located within, stretching from relatively straight proximal end of secondary gonopore to base of endosoma level with bifurcation of straps. Phallotheca: Large, somewhat attenuate, apical region with undulate margins and posterior surface with small crest shaped flanges distally and broad prominence proximally; aperture on anteroventral surface, long, evenly narrow to apex. Parameres: Left paramere: Posterior margin and shoulder region between posterior and anterior processes not appreciably elongate, otherwise typically phyline; posterior process short, gently attenuate from expanded base, straight distally, apex small, rounded. Right paramere: 
Subovate, moderately elongate with short distal region and small rounded apex.

Female (pl. 2): Coloration as in male, except red on endocorium merging with red on cuneus and only apex of antennal segment 2 black, otherwise differing from male as in generic description; mean total length 4.36 , mean pronotum width 1.58 . GENITALIA (pl. 12L-O): Posterior margin of sternite 7: With broadly triangular, attenuate projection. Vestibular sclerites: Large, J-shaped, convoluted, lateral margin curved, extending to right side; anterior edge level with anterior border of ring, reaching to middle of right ring in dorsal view; tube variably sclerotized, faint near ventral labiate plate, strongest on medioventral extension of ventral labiate plate and diminished at enlarged quadrate basal sclerites of first gonapophyses. Dorsal labiate plate: Large; posteroventral margin of dorsal labiate plate folded, enlarged posteriad, slightly tumid. Sclerotized rings: Large, subovoid, borders narrow, separated by width of ring, lateral margin of ring angled, removed from lateral margin of dorsal labiate plate. Posteromedial region: Strongly microspiculate, posterior margin deeply incised on midline, strongly upturned ventral to lateral ovipositors. Intersegmental process: Large, membranous, broad, bilobed apically, strongly microspiculate. Posterior wall: Large, anterior onehalf strongly sclerotized; with broad, vertical, medial invagination on anterior surface, posteriorly directed prominence abutting ovipositor bulb. Interramal sclerites: Ventrolateral regions with strongly sclerotized subrectangular extensions. Interramal lobes: Dorsolateral region hyaline, lateral regions with extensive microspicules; regions either side of medial prominence not tumid or produced into genital chamber.

ETymology: Named for its occurrence on Melaleuca halmaturorum.

Hosт: Recorded from Melaleuca halmaturorum (Myrtaceae: Melaleuceae) (pl. 39C, D).

Distribution (map 2): Only known from the type locality in Jeparit Environmental Park, Grampians region of west central Victoria, at the southeastern edge of the eastern desert phytogeographic subregion.
Discussion: Twenty-two adult specimens from Credo Station, WA (387568-387589) are very similar to M. halmaturorum in terms of the endosomal structure; however, the only genitalic preparations are from teneral specimens. All these specimens were taken on Melaleuca phoidophylla Barlow ex Craven (Melaleuceae) a plant not known as a host of any species treated in the current study. The posterior apical spine of the dorsal strap in M. halmaturorum is fusiform, and mostly parallel to the anterior apical spine of the dorsal strap. The same structures in the Credo specimens differ by the posterior apical spine bent and converging into the anterior apical spine of the dorsal strap. Because the structures of the endosoma are weakly sclerotized their shapes are probably distorted. There are obvious coloration differences that prevent us from placing Credo specimens in M. halmaturorum (compare photos of 371513 and 387572 in plate 2). The former specimens do not have a discrete red patch on the cuneus offset by pale borders, but have variable brown coloration on the cuneus; in addition, each cell of the hemelytral membrane-as well as adjacent to the apex of the large cell-has a discrete red blotch not observed in M. halmaturorum. The teneral condition of these specimens precludes their description.

Holotype: AUSTRALIA: Victoria: Jeparit Environmental Park, $36.14047^{\circ} \mathrm{S} 141.9643^{\circ} \mathrm{E}, 90$ m, 05 Nov 2002, Cassis, Schuh, Schwartz, Silveira, Melaleuca halmaturorum F. Muell. ex Miq. (Myrtaceae), det. NSW staff NSW 658110, $10^{\text {t }}$ (AMNH_PBI 00371513) (MVMA).

PARATyPES: AUSTRALIA: Victoria: Jeparit Environmental Park, $36.14047^{\circ} \mathrm{S} 141.9643^{\circ} \mathrm{E}, 90$ m, 05 Nov 2002, Cassis, Schuh, Schwartz, Silveira, Melaleuca halmaturorum F. Muell. ex Miq. (Myrtaceae), det. NSW staff NSW 658110, $30^{\star}$ (00371527-00371529), 3 ㅇ (00371497-00371499) (AM), 53 ○ิ (00059064, 00371418-00371441, 00371449-00371452, 00371510-00371512, 00371514-00371526, 00371532, 00371540, 00371542, 00371543, 00371453-00371456, 00371507), 34 우 (00059065, 00371457-00371462, 00371467-00371490, 00371504, 00371505) (AMNH), 2 đิ (00371537, 00371538), 1 우 
(00371492) (ANIC), 20ิ (00371533, 00371534), 1 우 (00371495) (CNC), 13 추 (0037144400371448, 00371544-00371551), 7 ㅇ (00371509, 00371500-00371503, 00371506, 00371508) (MVMA), 2 하 (00371539, 00371541), 1 우 (00371491) (UCR), 2 ㅎ (00371530, 00371531), 1 우 (00371494) (UNSW), 2 ๙ (00371535, 00371536), $1+$ (00371496) (USNM), 20 (00371442, 00371443), 1 우 (00371493) (ZISP).

Additional Specimens Examined: AUSTRALIA: Victoria: Jeparit Environmental Park, $36.14047^{\circ} \mathrm{S} 141.9643^{\circ} \mathrm{E}, 90 \mathrm{~m}, 05$ Nov 2002, Cassis, Schuh, Schwartz, Silveira, Melaleuca halmaturorum F. Muell. ex Miq. (Myrtaceae), det. NSW staff NSW 658110, 4 nymphs (0037146300371466) (AMNH).

\section{Melaleucaphylus kaputar, new species}

Map 2, plates 2, 13, table 1

Diagnosis: This species and M. sheathianae recognized by similar structure of endosomadorsal strap conspicuously bifurcate with strongly divergent apical spines. In M. kaputar entire endosoma smaller and dorsal strap with anterior spine short and posterior spine somewhat thick and directed to right side; in $M$. sheathianae anterior spine long and posterior spine narrow and directed posteriorly. Additionally, M. kaputar distributed in New South Wales and antennal segment 2 black; $M$. sheathianae found in Western Australia and antennal segment 2 pale medially with dark base and apex.

Description: MALE: Mean total length 3.32, mean pronotum width 1.32. COLORATION (pl. 2): Dusky yellow to tan; clypeus, labrum, apical one-half of labial segment 4 , and antennal segments 1 and 2 black, segments 3 and 4 darkened with pale bases; mesoscutum red, membrane dusky hyaline with black at apex of large membrane cell; cuneus and paracuneus diffusely darkened medially. SURFACE AND VESTITURE (pl. 2): Shining; dorsum with moderately densely distributed, curved, reclining to suberect, black, simple setae. STRUCTURE: Labium reaching to apex of metacoxa. Legs missing from all specimens. GENITALIA (pl. 13): Pygophore: Broad in dorsal view, deep in lateral view, otherwise as in generic description. Endosoma: Coiled; ventral strap bifurcate distally with anterior apex terminating proximal of secondary gonopore in smooth, curved margin even with middle of proximal secondary gonopore process, posterior surface with long, narrow, pointed apex, terminating at level of anterior apex, posterior edge not protruding beyond curvature of ventral strap; dorsal strap bifurcate level with base of secondary gonopore, divided into pair of sharply pointed apical spines, large posterior spine extending distad of secondary gonopore $2.5 \times$ length of secondary gonopore, small, gently curved anterior spine directed to right side and extending distad of secondary gonopore length of secondary gonopore. Secondary gonopore: Well sclerotized; proximal edge with large, long, well-sclerotized attenuate process; distal edge with small microspiculate membrane on lateral surface; interstrap membrane with extremely thin, wavy gonopore sclerite. Phallotheca: Large, stout, attenuate apical region with posterior and anterior crest shaped projections, anterior crest much larger than posterior crest, aperture on anteroventral surface, moderately and evenly open; strong internal strut on right side. Parameres: Left paramere: Triangular in dorsal view, posterior process abruptly narrowed, base expanded laterally, longer than anterior process; anterior process with short knoblike apex; posterior surface or shoulder of paramere expanded posteriorly into broad rounded prominence, not raised above bases of anterior and posterior processes. Right paramere: Moderately elongate with smoothly rounded margins, narrowed distally, apex short and knoblike.

Female (pl. 2): Coloration as in male; differing from male as in generic description; total length 3.32, pronotum width 1.38. GENITALIA: Not examined.

Eтymology: Named for its occurrence on Mt. Kaputar, New South Wales; a noun in apposition. 
Host: Unknown.

Distribution (map 2): Known from type locality in Mount Kaputar National Park, New South Wales in the southeastern phytogeographic subregion.

Holotype: AUSTRALIA: New South Wales: Mount Kaputar [National Park], Bullawa Creek, $30.23261^{\circ} \mathrm{S} 150.11138^{\circ} \mathrm{E}, 505 \mathrm{~m}, 28$ Apr 1985, G. Hangay, 1 đ (AMNH_PBI 00391149) (AM).

PARATyPes: AUSTRALIA: New South Wales: Mount Kaputar [National Park], Bullawa Creek, $30.23261^{\circ} \mathrm{S} 150.11138^{\circ} \mathrm{E}, 505 \mathrm{~m}, 28$ Apr 1985, G. Hangay, 4 주 (00391150-00391153), 1 우 (00391154) (AM), 1 đ (00391148) (AMNH).

\section{Melaleucaphylus kunzeae, new species}

Figures 4F, 7, map 3, plates 2, 14, table 1

DiAGNOsis: Recognized by overall pale yellow body, black antenna, parempodia broadly lamelliform with flat expanded apices, and endosoma with apically undivided dorsal and ventral straps.

Description: Male: Mean total length 3.36, mean pronotum width 1.07 . COLORATION (pl. 2): Generally pale yellow to yellow with clypeus dusky black, antenna and apical segment of labium black, pronotum somewhat pale green anteriorly, hemelytron tinged with reddish orange of variable intensity, cuneus and paracuneus with most obvious red coloration; membrane weakly infuscate, veins red or yellow; tibia without dark spots at bases of spines; tarsi dusky black to black; phallotheca black. SURFACE AND VESTITURE (pl. 2): Shining; dorsum with moderately dense, curved reclining black simple setae; tibia with black spines. STRUCTURE: Labium reaching apex of mesocoxa. Pretarsus: Claws moderate sized, broadly curved; parempodia broadly lamelliform, weakly lyrelike, length moderate expanding to apices; pulvilli minute, proximad of angle of claw (fig. 4F). GENITALIA (fig. 7D, pl. 14A-J): Pygophore: Relatively broad in dorsal view, caudal surface perpendicular to aperture in lateral view, otherwise as in generic description.
Endosoma: Ventral strap entire, anterior surface reaching to just proximad of secondary gonopore with broad, smooth curved apex, terminating at midpoint of proximal secondary gonopore process; dorsal strap undivided for entire length, gradually narrowed, terminating in thin, pointed apex, exceeding secondary gonopore by $2 \times$ length of latter. Secondary gonopore: Well sclerotized; gonopore process well sclerotized, conforming to proximal surface of gonopore and reaching proximally as irregularly bent slightly expanded process; spiculate membranous surface on proximal margin; interstrap membrane with very thin sclerite reaching from base of endosoma to secondary gonopore. Phallotheca: Moderate size, apical region relatively long and narrow, terminating in spinelike apex, anterior surface with short crest or ridge; posterior surface somewhat undulate; aperture on anterior surface, moderately and evenly open. Parameres: Left paramere: Small, triangular in dorsal view, posterior process relatively short, abruptly narrowed, distal region bent ventrad, base weakly expanded laterally, longer than anterior process; anterior process short with long subapical seta; posterior surface of paramere not expanded posteriorly, not raised above bases of anterior and posterior processes. Right paramere: Relatively short, gently narrowed distally with smoothly rounded margins; apex short.

Female (pl. 2): Coloration as in male; differing from male as in generic description; mean total length 3.29, mean pronotum width 1.15. GENITALIA (pl. 14K-N): Posterior margin of sternite 7: Bearing narrow, projection. Vestibular sclerites: Weakly J-shaped coiled tube; medially placed, anteriad reaching level with middle of ring, not attaining medial border of right ring in dorsal view; vestibulum variably sclerotized, faint near ventral labiate plate, strongest at medioventral extension of ventral labiate plate and weak at enlarged triangular basal sclerites of first gonapophyses. Dorsal labiate plate: Medium sized; posteroventral edge folded. Sclerotized rings: Medium size, ovoid, borders nar- 

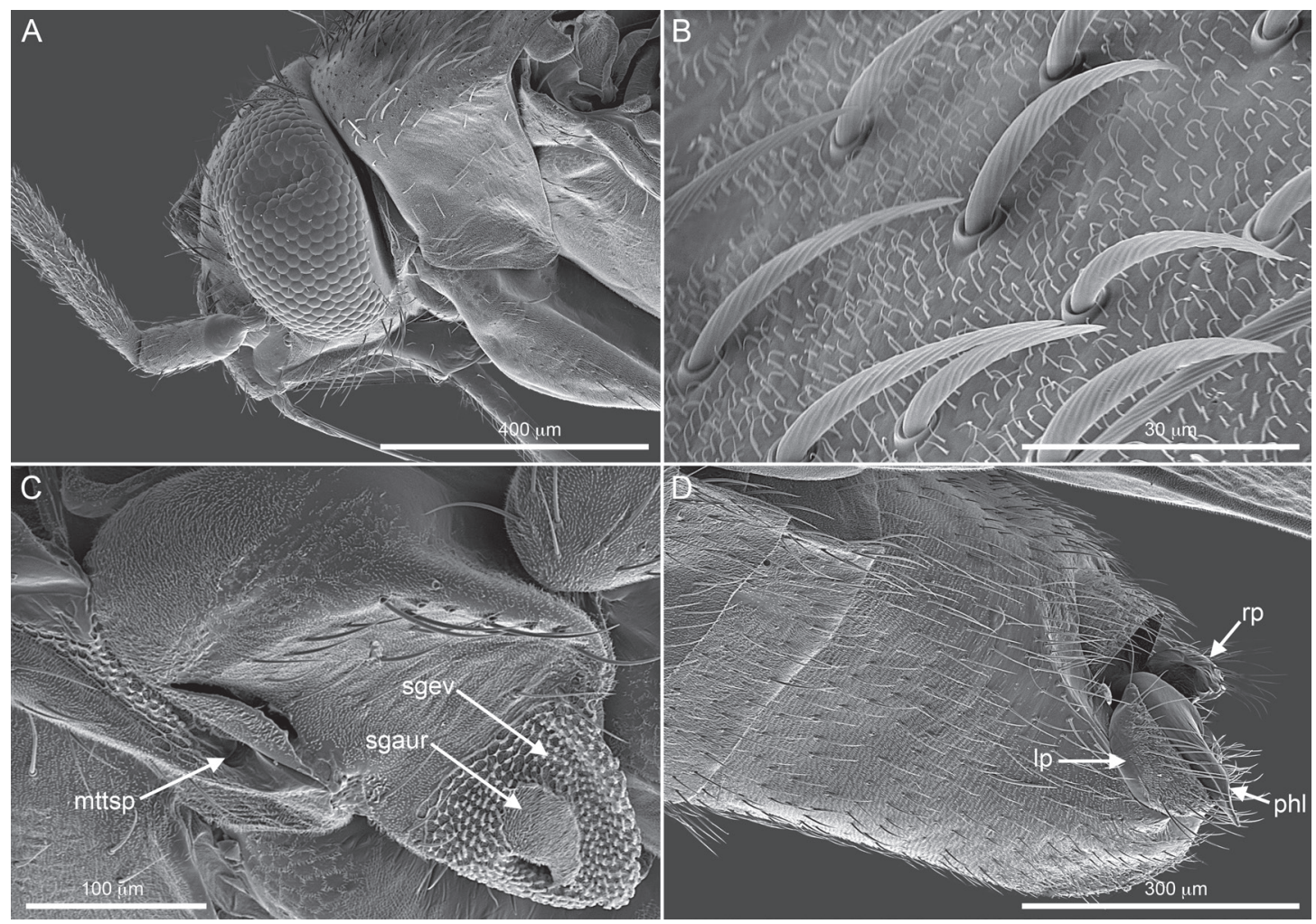

FIG. 7. Melaleucaphylus kunzeae, AMNH_PBI 00128299. Scanning electron micrographs. A. Head and pronotum, lateral view. B. Detail of pronotal setae, lateral view. C. Thoracic pleuron, lateral view, showing metathoracic spiracle opening, metathoracic scent-gland auricle, and evaporatory area. D. Pygophore, left paramere, phallotheca, and right paramere, lateral view. Abbreviations: lp, left paramere; mttsp, metathoracic spiracle; phl, phallotheca; rp, right paramere; sgaur, scent gland auricle; sgev, scent gland evaporatory area.

row, separated by width of ring, lateral margin of ring curved, almost reaching lateral margin of dorsal labiate plate. Intersegmental process: Relatively large, tongue shaped, membranous, lacking microspicules, apical margin slightly notched. Posterior wall: Medium size, anterior one-half strongly sclerotized. Interramal sclerites: Dorsomedially with large, subquadrate anterior invagination, forming large posteriorly directed prominence adjacent to ovipositor bulb; ventrolateral regions with sclerotized subrectangular extensions. Interramal lobes: Dorsolateral region membranous, lateral regions with sparse microspicules; regions either side of medial prominence not tumid or produced into genital chamber.
Eтymology: Named for its occurrence on the genus Kunzea.

Hosт: Recorded from Kunzea ambigua (Myrtaceae: Leptospermeae) (pl. 38D).

Distribution (map 3): Known from four collecting events from coastal New South Wales in Bournda and Royal National Parks and north of Sydney within the southeastern phytogeographic subregion.

Discussion: This is the only species of Melaleucaphylus with a host-plant association in the Leptospermeae; we consider the 3 specimens of $M$. nodosae from one collection event as incidental records. Otherwise, in the present work only species of Leptospermia and Xiphoides are associated with Leptospermeae host plants. Currently M. kun- 
zeae and $M$. nodosae are the only species of the genus found in coastal southeastern Australia.

Holotype: AUSTRALIA: New South Wales: Royal National Park, Wattamolla Beach Car Park, $34.13888^{\circ} \mathrm{S} 151.11333^{\circ} \mathrm{E}, 29 \mathrm{~m}, 14$ Nov 2001, Cassis, Schuh, Schwartz, Silveira, Kunzea ambigua (Sm.) Druce (Myrtaceae), det. NSW staff NSW $666409,10^{\Uparrow}$ (AMNH_PBI 00128259) (AM).

PARATyPes: AUSTRALIA: New South Wales: $65 \mathrm{~km}$ N of Sydney on Pacific Hiway, $33.53334^{\circ} \mathrm{S}$ $151.1833^{\circ} \mathrm{E}, 100 \mathrm{~m}, 19$ Oct 1995, Schuh and Cassis, Kunzea ambigua (Sm.) Druce (Myrtaceae), det. P.G. Wilson 1996 NSW 395902, 50 ๙ (00414755, 00414751-00414754), 1 우 (00414750) (AM). Bournda National Park, North Wallagoot, Turingal Head, $36.78452^{\circ} \mathrm{S} 149.9568^{\circ} \mathrm{E}, 16 \mathrm{~m}, 20$ Nov 2002, Cassis, Schuh, Schwartz, Silveira, Kunzea ambigua (Sm.) Druce (Myrtaceae), det. NSW staff NSW 658199, 2 ㅇ (00414838, 00414839), 1 우 (00414840) (AMNH). Royal National Park, Warumbul Picnic Area, $34.06667^{\circ} \mathrm{S} 151.1048^{\circ} \mathrm{E}, 20 \mathrm{~m}$, 14 Nov 2001, Cassis, Schuh, Schwartz, Silveira, Kunzea ambigua (Sm.) Druce (Myrtaceae), det. NSW staff NSW 666409, 2 (00128236, 00097206), 2 đ (00097205, 00058633) (AMNH). Royal National Park, Wattamolla Beach Car Park, $34.13888^{\circ} \mathrm{S} 151.11333^{\circ} \mathrm{E}, 29 \mathrm{~m}, 14 \mathrm{Nov} 2001$, Cassis, Schuh, Schwartz, Silveira, Kunzea ambigua (Sm.) Druce (Myrtaceae), det. NSW staff NSW 666409, 6우 (00128288-00128293), 7 우 (00128302-00128308) (AM), 22 ఫิ (00097207, 00368045, 00128294-00128301, 0012824900128256, 00128261-00128264), 25 (00097208, 00128310-00128314, 00128266-00128283, 00128286) (AMNH), 1 하 (00128258), 1 우 (00128284) (ANIC), 1 후 (00128260), 1 우 (00128285) (CNC), 1 주 (00128265), 1 우 (00128287) (UNSW), 1 ㅇ (00128309), 1 ๙ (00128257) (ZISP).

Additional Specimens Examined: AUS-

TRALIA: New South Wales: Royal National Park, Wattamolla Beach Car Park, $34.13888^{\circ} \mathrm{S}$ $151.11333^{\circ} \mathrm{E}, 29 \mathrm{~m}, 14$ Nov 2001, Cassis, Schuh, Schwartz, Silveira, Kunzea ambigua (Sm.) Druce (Myrtaceae), det. NSW staff NSW 666409, 1 adult sex unknown (00413015) (AMNH).

\section{Melaleucaphylus micranthae, new species}

\author{
Map 3, plates 2, 15, table 1
}

DiAgnosis: Recognized by general dusky yellow coloration with dark markings restricted to clypeus, ovoid mark medially on frons, apex of antennal segment 2 , and entirety of segments 3 and 4. Most similar to M. beaufortiae, another small species with endosoma having a short subapical spine on posterior edge of ventral strap, but former species with more extensive dark markings on head and antenna. Melaleucaphylus micranthae is further distinguished from $M$. beaufortiae by fine features of endosoma. In former species subapical spine on posterior edge of ventral strap approximately straight and apical spines of dorsal strap sublinear and subcontiguous in lateral view and strongly converging in dorsal view; in latter species subapical spine on posterior edge of ventral strap strongly bent dorsad and apical spines of dorsal strap curved ventrad, somewhat separated in lateral view and slightly converging in dorsal view.

Description: Male: Mean total length 2.87, mean pronotum width 1.01. COLORATION (pl. 2): Dusky yellow, black medial stripe extending dorsad from labrum and clypeus to frons as relatively narrow band with convex lateral margins reaching to middle of vertex leaving posterior margin of head pale; antennal segments 1 and 2 diffusely black distally, segments 3 and 4 black; pronotum including calli, posterior margin, and humeral angles concolorous pale; tibia without dark spots at bases of spines. SURFACE AND VESTITURE (pl. 2): Subshining; dorsum with moderately dense, curved, reclining black simple setae; tibia with black spines. STRUCTURE: Labium reaching apex of metacoxa. Pretarsus: Claws relatively small, gently curved; parempodia somewhat lamelliform, relatively long, parallel, apices slightly expanded, truncate; pulvilli small, short, restricted to just proximad of angle of claw. GENiTAliA (pl. 15A-J): Pygophore: Small; otherwise as in generic description. Endosoma: Base to middle of basal curve well-sclerotized then clearly bifurcate with broad split, 
distal one-half with torsion, twisted to left side; ventral strap entire, anterior surface terminating even with middle of secondary gonopore with smoothly truncate apex; posterior edge of ventral strap with small, narrow, smooth-margined, curved, pointed, subapical spine protruding beyond curvature of ventral strap with length equal to width of secondary gonopore; dorsal strap bifurcate at level of base of secondary gonopore, apical spines slightly diverging at level of apex of secondary gonopore, then parallel over remaining length, terminating with gradually tapering, converging pointed apices, distance between apices short. Secondary gonopore: Well sclerotized, deep; surface of aperture convoluted and with large, well-sclerotized, irregularly shaped process ringing and projecting proximal of aperture as short attenuate apex. Phallotheca: Small, attenuate apical region with short undulating ridge on right posterior surface; base of phallotheca with small expansion on left side; aperture on anteroventral surface, elongate, teardrop shaped, narrowed at tip. Parameres: Left paramere: Small triangular in dorsal view, posterior process short, abruptly narrowed, slightly bent ventrad, longer than anterior process, base weakly expanded laterally; anterior process of moderate size; apex narrow, rounded; posterior surface of paramere expanded posteriorly, not raised above bases of anterior and posterior processes. Right paramere: Relatively small with smoothly rounded margins; apex short.

Female (pl. 2): Coloration as in male; differing from male as in generic description; total length 2.94, pronotum width 1.03. GENITALIA (pl. $15 \mathrm{~K}-\mathrm{N}$ ): Posterior margin of sternite 7: With broadly triangular, attenuate projection. Vestibular sclerites: Moderately large, J-shaped, convoluted, lateral margin curved, extending to right side, anterior edge not extending anteriad of ring, just reaching within medial margin of right ring in dorsal view; tube weakly sclerotized throughout, basal sclerites of first gonapophyses enlarged, triangular. Dorsal labiate plate: Moderately large, ovoid; posteroventral edge strongly tumid, symmetrical. Scler- otized rings: Large, subovoid, borders narrow, separated by one-half width of ring, lateral margin of ring angled, not reaching lateral margin of dorsal labiate plate. Intersegmental process: Large, broad, bracket shaped apically, weakly sclerotized and microspiculate, apical margin entire. Posterior wall: Medium sized, weakly sclerotized. Interramal sclerites: With broad, vertical, posteriorly directed medial prominence with small knob on middle portion abutting ovipositor bulb; ventrolateral regions with faintly sclerotized subrectangular extensions. Interramal lobes: Dorsolateral region hyaline, lateral regions without microspicules; regions on either side of medial prominence not tumid or produced into genital chamber.

Eтymology: Named for its occurrence on Beaufortia micrantha.

Hosts: Recorded from Beaufortia micrantha (pl. 37B) and B. schaueri (Myrtaceae: Melaleuceae).

Distribution (map 3): Known from two collection events near Ravensthorpe on the southern coast of Western Australia in the southeastern edge of the southwestern phytogeographic subregion.

Discussion: The description of female genitalia above is based on a weakly sclerotized preparation.

Holotype: AUSTRALIA: Western Australia: Fitzgerald River National Park, Hammersley Road, $33.81038^{\circ} \mathrm{S} 119.787^{\circ} \mathrm{E}, 215 \mathrm{~m}, 06 \mathrm{Dec}$ 1997, Schuh, Cassis, Brailovsky, Asquith, Beaufortia micrantha Schauer (Myrtaceae), det. PERTH staff PERTH 05055482, 1 đ (AMNH_ PBI 00372218) (WAMP).

Paratypes: AUSTRALIA: Western Australia: Fitzgerald River National Park, Hammersley Road, $33.81038^{\circ} \mathrm{S} 119.787^{\circ} \mathrm{E}, 215 \mathrm{~m}, 06$ Dec 1997, Schuh, Cassis, Brailovsky, Asquith, Beaufortia micrantha Schauer (Myrtaceae), det. PERTH staff PERTH 05055482, 2 o (00372219, 00087245), 1 우 (00372223), 1 추 (00391094) (AM), 6 후 (00131443-00131447, 00131449), 1 우 (00131450) (AMNH), 3 ô (00372216, 00372217, 00131448), 19 (00372222) (WAMP). Pallarup 
Nature Reserve, $1.4 \mathrm{~km}$ W of Lake King-Ravensthorpe Road, $33.24062^{\circ} \mathrm{S} 119.7195^{\circ} \mathrm{E}, 310 \mathrm{~m}, 05$ Dec 1997, Schuh, Cassis, Brailovsky, Asquith, Beaufortia schaueri L. Preiss (Myrtaceae), det. PERTH staff PERTH 05055202, 2 đ (00087246, 00087472) (AM), 1 우 (00131451), 1 ơ (00131452) (AMNH), $1 \hat{0}$ (00372215) (WAMP).

Additional Specimens Examined: AUSTRALIA: Western Australia: Fitzgerald River National Park, Hammersley Road, 33.81038 ${ }^{\circ} \mathrm{S}$ 119.787E, 215 m, 06 Dec 1997, Schuh, Cassis, Brailovsky, Asquith, Beaufortia micrantha Schauer (Myrtaceae), det. PERTH staff PERTH 05055482, 2 nymphs (00372220, 00372221) (AM).

\section{Melaleucaphylus ngarkat, new species}

Map 3, plates 2, 16, table 1

Diagnosis: Distinguished from M. nodosae, another predominately dark-colored species, by dark posterior margin of head and castaneous dorsum with silvery sericeous setae and unequivocally from all congeners by endosoma with short apical spine of undivided dorsal strap, bifurcate ventral strap with large apical spines, anterior spine flat, angulate, posterior spine longer apically curved and marginally serrate, and secondary gonopore with large strongly sclerotized and serrate distal process and absence of proximal process.

Description: Male: Mean total length 2.99, mean pronotum width 1.09. COLORATION (pl. 2): Castaneous to dark reddish brown; frons with paler dusky yellowish brown narrowly in middle and near eyes; apex of scutellum, base of cuneus, basalar plate, posterior edge of metepisternal scent gland evaporative area, and tibiae also dusky yellow; membrane weakly infuscate, veins pale; tibia without dark spots at bases of spines. SURFACE AND VESTITURE (pl. 2): Shining; dorsum with moderately dense curved shining, silver, sericeous setae; similar setae on thoracic venter, erect on coxae; tibial spines black. STRUCTURE: Labium reaching apex of metacoxa. Pretarsus: Claws small, gently curved with somewhat expanded bases; parempodia setiform, parallel; pulvilli minute, situated within angle of claw. GENITALIA (pl. 16): Pygophore: Broadly conical in dorsal view, dorsal surface with broad patch of bristles ventrad of left paramere insertion; caudal surface extending perpendicular to aperture in lateral view, otherwise as in generic description. Endosoma: Distal one-third with torsion, twisted to left side, practically reflected over body of endosoma. Ventral strap: Wide, strongly bifurcate just proximal to base of secondary gonopore, marked by obvious dislocation in strap; anterior surface terminating at level of distal end of secondary gonopore aperture with prominent triangular pointed apex; posterior surface forming a broad, flat band, longer than apex of anterior surface, terminating just distal to apex of secondary gonopore as rounded truncate plate with serrate margin. Dorsal strap: Narrow, forming thin apex, apex just reaching distal edge of spiculate lobe of secondary gonopore, ventral surface of apical spine with subapical flange supported at apex of secondary gonopore. Secondary gonopore: Large, well-differentiated and sclerotized, distal edge tumid and rounded, with strong spicules on surface; basolateral edges of gonopore aperture without spiculate membrane, proximal portion of secondary gonopore with small elongate sclerotized overlapped edge; thin gonopore sclerite absent. Phallotheca: Relatively large, attenuate apical region with weakly undulate posterior surface; aperture on anteroventral surface short, moderately open; anteroventral surface ventral to distal end of aperture with flat flange. Parameres: Left paramere: Broadly triangular in dorsal view, posterior process relatively short, narrow; anterior process very short, weakly extending beyond base, apex poorly differentiated; posterior region between posterior and anterior processes broadly produced posteriorly, vaguely conical, not projecting dorsad of processes. Right paramere: Relatively large, gradually narrowed distally, margins smoothly rounded, apex short pointed.

FEMALE: Unknown.

Eтymology: Named for its occurrence in the Ngarkat Nature Reserve, South Australia.

Host: Unknown. 
Distribution (map 3): Known only from the type locality southeast of Adelaide in South Australia in the Adelaide phytogeographic subregion.

Discussion: As in M. glomeratae and $M$. vimineae, $M$. ngarkat has the distal edge of the secondary gonopore with obvious microspiculate lobes but does not have the proximal process of the secondary gonopore as in these two and all other congeners.

Holotype: AUSTRALIA: South Australia: $18 \mathrm{~km}$ S of Bews, Ngarkat Cons. Park, $35.55197^{\circ} \mathrm{S}$ 140.4332 ${ }^{\circ} \mathrm{E}, 60 \mathrm{~m}, 09$ Nov 1998, Schuh, Cassis, Silveira, 1 đ (AMNH_PBI 00130207) (SAMA).

Paratypes: AUSTRALIA: South Australia: $18 \mathrm{~km} \mathrm{~S}$ of Bews, Ngarkat Cons. Park, 35.55197 $\mathrm{S}$ 140.4332 ${ }^{\circ} \mathrm{E}, 60 \mathrm{~m}, 09$ Nov 1998, Schuh, Cassis, Silveira, 10 (AMNH_PBI 00130208) (AMNH).

\section{Melaleucaphylus nodosae, new species}

Figures 8, 9A, map 3, plates 2, 17, table 1

Diagnosis: Distinguished from M. ngarkat, another completely dark-colored species, by black body with pale posterior margin of head, vestiture of black and thin brown setae, endosoma with subapical spine on posterior edge of ventral strap and bifurcate dorsal strap with long apical spines.

Description: Male: Mean total length 3.10, mean pronotum width 1.10. COLORATION (pl. 2): Black; posterior margin and carinal area of head white; gula, maxillary, and mandibular plates bordering eyes pale; pro- and mesotibiae pale; membrane infuscate, veins dusky; tibia without dark spots at base of spines. SURFACE AND VESTITURE (pl. 2): Shining; dorsum with mixture of moderately dense, curved, reclining, black and thinner brown simple setae; thoracic venter with similar setae, erect setae on coxae; tibia with black spines. STRUCTURE: Labium reaching apex of metacoxa. Pretarsus: Claws small, narrow with unexpanded bases; parempodia setiform, length relatively long, parallel, apices sharp; pulvilli small, just proximal of angle of claw (fig. 9A). GENITALIA (pl. 17A-J): Pygophore: Relatively short and broad in dorsal view, caudal surface subperpendicular to aperture in lateral view, otherwise as in generic description. Endosoma: Distal one-half with torsion, twisted more caudad than to left side; ventral strap entire with anterior surface terminating basad of secondary gonopore with smooth curved distal margin; posterior surface with short, smoothmargined, sublinear, subsharp subapical spine protruding beyond curvature of ventral strap, subapical spine originating level with proximal end of, and with length equal to width of proximal secondary gonopore process; dorsal strap bifurcate at level of secondary gonopore, apical portion of strap forming pair of diverging, narrow, pointed spines, separated by distance equal to length of secondary gonopore, apices curving caudally, anterior spine longer than posterior spine. Secondary gonopore: Well sclerotized, deep, with well-sclerotized proximal process; interstrap membrane with very thin sclerite reaching from secondary gonopore to base of endosoma. Phallotheca: Attenuate, apical region with moderate height crest on posterior surface; aperture on anteroventral surface relatively wide and undulating. Parameres: Left paramere: Subquadrate in dorsal view, posterior process relatively short, gradually narrowed to truncate curved apex, base expanded laterally; anterior process of moderate length with rounded apex; posterior surface of paramere produced in form of a broad shoulder, not raised above bases of anterior and posterior processes. Right paramere: Moderately small, margins smoothly rounded, gently narrowed distally to small rounded apex.

Female (pl. 2): Coloration as in male; differing from male as in generic description; mean total length 3.13, mean pronotum width 1.17 . GENITALIA (pl. 17K-M): Posterior margin of sternite 7: With triangular projection. Vestibular sclerites: Moderately large, J-shaped, convoluted, lateral margin curved, extending to right side, anterior edge not extending anteriad of ring, just reaching within medial margin of right ring in dorsal view; vestibulum strongly sclero- 

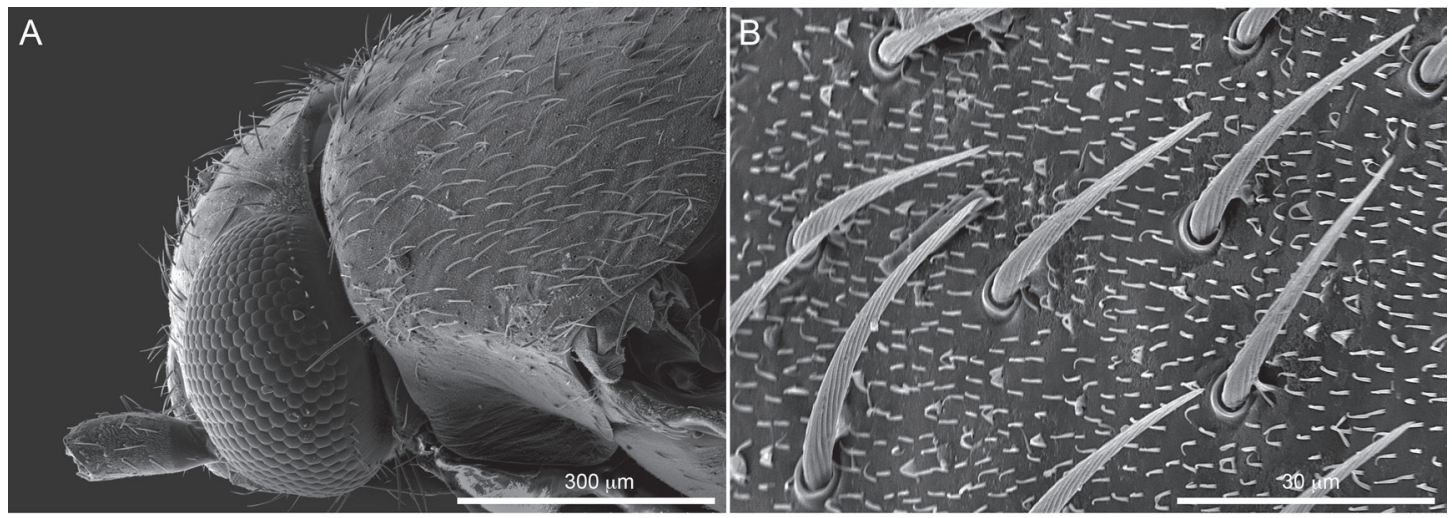

FIG. 8. Melaleucaphylus nodosae, AMNH_PBI 00371390. Scanning electron micrographs. A. Head and pronotum, caudolateral view. B. Detail of pronotal setae, lateral view.

tized throughout, basal sclerites of first gonapophyses enlarged, triangular. Dorsal labiate plate: Moderately large; posteroventral margin of dorsal labiate plate folded, enlarged posteriad, but not tumid. Sclerotized rings medium sized with narrow border, ovoid, separated by one-half width of ring, lateral margins subangulate, attaining lateral margin dorsal labiate plate. Intersegmental process: Ventral projection small, membranous, apical margin round, entire, anterior surface microspiculate. Posterior wall: Medium sized, ventral one-half well sclerotized. Interramal sclerites: With relatively broad posteriorly directed medial prominence, with small knob on middle portion abutting ovipositor bulb; ventrolateral regions with obvious sclerotized subrectangular extensions. Interramal lobes: Dorsolateral region predominately hyaline, lateral regions with a few scattered microspicules; regions on either side of medial prominence not tumid or produced into genital chamber.

EтyMology: Named for its occurrence on Melaleuca nodosa.

Host: Recorded from Melaleuca nodosa (pl. 39I) and M. sp. (Myrtaceae: Melaleuceae). The record of specimens from Acacia sp. (Fabaceae), we consider to be suspect and probably the result of commingled specimens or simple mislabeling.

Distribution (map 3): Known from several collecting events from coastal New South Wales in the southeastern phytogeographic subregion.
Discussion: The posteroventral margin of the dorsal labiate plate is not as strongly tumid in $M$. nodosae as in other species where the male has a subapical spine on ventral spine of the endosoma (M. beaufortiae, M. halmaturorum, M. micranthae, and M. rhaphiophyllae). Melaleucaphylus pauperiflorae has similar structure of the endosoma, but the female is unknown.

Holotype: AUSTRALIA: New South Wales: Booti Booti National Park, jct Lakes Way and Green Point, $32.33334^{\circ} \mathrm{S} 152.5333^{\circ} \mathrm{E}, 5 \mathrm{~m}, 21 \mathrm{Oct}$ 1995, Schuh and Cassis, Melaleuca nodosa (Sol. ex Gaertn.) Sm. (Myrtaceae), det. P.G. Wilson 1996 NSW 395914, 1 ơ (AMNH_PBI 00370950) (AM).

PARATYPES: AUSTRALIA: New South Wales: Booti Booti National Park, jct Lakes Way and Green Point, $32.33334^{\circ} \mathrm{S} 152.5333^{\circ} \mathrm{E}, 5 \mathrm{~m}, 21$ Oct 1995 , Schuh and Cassis, Melaleuca nodosa (Sol. ex Gaertn.) Sm. (Myrtaceae), det. P.G. Wilson 1996 NSW 395914, 15 (00371416, 00371417, 00058593, 00132869, 00132882-00132886, 0013289800132900, 00370956-00370958), 11 ðิ (0013286500132867, 00370944-00370949, 00370951, 00370952) (AM), 19 0 (00371383-00371390, 00132849-00132859), 47 우 (00371393-00371415, 00132868, 00132870-00132876, 0013289400132897, 00132901-00132912) (AMNH), 2 స (00132863, 00132864), 2 우 (00132880, 00132881)

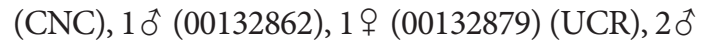
(00371391, 00371392), 2 ㅇ (00132913, 00132914) (USNM), 2 수 (00132860, 00132861), 2 우 (00132877, 

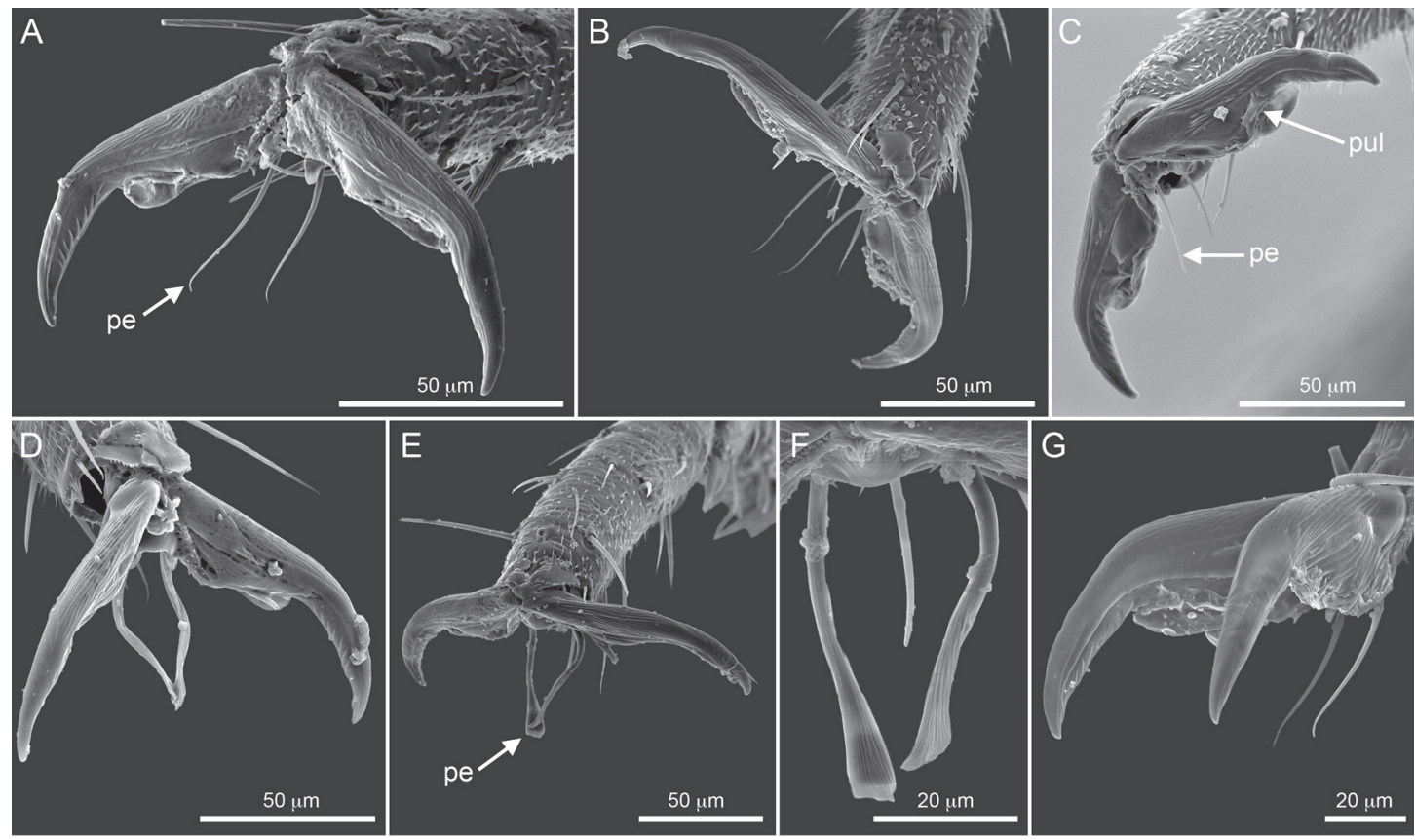

FIG. 9. Melaleucaphylus spp. Scanning electron micrographs of pretarsus. A. M. nodosae, AMNH_PBI 00371390, frontodorsal view. B. M. omnivorus, AMNH_PBI 00391104, frontodorsal view. C. M. phymatocarpi, AMNH_PBI 00372120, frontal view. D. M. polyphagus, AMNH_PBI 00132521, frontodorsal view. E., F. M. rhaphiophyllae, AMNH_PBI 00393437. E. Frontodorsal view. F. Detail of parempodia, ventral view. G. M. sheathianae, AMNH_PBI 00370823, frontolateral view. Abbreviations: pe, parempodium; pul, pulvillus.

00132878) (ZISP). Hat Head National Park near Kempsey, $31.06667^{\circ} \mathrm{S} 153.03333^{\circ} \mathrm{E}, 5 \mathrm{~m}, 22$ Oct 1995, Schuh and Cassis, Leptospermum sp. (Myrtaceae), 2 우 (00370959, 00370960) (AM), 1 우 (00370961) (UNSW). Kurnell, $34.015^{\circ} \mathrm{S} 151.201^{\circ} \mathrm{E}$, 19 Oct 1958, C. E. Chadwick, 90 , 4 우 (0041482300414826 with multiple specimens) (AM). Myall Lakes National Park, $10.3 \mathrm{~km}$ S of Seal Rocks Rd on Hawks Nest Rd, $32.5^{\circ} \mathrm{S} 152.35^{\circ} \mathrm{E}, 5 \mathrm{~m}, 20$ Oct 1995 , Schuh and Cassis, Melaleuca nodosa (Sol. ex Gaertn.) Sm. (Myrtaceae), det. P.G. Wilson 1996 NSW 395909, 2 ㅇ (00370955, 00131679), 20 (00370953, 00131664) (AM), 90 (0013166100131663, 00131665-00131669, 00414831), 9 우 (00131670-00131678) (AMNH), 1 (00370954) (UNSW). Royal National Park, $34.072^{\circ} \mathrm{S}$

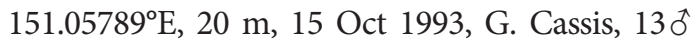
(00370962-00370974), 16 ㅇ (00370975-00370990), Melaleuca sp. (Myrtaceae), 2 † (00087158, 00087444), 1 ㅇ (00087159) (AM). Sydney, $33.8652^{\circ} \mathrm{S}$ $151.2096^{\circ} \mathrm{E}$, Oct 1931 , K.K. Spence, 2 ơ $^{\text {(00391155, }}$ 00391156) (AM). Wattamolla, Royal National Park, $34.08^{\circ} \mathrm{S} 151.07^{\circ} \mathrm{E}, 11$ Oct 1984, M. Stevens, Acacia

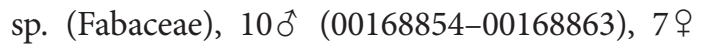
(00168864-00168870) (ANIC).

Additional Specimens Examined: AUSTRALIA: New South Wales: Royal National Park, $34.072^{\circ} \mathrm{S} 151.05789^{\circ} \mathrm{E}, 20 \mathrm{~m}, 15$ Oct 1993, G. Cassis, 2 nymphs (00370991, 00370992) (AM).

\section{Melaleucaphylus omnivorus, new species}

Figure 9B, map 3, plates 3, 18, table 1

Diagnosis: Because dorsal coloration of this new species is variable and similar to several other species of Melaleucaphylus, M. omnivorus is unequivocally recognized by male genitalia with sharp spur on posterior edge of ventral strap not protruding beyond curvature of strap 
and setiform parempodia. Pale olive specimens are similar to M. eremaeae, but in latter species posterior edge of ventral strap does not have a spine, antennal segment 2 in male is shorter and thicker, and parempodia are slightly lamelliform with expanded fanlike apices. Specimens with bright reddish orange cuneus are similar to $M$. halmaturorum, however, in the latter species posterior edge of ventral strap with curved subapical spine and apical spines of dorsal strap longer and separated for most of length, then converge at apex, and only known from Victoria state; $M$. omnivorus has apical spines of dorsal strap contiguous throughout length and are distributed in Western Australia. Melaleucaphylus pauperiflorae has similar overall reddish-orange coloration to some M. omnivorus specimens but in the former species posterior edge of ventral strap has a curved subapical spine and apical spines of dorsal strap are curved ventrad. Melaleucaphylus polyphagus and M. sheathianae can have similar reddish-orange coloration to some M. omnivorus, but the former species has a unique large spine on posterior edge of ventral strap and somewhat lamelliform parempodia, whereas the latter species has conspicuous large and small apical spines of dorsal strap; additionally, both these similar species have a variable medial stripe on scutellum not found in M. omnivorus.

Description: MAle: Mean total length 3.34, mean pronotum width 1.23. COLORATION (pl. 3): Variable general coloration; pale dusky olive to pale or intense orange red; regardless of general coloration cuneus always some shade of orange red; antennae black or sometimes with basal portion of segment 2 paler; abdomen black; wide periphery of hemelytral membrane infuscate, hyaline centrally; veins dusky yellow; tibia without dark spots at bases of black spines, tarsus black. SURFACE AND VESTITURE (pl. 3): Shining; dorsum with moderately dense, curved, reclining, black, simple setae; thoracic venter with black setae, erect on coxae. STRUCTURE: Labium reaching apex of mesocoxa. Pretarsus: Claws of moderate size, slightly curved, bases somewhat enlarged; parempodia setiform, rela- tively long, parallel, apices sharp; pulvilli moderate height, proximad of angle of claw (fig. 9B). GENITALIA (pl. 18A-J): Pygophore: Relatively broad in dorsal view, dorsal surface near paramere insertions with only a few longer bristles near both paramere insertions. Endosoma: Distal one-half with torsion, twisted to left side; ventral strap bifurcate, terminating at middle of secondary gonopore, anterior surface with smoothly curved distal margin, posterior edge with sharp spur, not protruding beyond curvature of ventral strap; dorsal strap bifurcate at level of apex of secondary gonopore, divided into pair of narrow, approximately equal length, converging sharp spines, both spines projecting over left side of endosoma, reaching approximately $3 \times$ length of secondary gonopore beyond distal margin of gonopore; posterior spine bowed away from anterior spine at base, then wavy, bypassing anterior spine by $2 \times$ diameter of apex of spine, anterior spine smoothly curved and not wavy. Secondary gonopore: Well-sclerotized, proximal edge with microspiculate membrane and wellsclerotized projection wrapped around proximal margin and then expanded into small trumpetlike apex, proximal edge of apex slightly extruded. Phallotheca: Moderate sized, relatively narrow apical region with short, low prominence on dorsal surface; elongate ovoid aperture on anterior surface. Parameres: Left paramere: Compressed triangular in dorsal view, posterior processes with expanded base, abruptly narrowed, longer than anterior process; anterior process short, apex small, smoothly rounded; posterior surface of paramere with small but relatively prominent protuberance, slightly reaching above anterior and posterior processes. Right paramere: Moderate length, margins smoothly rounded; apex short knoblike.

Female (pl. 3): Coloration as in male, except antenna dark at apex and base, not entirely black, otherwise differing from male as in generic description; mean total length 3.58, mean pronotum width 1.31. GENITALIA (pl. $18 \mathrm{~K}-\mathrm{M})$ : Posterior margin of sternite 7 : With broadly triangular projection. Vestibular scler- 
ites: Situated medially, moderately large, J-shaped, convoluted, lateral margin elongate, flat, extending to right side, anterior edge extending even with interior and occupying middle of right ring in dorsal view; vestibulum variably sclerotized, faint near ventral labiate plate, strongest on medioventral extension of ventral labiate plate and enlarged triangular basal sclerites of first gonapophyses. Dorsal labiate plate: Relatively small; posteroventral margin of dorsal labiate plate folded, not tumid. Sclerotized rings medium sized with narrow border, subquadrate, separated by width of ring, margins rounded, lateral margin not reaching lateral margin of dorsal labiate plate. Intersegmental process: Ventral projection with undulate, irregular apical margin, somewhat flattened on horizontal axis, microspiculate. Posterior wall: Medium sized, ventral one-half well sclerotized. Interramal sclerites: With small, prominent, posteriorly directed medial prominence; ventrolateral regions with obvious sclerotized subrectangular extensions. Interramal lobes: Dorsolateral region hyaline apparently not microspiculate; regions either side of medial prominence not tumid or produced into genital chamber.

Eтymology: Named for its occurrence on multiple hosts; from the Latin omnis, "all," vorare, "to devour."

Hosts: Recorded from the following plant species: Baeckea crispiflora, B. uncinella, Calytrix glutinosa, Scholtzia drummondii (pl. 41C) (Myrtaceae: Chamelaucieae), Beaufortia schaueri, Melaleuca laetifica (pl. 39F), M. sp., and Eremaea beaufortioides (pl. 37F) (Myrtaceae: Melaleuceae). The records of single specimens from Allocasuarina campestris (Casuarinaceae) and Hakea cygna (Proteaceae) we consider to be in error, as a result of commingling of specimens in the field.

Distribution (map 3): Known from several collection events in western and southern Western Australia within the southwest interzone and southwestern phytogeographic subregions.

Discussion: Three females from Lake Mullet Nature Reserve (00393460-00393462) without host information or associated males are not designated paratypes. The sclerotized rings in these specimens are angulate laterally and the vestibular sclerites are shorter and rounded distally; in paratype $M$. omnivorus the lateral margins are curved and the vestibular sclerites are longer and flattened. The coloration of the nonparatype females with black antennae and pale areas on the head, base of cuneus, and scutellum also differs from $M$. omnivorus. Other specimens from the same locality taken on Baeckea uncinella are typical of M. omnivorus (00390859) or M. polyphagus (00372128-00372131). Until males can be associated with the unique Lake Mullet Nature Reserve females we refrain from recognizing an additional new species of Melaleucaphylus.

Some specimens from Lillian Stoke Rock taken on Beaufortia have the cuneus more conspicuously red than the remainder of the hemelytron but have identical endosoma as in other specimens we designate as paratypes.

Holotype: AUSTRALIA: Western Australia: Kalbarri National Park, $37.7 \mathrm{~km}$ E of Kalbarri, $27.84818^{\circ} \mathrm{S} 114.47458^{\circ} \mathrm{E}, 500 \mathrm{~m}, 29 \mathrm{Oct}$ 1996, Schuh and Cassis, Melaleuca laetifica Craven (Myrtaceae), det. PERTH staff PERTH 05054540, 1 đิ (AMNH_PBI 00372183) (WAMP).

Paratypes AUSTRALIA: Western Australia: $1 \mathrm{~km} \mathrm{~S}$ of Lillian Stoke Rock, $33.07681^{\circ} \mathrm{S}$ $120.0982^{\circ}$ E, 380 m, 21 Nov 1999, R.T. Schuh, G. Cassis, and R. Silveira, Hakea cygna Lamont (Proteaceae), det. PERTH staff PERTH 05671760, 1 우 (00390895) (AM). $3.5 \mathrm{~km} \mathrm{E} \mathrm{of}$ Lillian Stoke Rock, $33.07679^{\circ} \mathrm{S} 120.132^{\circ} \mathrm{E}, 360$ m, 21 Nov 1999, R.T. Schuh, G. Cassis, and R. Silveira, Baeckea crispiflora F. Muell. (Myrtaceae), det. PERTH staff PERTH 05671078, 6 ㅇ (00393503-00393508), Beaufortia schaueri L. Preiss (Myrtaceae), det. PERTH staff PERTH 05671892, 1 đ (00390893), 1 (00390894) (AM). $4.2 \mathrm{~km} \mathrm{SE}$ of Esperance, Lake Mullet Nature Reserve, $33.79691^{\circ} \mathrm{S} 121.95427^{\circ} \mathrm{E}, 10 \mathrm{~m}$, 23 Nov 1999, R.T. Schuh, G. Cassis, and R. Silveira, Baeckea uncinella Benth. (Myrtaceae), det. PERTH staff PERTH 05671299, 1 ㅇ 
(00390859) (AM). $11 \mathrm{~km} \mathrm{~S}$ of Eneabba, Eneabba National Park, $29.9025^{\circ} \mathrm{S} 115.24321^{\circ} \mathrm{E}, 150$ m, 01 Nov 1996, Schuh and Cassis, Allocasuarina campestris (Diels) L.A.S. Johnson (Casuarinaceae), det. PERTH staff PERTH 05120063, $1 q$ (00393385) (AM), Scholtzia drummondii Benth. (Myrtaceae), det. PERTH staff PERTH 05120209, 3 ㅇ (00393463-00393465) (AM), Calytrix glutinosa Lindl. (Myrtaceae), det. PERTH staff PERTH 05120101, $1+$ (00414822) (AMNH). Eneabba on Brand Hiway, 29.80735 ${ }^{\circ} \mathrm{S}$ $115.2699^{\circ} \mathrm{E}, 100 \mathrm{~m}, 31$ Oct 1996, Schuh and Cassis, Eremaea beaufortioides Benth. var. beaufortioides (Myrtaceae), det. PERTH staff PERTH 05120187, 1 t (00136214), 1 (00136223) (AMNH). Frank Hann National Park, 37 km E of Lake King, $33.07753^{\circ} \mathrm{S} 120.0918^{\circ} \mathrm{E}, 400 \mathrm{~m}, 05$ Nov 1996, Schuh and Cassis, Melaleuca sp. (Myrtaceae), det. PERTH staff PERTH 05236908, 3 đิ (00087575, 00390810, 00390811), 1 우 (00390812) (AM). Kalbarri National Park, $37.7 \mathrm{~km}$ E of Kalbarri, $27.84818^{\circ} \mathrm{S} 114.47458^{\circ} \mathrm{E}$, 500 m, 29 Oct 1996, Schuh and Cassis, Melaleuca laetifica Craven (Myrtaceae), det. PERTH staff PERTH 05054540, 70 (00372186, 00372187, 00087419, 00087579, 00393457, 00391104, 00391105), 9 우 (00372200, 00372201, 00372211-00372213, 00087420, 0039344600393448) (AM), 14 đิ (00135045-00135058), 5 우인 $00372207-00372210,00372214)(\mathrm{AMNH})$, 5 호 (00372184, 00372185, 00393432-00393434), 7 (00372202-00372206, 00393449, 00393450) (WAMP).

Additional Specimens Examined AUSTRALIA: Western Australia: $4.2 \mathrm{~km}$ SE of Esperance, Lake Mullet Nature Reserve, $33.79691^{\circ} \mathrm{S}$ $121.95427^{\circ} \mathrm{E}, 10$ m, 23 Nov 1999, R.T. Schuh, G. Cassis, and R. Silveira, Baeckea uncinella Benth. (Myrtaceae), det. PERTH staff PERTH 05671299, 3 우 (00393460-00393462) (AM). Kalbarri National Park, $37.7 \mathrm{~km}$ E of Kalbarri, 27.84818 ${ }^{\circ} \mathrm{S}$ $114.47458^{\circ} \mathrm{E}, 500 \mathrm{~m}, 29$ Oct 1996, Schuh and Cassis, Melaleuca laetifica Craven (Myrtaceae), det. PERTH staff PERTH 05054540, 12 nymphs (00372188-00372199) (AM).

\section{Melaleucaphylus pauperiflorae, new species}

\author{
Map 3, plates 3, 19, table 1
}

Diagnosis: Distinguished by overall reddishorange coloration, including cuneus, and black on head, except for pale vertex, antennae, and calli; endosoma with short, curved subapical spine on posterior edge of ventral strap and contiguous, ventrally curved apical spines of dorsal strap. Somewhat similar in dorsal coloration to M. halmaturorum, but latter species with conspicuous pale margins around red cuneus. Endosoma also similar to M. halmaturorum but larger, with apical spines of dorsal strap longer, divergent at base then converging at apices, and blunt subapical spine on posterior edge of ventral strap; endosoma in M. pauperiflorae smaller, apical spines of dorsal strap shorter, contiguous for entire length, convergent apically, and pointed subapical spine on posterior edge of ventral strap. Length of secondary gonopore in M. halmaturorum longer than in $M$. pauperiflorae.

DesCription: MALE: Total length 3.50, pronotum width 1.15. COLORATION (pl. 3): General coloration faintly orange to reddish brown; black on head, except vertex, immediately near eyes, gula, and ventral edge of buccula pale, antenna, calli, mesoscutum medially, ventral aspect of thorax, except dorsal portion of propleuron, basalar plate, posterior edge of mesepimeron, metepisternal scent-gland evaporative area (including auricle but not dorsal modified surface), and venter; legs pale dirty yellow with dark areas on coxae and femora proximally, trochanters, metafemora distally, metatibiae diffusely, and tarsus; hemelytral membrane hyaline, with indistinct fumose areas near cells and within large cell; veins dusky yellow; tibiae without dark spots at bases of black spines. SURFACE AND VESTITURE (pl. 3): Shining; dorsum with moderately dense, curved, reclining, black, simple setae; head, pronotum, and thoracic venter with some shining golden setae; coxae with erect golden setae, without strong black setae. STRUCTURE: Labium reaching apex of metacoxa. Pretarsus: Claws moderate sized, slightly curved, bases somewhat enlarged; parempodia setiform, relatively long, par- 
allel, apices apparently sharp; pulvilli height low, proximal of angle of claw. GENITALIA (pl. 19): Pygophore: As in generic description. Endosoma: Distal one-third with torsion, twisted to left side; ventral strap entire, anterior surface with small rounded apical margin reaching level to middle of proximal secondary gonopore process, posterior edge with hooked, horn shaped, pointed subapical spine, protruding beyond curvature of ventral strap, with length subequal to apex of anterior surface, subapical spine originating just below proximal secondary gonopore process; dorsal strap bifurcate level at proximal end of secondary gonopore, divided into pair of sharply pointed apical spines-large anterior spine extending distad of secondary gonopore $3.5 \times$ length of gonopore; small posterior spine of uniform diameter at base, adjacent to anterior apex for entire length, parallel at apex; apices of dorsal strap separated by length of secondary gonopore. Secondary gonopore: Well sclerotized, located medially, aperture on ventroanterior surface, proximal edge with medium-sized, well-sclerotized lanceolate process, distal surface with microspiculate membrane; extremely thin and obscure gonopore sclerite located within interstrap region, stretching from relatively wavy proximal end of secondary gonopore to region proximal to bifurcation of endosomal straps. Phallotheca: Large, somewhat attenuate apical region with undulate margins, posterior surface with small crest-shaped flanges distally and broad prominence proximally; aperture on anteroventral surface, long, evenly narrow to apex. Parameres: Left paramere: Posterior margin and shoulder region between posterior and anterior processes moderately elongate, otherwise typically phyline; posterior process short, gently attenuate from expanded base, straight distally, apex small, rounded. Right paramere: Subovate, slightly elongate with short distal region and small rounded apex.

FEMALE: Unknown.

Eтymology: Named for its occurrence on Melaleuca pauperiflora.

Host: Recorded from Melaleuca pauperiflora ssp. pauperiflora (Myrtaceae: Melaleuceae) (pl. 39J).
Distribution (map 3): Known from the type specimen collected in Frank Hann National Park, Great Southern region, Western Australia, within the southwestern phytogeographic subregion near collections sites of $M$. micranthae and M. omnivorus.

Discussion: Both M. pauperiflorae and $M$. omnivorus were taken near Lillian Stoke Rock but from different species of Myrtaceae, the former on Melaleuca pauperiflora, the latter on Baeckea crispiflora and B. schaueri. The two species can be distinguished by features presented in the above diagnoses. The ventral strap with a curved, stout subapical spine on the posterior edge, a feature of $M$. pauperiflorae, is also present in M. beaufortiae, M. halmaturorum, M. micranthae, M. nodosae, M. phymatocarpi, and $M$. rhaphiophyllae.

Holotype: AUSTRALIA: Western Australia: Frank Hann National Park, Lillian Stoke Rock, $33.06773^{\circ} \mathrm{S} 120.0971^{\circ} \mathrm{E}, 400 \mathrm{~m}, 05$ Nov 1996, Schuh and Cassis, Melaleuca pauperiflora F. Muell. subsp. pauperiflora (Myrtaceae), det. PERTH staff PERTH 05236568, 10 (AMNH_ PBI 00390855) (WAMP).

\section{Melaleucaphylus phymatocarpi, new species}

Figures 9C, 10, map 4, plates 3, 20, table 1

DiAgnosis: Distinguished by predominately drab olive coloration with small variable black and pale areas, short, curved, and laterally directed apical spines of dorsal strap, short subapical spine on posterior edge of ventral strap, and folded posteroventral margin of dorsal labiate plate. All other species with a subapical spine on posterior edge of ventral strap with posteroventral margin of dorsal labiate plate conspicuously tumid.

Description: Male: Mean total length 3.21, mean pronotum width 1.15. COLORATION (pl. 3): Pale or dark dusky tannish olive; head dark brown to black with pale yellowish tan on mandibular plate, gula and frons near eyes, vertex, and collum; antenna and labium black; dark 
marking on frons extending in relatively broad band dorsally from clypeus to majority of vertex. Thorax with calli variously black, mesoscutum black medially, dull orange, then black laterally, scutellum dusky black medially, black apically; hemelytron dusky and variably infuscate on apices of embolium and cuneus, membrane infuscate, veins dusky yellow; tibia without dark spots at bases of spines, tarsus black; ventral surface pale on maxillary plate, gula, buccula, xyphus, ventral portion of propleuron, lateral surface of mesosternum, mesepimeron, entire metepisternal scent gland, and basalar plate; venter dark dusky brown to black. SURFACE AND VESTITURE (pl. 3): Shining (fig. 10A); dorsum with moderately dense, curved, reclining, black, simple setae; thoracic venter and venter with similar black setae, erect on coxae; tibiae with black spines (fig. 10B). STRUCTURE: Labium reaching base of metacoxa. Pretarsus: Claws moderate sized, slightly curved with bases slightly expanded; parempodia setiform, moderate length, parallel, apices pointed; pulvilli wide, height low, proximad of angle to base of claw (fig. 9C). GENITALIA (pl. 20A-J): Pygophore: As in generic description. Endosoma: Distal one-quarter with torsion, twisted to left side; ventral strap entire with anterior surface terminating level with proximal end of secondary gonopore with smoothly curved distal margin, posterior edge terminating in small, hooked, smooth-margined, subapical spine slightly protruding beyond curvature of ventral strap, apex of spine even with middle of proximal secondary gonopore process; dorsal strap bifurcate level with base of secondary gonopore, divided into pair of equal-length, sigmoid, sharply pointed, somewhat apically divergent sclerites reaching distad beyond apex of secondary gonopore by length of gonopore; dorsal strap wide proximad of gonopore, notched level with proximal end of gonopore, strap continuing distad as narrow spines. Secondary gonopore: Proximal edge with large well-sclerotized process, proximal end of process broadly attenuate, distal and proximal edges of secondary gonopore with spiculate patches on lateral surface; interstrap membrane with very thin sclerite reaching from secondary gonopore to base of endosoma. Phallotheca: Moderate sized, relatively short, attenuate apical region slightly compressed anteriorly and posteriorly; aperture narrow, undulate on anterior surface; ventroposterior surface with outpocket. Parameres: Left paramere: Triangular in dorsal view, posterior and anterior processes with expanded bases; posterior process abruptly narrowed, longer than anterior process, but relatively short; anterior process relatively long, apex smoothly rounded; posterior surface of paramere not expanded posteriorly or above anterior and posterior processes. Right paramere: Moderate length, somewhat expanded posteriorly, margins smoothly rounded; apex short, knoblike.

Female (pl. 3): Coloration as in male; differing from male as in generic description; mean total length 3.59, mean pronotum width 1.30 . GENITALIA (pl. 20K-M): Posterior margin of sternite 7: Bearing elongate, narrow projection. Vestibular sclerites: Situated medially, moderate sized, C-shaped, convoluted, extending to right side, anterior edge extending even with medial side of right sclerotized ring in dorsal view; strongest sclerotization on medioventral extension of ventral labiate plate and basal sclerites of first gonapophyses. Dorsal labiate plate: Moderate sized, ovoid; posteroventral margin of dorsal labiate plate folded, not tumid. Sclerotized rings moderately large with narrow margins, subquadrate, separated by one-half width of ring, medial margin of ring rounded, lateral margin sublinear, almost reaching lateral margin of dorsal labiate plate. Intersegmental process: Ventral projection broadly rounded, apical margin entire, flattened, compressed on horizontal axis, microspiculate. Posterior wall: Moderately large, well sclerotized. Interramal sclerites: With small, prominent, posteriorly directed medial prominence; ventrolateral regions with obvious sclerotized subrectangular extensions. Interramal lobes: Dorsolateral region hyaline; regions either side of medial prominence not produced into genital chamber.

EтумоLOgY: Named for its occurrence on the genus Phymatocarpus. 
Hоsт: Recorded from Eremaea pauciflora (Myrtaceae: Melaleuceae) and Pileanthus vernicosus (Myrtaceae: Chamelaucieae), but with the preponderance of specimens known from Phymatocarpus porphyrocephalus (Myrtaceae: Melaleuceae) (pl. 41B).

Distribution (map 4): Known from three localities on the west coast of Western Australia in the southwestern phytogeographic subregion.

Holotype: AUSTRALIA: Western Australia: NW Coastal Hiway $57 \mathrm{~km} \mathrm{~N}$ of Kalbarri Road, $27.44756^{\circ} \mathrm{S} 114.6867^{\circ} \mathrm{E}, 500 \mathrm{~m}, 30$ Oct 1996, Schuh and Cassis, Phymatocarpus porphyrocephalus F. Muell. (Myrtaceae), det. PERTH staff PERTH 05879264, 10 (AMNH_PBI 00372116) (WAMP).

PARATYPES: AUSTRALIA: Western Australia: $49 \mathrm{~km} \mathrm{~S}$ of Eneabba, Coomallo Rest Area, jct of Brand Hiway and Jurien East Rd, $30.22333^{\circ} \mathrm{S}$ $115.39808^{\circ} \mathrm{E}, 162 \mathrm{~m}, 21$ Oct 2004, Cassis, Wall, Weirauch, Symonds, Eremaea pauciflora (Endl.) Druce (Myrtaceae), det. PERTH staff PERTH6987028, 1 đิ (00129885) (AMNH). 54.3 $\mathrm{km} \mathrm{N}$ of jct of Agana Kalbarri Rd and Brand Hiway (rest area), $27.47362^{\circ} \mathrm{S} 114.7054^{\circ} \mathrm{E}, 240 \mathrm{~m}$, 24 Oct 2004, Cassis, Wall, Weirauch, Symonds, 10 (00368519), 1 우 (00368520) (AMNH). NW Coastal Hiway $57 \mathrm{~km} \mathrm{~N}$ of Kalbarri Road, $27.44756^{\circ} \mathrm{S} 114.6867^{\circ} \mathrm{E}, 500 \mathrm{~m}, 30$ Oct 1996, Schuh and Cassis, Phymatocarpus porphyrocephalus F. Muell. (Myrtaceae), det. PERTH staff PERTH 05879264, 13 के (00372115, 0037211700372127, 00087184), 18 ㅇ (00393355-00393357, 00393360, 00393370-00393377, 0013667100136676) (AM), 7ð (00136643-00136649), 14 우 (00393363-00393369, 00136663-00136669) (AMNH), 1 đ (00087456), 1 ㅇ (00136670) (CNC), 8 के (00136650-00136657), 8 우 (00393358, 00393359, 00393361, 00393362, 00136658, 00136659, 00136661, 00136662) (WAMP).

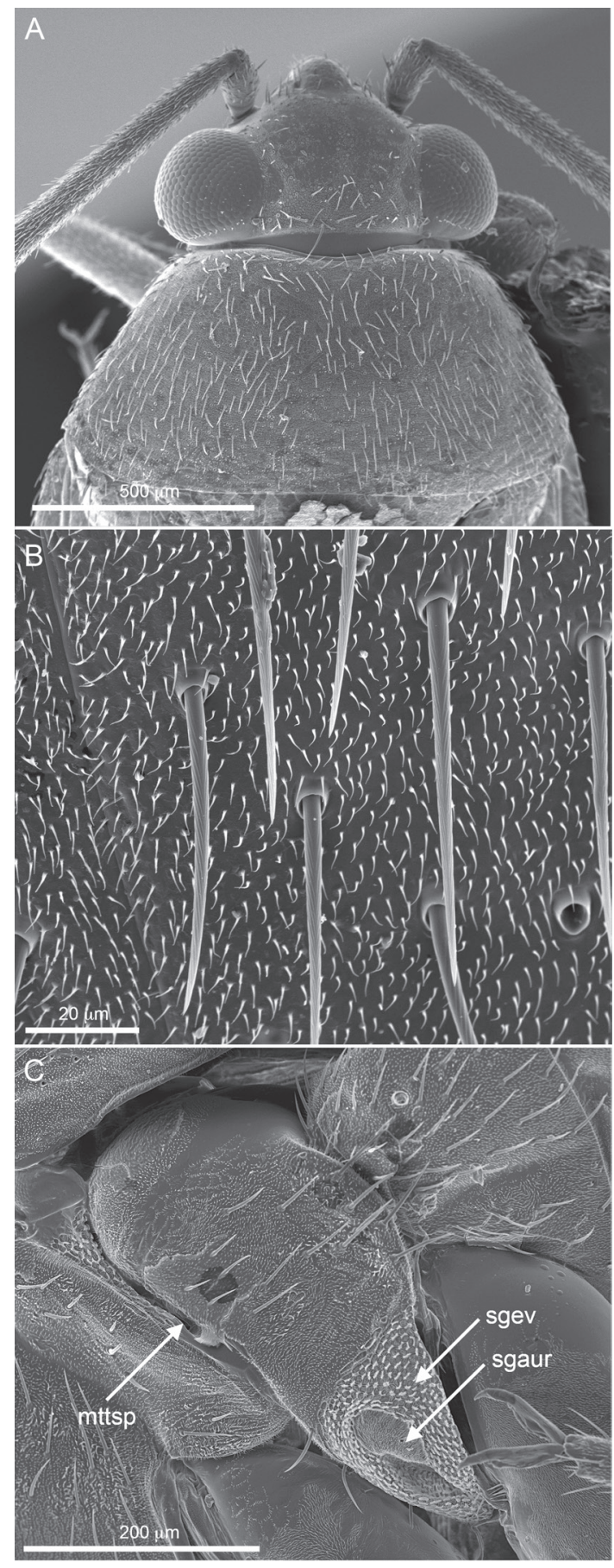

FIG. 10. Melaleucaphylus phymatocarpi, AMNH_PBI 00372120. Scanning electron micrographs. A. Head and pronotum, dorsal view. B. Detail of pronotal setae, dorsal view. C. Thoracic pleuron, lateral view, showing metathoracic spiracle opening, metathoracic scent-gland auricle, and evaporatory area. Abbreviations: mttsp, metathoracic spiracle; sgaur, scent gland auricle; sgev, scent gland evaporatory area. 
Additional Specimens Examined: AUSTRALIA: Western Australia: NW Coastal Hiway $57 \mathrm{~km} \mathrm{~N}$ of Kalbarri Road, $27.44756^{\circ} \mathrm{S}$ $114.6867^{\circ} \mathrm{E}, 500 \mathrm{~m}, 30$ Oct 1996, Schuh and Cassis, Pileanthus vernicosus F. Muell. (Myrtaceae), det. PERTH staff PERTH 05120306, 1 \% (00393452) (AM), Phymatocarpus porphyrocephalus F. Muell. (Myrtaceae), det. PERTH staff PERTH 05879264, 1 우 (00136660 severely damaged) (AMNH).

\section{Melaleucaphylus polyphagus, new species}

Figures 9D, 11. map 4, plates 3, 21, table 1

DiAgnosis: Coloration ranging from almost completely dark to pale and therefore potentially confused with other species, but very large, hollow, subapical spine on posterior edge of ventral strap of endosoma will unequivocally distinguish this species from all congeners.

Description: Male: Mean total length 3.20, mean pronotum width 1.13. COLORATION (pl. 3): Variable; in darkest specimens dark brownish black to black with pale cream color on portions of buccula, gena, vertex, collum, collar, posterior lobe of pronotum medially, scutellum laterally, claval suture, base of cuneus, xyphus, propleuron bordering coxae, and legs, except tarsus; membrane infuscate, veins dark brown; in palest specimens entirely pale with black on clypeus, antennal segment 1 , apical segments of labium, tarsi, and phallotheca; dark areas often reddish orange or brown; tibia without dark spots at bases of spines; hemelytral membrane translucent, sometimes with dark streak near apex of large cell. SURFACE AND VESTITURE (pl. 3): Shining (fig. 11A); dorsum with moderately dense curved reclining black simple setae; thoracic venter and coxae with erect black setae (fig. 11B); tibia with black spines. STRUCTURE: Labium reaching apex of metacoxa. Pretarsus: Claws medium sized, gently curved with slightly expanded bases; parempodia somewhat lamelliform, lyrelike, relatively long, apices slightly expanded, truncate; pulvilli small, short, restricted to just proximad of angle of claw (fig. 9D). GENITALIA (fig. 11D, pl. 21A-I): Pygophore: As in generic description. Endosoma: Approximately distal one-half with torsion, twisted more caudad than to left side; base to middle of basal curve sclerotized and entire, then bifurcate with broad split; ventral strap entire, anterior surface terminating in broadly attenuate flat apex even with distal margin of proximal secondary gonopore process and posterior surface with large, smooth, hollow, apically rounded, subapical prong, originating level with proximal end of secondary gonopore process, about $3 \times$ length of secondary gonopore, reaching to distal end of secondary gonopore; dorsal strap undivided, narrow over entire length, terminating in thin pointed apex. Secondary gonopore: Well-sclerotized, deep, surface of aperture convoluted, with large, well-sclerotized, irregularly shaped, proximally attached secondary gonopore process, caudal surface of process broadly hatchet shaped; interstrap membrane with very thin sclerite reaching from base of endosoma to secondary gonopore. Phallotheca: Large, attenuate apical region with undulating posterior surface; base of exposed portion expanded and angulate on right side; aperture large, located on anteroventral surface. Parameres: Left paramere: Broadly triangular in dorsal view, posterior process short, abruptly narrowed, base weakly expanded laterally, longer than anterior process; anterior process short with long apical seta; posterior surface of paramere moderately expanded posteriorly, not raised above bases of anterior and posterior processes. Right paramere: Moderately elongate, somewhat broad distally, margins smoothly rounded; apex short.

Female (pl. 3): Coloration as in male; differing from male as in generic description; mean total length 3.37 , mean pronotum width 1.22 . GENITALIA (pl. 21J-L): Posterior margin of sternite 7: With broadly triangular projection. Vestibular sclerites: Situated medially, relatively small, J-shaped, convoluted, lateral margin curved, weakly extending to right side, anterior edge extending even with anterior mar- 

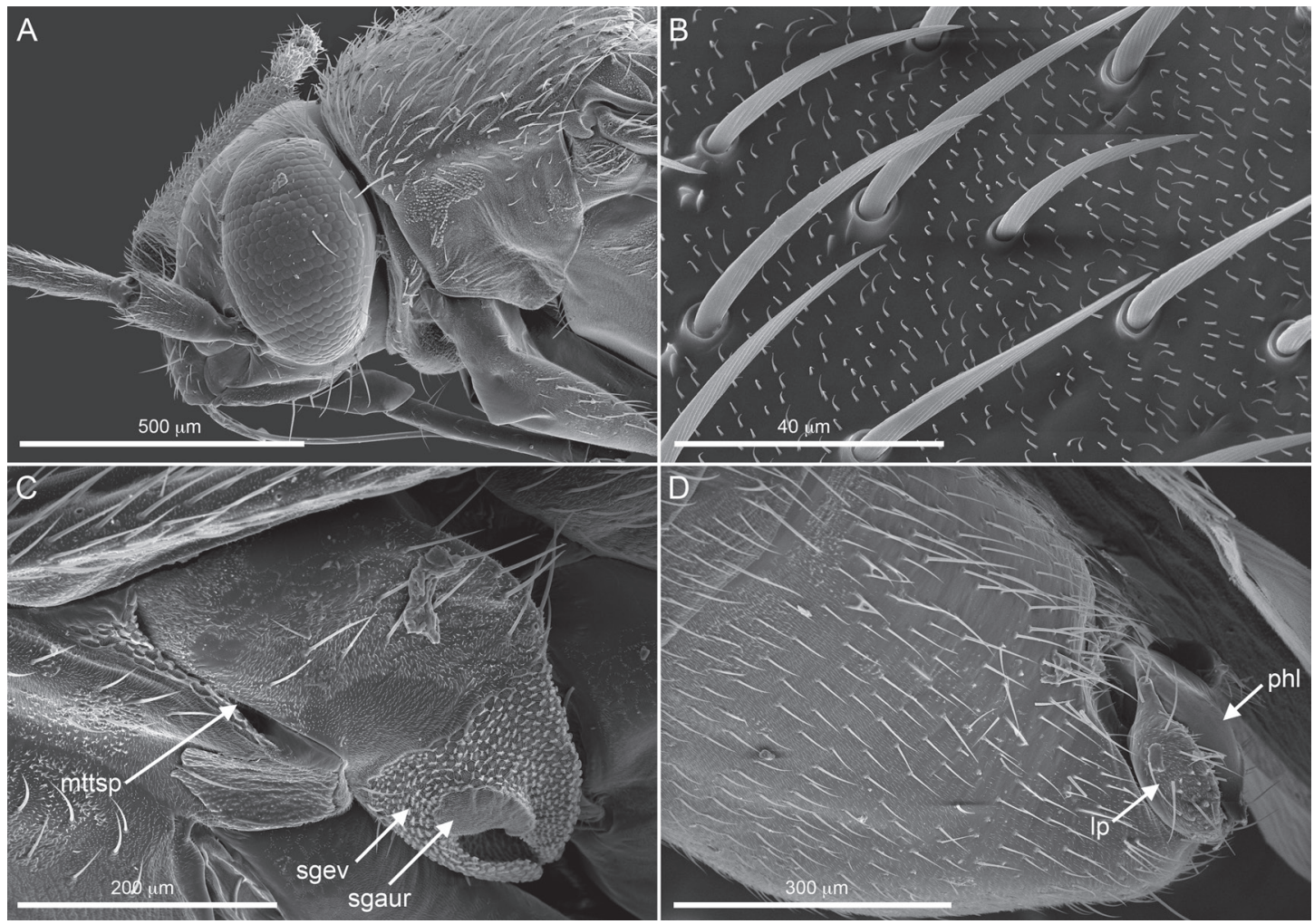

FIG. 11. Melaleucaphylus polyphagus, AMNH_PBI 00132521. Scanning electron micrographs. A. Head and pronotum, lateral view. B. Detail of pronotal setae, dorsal view. C. Thoracic pleuron, lateral view, showing metathoracic spiracle opening, metathoracic scent-gland auricle, and evaporatory area. D. Pygophore, left paramere, and phallotheca, lateral view. Abbreviations: lp, left paramere; mttsp, metathoracic spiracle; phl, phallotheca; sgaur, scent gland auricle; sgev, scent gland evaporatory area.

gins of rings and occupying interring region in dorsal view; vestibulum weakly sclerotized from posterior margin of ventral labiate plate to first gonapophyses. First gonapophyses: Weakly sclerotized. Ventral labiate plate: Left and right portions symmetrically developed. Dorsal labiate plate: Relatively small, ovoid; posteroventral edge folded. Sclerotized rings: Relatively small, subovoid, margins narrow, separated by width of ring, anterior and lateral margins slightly, not reaching lateral margin of dorsal labiate plate. Posteromedial region: Sunken microspiculate invaginated plates, abutting on midline, posterior margins slightly uneven. Intersegmental process: Triangular, tilted and directed anteriad, microspiculate, apical margin entire. Posterior wall: Moderately large, well sclerotized. Interramal sclerites: With shallow, vertical, posteriorly directed medial prominence; ventrolateral regions with obvious sclerotized subrectangular extensions. Interramal lobes: Dorsolateral region hyaline; regions either side of medial prominence with microspiculate surfaces, somewhat produced into genital chamber.

EтумоLogy: Named for its occurrence on multiple hosts; from the Greek, polys, "many, much," and, phagein, "to eat."

Hosts: Recorded from Baeckea uncinella (Myrtaceae: Chamelaucieae), Melaleuca brevifolia (pl. 39A), M. cucullata, M. hamulosa (pl. 39E), M. halmaturorum (pl. 39C, D) and M. wilsonii (pl. 40H) (Myrtaceae: Melaleuceae). 
Distribution (map 4): Known from several collecting events from the west and south coasts of Western Australia in the southwest interzone and southwestern phytogeographic subregions. Also known from Little Desert National Park, Victoria, and adjacent southeastern South Australia in the Adelaide phytogeographic subregion.

Discussion: This is one of a handful of phyline species with disjunct distributions including coastal Western Australia, southern South Australia, and Victoria. Careful examination of male genitalic preparations from across the known distribution reveals remarkable uniformity of structure and we therefore treat specimens from a broad distributional range as conspecific.

Specimens collected on Melaleuca hamulosa from Lake Magenta Road, $4 \mathrm{~km} \mathrm{~N}$ of South Coast Highway are uniformly pale with black coloration restricted to the clypeus and antennal segment 1 but have identical male genitalia as in dark patterned specimens. We therefore treat them as conspecific. These pale specimens are similar in coloration and overall appearance to Leptospermia cassisi, but the structure of the endosoma is distinctive and the posterior margin of the pygophore in $M$. polyphagus is more pointed and not as deep ventrally as in L. cassisi, in which the caudal surface of the pygophore is perpendicular to the aperture in lateral view. Additionally, the dorsal vestiture of the former is more sparse and shorter than in the latter.

Holotype: AUSTRALIA: Victoria: Little Desert National Park, $23 \mathrm{~km}$ E on McDonald Hiway, $36.56668^{\circ} \mathrm{S} 141.5^{\circ} \mathrm{E}, 150 \mathrm{~m}, 04$ Nov 1995 , Schuh and Cassis, Melaleuca wilsonii F. Muell. (Myrtaceae), det. P.G. Wilson 1996 NSW 395989, 1 đ (AMNH_PBI 00372229) (MVMA).

Paratypes: AUSTRALIA: South Australia: Scorpion Springs Cons. Park, 35.60421 ${ }^{\circ} \mathrm{S}$ $140.8646^{\circ} \mathrm{E}, 125 \mathrm{~m}, 10$ Nov 1998, Schuh, Cassis, Silveira, Melaleuca brevifolia Turcz. (Myrtaceae), det. Royal Bot Gard. NSW 427362, 7 † (00087249, 00087474, 00393607-00393611), 5 우 (00087250, 00393616-00393619) (AM), 1 ๙ (00414793), 2 ㅇ (00414794, 00414795) (AMNH),
40 (00393612-00393615), 3 우 (0039362000393622) (SAMA). Victoria: Little Desert National Park, $23 \mathrm{~km}$ E on McDonald Hiway, $36.56668^{\circ} \mathrm{S} 141.5^{\circ} \mathrm{E}, 150 \mathrm{~m}, 04$ Nov 1995, Schuh and Cassis, Melaleuca wilsonii F. Muell. (Myrtaceae), det. P.G. Wilson 1996 NSW 395989, 12 ๙ (00372224, 00372225, 00372227, 00372228, 00372230-00372235, 00087295, 00087495), 7 (00372238-00372243, 00087296) (AM), 43 ๙ (00132515-00132522, 00132524, 0013253000132555, 00132559-00132566), 21 (00132571-00132583, 00132586, 00132587, 00132593-00132598) (AMNH), 3 đే (0013255600132558), 2 ㅇ (00132584, 00132585) (ANIC), 1 đิ (00132511), 1 ㅇ (00132567) (CNC), 7 ๙ (00372226, 00132523, 00132525-00132529), 7 ㅇ (00372236, 00372237, 00132588-00132592) (MVMA), 1 후 (00132513), 1 우 (00132569) (UCR), 1 ऽ (00132514), 19 (00132570) (USNM), 1 đิ (00132512), 1 ㅇ (00132568) (ZISP). Little Desert National Park, Broughton's Waterhole, McDonald Highway, $36.56868^{\circ} \mathrm{S} 141.3357^{\circ} \mathrm{E}, 136$ m, 06 Nov 2002, Cassis, Schuh, Schwartz, Silveira, Melaleuca wilsonii F. Muell. (Myrtaceae), det. Field ID, 7 0 (00368521-00368526, 00368528), 11 ㅇ (00368529-00368539) (AMNH), 10 (00368527), 3 우 (00368540-00368542) (MVMA). Little Desert National Park, Stans Camp Track, $36.58686^{\circ} \mathrm{S} 141.5622^{\circ} \mathrm{E}, 173 \mathrm{~m}, 06$ Nov 2002, Cassis, Schuh, Schwartz, Silveira, Melaleuca wilsonii F. Muell. (Myrtaceae), det.

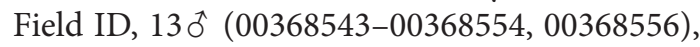
4 우 (00368558-00368560, 00368562) (AMNH), 2 주 (00368555, 00368557), 1 우 (00368561) (MVMA). Western Australia: $4.2 \mathrm{~km}$ SE of Esperance, Lake Mullet Nature Reserve, $33.79691^{\circ} \mathrm{S} 121.95427^{\circ} \mathrm{E}, 10 \mathrm{~m}, 23$ Nov 1999, R.T. Schuh, G. Cassis, and R. Silveira, Baeckea uncinella Benth. (Myrtaceae), det. PERTH staff PERTH 05671299, 1 के (00372128), 3 ㅇ (00372129-00372131) (AM). 7.9 km N of Ravensthorpe, $33.53626^{\circ} \mathrm{S} 119.9993^{\circ} \mathrm{E}, 400 \mathrm{~m}, 05 \mathrm{Nov}$ 1996, Schuh and Cassis, Melaleuca cucullata Turcz. (Myrtaceae), det. PERTH staff PERTH 05236657, 1 ơ (00391145), 2 ㅇ (00391146, 00391147) (AM), 1 주 (00414810), 1 우 (00414811) 
(AMNH). Gingin, $31.21^{\circ} \mathrm{S} 115.55^{\circ} \mathrm{E}, 104 \mathrm{~m}, 17$ Sep 1969, K. T. Richards, $11 \delta^{\text {tै }}$ (00391109, 00391117, 00391143, 00391107, 00391108, 00391111, 00391114, 00391115, 00391122, 00391129, 00391142), 3 우 (00391134, 00391136, 00391138) (AM); 29 Aug 1969, K. T. Richards, 11 đิ (00391112, 00391113, 00391116, 00391118, 00391120, 00391123, 00391125-00391128, 00391157), 6 ㅇ (00391131-00391133, 00391137, 00391139, 00391140) (AM); 09 Sep 1969, P.J. Lawrence, 3 o (00391110, 00391119, 00391130), 1 잉 (00391135) (AM); 12 Sep 1969, P.J. Lawrence, 2 o (00391124, 00391121), 1 ㅇ (00391141) (AM). Lake Magenta Road, $4 \mathrm{~km} \mathrm{~N} \mathrm{of} \mathrm{South}$ Coast Hiway, $33.77872^{\circ} \mathrm{S} 119.2887^{\circ} \mathrm{E}, 400 \mathrm{~m}, 07$ Dec 1997, Schuh, Cassis, Brailovsky, Asquith, Melaleuca hamulosa Turcz. (Myrtaceae), det. PERTH staff PERTH 05054567, 12 đ (0039356000393571), 15 ㅇ (00393592-00393606) (AM), 6 đิ (00131494-00131499), 10 ㅇ (0013150000131509) (AMNH), 3 ऽิ (00393577-00393579), 3 우 (00393580-00393582) (UNSW), 5 주 (00393572-00393576), 5 우 (0039358700393591) (WAMP).

Additional Specimens Examined: AUSTRALIA: Victoria: Jeparit Environmental Park, $36.14047^{\circ} \mathrm{S} 141.9643^{\circ} \mathrm{E}, 90 \mathrm{~m}, 05$ Nov 2002, Cassis, Schuh, Schwartz, Silveira, Melaleuca halmaturorum F. Muell. ex Miq. (Myrtaceae), det. NSW staff NSW 658110, $10^{\text {(0 }}$ (00414809) (AMNH). Little Desert National Park, McDonald Highway, $36.58255^{\circ} \mathrm{S} 141.6418^{\circ} \mathrm{E}, 190 \mathrm{~m}, 05$ Nov 2002, Cassis, Schuh, Schwartz, Silveira, Melaleuca wilsonii F. Muell. (Myrtaceae), det. NSW staff NSW 658111, 1 के (00414808) (AMNH). Little Desert National Park, Stans Camp Track, $36.58686^{\circ} \mathrm{S} 141.5622^{\circ} \mathrm{E}, 173 \mathrm{~m}, 06$ Nov 2002, Cassis, Schuh, Schwartz, Silveira, Melaleuca wilsonii F. Muell. (Myrtaceae), det. Field ID, 1 nymph (00368563) (AMNH). Western Australia: Lake Magenta Road, $4 \mathrm{~km} \mathrm{~N}$ of South Coast Hiway, $33.77872^{\circ} \mathrm{S} 119.2887^{\circ} \mathrm{E}, 400$ m, 07 Dec 1997, Schuh, Cassis, Brailovsky, Asquith, Melaleuca hamulosa Turcz. (Myrtaceae), det. PERTH staff PERTH 05054567, 4 nymphs (00393583-00393586) (AM).
Melaleucaphylus rhaphiophyllae, new species

Figure 9E, F, map 4, plates 4, 22, table 1

DiAgnosis: Distinguished by large size of body and endosoma, narrow, straight subapical spine on posterior edge of ventral strap, apical spines of dorsal strap of almost equal length, parempodia somewhat lamelliform with fan shaped apices, coloration of dorsal vestiture matching underlying surface color, and dorsal labiate plate in female with large tumid posteroventral margin and large, flat bracket-shaped intersegmental process. Melaleucaphylus rhaphiophyllae and M. beaufortiae have roughly similar endosomal structure but can be distinguished on fine structure of apical region of dorsal straps; $M$. rhaphiophyllae with apical spines longer, curved dextrad, and with slightly divergent apices; $M$. beaufortiae with apical spines shorter, curved ventrad, and with parallel apices.

Description: Male: Mean total length 3.87, mean pronotum width 1.39 . COLORATION (pl. 4): Dusky yellow with variable size and intensity of darker coloration on frons, posterior lobe of pronotum, pair of parallel medial stripes on mesoscutum, clavus, posterior portion of corium, paracuneus, and thoracic venter; middle of cuneus and hemelytral membrane with faint dark color; pygophore always dark brown to black; appendages, especially tarsal segment 3, and claw usually slightly darker than pale portions of dorsum; vertex, calli, mesoscutum laterally, and scutellum always pale; tibia without dark spots at bases of spines. SURFACE AND VESTITURE (pl. 4): Subshining; dorsum with moderately dense, curved, reclining simple setae with coloration matching surface; coxae with erect pale setae; tibia with black spines. STRUCTURE: Labium reaching apex of metacoxa. Pretarsus: Claws moderately large, gently curved with somewhat expanded bases; parempodia relatively long, slightly lamelliform, parallel, with converging, expanded, and truncate apices; pulvilli minute, low, proximad of angle of claw (fig. 9E, F). GENiTAliA (pl. 22A-J): Pygophore: As in generic description. Endosoma: Well sclero- 
tized from base to middle of basal curve, then clearly bifurcate with broad split, distal one-half with torsion, twisted to left side; ventral strap entire, anterior surface with smoothly curved apex, terminating at proximal end of secondary gonopore; posterior surface with small, narrow, smooth-margined, sinuate, pointed subapical spine, protruding beyond curvature of ventral strap, subapical spine originating at proximal end of secondary gonopore process, as long as width of secondary gonopore; dorsal strap bifurcate level with base of secondary gonopore, apical spines gradually diverging over entire length, apices pointed, curving to right, separated by distance equal to width of secondary gonopore. Secondary gonopore: Well sclerotized, deep, surface of aperture convoluted, well sclerotized, with $\mathrm{C}$-shaped process ringing and projecting proximad of aperture with broad apex; small field of spicules on membrane adjoining ventrolateral surface of secondary gonopore; interstrap membrane with obscure, very thin sclerite reaching from secondary gonopore to base of endosoma. Phallotheca: Moderate sized, apical region attenuate; posterior surface with short, gently curved ridge on right surface and small basal protuberance or outpocket on left surface; aperture on anteroventral surface, elongate teardrop shaped, narrowed at apex. Parameres: Left paramere: Triangular in dorsal view, posterior process moderately short, gradually narrowed, base weakly expanded laterally, clearly longer than anterior process; anterior process moderately long; posterior surface of paramere broadly rounded, with small prominence, only slightly raised above bases of anterior and posterior processes. Right paramere: Medium sized, slightly elongate, somewhat attenuate posteriad, margins smoothly rounded, apex short.

Female (pl. 4): Coloration as in male, except hemelytron with pale or golden setae, posterior lateral portion of corium and cuneus with black setae; otherwise differing from male as in generic description; mean total length 4.21, mean pronotum width 1.53 . GENITALIA (pl. $22 \mathrm{~K}-\mathrm{O})$ : Posterior margin of sternite 7: With broadly triangular medial projection. Vestibular sclerites: Moderately large, vestibulum J-shaped, coiled, extending just within medial margin of right sclerotized ring in dorsal view; vestibulum convoluted, strongly sclerotized from posterior margin of ventral labiate plate, reaching first gonapophyses with fainter sclerotization. First gonapophyses: Pair of symmetrical triangular basal sclerites abutting ventral portion of right vestibular sclerite. Ventral labiate plate: Left and right portions symmetrically developed. Dorsal labiate plate: Moderately large, ovoid; posteroventral edge strongly tumid, asymmetrical, right side larger than left. Sclerotized rings: Large, subovoid, margins narrow, separated by one-half width of ring, lateral margin of ring angled, reaching lateral margin of dorsal labiate plate. Posteromedial region: Sunken microspiculate invaginated plates, slightly separated at midline, posterior margin strongly rolled. Intersegmental process: Large, broad, bracket shaped, tilted and directed anteriad, membranous, weakly microspiculate at base; apical margin with small medial notch. Posterior wall: Large, deep, well sclerotized. Interramal sclerites: With broad, vertical, posteriorly directed medial prominence; ventrolateral regions with obvious sclerotized subrectangular extensions. Interramal lobes: Dorsolateral region strongly sclerotized, with microspiculate surface; regions either side of medial prominence somewhat produced into genital chamber.

Eтумоlogy: Named for its occurrence on Melaleuca rhaphiophylla.

Host: Recorded from Melaleuca rhaphiophylla (Myrtaceae: Melaleuceae) (pl. 39K).

Distribution (map 4): Known only from the type locality near Eneabba in central west coastal Western Australia within the southwestern phytogeographic subregion.

Holotype: AUSTRALIA: Western Australia: Brand Hiway, $8.2 \mathrm{~km} \mathrm{~N}$ of Eneabba, $29.74618^{\circ} \mathrm{S} 115.254^{\circ} \mathrm{E}, 100 \mathrm{~m}, 31$ Oct 1996 , Schuh and Cassis, Melaleuca rhaphiophylla Schauer (Myrtaceae), det. PERTH staff PERTH 05120195, 1 đิ (AMNH_PBI 00137528) (WAMP). 
Paratypes: AUSTRAliA: Western Australia: Brand Hiway, $8.2 \mathrm{~km} \mathrm{~N}$ of Eneabba, $29.74618^{\circ} \mathrm{S} 115.254^{\circ} \mathrm{E}, 100 \mathrm{~m}, 31$ Oct 1996 , Schuh and Cassis, Melaleuca rhaphiophylla Schauer (Myrtaceae), det. PERTH staff PERTH 05120195, 37 o (00393330, 00087164, 00087448, 00393435-00393437, 00393477-00393495, 00393509-00393520), 28 우 (0008893300088936, 00088967-00088969, 00088930, 00088932, 00393331-00393340, 00087165, 00393502, 00391160-00391166) (AM), 40 శึ (00137598-00137610, 00137527, 00137529, 00137530, 00137532-00137549, 0013756600137571), 19 우 (00137613-00137623, 00137628-00137631, 00088929, 00088931, 00414836, 00414837) (AMNH), 40 (0013755600137559) (ANIC), 40 (00393498-00393501) (CNC), 2 ఫิ (00137554, 00137555) (UCR), 2 ๙ิ (00393496, 00393497) (UNSW), 2 ऽิ (00137552, 00137553) (USNM), 16 ㅈ (00137531, 0013756000137565, 00393521-00393529), 11 우 (00088970-00088974, 00137611, 00137612, 00137624-00137627) (WAMP), 2 đิ (00137550, 00137551) (ZISP).

Additional Specimens Examined: AUSTRALIA: Western Australia: Brand Hiway, 8.2 $\mathrm{km} \mathrm{N}$ of Eneabba, $29.74618^{\circ} \mathrm{S} 115.254^{\circ} \mathrm{E}, 100 \mathrm{~m}$, 31 Oct 1996, Schuh and Cassis, Melaleuca rhaphiophylla Schauer (Myrtaceae), det. PERTH staff PERTH 05120195, 3 nymphs (00088975, 00391158, 00391159) (AM).

\section{Melaleucaphylus sheathianae, new species}

Figures 9G, 12, map 4, plates 4, 23, table 1

DiAgnosis: Distinguished by generally yellowish tan coloration with dark on head, antennae, and hemelytral membrane, with reddish orange markings on mesoscutum, scutellum, and cuneus. Endosomal structure in this species and M. kaputar unique within genus, dorsal strap conspicuously bifurcate with strongly divergent apical spines. In M. sheathianae anterior spine long and posterior spine narrow and directed posteriorly; in $M$. kaputar entire endosoma smaller and dorsal strap anterior spine short and posterior spine somewhat thick and directed to right side. Antennal segment 2 pale medially with dark base and apex, whereas entirely black in $M$. sheathianae. The two species with allopatric distributions.

Description: Male: Mean total length 3.96, mean pronotum width 1.48. COLORATION (pl. 4): Generally pale dusky yellow to tan with variable dark markings; head with diffuse brown markings; frons with wide lateral stripes, sometimes entire frons dark, clypeus entirely; antennal segment 1 black, 2 dark tan, darker distally; mesoscutum orange yellow, scutellum cream colored with pale triangular orange mark medially, paracuneus and cuneus diffusely pink to red, membrane hyaline; large cell with two distinctive black marks, large one at apex, small one on distal interior margin; tibiae without dark spots at base of spines; entire tarsus or only tarsal segment 3 black; phallotheca black; sometimes dark markings on ventral margin and dorsal edge of mesosternum, pygophore dorsoproximally, and parameres. SURFACE AND VESTITURE (pl. 4): Shining; dorsum with moderately dense, curved, reclining black simple setae; thoracic venter and coxae with erect black setae; tibiae with black spines. STRUCTURE: Labium reaching to apex of mesocoxa. Pretarsus: Claws moderately large, slightly curved, with narrow bases; parempodia setiform, relatively long, parallel, apices sharp; pulvilli relatively long, height short, reaching from base to angle of claw (fig. 9G). GENITALIA (fig. 12D, pl. 23A-J): Pygophore: Large, broadly conical, with slight dorsal subbasal prominence each side; paramere insertions without tubercles or discrete patches of bristles. Endosoma: Distal one-half with torsion, twisted to left side; ventral strap bifurcate at base of proximal secondary gonopore process, apices of ventral strap level with base of secondary gonopore-anterior apex broadly rounded; posterior apex with large pointed spur, not protruding beyond curvature of ventral strap; dorsal strap bifurcate at base of secondary gonopore, divided into pair of sharply 


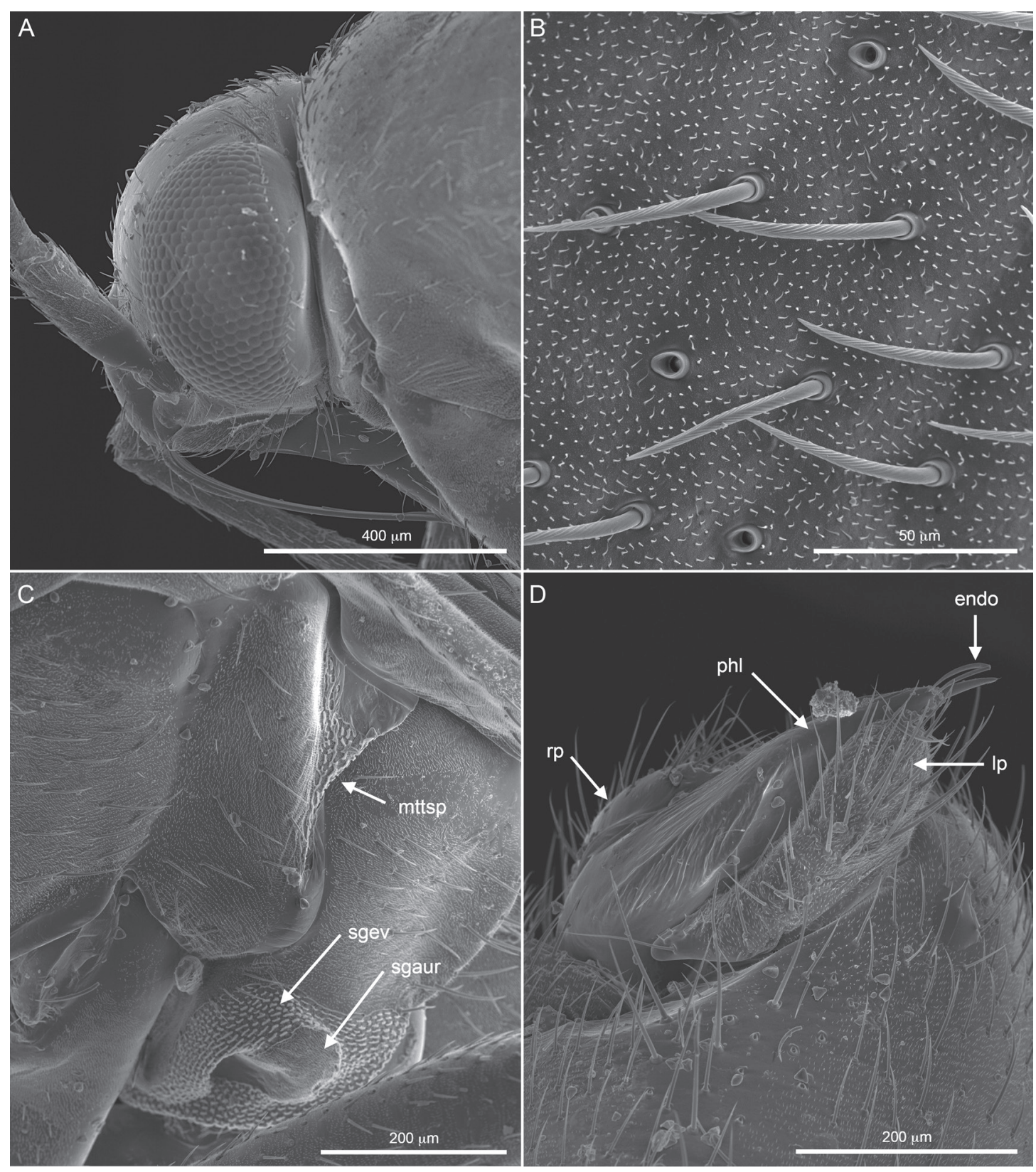

FIG. 12. Melaleucaphylus sheathianae, AMNH_PBI 00370823. Scanning electron micrographs. A. Head and pronotum, lateral view. B. Detail of pronotal setae, dorsal view. C. Thoracic pleuron, lateral view, showing metathoracic spiracle opening, metathoracic scent-gland auricle, and evaporatory area. D. Pygophore, left paramere, phallotheca, apical spines of dorsal endosomal strap, lateral view. Abbreviations: endo, endosoma; lp, left paramere; mttsp, metathoracic spiracle; phl, phallotheca; rp, right paramere; sgaur, scent gland auricle; sgev, scent gland evaporatory area. 
pointed apical spines-large anterior spine extending distad of secondary gonopore $3 x$ length of secondary gonopore; small posterior spine narrow, with sinuate margins, directed away from apex of anterior spine and extending distad of secondary gonopore slightly more than length of secondary gonopore. Secondary gonopore: Well sclerotized, located medially; aperture open on ventroanterior surface, proximal edge with large, well-sclerotized lanceolate process, distal edge with microspiculate membranous patch on lateral surface; interstrap region with extremely thin, wavy gonopore sclerite, reaching from proximal end of secondary gonopore to bifurcation of endosomal straps. Phallotheca: Large, attenuate apical region with undulate margins and posterior and anterior dorsal crestshaped flanges; aperture on anteroventral surface, long, narrow, more broadly open at apex. Parameres: Left paramere: Posterior margin and shoulder region between posterior and anterior processes slightly elongate, otherwise typically phyline; posterior process of moderate length, straight, gently attenuate from unexpanded base, apex small, rounded. Right paramere: Subrectangular, moderately elongate with short distal region and small rounded apex.

Female (pl. 4): Coloration as in male; differing from male as in generic description; mean total length 4.49 , mean pronotum width 1.61 . GENITALIA (pl. 23K-O): Posterior margin of sternite 7: Bearing elongate triangular projection. Vestibular sclerites: Large, J-shaped coiled tube projecting from right paramedial side of ventral labiate plate; in dorsal view extending just anteriad of anterior margin of and within middle of right sclerotized ring; vestibulum well sclerotized, continuous, strongly sclerotized from posterior margin of ventral labiate plate, reaching first gonapophyses. First gonapophyses: Pair of expanded symmetrical triangular basal sclerites abutting ventral portion of right vestibular sclerite. Ventral labiate plate: Right portion forming almost entire vestibulum, anteroventral extension relatively long; surface of ventral labiate plate ventral to sclerotized rings microspicu- late. Dorsal labiate plate: Relatively large, subhexagonal; posteroventral edge folded. Sclerotized rings: Large, subovoid, margins narrow, separated by one-half width of ring, lateral margin of ring angled, reaching lateral margin of dorsal labiate plate. Posteromedial region: Sunken microspiculate invaginated plate, divided on midline with overlapping slightly tumid posterior margins. Intersegmental process: Large, strongly triangular; apical margin entire; anterior surface microspiculate, posterior surface well sclerotized, merged with dorsoposterior portion of posterior wall. Posterior wall: Large, deep, well sclerotized. Interramal sclerites: With broad, vertical, posteriorly directed medial prominence; ventrolateral regions with obvious sclerotized subrectangular extensions. Interramal lobes: Dorsolateral region strongly sclerotized, with microspiculate surface, entire, anterior surface microspiculate; well sclerotized, wedge shaped; interramal sclerites widely separated and placed on ventrolateral margins, posterodorsal; portion membranous, with pair of widely separated, tumid, microspiculate interramal lobes projecting anteriorly into genital chamber; midline of wall strongly sclerotized, moderately projecting posteriad.

EтумоLogy: Named for its occurrence on Melaleuca sheathiana.

Hosts: Recorded from Melaleuca sheathiana (pl. 40A, B) and M. teuthidoides (pl. 40C) (Myrtaceae: Melaleuceae).

Distribution (map 4): Known from three collection events in southern portion of GoldfieldsEsperance region, Western Australia, within the southwest interzone phytogeographic subregion.

Holotype: AUSTRALIA: Western Australia: $11 \mathrm{~km} \mathrm{~N}$ of Coolgardie-Esperance Hiway on Kambalda Road, $31.25231^{\circ} \mathrm{S} 121.5899^{\circ} \mathrm{E}, 320 \mathrm{~m}$, 18 Nov 1999, R.T. Schuh, G. Cassis, and R. Silveira, Melaleuca sheathiana W. Fitzg. (Myrtaceae), det. PERTH staff PERTH 05671396, $10^{\star}$ (AMNH_PBI 00371350) (WAMP).

PARATYPES: AUSTRALIA: Western Australia: $11 \mathrm{~km}$ N of Coolgardie-Esperance Hiway on Kambalda Road, $31.25231^{\circ} \mathrm{S} 121.5899^{\circ} \mathrm{E}, 320 \mathrm{~m}, 18 \mathrm{Nov}$ 
1999, R.T. Schuh, G. Cassis, and R. Silveira, Melaleuca sheathiana W. Fitzg. (Myrtaceae), det. PERTH staff PERTH 05671396, 89 ơ (00091642-00091665, 00091689-00091702, 00370796-00370823, 00371974, 00372075, 00372036-00372054, 00087297, 00087497), 55 (00091666-00091688, 00370864, 00370897-00370913, 00371977, 00371979, 00372055-00372065, 00087298) (AM), 52 ð (00129399-00129411, 00371339-00371349, 00371351-00371362, 00371381, 00371382, 00129516-00129518, 00129445-00129454, 00129586), $39 q$ (00371316-00371319, 00371335, 00129412-00129416, 00129519-00129530, 00129455-00129471) (AMNH), 3 స (0037137500371377), 3 우 (00371323-00371325) (ANIC), 3ð (00371372-00371374), 3 우 (00371326-00371328) (CNC), 3 ơ (00371366-00371368), 3 우 (0037133200371334) (UCR), 3 후 (00371363-00371365), 3 우 (00371336-00371338) (UNSW), 3 సิ (0037136900371371), 3 우 (00371329-00371331) (USNM), 32 đิ (00370865-00370896), 40 ㅇ (0037082400370863) (WAMP), 3ð (00371378-00371380), 3 ㅇ (00371320-00371322) (ZISP). $33.3 \mathrm{~km} \mathrm{~S}$ of Norseman, $32.46461^{\circ} \mathrm{S} 121.6778^{\circ} \mathrm{E}, 300 \mathrm{~m}, 19$ Nov 1999, R.T. Schuh, G. Cassis, and R. Silveira, 9ô (00089118-00089120, 00089122-00089126, 00089128), Melaleuca sheathiana W. Fitzg. (Myrtaceae), det. Field ID, 19 (00393474), Melaleuca sheathiana W. Fitzg. (Myrtaceae), det. PERTH staff PERTH 05671396, 20 o (00370914-00370931, 00089121, 00089127), $25+$ (00370932-00370943, 00089129-00089141) (AM). 91.4 km SE of Southern Cross, $31.97145^{\circ} \mathrm{S} 119.287^{\circ} \mathrm{E}, 375 \mathrm{~m}, 04 \mathrm{Dec}$ 1997, Schuh, Cassis, Brailovsky, Asquith, Melaleuca teuthidoides Barlow (Myrtaceae), det. PERTH staff PERTH 05054834, 4 ऽ (00372132, 00372133, 00087108, 00088009), 12 (00372135-00372145, 00087109) (AM), 14 ชิ (00130807-00130820), 15 우 (00130821-00130835) (AMNH).

Additional Specimens Examined: AUSTRALIA: Western Australia: $91.4 \mathrm{~km}$ SE of Southern Cross, $31.97145^{\circ} \mathrm{S} 119.287^{\circ} \mathrm{E}, 375 \mathrm{~m}, 04$ Dec 1997, Schuh, Cassis, Brailovsky, Asquith, Melaleuca teuthidoides Barlow (Myrtaceae), det. PERTH staff PERTH 05054834, 1 nymph (00372134) (AM).

\section{Melaleucaphylus vimineae, new species}

Figure 13, map 4, plates 4, 24, table 1

Diagnosis: Recognized by endosoma with single short apical spine of dorsal strap, relatively large secondary gonopore, wide membranous area distad and laterad of secondary gonopore, parempodia flat, strongly lamelliform and wide apically, black tibial spines, and dorsum with widespread dark setae. Very similar to M. glomeratae, but that species with pale dorsal setae, pale or pale brown tibial spines, narrower parempodia, endosoma with longer single apical spine of dorsal strap, and large strongly spiculate distal process of secondary gonopore.

Description: Male: Mean total length 3.37, mean pronotum width 1.16. COLORATION (pl. 4): Dusky yellow with small diffuse paler areas; vertex near eyes, calli, and mesoscutum blotchy orange; antenna slightly darker than body; membrane weakly hyaline with small, diffuse, black area at apex of large membrane cell; interior of cells darker than rest of membrane; tibia with black spines without dark spots at bases. SURFACE AND VESTITURE (pl. 4): Weakly shining; dorsum with moderately dense, curved, reclining black simple setae, sometimes dark setae restricted to distal portions of clavus and corium and on cuneus. STRUCTURE: Labium reaching apex of mesocoxa. Pretarsus: Claws moderate sized, curved; parempodia lamelliform, thickened and rounded apically; pulvilli small, proximad of angle of claw (figs. 13). GENITALIA (pl. 24A-J): Pygophore: Conical in dorsal view, with small clump of bristles ventrad of left paramere insertion. Endosoma: Region just proximal to apex with torsion to left side; ventral strap wide, entire, anterior surface terminating at base of secondary gonopore with gently rounded minutely serrate edge, posterior edge without process; dorsal strap narrow, not bifurcate, strap narrowing over length, apex just surpassing distal edge of secondary gonopore. Secondary gonopore: Large, well differentiated, and sclerotized, flattened and pointed apically, lateral surface strongly microspiculate ventroproximally, with 

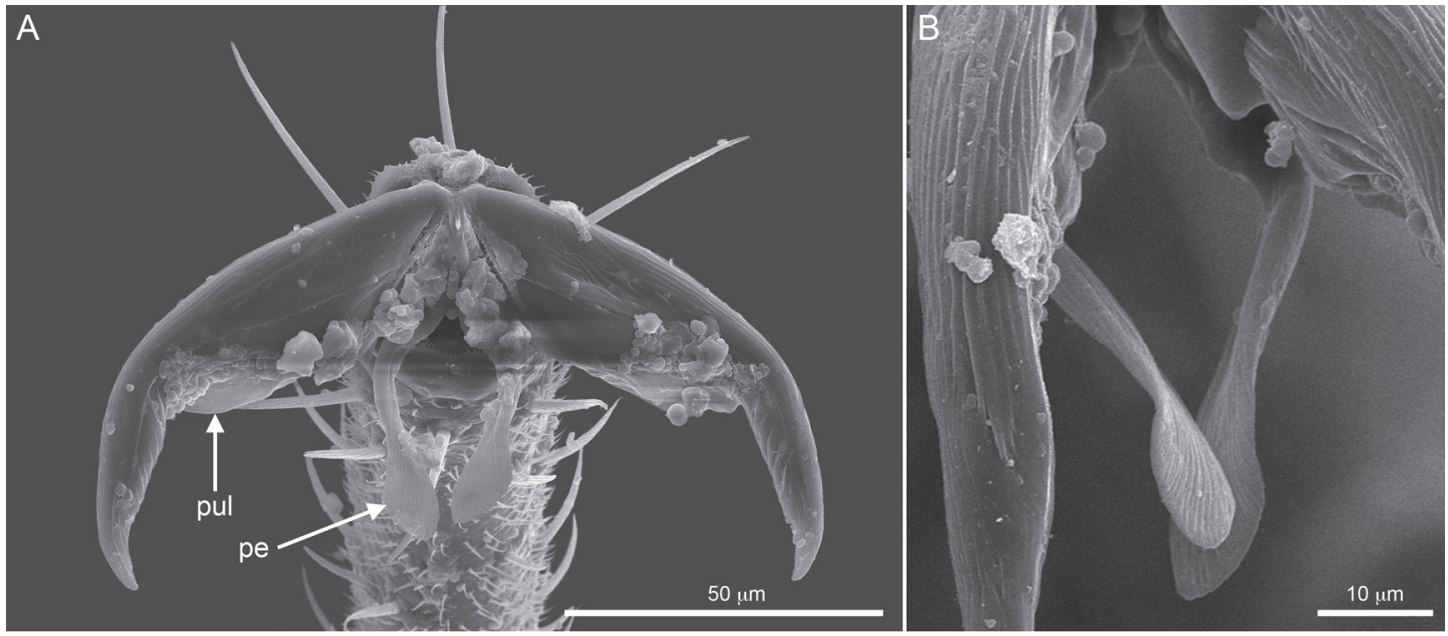

FIG. 13. Melaleucaphylus vimineae, AMNH_PBI 00393536. Scanning electron micrographs. A. Pretarsus, frontal view. B. Detail of parempodia, caudal view. Abbreviations: pe, parempodium; pul, pulvillus.

strongly sclerotized and overlapping proximal process; proximal process of secondary gonopore absent, gonopore sclerite present. Phallotheca: Moderately large, attenuate apical region with weakly undulate anterior surface and weak crest along dorsal edge; aperture on anteroventral surface short, narrowly open. Parameres: Left paramere: Triangular in dorsal view, posterior process relatively short; anterior process very short, weakly extending beyond base, apex poorly differentiated with long terminal seta. Right paramere: Moderately small with smoothly rounded margins; apex short.

Female (pl. 4): Coloration as in male; differing from male as in generic description; mean total length 3.58, mean pronotum width 1.26. GENITALIA (pl. 24K-Q): Posterior margin of sternite 7: Bearing elongate, relatively narrow projection. Vestibular sclerites: Relatively small, convoluted, weakly extending to right side, anterior margin extending even with middle of medial side of right sclerotized ring and occupying interring region in dorsal view. Dorsal labiate plate: Sclerotized rings large with narrow margins, subovoid and separated by less than width of ring, lateral margin of ring rounded, reaching lateral margin of dorsal labiate plate; posteroventral margin of dorsal labiate plate folded, not tumid. Intersegmental process: Strongly invaginated, large; apical margin unnotched, gently rounded, microspiculate. Posterior wall: Anterior surface of posterior wall microspiculate; interramal sclerites well sclerotized, wedge shaped, widely separated and placed on ventrolateral margins; posterodorsal portion of wall membranous, with pair of widely separated, tumid, microspiculate interramal lobes projecting anteriorly into genital chamber; midline of wall strongly sclerotized and strongly projecting posteriad.

Eтymology: Named for its occurrence on Melaleuca viminea.

Hosts: Recorded from the following plant species: Melaleuca filifolia, M. glomerata ( $\mathrm{pl}$. 39B), M. megacephala (pl. 39H), M. sp., M. systena, M. teuthidoides (pl. 40C), M. uncinata (pl. 40D), M. viminea (pl. 40E) (Myrtaceae: Melaleuceae), and Verticordia polytricha (pl. 41E) (Myrtaceae: Chamelaucieae). We do not regard the record of three specimens from Grevillea hookeriana (Proteaceae) and two from Allocasuarina corniculata (Casuarinaceae) as hosts.

Distribution (map 4): Known from several collecting events in Western Australia and two 
localities in south-central Northern Territory within four phytogeographic subregions: eastern desert, southwest interzone, southwestern, and western desert.

Holotype: AUSTRALIA: Western Australia: Kalbarri National Park, Loop Road, $27.56163^{\circ} \mathrm{S} 114.4376^{\circ} \mathrm{E}, 300 \mathrm{~m}, 28$ Oct 1996 , Schuh and Cassis, Verticordia polytricha Benth. (Myrtaceae), det. PERTH staff PERTH 05120594, 10 (AMNH_PBI 00136904) (WAMP).

PARATyPes: AUSTRALIA: Northern Territory: $11 \mathrm{mi} \mathrm{N}$ of Alice Springs, $23.53956^{\circ} \mathrm{S}$ $133.8807^{\circ} \mathrm{E}, 625 \mathrm{~m}, 28$ Oct 1962 , Ross and Cavagnaro, $1 \delta^{\hat{~}}$ (00418715) (AMNH). Finke Gorge National Park, Palm Valley, $24.03333^{\circ} \mathrm{S}$ $132.7101^{\circ} \mathrm{E}, 586 \mathrm{~m}, 04$ Nov 2001, Cassis, Schuh, Schwartz, Silveira, Wall, Melaleuca glomerata F. Muell. (Myrtaceae), det. NSW staff NSW 666320, 1 đิ (00414881) (AMNH). Western Australia: 2 $\mathrm{km} \mathrm{E}$ of Nungarin on Rt $50,31.43596^{\circ} \mathrm{S}$ $118.2627^{\circ}$ E, 330 m, 16 Nov 1999, R.T. Schuh, G. Cassis, and R. Silveira, Grevillea hookeriana Meisn. subsp. apiciloba (Proteaceae), det. PERTH staff PERTH 05670195, 1 đ (00391074) (AM), 2 đิ (00099392, 00129133) (AMNH). $8.2 \mathrm{~km} \mathrm{E} \mathrm{of}$ Indian Ocean $\mathrm{Rd}$ on Coorow-Greenhead $\mathrm{Rd}$, Lesuer National Park, $30.04767^{\circ} \mathrm{S} 115.0551^{\circ} \mathrm{E}, 30$ m, 06 Nov 2004, Cassis, Weirauch, Tatarnic, Symonds, Melaleuca systena (Schauer) Craven (Myrtaceae), det. PERTH staff PERTH 6990401, 1 万ิ (00414790) (AMNH). $13.5 \mathrm{~km}$ W of Nungarin on Rt $50,31.11547^{\circ} \mathrm{S} 117.945^{\circ} \mathrm{E}, 300 \mathrm{~m}, 16$ Nov 1999, R.T. Schuh, G. Cassis, and R. Silveira, Melaleuca uncinata R. Br. (Myrtaceae), det. PERTH staff PERTH 05670179, 4 đ (0039082400390827), 4 우 (00390820-00390823) (AM), 3 추 (00129315, 00099393, 00110751), 4 우 (00099394, 00129316-00129318) (AMNH). $15 \mathrm{~km} \mathrm{E} \mathrm{of}$ Merredin, $31.37749^{\circ} \mathrm{S} 118.6933^{\circ} \mathrm{E}, 330 \mathrm{~m}, 16 \mathrm{Nov}$ 1999, R.T. Schuh, G. Cassis, and R. Silveira, Allocasuarina corniculata (F. Muell.) L.A.S. Johnson (Casuarinaceae), det. PERTH staff PERTH 05670608, $10^{\widehat{0}}$ (00099390), 1 ㅇ (00099391) (AMNH). $46.5 \mathrm{~km} \mathrm{~W}$ of Yalgoo, $28.41302^{\circ} \mathrm{S}$ $116.2151^{\circ} \mathrm{E}, 600 \mathrm{~m}, 27$ Oct 1996, Schuh and Cassis, Melaleuca sp. (Myrtaceae), det. PERTH staff
PERTH 05120691, 1 đิ (00128707) Melaleuca filifolia F. Muell. (Myrtaceae), det. PERTH staff PERTH 05120691, 6 우 (00128708-00128710, 00128712, 00128713, 00128711) (AMNH). 56.6 $\mathrm{km}$ W of Yalgoo, $28.42397^{\circ} \mathrm{S} 116.1233^{\circ} \mathrm{E}, 600 \mathrm{~m}$, 27 Oct 1996, Schuh and Cassis, Melaleuca uncinata R. Br. (Myrtaceae), det. PERTH staff PERTH 05120640, 7 ๙ (00372154-00372160), 18 우 (00372162-00372178, 00393384) (AM), 3 ๙ (00368593-00368595), 1 (00368596) (AMNH), 1 đิ (00372161), 4 우 (00372179-00372182) (WAMP). $91.4 \mathrm{~km} \mathrm{SE}$ of Southern Cross, $31.97145^{\circ} \mathrm{S} 119.287^{\circ} \mathrm{E}, 375 \mathrm{~m}, 04 \mathrm{Dec} 1997$, Schuh, Cassis, Brailovsky, Asquith, Melaleuca teuthidoides Barlow (Myrtaceae), det. PERTH staff PERTH 05054834, $2 \hat{0}$ (00390889, 00390890), 1 우 (00390891) (AM). Cervantes, $30.49902^{\circ} \mathrm{S} 115.0684^{\circ} \mathrm{E}, 3 \mathrm{~m}, 10 \mathrm{Dec} 1997$, Schuh, Brailovsky, Melaleuca viminea Lindl. (Myrtaceae), det. PERTH staff PERTH 05879205, 8 ๙ (00130609-00130615, 00130619), 12 ㅇ (00130624-00130633, 00130643, 00130645) $(\mathrm{AMNH}), 1$ 우 $(00130637)$ (ANIC), 3 주 (00130616-00130618), 9 (00130634-00130636, 00130638-00130642, 00130644) (WAMP). Green Head, $30.06667^{\circ} \mathrm{S} 114.9667^{\circ} \mathrm{E}, 3 \mathrm{~m}, 10 \mathrm{Dec} 1997$, Schuh, Brailovsky, Melaleuca viminea Lindl. (Myrtaceae), det. PERTH staff PERTH 05879205, $10^{\hat{t}}$ (00130646), 12 ㅇ (00130647-00130658) (AMNH). Kalbarri National Park, Loop Road, $27.56163^{\circ} \mathrm{S} 114.4376^{\circ} \mathrm{E}, 300 \mathrm{~m}, 28$ Oct 1996 , Schuh and Cassis, Melaleuca megacephala F. Muell. (Myrtaceae), det. PERTH staff PERTH 05120616, 11 ô (00393530-00393536, 0039353800393541), 11 우 (00393545-00393551, 00393556-00393559) (AM), Verticordia polytricha Benth. (Myrtaceae), det. PERTH staff PERTH 05120594, 4 के (00136905-00136908), 19 우 (00136909-00136927) (AMNH), 3 ㅇ (0013692800136930) (CNC), Melaleuca megacephala F. Muell. (Myrtaceae), det. PERTH staff PERTH 05120616, 2 하 (00393537, 00393542), 2 우 (00393552, 00393553) (UNSW), 2 † (00393543, 00393544), 2 ㅇ (00393554, 00393555) (WAMP). Moorine Rocks, $11.7 \mathrm{~km} \mathrm{~N}$ of Great Eastern Hiway on Noongar Road, $31.22843^{\circ} \mathrm{S} 118.979^{\circ} \mathrm{E}$, 

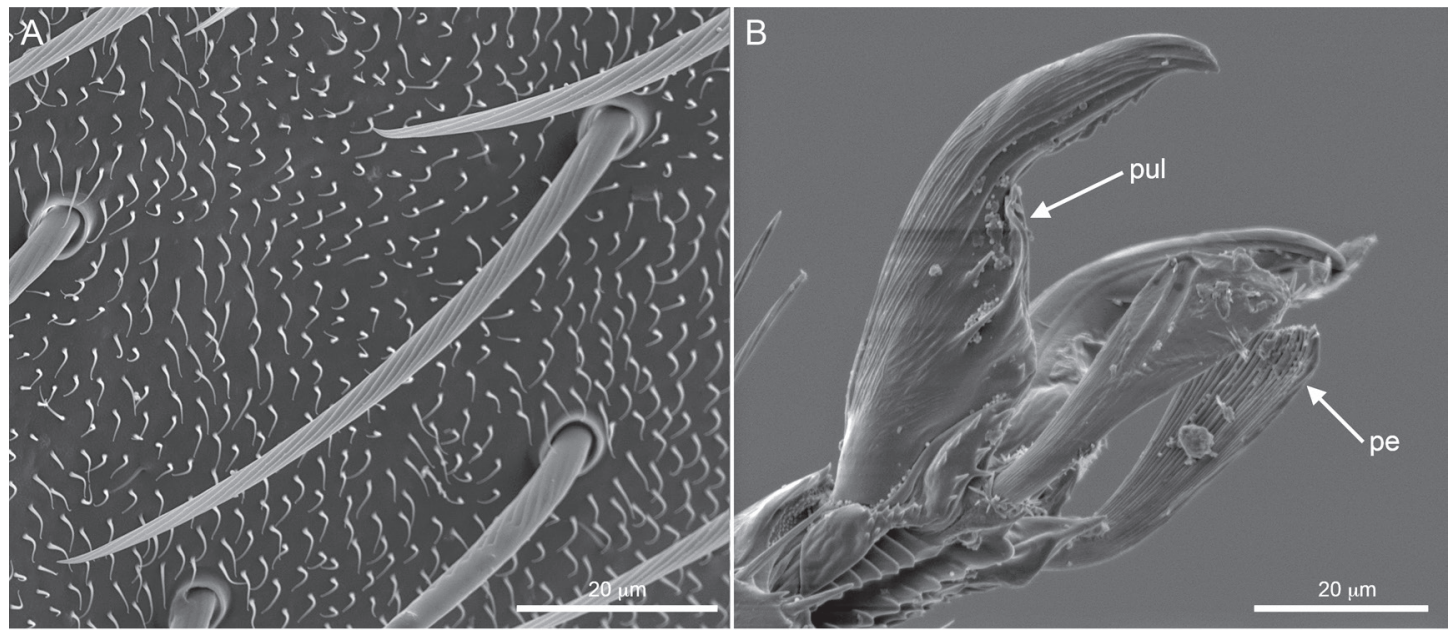

FIG. 14. Melaleucaphylus viridiflorae, UNSW_PBI 00025515. Scanning electron micrographs. A. Detail of pronotal setae, dorsal view. B. Pretarsus, lateral view. Abbreviations: pe, parempodium; pul, pulvillus.

345 m, 04 Dec 1997, Schuh, Cassis, Brailovsky, Asquith, Melaleuca sp. (Myrtaceae), $7 \delta^{\star}$ (00368564-00368570), 7 ㅇ (00368577-00368582, 00368587) (AMNH), 1 ô (00368572), 2 우 (00368583, 00368584) (ANIC), 1 đิ (00368571) (CNC), 4 के $(00368573-00368576), \quad 4$ 우 (00368585, 00368586, 00368588, 00368589) (WAMP). Newman Rocks, $136.5 \mathrm{~km}$ E of Norseman, $32.11084^{\circ} \mathrm{S} 123.1704^{\circ} \mathrm{E}, 250 \mathrm{~m}, 22$ Oct 1996, Schuh and Cassis, 1 đo (00390848) (AM).

Additional Specimens Examined: AUSTRALIA: Western Australia: Cervantes, $30.49902^{\circ} \mathrm{S} 115.0684^{\circ} \mathrm{E}, 3 \mathrm{~m}, 10 \mathrm{Dec} 1997$, Schuh, Brailovsky, Melaleuca viminea Lindl. (Myrtaceae), det. PERTH staff PERTH 05879205, 4 nymphs (00130620-00130623) (AMNH). Moorine Rocks, $11.7 \mathrm{~km} \mathrm{~N}$ of Great Eastern Hiway on Noongar Road, $31.22843^{\circ} \mathrm{S} 118.979^{\circ} \mathrm{E}$, 345 m, 04 Dec 1997, Schuh, Cassis, Brailovsky, Asquith, Melaleuca sp. (Myrtaceae), 3 nymphs (00368590-00368592) (AMNH).

\section{Melaleucaphylus viridiflorae, new species}

Figure 14, map 4, plates 4, 25, table 1

DiAgnosis: Recognized by dorsal coloration with dark head, darkened posterior one-half of pronotum, mesoscutum, and scutellum, and prominent well-sclerotized, strongly microspiculate distal swellings of secondary gonopore of endosoma. Distinguished from M. beaufortiae, also with darkened frons, vertex and posterior margin of pronotum, but lacking darkened mesoscutum and scutellum and enlarged projecting microspiculate prominences of secondary gonopore as in M. viridiflorae.

Description: Male: Mean total length 3.27, mean pronotum width 1.18. COLORATION (pl. 4): Pale yellow tan with variable dark brown vertex, frons, antennal segments 3 and 4, dark brown to black on posterior one-half of pronotum, mesoscutum, and scutellum, except reddishbrown lateral margins, hemelytron very faintly infuscate, hemelytral membrane faintly fumose with dark small cell and anal ridge, tibiae with dark apices; claws and phallotheca black; dark pronotal marking always with distinct anterior margin; thoracic venter pale orange brown except propleuron, ventral portion of metepisternal scent-gland evaporative area, and auricle; in palest specimens dark markings largely indistinct on pronotum, but always present on frons, vertex, mesoscutum, and scutellum; tibia without dark spots at bases of spines. SURFACE AND VESTITURE (pl. 4): Subshining; dorsum with moder- 
ately dense, curved, reclining black simple setae (fig. 14A); coxae with erect pale setae, tibia with dark or vaguely darkened spines. STRUCTURE: Labium reaching to base of metacoxa. Pretarsus: Claws moderate sized, curved; parempodia lamelliform, thickened and truncate apically; pulvilli minute, situated within angle of claw (fig. 14B). GENITALIA (pl. 25A-L): Pygophore: As in generic description. Endosoma: Dorsal strap with torsion, but only with distal portion of apical spine slightly twisted to left side; ventral strap entire, reaching to proximal end of secondary gonopore, anterior surface smoothly concave, posterior surface without projection on edge, reaching under secondary gonopore as well-sclerotized undulating plate; dorsal strap entire with posterior edge a long, smooth-margined, narrow, pointed, apical spine, extending beyond distal apex of ventral strap by length of secondary gonopore. Secondary gonopore: Well sclerotized, deep, located distal to middle of endosoma by length of secondary gonopore; aperture convoluted, proximal edge with medium-sized, wellsclerotized, irregular process ringing and projecting somewhat proximal to aperture, distal edge with large, well-sclerotized microspiculate tumid prominence, anterolateral edge with faintly microspiculate membranous sac extending beyond apical sclerotized spine of ventral strap. Phallotheca: Protruding apical portion thick at base, then sharply attenuate to narrow apex; dorsal surface with long narrow carina, posterior surface with short carina; otherwise as in generic description. Parameres: Left paramere: Posterior margin and shoulder region between posterior and anterior processes broadly produced with slight shoulder; posterior process short, narrow, anterior process short with weakly serrate apex. Right paramere: As in generic description.

Female (pl. 4): Coloration much paler than in male, otherwise differing from male as in generic description; mean total length 3.82, mean pronotum width 1.41. GENITALIA (pl. 25M-Q): Subgenital plate: Elongate, relatively narrow. Vestibular sclerites: Situated medially, moderate sized, convoluted, extending to right side, anterior margin extending even with middle of medial side of right sclerotized ring and occupying posteromedial quarter of ring in dorsal view. Dorsal labiate plate: Sclerotized rings large with narrow margins, subcircular, and separated by almost width of ring, lateral margin of ring rounded, reaching lateral margin of dorsal labiate plate; posteroventral margin of dorsal labiate plate folded, not tumid. Posteromedial region: Sunken microspiculate invaginated plate, divided on midline, strongly concave and rolled dorsad. Intersegmental process: Strongly invaginated pair of well-sclerotized, cone-shaped paramedial prominences. Posterior wall: Anterior surface microspiculate, well sclerotized, wedgeshaped interramal sclerites widely separated and placed on ventrolateral margins; posterodorsal portion membranous, with pair of widely separated, tumid, microspiculate interramal lobes projecting anteriorly into genital chamber; midline of wall strongly sclerotized, moderately projecting posteriad.

EтумоLOgY: Named for its occurrence on Melaleuca viridiflora.

Host: Recorded from Melaleuca viridiflora (Myrtaceae: Melaleuceae) (pl. 40F, G).

Distribution (map 4): Known only from the type locality in the Armhen Land phytogeographic subregion near Daly River Conservation Area, Northern Territory, taken during the 2012 Fish River Bush Blitz.

Discussion: The strongly sclerotized serrate apical spine of the ventral strap and entire apical spine of the dorsal strap in $M$. viridiflorae are most similar to the structure observed in $M$. glomeratae. The coloration of the pronotum in M. viridiflorae is similar to that in M. beaufortiae. The endosoma is superficially similar to that of some Campylomma spp. (tribe Nasocorini), but the fact that $M$. viridiflorae lacks a single row of short bristlelike setae on the dorsal edge of the metafemora (a diagnostic feature of Nasocorini) leads us to refute a relationship between these taxa placed in different phyline tribes. Careful comparison of the endosoma in Campylomma spp. and M. viridiflora reveals that the apical por- 
tion of the endosomal strap(s) has divergent structure. Apically the strongly serrate sclerite and longer smooth spine are located on separate straps in M. viridiflora, whereas they are on the same strap in Campylomma spp. (Schuh, 1984; Yasunaga et al., 2015; Yasunaga, 2016).

Holotype: AUSTRALIA: Northern Territory: Fish River Station, Site B3, $13.82642^{\circ} \mathrm{S}$ $130.71502^{\circ} \mathrm{E}, 25 \mathrm{~m}, 23$ Apr 2012, C. Symonds, Melaleuca viridiflora Sol. ex Gaertn. (Myrtaceae), det. NT Herbarium D0217498, 10 (UNSW_ ENT 00025510) (MAGNT).

Paratypes: AUSTRALIA: Northern Territory: Fish River Station, Site B3, $13.82642^{\circ} \mathrm{S}$ $130.71502^{\circ} \mathrm{E}, 25 \mathrm{~m}, 23$ Apr 2012, C. Symonds, Melaleuca viridiflora Sol. ex Gaertn. (Myrtaceae), det. NT Herbarium D0217498, 30 (UNSW_ENT 00025507, UNSW_ENT 00025508, UNSW_ENT 00025515), 2 ㅇ (UNSW_ENT 00025500, UNSW_ ENT 00025502) (AMNH), 40 (UNSW_ENT 00025512-UNSW_ENT 00025514, UNSW_ ENT 00025516), $11+$ (UNSW_ENT 00025488, UNSW_ENT 00025490-UNSW_ENT 00025499) (MAGNT), 30 (UNSW_ENT 00025509, UNSW_ ENT 00025511, UNSW_ENT 00025517), 4 우 (UNSW_ENT 00025486, UNSW_ENT 00025487, UNSW_ENT 00025489, UNSW_ENT 00025501) (UNSW).

Additional Specimens Examined: AUSTRALIA: Northern Territory: Fish River Station, Site B3, $13.82642^{\circ} \mathrm{S} 130.71502^{\circ} \mathrm{E}, 25 \mathrm{~m}, 23$ Apr 2012, C. Symonds, Melaleuca viridiflora Sol. ex Gaertn. (Myrtaceae), det. NT Herbarium D0217498, 4 nymphs (UNSW_ENT 00025503UNSW_ENT 00025506) (MAGNT).

\section{Tribe Semiini}

\section{Subtribe Exocarpocorina}

Revised Diagnosis: Female with enlarged sclerotized plates in vestibulum; endosoma in male either long, forming partial to complete coil, and with secondary gonopore subapical, or relatively short, J-shaped, secondary gonopore submedial, and with spine arising at level of sec- ondary gonopore and sometimes one or more additional medial or apical spines; left paramere sometimes uniquely and bizarrely modified.

Discussion: Our assignment of taxa to the Exocarpocorina may benefit from a brief discussion of the history of recognition of the group and the rather casual interpretation of their interrelationships to date. Polyozus Eyles and Schuh (2003), with six new species from New Zealand, was assigned to the Phylini by its authors. Weirauch (2007) extended the distribution of the taxon to Australia, and included two additional genera (Ancoraphylus Weirauch, Exocarpocoris Weirauch) in her "Polyozus group," for which she recognized the unique nature of the endosoma in the male and the posterior wall in the female. In her phylogenetic analysis of relationship among Polyozus-group species, Weirauch (2007) included Xiphoides sp. (also described by Eyles and Schuh, 2003, with 6 spp. from New Zealand) as one of the outgroup taxa. Schuh et al. (2014) treated Polyozus as a junior synonym of Leptidolon Reuter, 1904, originally described with one species from SE Australia. Genera now placed in the Exocarpocorina, including the four described in the present paper, are:

Ampimpacoris Weirauch and Schuh, 2011, 1 sp. from Argentina

Ancoraphylus Weirauch, 2007, 4 spp. from Australia

Araucanophylus Carvalho, 1984, 2 spp. from Chile

Basileobius Eyles and Schuh, 2003, 1 sp. from New Zealand

Calytriphylus Schwartz, Weirauch, and Schuh, new genus, $1 \mathrm{sp}$. from Australia

Chileophylus Carvalho, 1984, $1 \mathrm{sp}$. from Chile

Cyrtodiridius Eyles and Schuh, 2003, 1 sp. from New Zealand

Exocarpocoris Weirauch, 2007, 3 spp. from Australia

Gonzalezinus Carvalho, 1981, 2 spp. from Chile

Halormus Eyles and Schuh, 2003, 1 sp. from New Zealand

Harpagophylus Schuh and Weirauch, 2010, 5 spp. from Australia 
Jiwarli Soto and Weirauch, 2009, 4 spp. from Australia

Leptidolon Reuter, 1904, 1 sp. from Australia and 6 spp. from New Zealand

Leptospermia Schwartz, Weirauch, and Schuh, new genus, 2 spp. from Australia

Mecenopa Eyles and Schuh, 2003, 1 sp. from New Zealand

Melaleucacoris Schwartz, Weirauch, Schuh, new genus, $1 \mathrm{sp}$. from Australia

Melaleucoides Schuh and Weirauch, 2010, 18 spp. from Australia

Pimeleocoris Eyles and Schuh, 2003, 3 spp. from New Zealand

Protemiris Russell and Weirauch, 2017, 5 spp. from Australia

Scholtzicoris Schuh, 2016, 1 sp. from Australia

Teddus Schwartz, Weirauch, and Schuh, new genus, $1 \mathrm{sp}$. from Australia

Tryptomenomiris Schuh and Weirauch, 2010, 2 spp. from Australia

Wallabicoris Schuh and Pedraza, 2010, 37 spp. from Australia

Xiphoidellus Weirauch and Schuh, 2011, 6 spp. from Australia

Xiphoides Eyles and Schuh, 2003, 6 spp. from New Zealand

Cladograms of relationships of some of these taxa, and their contained species, are included in the works of Weirauch (2007), Schuh and Pedraza (2010), Schuh and Weirauch (2010), Weirauch and Schuh (2011), and Russell and Weirauch (2017). Unfortunately, none of these analyses come close to including representatives of all the genera now included in this presumed Gondwanean subtribe by Menard et al. (2013) and Schuh and Menard (2013). In addition, the choice of outgroup taxa has not been consistent, in part because most of the analyses were prepared prior to the larger analysis of Menard et al. (2013) on which current tribal-level assignments are heavily based or before the currently understood range of taxonomic and morphological diversity was recognized.

Our placement of four new genera in the Exocarpocorina includes decisions based heavily on male and female genitalic morphology. Description of these new taxa extends the range of known morphological, geographic, and host diversity in the Exocarpocorina. We do not attempt, however, to prepare a classification that recognizes monophyletic generic groupings within the Exocarpocorina. Nonetheless, having participated in extensive fieldwork in Australia and South America, as well as having examined nearly all relevant available collections of Phylinae from these continental areas, we are confident that the point has been reached where a detailed analysis of relationships within the Exocarpocorina should be undertaken.

\section{Ancoraphylus victoriensis, new species}

Map 5, plates 4, 26, table 1

DiAgnosis: Recognized by uniform pale coloration, practically hyaline hemelytral membrane, and J-shaped endosoma with ventral apical process closely adhering to endosomal strap, short dorsal apical process, and faint process arising near secondary gonopore. All other species of Ancoraphylus have longer apical processes providing endosoma with an obvious anchor-shaped profile; in addition, A. victoriensis has a simple C-shaped endosomal strap.

Description: Male: Macropterous, mean total length 2.99 , mean pronotum width 0.89 . COLORATION (pl. 4): Uniformly pale with very faint yellow-orange cast, hemelytral membrane faintly fumose; antennal segment 1 pale dusky yellow, antennal segments as dorsum; apical portion of labium brown; pro- and mesofemora with a few and metafemora with many dark spots; tibiae with large black spots; claws pale brown. SURFACE AND VESTITURE: Dorsum weakly shining, vestiture with moderately dense dark suberect simple setae and flattened, subadpressed silvery setae; tibiae with black spines (pl. 4). STRUCTURE: Head: Relatively narrow, posterior margin of eyes contiguous with anterior margin of pronotum, eyes medium sized in dorsal view, just reaching to below ventral margin of 
antennal insertion in lateral view, weakly emarginate at fossa; antennal segment 2 apex with greatest diameter, tapering to base, length approximately equal to $80 \%$ of pronotal width. Thorax: Pronotum: Subtriangular, lateral margins gently curved, calli faintly demarcated, posterior lobe flat, posterior margin straight; mesoscutum moderately exposed. Pretarsus: Claws moderately long, parempodia setiform; pulvilli reaching to middle of claw. Hemelytron: Costal margin straight. GENITALIA (pl. 26): Pygophore: Medium sized, conical; ventral posterior region with a few short, blunt bristles distinct from simple setae, paramere insertions without tubercles or discrete patches of bristles. Endosoma: With one primary strap sclerotized to apex, C-shaped, without torsion, only apex curved to left; diameter practically evenly thick, apical region pointed, thin; ventral apical process weakly sclerotized, needlelike, directed proximally; dorsal apical process very short, sharp, projecting from left side of strap; process arising near secondary gonopore very faint or absent. Secondary gonopore: Small, well formed, situated just basad of middle of endosoma, open on ventral surface. Phallotheca: Relatively short and flat; apex broadly pointed; aperture narrow, terminus at apex; small flange on posterior surface; short thumblike process on right anterior margin. Parameres: Left paramere: Large, with posterior margin or shoulder between anterior and posterior processes, enlarged, quadrate in posterior view, anterolateral margin with pointed process with length as long as anterior process; posterior process short, curved ventrad, base with small anterior flange, apex chiselled. Right paramere: Not examined.

Female: Unknown.

Eтymology: Named for its occurrence in the state of Victoria.

Host: Recorded from Melaleuca lanceolata (Myrtaceae: Melaleuceae) (pl. 39G).

Distribution (map 5, table 4): Known only from type locality in Murray Sunset National Park, northwestern Victoria within the eastern desert phytogeographic subregion.
Discussion: We place this new species in Ancoraphylus based on the structure of the male genitalia, especially the presence of a slender spine arising near the secondary gonopore and the dorsal process on the anterolateral margin of the left paramere. This is the first species of Ancoraphylus known to occur in the state of Victoria and taken on a host other than a species of Acacia (Fabaceae: Mimosoideae).

Holotype: AUSTRALIA: Victoria: $27 \mathrm{~km} \mathrm{~W}$ of Hattah, Murray Sunset National Park, $34.73835^{\circ} \mathrm{S} 142.01^{\circ} \mathrm{E}, 45 \mathrm{~m}, 03 \mathrm{Nov} 2002$, Cassis, Schuh, Schwartz, Silveira, Melaleuca lanceolata Otto (Myrtaceae), det. NSW staff NSW 658087, 10 (AMNH_PBI 00414827) (MVMA).

PARATYPes: AUSTRALIA: Victoria: $27 \mathrm{~km}$ W of Hattah, Murray Sunset National Park, $34.73835^{\circ} \mathrm{S} 142.01^{\circ} \mathrm{E}, 45 \mathrm{~m}, 03 \mathrm{Nov} 2002$, Cassis, Schuh, Schwartz, Silveira, Melaleuca lanceolata Otto (Myrtaceae), det. NSW staff NSW 658087, 20 (00414829, 00414830) (AMNH), 1 के (00414828) (MVMA).

\section{Calytriphylus, new genus}

Type Species: Calytriphylus menzies, new species.

Diagnosis: Primarily recognized by coloration including dark reddish-brown scutellum and femora; eyes relatively small; sexually dimorphic: male narrow and elongate, female shorter and costal margin curved. Narrower head, smaller eyes, and distinct endosoma of C. menzies will distinguish it from somewhat similarly colored Eucalyptophylus macrocarpae.

Description: Male: Macropterous, total length 2.83-3.06, pronotum width 0.83-0.95. COLORATION (pl. 4): Practically unicolorous pale yellowish tan with darker orange tan or brown on head ventrad of middle of eyes, collum, antennal segments 3 and 4, and faintly on calli; darkest orange brown on mesoscutum and scutellum except apex; very faintly darkened on apices of corium and cuneus; dark brown on sternum, base of coxae, metafemora, venter, apical segment of labium, apex of tibiae, 
and tarsomeres; tibiae without black spots; hemelytral membrane faintly fumose. SURFACE AND VESTITURE: Dorsum weakly shining; dorsal vestiture with moderately sparse, curved silvery shining or golden setae; dark simple setae on darker colored region of cuneus; tibiae pale with pale spines (pl. 4). STRUCTURE: Head: Narrow, posterior margin of eyes separated from anterior margin of pronotum, eyes relatively small in dorsal view but reaching to buccula in lateral view; broadly emarginate near antennal fossa. Antenna: Segment 2 relatively narrow with length equal to width of pronotum. Labium: Reaching just beyond metacoxa. Thorax: Pronotum: Subquadrate, lateral margins nearly straight, calli weakly demarcated, posterior lobe flat, posterior margin straight; mesoscutum broadly exposed. Pretarsus: Claws small, delicate, gently curved; parempodia fleshy, lyriform, apices expanded and truncate; pulvilli absent (fig. 15). Hemelytron: Costal margin straight, elongate. GENiTAliA (pl. 27A-G): Pygophore: Medium sized, broadly conical; paramere insertions without tubercles or discrete patches of bristles; posterior surface somewhat produced beyond right paramere. Endosoma: With one strap, J-shaped, without torsion; fusiform in ventral view, broadly pointed apex of strap terminating distad of secondary gonopore by $3 \times$ length of gonopore; nonsclerotized apical portion of endosoma covered with microspicules on dorsal surface; two short serrate processes (dorsal and ventral) present on left side of endosoma just distad to secondary gonopore. Secondary gonopore: Well formed, situated distad of middle of strap by $3 \times$ length of gonopore. Phallotheca: Relatively short, apically truncate with small flange, aperture wide, spanning anterior margin of phallotheca; right side of anterior surface with relatively long spine. Parameres: Left paramere: Typically phyline; region between posterior and anterior processes not produced; posterior process bent ventrad, apex chiselled. Right paramere: Short, broad, with short acuminate apex.
Female (pl. 4): Coloration and structure similar to male, except posterior portion of hemelytron more intensely reddish brown, costal margin slightly more convex, and antennal segment 2 more slender and tapering proximally than in male, all femora dark; total length 2.54, pronotum width 0.88 . GENITALIA (pl. 27H-N): Posterior margin of sternite 7: With broad, medial projection. Vestibular sclerites: Moderately large, strongly convoluted and sclerotized, not projecting beyond anterior edge of dorsal labiate plate in dorsal view. First gonapophyses: Strongly asymmetrical; left side larger than right side, folded to right and covering opening of vestibulum; right side smaller, strongly confluent with posterior medial plate; pair of large globular sclerites flanking aperture of vestibulum. Ventral labiate plate: Strongly sclerotized, anterior base asymmetrical; left side large and adjacent to tumid left interramal lobe. Dorsal labiate plate: Moderately large, shield shaped, long and concave longitudinally; posterior margin membranous. Sclerotized rings: Large, moderately separated, subovoid, relatively thick walled, medial angle pointed, medial angle of left ring folded and produced dorsad. Posteromedial region: Concave, surface undulate without apparent microstructure. Anterolateral region: Barely projecting anteriad of sclerotized rings. Intersegmental region: Thinly membranous anteriad near dorsal labiate plate, extending posteriad as pair of thick, tumid paramedial membranous lobes attached to dorsoposterior region of posterior wall. Posterior wall: Complex; posteromedial region with pair of paramedial tumid lobes, projecting anteriad into genital chamber, surface microspiculate. Interramal sclerites: Well sclerotized, spanning width of posterior wall, lateral margins pointed; midline knoblike moderately produced posteriad, abutting base of ovipositor. Interramal lobes: Present laterally, surface microspiculate, asymmetrical, left lobe tumid, right lobe flat.

ETymology: A combination of the generic names Calytris and Phylus; masculine. 

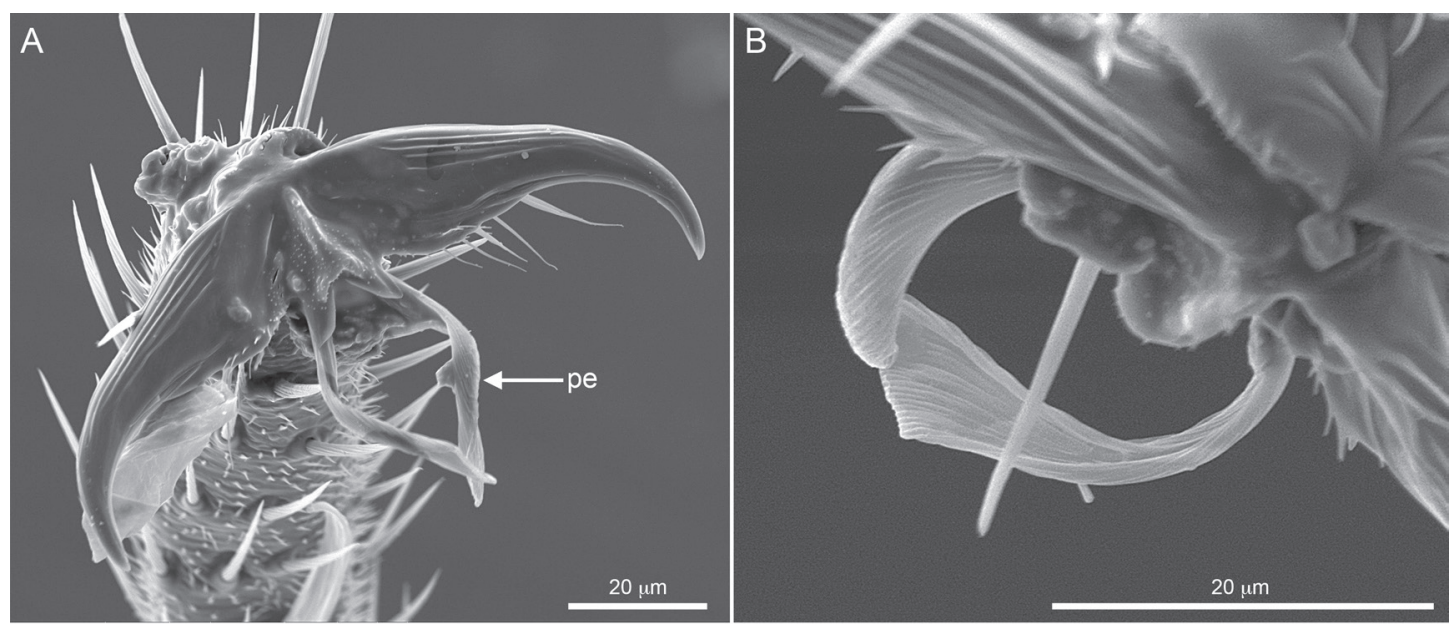

FIG. 15. Calytriphylus menzies, AMNH_PBI 00128941. Scanning electron micrographs. A. Pretarsus, frontal view. B. Detail of parempodia, dorsal view. Abbreviations: pe, parempodium.

Discussion: The external appearance and coloration of the only known species of Calytriphylus is similar to species we place in Eucalyptophylus. However, the structure of the male and female genitalia is distinctive, which clearly suggests that Calytriphylus is a member of the Exocarpocorina and the resemblance to Eucalyptophylus is superficial.

\section{Calytriphylus menzies, new species}

Figure 15, map 5, plates 4, 27, table 1

Diagnosis: Known only from the type species and therefore recognized by characters in the generic diagnosis.

Description: Male: (fig. 15, pls. 4, 27A-G): As in generic description. Mean total length 2.98, mean pronotum width 0.89 .

Female (pls. 4, 27H-N): As in generic description. Mean total length 2.63, mean pronotum width 0.89 .

Eтymology: Named for its occurrence near the Western Australian town of Menzies; a noun in apposition.

Hosts (tables 2, 3): Recorded from Calytrix amethystina (pl. 37D) and C. angulata (pl. 37E) (Myrtaceae: Chamelaucieae).
Distribution (map 5, table 4): Only known from the type locality near Menzies, GoldfieldsEsperance region, Western Australia located in the western desert phytogeographical subregion.

Discussion: The female of this new species bears a striking resemblance to Harpagophylus calytrix Schuh and Weirauch, 2010. Without associated males the somewhat variable coloration of the head and distal region of the corium in females of both species makes assigning specimens to the correct genus difficult. Based on all known specimens these two exocarpocorines species do not utilize the same host plants $-C$. menzies on the two Calytrix spp. listed above and H. calytrix on C. variabilis Lindl.

Holotype: AUSTRALIA: Western Australia: $28 \mathrm{~km} \mathrm{~S}$ of Menzies (3.5 km E of Hiway), $29.91917^{\circ} \mathrm{S} 121.1514^{\circ} \mathrm{E}, 500 \mathrm{~m}, 25$ Oct 1996 , Schuh and Cassis, Calytrix amethystina Craven (Myrtaceae), det. PERTH staff PERTH 05099986, 10 (AMNH_PBI 00087223) (WAMP).

Paratypes: AUSTRALIA: Western Australia: $28 \mathrm{~km}$ S of Menzies (3.5 km E of Hiway), 29.91917 $\mathrm{S}$ $121.1514^{\circ} \mathrm{E}, 500 \mathrm{~m}, 25$ Oct 1996, Schuh and Cassis, Calytrix amethystina Craven (Myrtaceae), det. PERTH staff PERTH 05099986, 2 \% (00390842, 00414711), 4 đ (00390843-00390846) (AM), 1 ㅇ (00087224) (AMNH), 1 ๙ (00087512) (WAMP), 
Calytrix angulata Lindl. (Myrtaceae), det. PERTH staff PERTH 05099706, 3 ô (00128940-00128942) (AMNH), 1 (00128943) (WAMP).

Other Specimens Examined: AUSTRALIA: Western Australia: $28 \mathrm{~km} \mathrm{~S}$ of Menzies (3.5 km E of Hiway), $29.91917^{\circ} \mathrm{S} 121.1514^{\circ} \mathrm{E}, 500 \mathrm{~m}, 25$ Oct 1996, Schuh and Cassis, Calytrix angulata Lindl. (Myrtaceae), det. PERTH staff PERTH 05099706, 2 우 (00128515, 00128516), 1 우 (00128517) (AMNH).

\section{Leptospermia, new genus}

Type Species: Leptospermia cassisi, new species.

DiAgnosis: Shares some features of male and female genitalia, especially coiled endosoma, long apical portion of right paramere, large coiled vestibular sclerites, and simple membranous posterior wall and adjacent intersegmental region with genera of the Xiphoides clade of Exocarpocorina (Weirauch and Schuh, 2011). Distinguished from these taxa (Arucanophylus, Xiphoidellus, Xiphoides) by mostly uniform pale yellowish green coloration, black simple setae on dorsum; black tibial spines without dark basal spots, long straight setiform parempodia, absence of pulvilli, much larger endosoma with larger secondary gonopore, and paired lateral interramal sclerites without sclerotization on dorsoposterior margin.

Description: Male: Macropterous, total length 3.49-4.35, pronotum width 1.14-1.35. COLORATION (pls. 4, 5): Uniformly dull yellowish to grayish tan with darker orange tan on head, except near eyes and sometimes on mandibular plate, mesoscutum, scutellum, cuneus, and mesosternum; sometimes frons dark gray; black on distal portion of, or entire clypeus, antennal segment 1 , segments 3 and 4 of labium, tarsal segments, claws, and phallotheca; remainder of antenna and tibiae tan or pale brown; tibiae without dark spots at base of black spines; hemelytral membrane slightly fumose. SURFACE AND VESTITURE: Dorsum weakly shin- ing; vestiture with moderately dense, dark, suberect, simple setae and posterior margin of pronotum and mesoscutum with sericeous, suberect, silvery setae; entire ventral surface with pale suberect simple setae (fig. 16B). STRUCTURE: Head: Medium sized, posterior margin of eyes contiguous with anterior margin of pronotum, eyes medium sized in dorsal view, occupying $80 \%$ of height of head and surpassing antennal insertion by width of fossa in lateral view; eyes broadly emarginate near fossa (figs. 16A, 17A). Antenna: Segment 2 of practically uniform diameter, length approximately equal to $80 \%$ of pronotal width. Labium: Length variable. Thorax: Pronotum: Subrectangular, lateral margins straight, calli faintly demarcated, posterior lobe flat, posterior margin straight; mesoscutum broadly exposed; metathoracic spiracle and scent-gland system typically phyline (figs. 16C, 17B). Pretarsus: Claws moderately long, gently curved; parempodia straight, length from moderately to relatively long, setiform; pulvilli with moderate size and height, situated on claw base proximad of angle (figs. 16D, 17D). Hemelytron: Costal margin slightly convex. GENITALIA (figs. 16E, 17C, pls. 28, 29A-J): Pygophore: Large, broadly conical in dorsal view, laterally compressed, forming keellike caudal surface, perpendicular to aperture in lateral view; left margin of aperture with small elongate patch of short bristles. Endosoma: Forming a complete coil, with two confluent straps, ventral strap terminating just distad of distal margin of secondary gonopore; dorsal strap surpassing gonopore by slightly more than $3 \times$ gonopore, terminating in narrow apex; subapical region between apex and secondary gonopore slightly widened with undulating ventral margin or with delicate, weakly sclerotized, ventrally directed process at distal edge of secondary gonopore. Secondary gonopore: Subapical, well formed; orientation of aperture ventrad or laterad; conspicuous gonopore sclerite on proximal margin. Phallotheca: Elongate, basal region of uniform width, gradually narrowed toward apex, aperture on anterior surface, slitlike, uniformly narrow; sometimes apical region 
with posterior edge wider than anterior edge, right lateral surface at about midpoint with sclerotized strut extending to middle of basal region; basal region strongly sclerotized on surface adhering pygophore. Parameres: Left paramere: Body elongate, region between anterior and posterior processes extending posteriad; posterior process moderately long, straight, broad basally, apex narrowly rounded; anterior process shorter than posterior process, projecting slightly dorsad, broad basally, rounded in cross section; apex rounded or sharp and bent toward middle of paramere. Right paramere: Large, subrectangular, apical one-third directed ventrad; apex variable-conspicuously narrow, short, and pointed or long and gently attenuate.

Female (pls. 4, 5): Coloration and structure similar to male, except costal margin slightly more convex than in male; antennal segment 2 more slender and tapering proximally in contrast to male; total length $3.20-4.00$, pronotum width 1.08-1.29. GENITALIA (pl. 29K-N): Posterior margin of sternite 7: With triangular medial projection. Vestibular sclerites: Large, strongly coiled, relatively weakly sclerotized, with large loop on right side, greatly projecting beyond anterior edge of dorsal labiate plate. First gonapophyses: Medium sized, in form of basal quadrate blocks. Ventral labiate plate: Medium sized, moderately sclerotized, convoluted, paramedial anteroventral extension very large and modified, projecting from right side, right side flattened and covering anterior surface of basal structures. Dorsal labiate plate: Large, shield shaped with undulate anterior and lateral margins, long and concave longitudinally; ventral surface with relatively large spicules. Sclerotized rings: Moderately large, teardrop shaped, medial margin wider than lateral attenuate auricleshaped lateral margin, thick walled. Posteromedial region: Entire medial plate concave or sunken ventrad of lateral oviducts and spermathecal gland, plate not apparently microspiculate. Anterolateral region: Extending anteriad of sclerotized rings, surface microspiculate ventrad of rings. Intersegmental membrane: Weakly sclero- tized, fringelike, serrate, transverse band spanning genital chamber, weakly projecting into genital chamber. Posterior wall: Dorsoposterior margin of wall entire, smooth, shallowly concave into genital chamber anteriad. Interramal sclerites: Pair of well-sclerotized, elongate plates forming ventrolateral margin of wall; dorsal region wide, weakly sclerotized, spanning interramal area, base of sclerite notched. Interramal lobes: Membranous, without microspicules.

Eтумоlogy: Named after the host-plant genus Leptospermum; feminine.

Discussion: Leptospermia is one of several exocarpocorine taxa of nearly uniform yellow/ green coloration (in preserved specimens) with at least some dark recumbent simple setae on the dorsum, all of which feed on a variety of genera of Myrtaceae. These include several species of Melaleucoides and Scholtzicoris linnavuorii. However, the setiform parempodia and simple posterior wall indicate that Leptospermia is not a member of the Melaleucoides group (Harpagophylus, Melaleucoides, Thryptomenomiris) of Exocarpocorina (Schuh and Weirauch, 2010). In body size and form Leptospermia resembles many species of Wallabicoris, but no species in that genus has the yellow/green coloration of Leptospermia, never feeds on the Myrtaceae, and each has its own distinctive features in the endosoma, even though it is long and forms a single coil in both genera.

Within the Exocarpocorina a relationship to Xiphodellus is suggested by the deep posterior aspect of the pygophore, elongate or deep dimension to the left paramere, and elongate apical portion of the right paramere. Leptospermia anatoles also possesses an accessory spine projecting from the distal margin of secondary gonopore as in Xiphodellus. Additionally, the relatively simple, undivided posterior wall and adjacent intersegmental region and the large, strongly coiled vestibular sclerites in the female indicate a relationship between Arucanophylus, Leptospermia, Xiphodellus, and Xiphoides. A number of Xiphoidellus spp. have Myrtaceae hosts. 
We have examined specimens $(6 \hat{0}, 3 \stackrel{9}{)}$ taken at $20 \mathrm{~km}$ E of Retreat (W. of Uralla), New South Wales, on Leptospermum brevipes we place in Leptospermia based on preparations of teneral endosomae; however, assigning them to either of our new species is problematic. These specimens have a smaller, generally slightly orange-tinged body with reddish costal margin and cuneus and dusky brown collum, clypeus, labrum, antennal segment 1 , and apices of hind femora. Description of this potential new taxon awaits examination of males with fully developed endosomae.

As currently understood the genus Leptospermia is distributed across the Nullarbor Plain of southern Australia with its two distinct species restricted to Western Australia or New South Wales plus South Australia (table 4). All 10 species of the known myrtaceous host plants utilized by Leptospermia spp. belong to the tribes Chamelaucieae and Leptospermeae. Almost all specimens of Leptospermia (90\%) were taken on Leptospermeae hosts. All individuals taken in New South Wales and South Australia (L. anatoles) were found on two species of Leptospermum. Only specimens from Western Australia were found on Chamelaucieae host plants (tables 2, 3).

\section{Leptospermia anatoles, new species}

Figure 16, map 5, plates 4, 28, table 1

Diagnosis: Distinguished from L. cassisi by male genitalia with aperture of secondary gonopore directed laterally (pl. 28A, B, D, E), presence of ventrally projecting sclerite adjacent to distal edge secondary gonopore (pl. 28A-F), narrow apical region of endosoma ( $\mathrm{pl}$. 28A-F), left paramere with sharp medially directed apex of anterior process (pl. 28K), and abruptly narrow, short apical region of right paramere (pl. 28L), as well as by more intense black clypeus and antennal segment 1, labium reaching to apex of metacoxa, and shorter parempodia (fig. 16D).

Description: Male: Mean total length 3.66, mean pronotum width 1.24. COLORATION (pl.
4): As in generic description but entire clypeus black, antennal segment 1 intensely black, and frons sometimes dark gray. STRUCTURE: Labium reaching apex of metacoxa. Pretarsus: Parempodia moderately long (fig. 16D). GENITALIA (fig. 16E, pl. 28): Endosoma: Somewhat loosely coiled; subapical region of dorsal strap of uniform diameter between apex and distal margin of secondary gonopore; distal edge of secondary gonopore with weakly sclerotized ventrally directed process. Secondary gonopore: Aperture lateral. Phallotheca: Apical region with posterior edge wider than anterior edge. Parameres: Left paramere: Apex of anterior process sharp and bent toward middle of paramere. Right paramere: Apical region narrow, short, and pointed.

Female (pl. 4): Coloration as in male; differing from male as in generic description; mean total length 3.75 , mean pronotum width 1.23. GENITALIA: As in generic description.

Eтymology: Named for its occurrence in eastern New South Wales and South Australia, in contrast to $L$. cassisi, which is apparently restricted to Western Australia; from the Greek, anatole, thus, "of the rising [sun]."

Hosts: Recorded from Leptospermum brevipes (pl. 38E) and L. coriaceum (pl. 38F) (Myrtaceae: Leptospermeae).

Distribution (map 5): Known from two localities in the Murry Lands region of South Australia and one widely disjunct locality in the northern tablelands region of New South Wales. This new eastern species is found in the Adelaide and southeastern phytogeographical subregions.

Discussion: The shape of the small process distal to the secondary gonopore is not identical in New South Wales (pl. 28A-D, F) and South Australia (pl. 28E) males.

Holotype: AUSTRALIA: South Australia: $15 \mathrm{~km} \mathrm{~S}$ of Bews, $35.48474^{\circ} \mathrm{S} 140.4332^{\circ} \mathrm{E}, 130 \mathrm{~m}$, 08 Nov 1998, Schuh, Cassis, Silveira, Leptospermum coriaceum (F. Muell. ex Miq.) Cheel (Myrtaceae), det. Royal Bot Gard. NSW 427369, 10 (AMNH_PBI 00393396) (SAMA).

Paratypes: AUSTRALIA: New South Wales: $20 \mathrm{~km}$ E of Retreat (W of Uralla), 


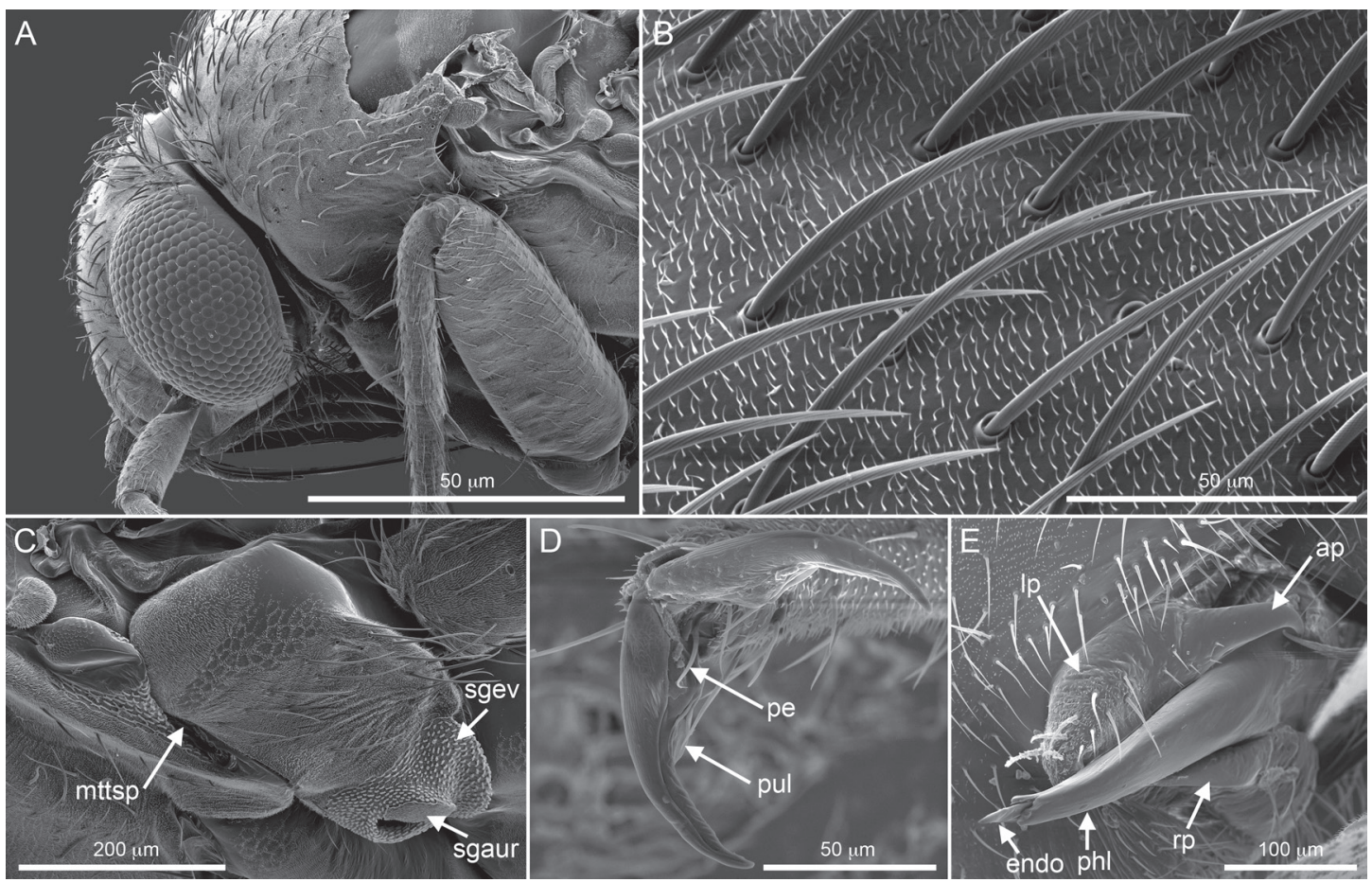

FIG. 16. Leptospermia anatoles. Scanning electron micrographs. A. Head and pronotum, lateral view. B. Detail of pronotal setae, dorsal view. C. Thoracic pleuron, lateral view, showing metathoracic spiracle opening, metathoracic scent-gland auricle, and evaporatory area. D. Pretarsus, frontal view. E. Pygophore, left paramere, phallotheca, apical spine of dorsal endosomal strap, dorsal view. AMNH_PBI 00393353: A-C; AMNH_ PBI 00390632: D, E. Abbreviations: ap, anterior process; endo, endosoma; lp, left paramere; mttsp, metathoracic spiracle; pe, parempodium; phl, phallotheca; pul, pulvillus; rp, right paramere; sgaur, scent gland auricle; sgev, scent gland evaporatory area.

$30.63335^{\circ} \mathrm{S} 151.25^{\circ} \mathrm{E}, 1000 \mathrm{~m}, 23$ Oct 1995 , Schuh and Cassis, Leptospermum brevipes $\mathrm{F}$. Muell. (Myrtaceae), det. P.G. Wilson 1996 NSW 395916, 15 के (00393343-00393349, 00393353, 00132887, 00132888, 00132963, 00132964, 00132889, 00088863, 00088862), 11 우 (00393386-00393391, 0013289100132893, 00132965, 00132966) (AM). South Australia: $15 \mathrm{~km} \mathrm{~S}$ of Bews, $35.48474^{\circ} \mathrm{S}$ $140.4332^{\circ} \mathrm{E}, 130 \mathrm{~m}, 08$ Nov 1998, Schuh, Cassis, Silveira, Leptospermum coriaceum (F. Muell. ex Miq.) Cheel (Myrtaceae), det. Royal Bot Gard. NSW 427369, $130^{\star}$ (00393394, 00393395, 00393398, 0039055000390555, 00390557-00390560), 19 우 (00393399-00393406, 00393408, 00390563-
00390569, 00390574-00390576) (AM), 1 ๙ (00393397), 1 우 (00393411) (AMNH), 4 후 (00393392, 00393393, 00390561, 00390562), 6 ㅇ (00393407, 00393409, 00393410, 00393412, 00390572, 00390573) (SAMA), 1 đิ (00390556), 2 ㅇ (00390570, 00390571) (USNM). $38.1 \mathrm{~km} \mathrm{~S}$ of Bews, Ngarkat Cons. Park, $35.65981^{\circ} \mathrm{S} 140.449^{\circ} \mathrm{E}, 90 \mathrm{~m}, 09$ Nov 1998, Schuh, Cassis, Silveira, Leptospermum coriaceum (F. Muell. ex Miq.) Cheel (Myrtaceae), det. Field ID, $7 \widehat{0}$ (00393413-00393419), 12 우 (00393420-00393428, 0039063800390640) (AM), 2 §ิ (00390633, 00390634), 2 웅 $(00390636,00390637)(\mathrm{AMNH}) .3 \widehat{0}$ $(00390631,00390632,00390635), \quad 3$ ㅇ (00390641-00390643) (SAMA) 
Additional Specimens Examined: AUSTRALIA: New South Wales: $20 \mathrm{~km}$ E of Retreat (W of Uralla), $30.63335^{\circ} \mathrm{S} 151.25^{\circ} \mathrm{E}, 1000 \mathrm{~m}, 23$ Oct 1995, Schuh and Cassis, Leptospermum brevipes F. Muell. (Myrtaceae), det. P.G. Wilson 1996 NSW 395916, 2 nymphs (00393350, 00393351) (AM). South Australia: $38.1 \mathrm{~km} \mathrm{~S} \mathrm{of}$ Bews, Ngarkat Cons. Park, 35.65981 ${ }^{\circ} \mathrm{S}$ 140.449² E, 90 m, 09 Nov 1998, Schuh, Cassis, Silveira, Leptospermum coriaceum (F. Muell. ex Miq.) Cheel (Myrtaceae), det. Field ID, 2 nymphs (00390644, 00390645) (AM).

\section{Leptospermia cassisi, new species}

Figure 17, map 5, plates 5, 29, table 1

Diagnosis: Distinguished from L. anatoles by male genitalia with aperture of secondary gonopore directed ventrally, absence of a sclerite adjacent to distal edge secondary gonopore, distal region of endosoma with undulate ventral margin (pl. 29A-C), left paramere with rounded apex of anterior process (pl. 29H), and long, substantial distal region of right paramere (pl. 29J), as well as by black on clypeus confined to apex, faintly black antennal segment 1 , labium exceeding apex of metacoxa, and longer shorter parempodia (fig. 17D).

Description: Male: Mean total length 3.88, mean pronotum width 1.22. COLORATION (pl. 5): As in generic description but apex of clypeus black, antennal segment 1 mostly diffusely black, and frons at most tinged with orange. STRUCTURE: Labium just exceeding apex of metacoxa. Pretarsus: Parempodia relatively long (fig. 17D). GENITALIA (fig. 17C, pl. 29A-J): Endosoma: Tightly coiled; subapical region between apex and secondary gonopore of dorsal strap with somewhat tumid ventral margin; distal edge of secondary gonopore without process. Secondary gonopore: Aperture ventral. Phallotheca: Apical region with posterior and anterior edges of equal width. Parameres: Left paramere: Apex of anterior process rounded. Right paramere: Apical region long, apex rounded.
Female (pl. 5): Coloration as in male; differing from male as in generic description; mean total length 3.47 , mean pronotum width 1.19. GENITALIA (pl. 29K-N): As in generic description.

Eтумоlogy: Named in honor of Gerasimos Cassis, collector of many of the known specimens.

Hosts: Recorded from the following species of Myrtaceae: Calytrix angulata (pl. 37E), C. strigosa, Micromyrtus obovata, Verticordia densiflora (pl. 41D), V. picta (Chamelaucieae), Leptospermum crassipes, L. fastigiatum (pl. 38G), L. sp., and Pericalymma ellipticum (pl. 41A) (Leptospermeae). We regard the record from Grevillea armigera (Proteaceae) as the result of commingling of specimens in the field.

Distribution (map 5): Known from nine localities in the Goldfields, Great Southern, Southwest, and coastal portions of Mid-West and Gascoyne regions of Western Australia. This new western species is found in the southwest interzone, southwestern and western desert phytogeographical subregions.

Discussion: This is one of the most frequently collected species of Myrtaceae-feeding Exocarpocorina as well as having probably the broadest host range.

Holotype: AUSTRALIA: Western Australia: $28 \mathrm{~km} \mathrm{~S}$ of Menzies (3.5 km E of Hiway), $29.91917^{\circ} \mathrm{S} 121.1514^{\circ} \mathrm{E}, 500 \mathrm{~m}, 25$ Oct 1996 , Schuh and Cassis, Leptospermum fastigiatum S. Moore (Myrtaceae), det. PERTH staff PERTH 05056527, 1 đ (AMNH_PBI 00134640) (WAMP).

Paratypes: AUSTRALIA: Western Australia: $15 \mathrm{~km} \mathrm{NW}$ of Northampton, on Port Gregory Rd (toward Gregory), $28.30029^{\circ} \mathrm{S} 114.5096^{\circ} \mathrm{E}$, 167 m, 22 Oct 2004, Cassis, Wall, Weirauch, Symonds, Calytrix strigosa A. Cunn. (Myrtaceae), det. PERTH staff PERTH6989667, 10 (00368368), 2 ㅇ (00368369, 00368370) (AMNH). $17 \mathrm{~km}$ N of Albany, Simpson Road at Chester Pass Hiway, $34.89933^{\circ} \mathrm{S} 117.9148^{\circ} \mathrm{E}, 170 \mathrm{~m}, 30$ Nov 1999, R.T. Schuh, G. Cassis, and R. Silveira, Pericalymma ellipticum Schauer var. ellipticum (Myrtaceae), det. PERTH staff PERTH 05671868, 

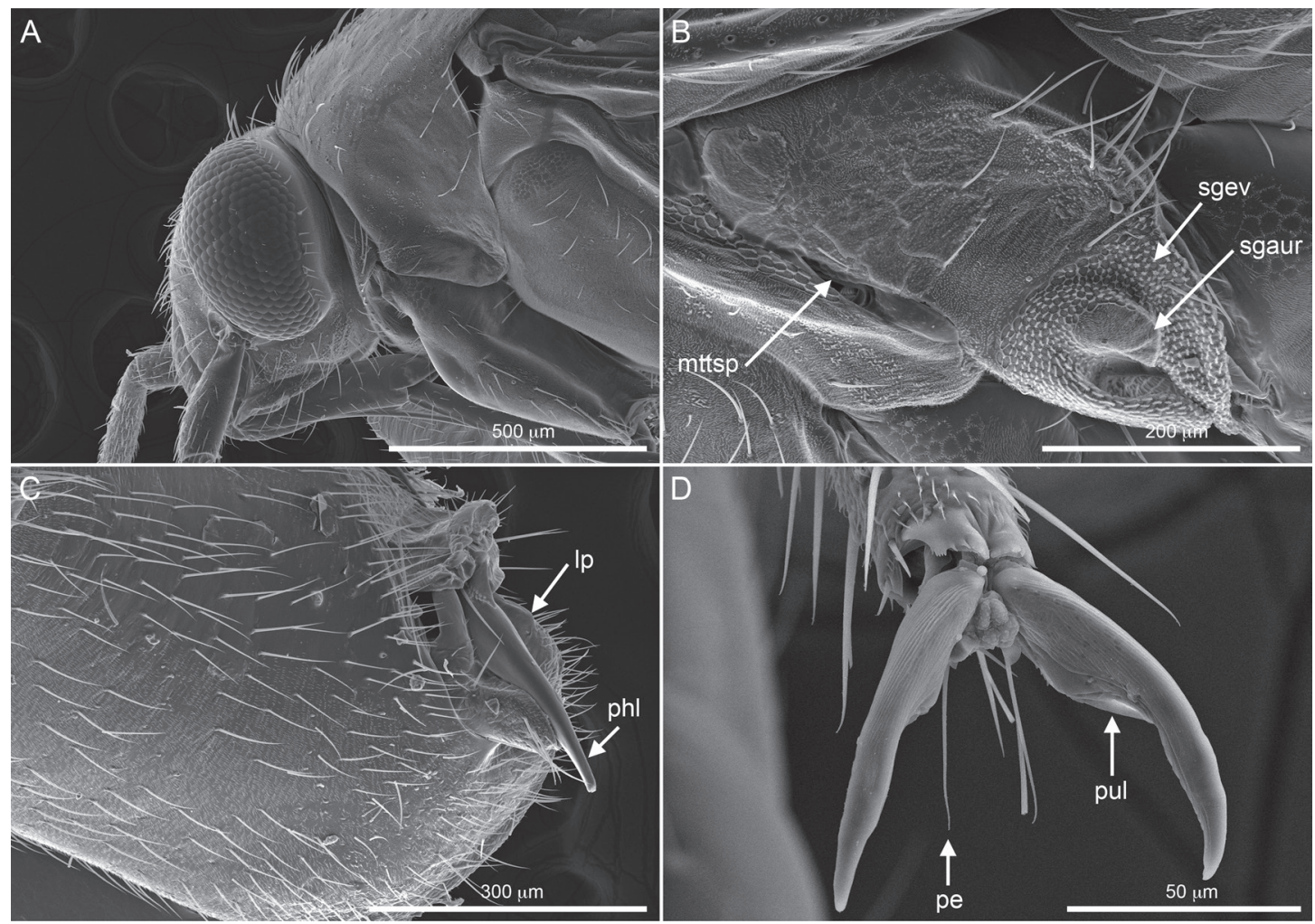

FIG. 17. Leptospermia cassisi, AMNH_PBI 00134650. Scanning electron micrographs. A. Head and pronotum, lateral view. B. Thoracic pleuron, lateral view, showing metathoracic spiracle opening, metathoracic scentgland auricle, and evaporatory area. C. Pygophore, left paramere, and phallotheca, lateral view. D. Pretarsus, frontodorsal view. Abbreviations: lp, left paramere; mttsp, metathoracic spiracle; pe, parempodium; phl, phallotheca; pul, pulvillus; sgaur, scent gland auricle; sgev, scent gland evaporatory area.

17 đิ (00390491-00390507), 12 우 (0039051700390520, 00390526-00390533) (AM), Pericalymma ellipticum Schauer var. ellipticum (Myrtaceae), det. PERTH staff PERTH 05671868, 36 đै (00390473-00390490, 00128886-00128900, $00414817,00129513,00129514), 8$ ㅇ (0039052100390525, 00128901, 00128902, 00129515) $(\mathrm{AMNH}), \quad 30^{\pi}(00390508-00390510), \quad 7$ 우 (00390534-00390540) (WAMP). $21 \mathrm{mi} \mathrm{N}$ of Perth, Wildlife Reserve, $31.50749^{\circ} \mathrm{S} 115.87532^{\circ} \mathrm{E}$, 18 Dec 1971, J. A. Slater, Verticordia densiflora Lindl. (Myrtaceae), 10 (00412956), 5 ㅇ (00412975-00412979) (AMNH). $28 \mathrm{~km} \mathrm{~S}$ of Menzies (3.5 km E of Hiway), $29.91917^{\circ} \mathrm{S}$ $121.1514^{\circ} \mathrm{E}, 500 \mathrm{~m}, 25$ Oct 1996, Schuh and Cassis, 10 (00414816) (AMNH), Calytrix angulata
Lindl. (Myrtaceae), det. PERTH staff PERTH 05099706, 3 ô (00135537, 00135557, 00414835), 1 우 (00135551) (AMNH), 10 후 (0013553300135536, 00135538-00135540, 00135556, 00135558, 00135559), 27 (00135541-00135550, 00135552-00135555, 00135560-00135572) (WAMP), Leptospermum fastigiatum S. Moore (Myrtaceae), det. PERTH staff PERTH 05056527, 38 ơ (00390685-00390703, 00390717-00390726, 00390728-00390736), 22 우 (00390727, 00390782-00390801, 00390815) (AM), 28 ๙ (00088859-00088861, 00134637-00134639, 00134641-00134659, 00136831, 00393341, 00393342), 34 ㅇ (00088864-00088868, 00134660-00134681, 00136860, 0039337800393383) (AMNH), 3 † (00136840-00136842), 
3 우 (00136849-00136851) (ANIC), 3 주 (00136843-00136845), 3 ㅇ (0013684600136848) (CNC), 2 † (00136838, 00136839), 2 우 $\quad(00136852,00136853) \quad(\mathrm{UCR}), \quad 3$ 주 (00390704-00390706), $3+$ (00390802, 00390813, 00390814) (UNSW), 3 ơ (00136832-00136834), 3 우 (00136854-00136856) (USNM), 10 후 (00390707-00390716), 26 (0039075600390781) (WAMP), 3 ๙ิ (00136835-00136837), 3 ㅇ (00136857-00136859) (ZISP). $39.7 \mathrm{~km} \mathrm{~N}$ of Ravensthorpe, $33.32199^{\circ} \mathrm{S} 119.82^{\circ} \mathrm{E}, 500 \mathrm{~m}, 06$ Dec 1997, Schuh, Cassis, Brailovsky, Asquith, Grevillea armigera Meisn. (Proteaceae), det. Perth Staff PERTH 05099900, 2 ô (00390579, 00390580) (AM), Leptospermum sp. (Myrtaceae), 14 đิ (00390581-00390592, 00087096, 00087424), 17 우 (00390595-00390610, 00087097) (AM), 2 우 (00390577, 00390578) (AMNH), 1 đ (00390593), 8 우 (00390611-00390618) (WAMP). $92.5 \mathrm{~km} \mathrm{~W}$ of Coolgardie at east side of Boorabbin National Park on Great Eastern Hwy, $31.21233^{\circ} \mathrm{S} 120.31^{\circ} \mathrm{E}$, 445 m, 17 Nov 1999, R.T. Schuh, G. Cassis, and R. Silveira, Micromyrtus obovata (Turcz.) J.W. Green (Myrtaceae), det. PERTH staff PERTH 05670659, 2 하 (00390544, 00390545), 4 우 (00390546-00390549) (AM). Frank Hann National Park, $37 \mathrm{~km}$ E of Lake King, 33.07753 $\mathrm{S}$ $120.0918^{\circ} \mathrm{E}, 400 \mathrm{~m}, 05$ Nov 1996, Schuh and Cassis, Leptospermum fastigiatum S. Moore (Myrtaceae), det. PERTH staff PERTH 05236894, 2 ๙ (00390619, 00390620), 10 ㅇ (0039062100390630) (AM). Pemberton, $34.5^{\circ} \mathrm{S} 115.08333^{\circ} \mathrm{E}$, 21 Dec 1971, J. A. Slater, Leptospermum crassipes Lehm. (Myrtaceae), 18 ơ (00412957-00412974), 17 우 (00412980-00412996) (AMNH).

Additional Specimens Examined: AUSTRALIA: Western Australia: $1 \mathrm{~km} \mathrm{~S}$ of Lillian Stoke Rock, $33.07681^{\circ} \mathrm{S} 120.0982^{\circ} \mathrm{E}, 380 \mathrm{~m}, 21$ Nov 1999, R.T. Schuh, G. Cassis, and R. Silveira, Verticordia picta Endl. (Myrtaceae), det. PERTH staff PERTH 05670276, 3 nymphs (0039054100390543) (AM). $17 \mathrm{~km} \mathrm{~N}$ of Albany, Simpson Road at Chester Pass Hiway, $34.89933^{\circ} \mathrm{S}$ 117.9148 E, 170 m, 30 Nov 1999, R.T. Schuh, G. Cassis, and R. Silveira, Pericalymma ellipticum Schauer var. ellipticum (Myrtaceae), det. PERTH staff PERTH 05671868, 11 nymphs (0039046800390472, 00390462-00390467) (AM). 28 km S of Menzies (3.5 km E of Hiway), $29.91917^{\circ} \mathrm{S}$ $121.1514^{\circ} \mathrm{E}, 500 \mathrm{~m}, 25$ Oct 1996, Schuh and Cassis, Leptospermum fastigiatum S. Moore (Myrtaceae), det. PERTH staff PERTH 05056527, 4 nymphs (00390737-00390740) (AM).

Melaleucacoris, new genus

Type Species: Melaleucacoris glomeratae, new species.

Diagnosis: Recognized among Australian phyline taxa by pale general coloration with reddish spots and patches, sericeous silvery setae, posteromedial tubercle of left paramere, secondary gonopore located at midpoint of endosoma, dorsal endosomal spine membranous, inflated, and microspiculate at base and serrate on anterior edge of apex, ventral apical endosomal spine long, strongly serrate, and absence of process arising close to secondary gonopore; posterior wall of female genitalia divided with strong longitudinal fold and posteromedial projection abutting ovipositor bulb and vestibular sclerites thick, well sclerotized, and triangular.

Description: Male: Macropterous, total length 2.35-2.51, pronotum width $0.86-0.88$. COLORATION (pl. 5): Dirty pale or faintly rusty cream base color with contrasting reddish mahogany color in discreet spots, blotchy and coagulated patches, and unbroken regions distally on corium including costal margin and apex of cuneus; hemelytral membrane uniformly fuscous; antennal segment 1 with discrete dark blotch, antennal segments 3 and 4 somewhat darkened; apical portion of labium dark brown; legs predominately pale with dark spots on apices of femora; metafemora with solid dark markings on dorsal margin blending into ragged stripes distally; thoracic venter, including metepisternal scent auricle, with large dark mahogany regions, abdominal sterna with irregular dark color; tibiae with large black spots; claws dark brown. SURFACE AND VESTITURE (pl. 5): Dorsum very weakly shining; dorsal vestiture with relatively 
dense, sericeous, shining, silvery setae; black setae absent; tibiae with black spines. STRUCTURE: Head: Relatively narrow, posterior margin of eyes slightly separated from anterior margin of pronotum, eyes medium sized in dorsal view, just reaching to level of antennal insertion in lateral view, weakly emarginate near fossa. Antenna: Segment 2 of greatest diameter at apex, tapering to base, length approximately equal to $80 \%$ of pronotal width. Labium: Reaching apex of metacoxa. Thorax: Pronotum: Subquadrate, lateral margins gently curved, calli faintly demarcated, posterior lobe flat, posterior margin straight; mesoscutum moderately exposed. Pretarsus: Claws small, gently curved; parempodia short setiform; pulvilli moderately short, located within and proximad of angle of claw (fig. 18A). Hemelytron: Costal margin weakly curved. GENITALIA (pl. 30A-G): Pygophore: Medium sized, conical; paramere insertions without tubercles or discrete patches of bristles. Endosoma: With one strap, J-shaped, without torsion; endosoma thickest at midpoint; endosomal strap sclerotized beyond secondary gonopore extending to apex of dorsal spine; base of dorsal spine with inflated microspiculate membrane and moderately long, narrow accessory spine, apical region of dorsal spine with serrate margin on anterior edge; long marginally serrate ventral spine emanating at level of insertion of dorsal spine. Secondary gonopore: Well formed, located just proximal to midpoint of endosoma. Phallotheca: Relatively short and flat; apex slightly rounded; aperture small, occupying posterodistal surface of phallotheca; right side of anterior surface with long spine, almost reaching apex of phallotheca. Parameres: Left paramere: Dorsal tubercle on anterolateral margin near base of posterior process, length of tubercle equal to length of posterior process; posterior process short strongly bent ventrad, apex rounded. Right paramere: Short, broad, with moderately long acuminate apex.

Female (pl. 5): Coloration and structure similar to male, except body slightly wider, antennal segment 2 more slender and tapering proximally in contrast to male; total length $2.51-2.70$, pro- notum width 0.87-0.94. GENITALIA (pl. 30H$\mathrm{M})$ : Posterior margin of sternite 7: Medial shield-shaped projection. Vestibular sclerites: Moderate in size, strongly sclerotized, triangular, not projecting beyond anterior edge of dorsal labiate plate. First gonapophyses: Asymmetrical, well sclerotized; right side triangular, larger than left, left side quadrate. Ventral labiate plate: Symmetrical, well sclerotized, triangular, right and left sides meeting on linear surface. Dorsal labiate plate: Medium sized, subquadrate, convex longitudinally. Sclerotized rings: Medium sized, symmetrical, separated by width of ring, subrectangular, relatively thick walled. Posteromedial region: Weakly sclerotized paramedially, midline with posterior projection; surface smooth not particularly sunken. Anterolateral region: Microspiculate, greatly projecting anteriad of sclerotized rings. Intersegmental membrane: Undifferentiated, merely folded. Posterior wall: Well sclerotized and divided on midline with strong longitudinal fold; each half of dorsoanterior surface rounded proximally and at lateral margin, tumid, microspiculate bulging anteriorly into genital chamber; posteromedial surface with solid, strongly sclerotized process projecting posteriad and abutting ovipositor bulb. Interramal sclerites: Well sclerotized, bat shaped with paramedial notches. Interramal lobes: Microspiculate, tumid, situated at lateral margins.

Eтymology: A combination of the generic name Melaleuca and the Greek word coris, "bug"; masculine.

Discussion: The strongly spotted coloration of the single described species of this taxon suggests an association with species of Ancoraphylus of the Leptidolon group of genera (Weirauch, 2007). Even though the structure of the male and female genitalia of the new species clearly indicates placement in the Exocarpocorina, a number of characters argue against placement in Ancoraphylus. We therefore propose a new genus to accommodate the unique features of this taxon. The endosoma does not have a process arising near the secondary gonopore and the apical region is more or less membranous; the posteromedial portion of the 
middle dorsal labiate plate is weakly sclerotized and not microspiculate, and the posterior wall has a prominent well-sclerotized posterior projection abutting the ovipositor bulb.

An additional species of Melaleucacoris from Western Australia, taken on Calothamnus quadrifidus R. Br. ex W.T. Aiton (Myrtaceae: Melaleuceae), was recognized by us based on its unique endosoma, dorsoposterior surface of posterior wall, and conspurcate hemelytral membrane. Unfortunately, the male is lost and we refrain from describing the potential new species based on the two available female specimens.

The current sole member of Melaleucacoris is seemingly distributed only in the arid center of Australia, a distribution shared with two other new species (Melaleucaphylus glomeratae, Xiphoides anangu) treated herein (table 4). Other Heteroptera known from only the desertic region of the Northern Territory are seven species of Cremnorrhinina (Schuh and Schwartz, 2016), among orthotyline plant bugs Acaciacapsus amadeus (Cassis and Symonds, 2014), one species of callitroid-inhabiting Orthotylini (Symonds and Cassis, 2018), and three species of the Lattinova complex of genera (Cassis, 2008). Seven species of lace bugs (Cassis and Symonds, 2008; Cassis and Symonds, 2011; Cassis et al., 2017) are also uniquely known from central Northern Territory. However, the distribution of many more heteropteran species taken in central Northern Territory also extend to other arid regions of Australia, especially southwestern Western Australia; with more exploration Melaleucacoris could exhibit this wider geographic pattern.

\section{Melaleucacoris glomeratae, new species}

Figure 18A, map 5, plates 5, 30, table 1

Diagnosis: Currently known only from the type species and therefore recognized by the characters in the generic diagnosis.

Description: Male (fig. 18A, pls. 5, 30A-G): As in generic description. Mean total length 2.43, mean pronotum width 0.87 .
Female (pls. 5, 30H-M): As in generic description. Mean total length 2.62 , mean pronotum width 0.91 .

Eтумоlogy: Named for its occurrence on Melaleuca glomerata.

Host: Recorded from Melaleuca glomerata (Myrtaceae: Melaleuceae) (pl. 39B).

Distribution (map 5): Known only from the type locality in Palm Valley, Finke Gorge National Park, in southcentral Northern Territory within the eastern desert phytogeographical subregion.

Holotype: AUSTRALIA: Northern Territory: Finke Gorge National Park, Palm Valley, $24.03333^{\circ} \mathrm{S} 132.7101^{\circ} \mathrm{E}, 586 \mathrm{~m}, 04$ Nov 2001, Cassis, Schuh, Schwartz, Silveira, Wall, Melaleuca glomerata F. Muell. (Myrtaceae), det. NSW staff NSW666320, 10 (AMNH_PBI 00097843) (MAGNT).

Paratypes: AUSTRALIA: Northern Territory: Finke Gorge National Park, Palm Valley, $24.03333^{\circ} \mathrm{S} 132.7101^{\circ} \mathrm{E}, 586 \mathrm{~m}, 04$ Nov 2001, Cassis, Schuh, Schwartz, Silveira, Wall, Melaleuca glomerata F. Muell. (Myrtaceae), det. NSW staff NSW 666320, 2 ㅇ (00097798, 00097810), 14 우 (00097152, 00097811, 00097817, 00097818, 00097820-00097822, 00097824-00097826, 00097828, 00097831, 00097939, 00414872) (AM), 30 oิ (00097151, 00097799-00097801, 0009780400097809, 00097934, 00097935, 0009783400097838, 00097848, 00097913-00097919, 00414874-00414876, 00414878, 00130018), 32 우 (00097812-00097816, 00097819, 00097823, 00097830, 00097936-00097938, 00097854, 00097857, 00097868, 00097920-00097922, 00097924-00097933, 00414869-00414871, 00414879, 00097923) (AMNH), 1 đิ (00097802), 1 우 (00097827) (ANIC), 1 후 (00097803), 1 우 (00097829) (CNC), 7 † (00097839-00097842, 00097845, 00097846, 00097849), 18 우 (0009785000097853, 00097855, 00097858-00097865, 00097869, 00097870, 00097872-00097874) (MAGNT), $1 \hat{0}$ (00097844), 19 (00097856) (UCR), 1 đิ (00097847), 1 우 (00097866) (UNSW), 1 ๙ิ (00414873), 19 (00097867) (USNM), 1 ๙ (00414877), 1 우 (00097871) (ZISP). 

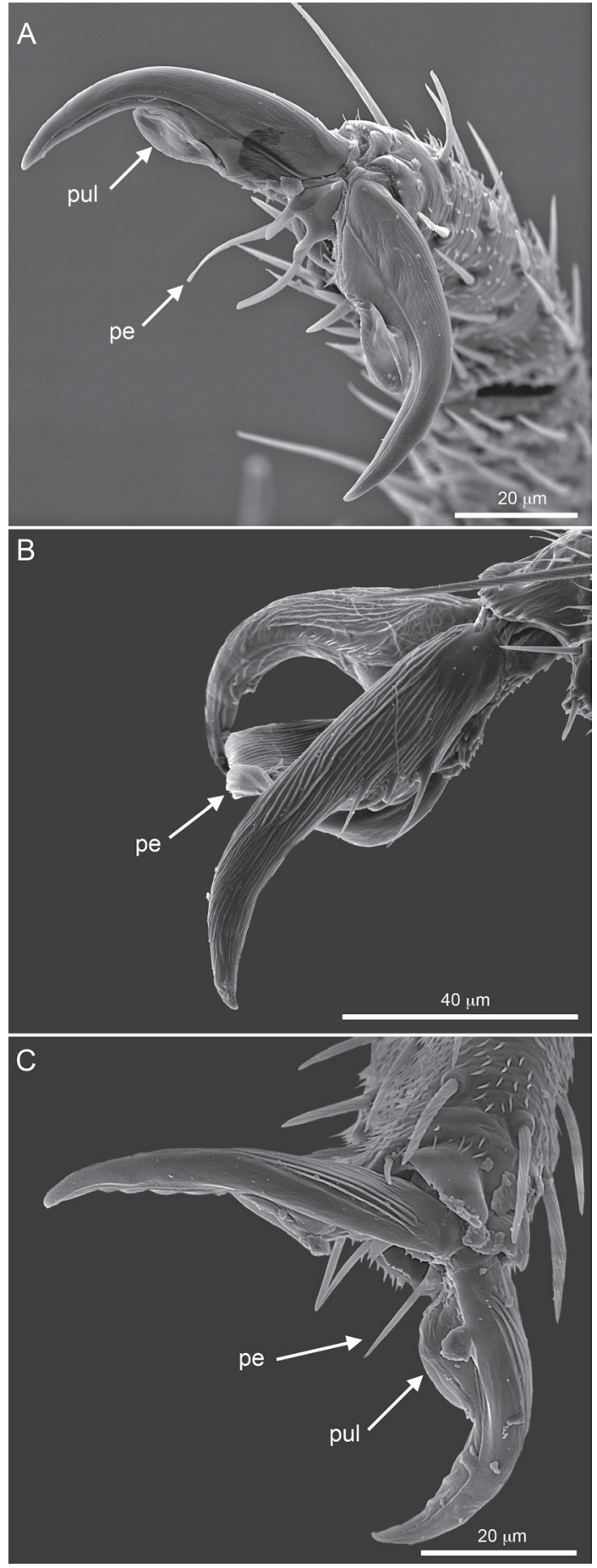

\section{Scholtzicoris linnavuorii Schuh}

Figure 18B, plate 31

\section{Scholtzicoris linnavuorii Schuh, 2016: 161 (new} species).

Discussion: Pretarsal structure in this species was not documented with images as part of the original description (Schuh, 2016). Figure 18B shows the broad base of the curving claw, fleshy, lyriform parempodia, and absence of pulvilli in this member of the Melaleucoides group of Exocarpocorina (Schuh and Weirauch, 2010). Photos of the female genitalia (pl. 31) document the posterior wall with depressed or divided midline, sclerotized interramal sclerite, broad posterodorsally and narrow anteroventrally, interramal lobes produced anteriad into the genital chamber, no posterior prominence abutting ovipositor base, and flat intersegmental process membranous and projecting into genital chamber anteriorly and sclerotized posteriorly adjacent to interramal lobes.

Specimens Examined: AUSTRALIA: Western Australia: NW Coastal Hiway $58 \mathrm{~km} \mathrm{~N}$ of Kalbarri Road, $27.43701^{\circ} \mathrm{S} 114.6768^{\circ} \mathrm{E}, 500 \mathrm{~m}, 30$ Oct 1996, Schuh and Cassis, Baeckea pentagonantha F. Muell. (Myrtaceae), det. PERTH staff PERTH 05879248, 2 क (00414760, 00414756), $1+(00414777)(\mathrm{AMNH})$.

\section{Teddus, new genus}

Type Species: Teddus katrinae, new species.

DiAgnosis: Habitus including scalelike setae and coloration pattern with transverse fascia reminiscent of many species placed in the Leucophoropterini and Pilophorini, but these tribal associations rendered as myrmecomorphic convergence when examining the unique genitalia of both sexes of Teddus. Genitalic structure unequivocally places Teddus in the Leptidolon group of genera, within which it can be distinguished by the conspicuous habitus.

FIG. 18. Pretarsus. Scanning electron micrographs. A. Melaleucacoris glomeratae, AMNH_PBI 00097804, frontal view. B. Scholtzicoris linnavuorii, AMNH_PBI 00414756, lateral view. C. Teddus katrinae, AMNH_PBI 00110752, frontodorsal view. Abbreviations: pe, parempodium; pul, pulvillus. 
Description: Male: Macropterous, body elongate; total length 2.79-2.97, pronotum width 0.95-0.98. COLORATION (pl. 5): Dark mahogany brown with four conspicuous, bright white, elongate triangular sections at base of corium and cuneus, and adjacent portion of embolium; apex of scutellum obscurely pale; ventral portion of head, antennal segment 1, xyphus, procoxa, basalar plate with varying intensity of pale slightly reddish coloration; tibial spines black without dark bases; hemelytral membrane slightly fumose with central area pale, long vein of large cell dark, short vein pale; abdominal sterna 2-6 pale on central patch. SURFACE AND VESTITURE (fig. 19D): Subshining; mixed vestiture of dense white or black scalelike setaeblack setae generally distributed, except on white colored areas of hemelytron and cuneus; white setae on head, mesoscutum, scutellum basally, white colored patches on corium and cuneus, distal margin of corium, and paracuneus; scalelike setae present on ventral surfaces including femora; dorsum also with sparse, black, simple setae. STRUCTURE: Head (figs. 19A, B, pl. 5): Short, transverse, conforming to anterior margin of pronotum; in lateral view frons surpassing anterior margin of eyes by one-half width of eye, eyes occupying $75 \%$ height of head, and antenna fossa dorsal to ventral margin of eye by diameter of fossa; eyes large, shallowly emarginate near fossa. Antenna: Segment $286 \%$ of head width. Labium: Reaching to apex of mesosternum. Thorax (figs. 19A, B, pl. 5): Pronotum: Relatively short, subcampanulate, lateral margins slightly concave, calli separate, weakly raised, posterior lobe flat, posterior margin straight; mesoscutum moderately exposed. Pretarsus: Claw relatively small, slightly curved; parempodia short, setiform; pulvilli small attached to claw base proximad of angle (fig. 18C). Hemelytron: Costal margin straight. GENITALIA (fig. 19C, pl. 32AJ): Pygophore: Small, broadly conical; caudal surface broad, covered with dense field of short, fluted, peglike bristles (fig. 19C, pl. 32J); left side of aperture without clump of bristles or tubercle. Endosoma: J-shaped medium sized, consisting of two straps, ventral strap terminating at base of secondary gonopore just distad of middle of endosoma in thin spine with slender apex, dorsal strap continuing distad of secondary gonopore, terminating in well-sclerotized somewhat flat, pointed, dorsal apical spine; short ventral apical spine situated just distad of secondary gonopore, equal in length to secondary gonopore; slender, smooth, apically pointed, C-shaped process arising at midpoint of secondary gonopore on right side of endosoma, wrapped around left side of endosoma; region near secondary gonopore slightly expanded and smoothly membranous on ventral surface; dorsal strap without spines basad of secondary gonopore. Secondary gonopore: Well formed, open on caudal surface, very faint, situated within membrane, about $5 \times$ length of secondary gonopore from apex of dorsal strap. Phallotheca: Narrow, gently tapered to small flattened palmate tip; entire anterior surface with long crested flange; moderate-sized ovate aperture on left apical surface; right internal surface with long strut. Parameres: Left paramere: Elongate shoulder between posterior and anterior processes extruded, without marginal lobe; posterior process short, bent ventrad, apex chiseled; anterior process relatively long, with two long terminal setae. Right paramere: Small, ovate with short beveled apex.

Female (pl. 5): Coloration as in male; differing from male with subovoid body, less transverse head, slightly more rounded frons, wider vertex, smaller eyes, antennal segment 2 more slender, pronotum narrower anteriorly, costal margin more curved; total length 2.722.99, pronotum width 0.99-1.07. GENITALIA (pl. $32 \mathrm{~K}-\mathrm{N}$ ): Posterior margin of sternite 7: With wide shield-shaped projection. Vestibular sclerites: Relatively small, pair of parallel sclerites, oriented in dorsoventral plane; flat paramedial triangular plates forming anterior wall of genital chamber; vestibular sclerites situated between and reaching anteriad to level of posterior margin of sclerotized rings in dorsal view. First gonapophyses: Ventral extension attached to pair of small globular sclerites. 
Ventral labiate plate: Paramedial anteroventral extension small and short; entire anterior surface of covered with weakly sclerotized sheet; surface of ventral labiate plate ventral to sclerotized rings membranous. Dorsal labiate plate: Relatively small, transverse, with wavy margins, concave lateral to ring. Sclerotized rings: Relatively small, subovoid with sunken lateral margin, not reaching lateral margin of dorsal labiate plate; rings separated by width of ring, relatively thick walled. Posteromedial region: Divided, sunken, medial microspiculate membrane, located ventrad of lateral oviducts and spermathecal gland. Intersegmental membrane: With small bowtie- or shield-shaped sclerite situated posteriad of posteromedial region of dorsal labiate plate; not projecting into genital chamber. Anterolateral region: Region anterior to rings with microspicules. Posterior wall: Complex among phylines, entirely sclerotized somewhat bat shaped, convex in dorsal view, broadly bowed anteriad; medial region strongly sclerotized with flat dorsoposterior plate and unique ornamentation. Interramal sclerites: Strongly sclerotized plate occupying entire interramal space, except for ventromedial opening; dorsoposterior region wide and clearly attached to paired ventrolateral regions; anterior surface of posterior wall with two sets of paired paramedial undulating prominences directed into the genital chamber; dorsoposteriormost paramedial region with concave microspiculate surface and an adjacent pair of short, discrete, smooth lobes; minute sclerite barely projecting posteriad. Interramal lobes: Absent.

Eтyмology: A fanciful name for its "teddy bear" appearance as originally coined by Katrina Menard, especially the faux furry appearance of the dense scalelike setae.

Discussion: The widely distributed scalelike setae, relatively broad head, and boxlike pronotum give a rectangular habitus, similar to that of Hypseloecus Reuter but divergent from the more sinuous body forms of many other Pilophorini and most Leucophoropterini. The relatively short hemelytron is not typical even in the weakly myrmecomorphic genera (Ausejanus, Tuxedo, and Sthenaridea) of these two other phyline tribes.

Nonetheless, the structure of genitalia in both sexes clearly demonstrates that Teddus belongs to the Leptidolon group of genera and of the known taxa of this group is most closely related to Ancoraphylus. The endosoma, with dorsal and ventral apical spines and a curved process near the secondary gonopore, as well as female genitalia with a strongly sclerotized posterior wall and unique dorsoposterior elaboration, are currently not known in other phylines.

\section{Teddus katrinae, new species}

Figure 18C, 19, map 6, plates 5, 32, table 1

DiAgnosis: Distinguished from other Australian phylines by the presence of black and white scalelike setae on the dorsum augmenting the striking black and white markings on the hemelytron. The genitalic structure of both sexes as in other Leptidolon group genera, but habitus similar to some Leucophoropterini.

Description: Male (figs. 18C, 19, pls. 5, 32A-J): As in generic description. Mean total length 2.87 , mean pronotum width 0.97 .

Female (pls. 5, 32K-N): As in generic description. Coloration as in male; differing from male as in generic description; mean total length 2.91, mean pronotum width 1.03 .

EтумоLоgy: Named in honor of Katrina L. Menard, who first recognized the correct tribal placement of this taxon and who shared information that influenced the formulation of our discussions.

Hosts: Recorded from a broad range of hosts, most represented by only a few specimens of $T$. katrinae (see Specimens Examined and table 3), as well as 79 specimens with no recorded host. Only two specimens (from South and Western Australia) were collected on myrtaceous plants. Significant numbers of specimens are documented from the following unrelated plant species: Grevillea nematophylla (Proteaceae: 46 specimens/ 1 collect- 

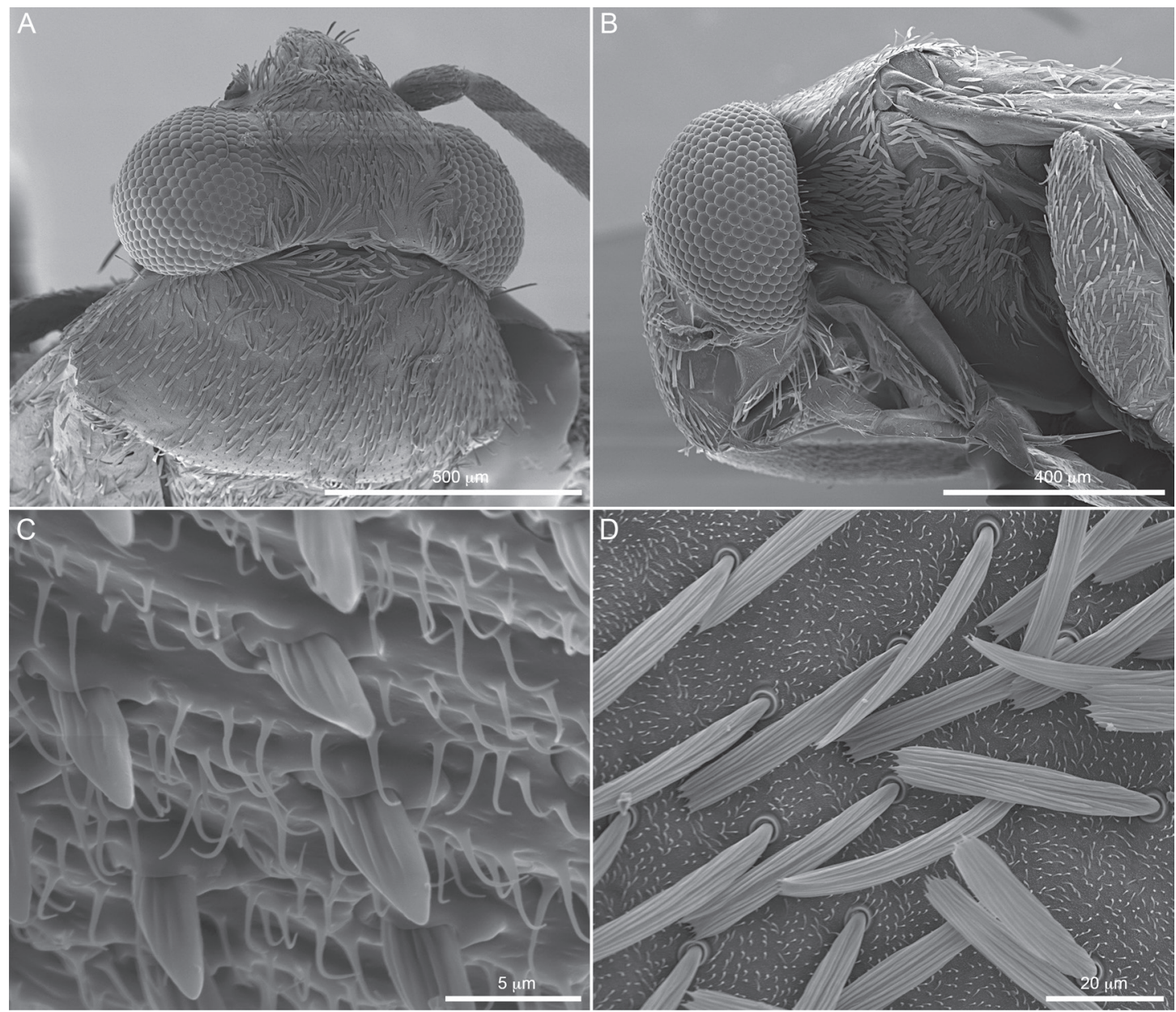

FIG. 19. Teddus katrinae, AMNH_PBI 00110752. Scanning electron micrographs. A. Head and pronotum, dorsal view. B. Head, lateral view. C. Detail of fluted bristles on pygophore, lateral view. D. Detail of pronotal setae, dorsal view.

ing event) and Dodonea viscosa (Sapindaceae: 13 specimens/ 1 collecting event). Also 13 specimens were taken on two genera of Fabaceae (6 spp. of Acacia and 1 sp. of Senna).

Distribution (map 6, table 4): Currently known from 50 localities (54 collecting events) representing every Australian state except Tasmania. Inhabiting the southwestern, southwest interzone, Pilbara, western desert, central desert, eastern desert, and Adelaide terrestrial phytogeographical subregions of Ebach et al. (2015).

Discussion: This new species is distributed across the arid regions of mainland Australia, a relatively rare distribution pattern for phyline Miridae that also occur in the southwestern subregion (table 4). Examination of eight males from NSW, NT, QLD, SA, and WA confirmed that all features of the endosoma are identical across the range of the distribution.

Holotype: AUSTRALIA: South Australia: $14.3 \mathrm{~km} \mathrm{~S}$ of Erudina Woolshed, $31.53334^{\circ} \mathrm{S}$ $139.5506^{\circ} \mathrm{E}, 86 \mathrm{~m}, 09$ Nov 2001, Cassis, Schuh, and Schwartz, 10 (AMNH_PBI 00274731) (SAMA).

Paratypes: AUSTRALIA: New South Wales: $38 \mathrm{~km}$ WNW of Carinda toward Brewarrina, 
$30.25001^{\circ} \mathrm{S} 147.1667^{\circ} \mathrm{E}, 150 \mathrm{~m}, 26$ Oct 1995 , Schuh and Cassis, Acacia pendula A. Cunn. ex G. Don (Fabaceae), det. B.J. Conn 1996 NSW 395941, 10 (00390816), 3 (0039081700390819) (AM). Fowler's Gap Research Station, $31.08333^{\circ} \mathrm{S} 141.7^{\circ} \mathrm{E}, 08 \mathrm{Dec} 1982$ - 09 Dec 1982, I. D. Naumann and J. C. Cardale, $1 \delta^{\top}$ (00110762), 1 웅 (00110764) (ANIC). Northern Territory: 1 km S of Henbury Craters Nature Reserve, $24.56668^{\circ} \mathrm{S} 133.1234^{\circ} \mathrm{E}, 457 \mathrm{~m}, 29$ Oct 2001 , Cassis, Schuh, Schwartz, Silveira, Wall, Acacia aneura F.Muell. ex Benth. (Fabaceae), det. NSW staff NSW 658409, 1 ㅇ (00414718) (AMNH). 5 $\mathrm{mi}$ E of Jervois, $35.26577^{\circ} \mathrm{S} 139.52444^{\circ} \mathrm{E}, 07 \mathrm{Dec}$ 1960, B. Daily, 1 ㅇ (00169111) (SAMA). 8 km E of Jervois, $35.26577^{\circ} \mathrm{S} 139.52444^{\circ} \mathrm{E}, 07 \mathrm{Dec} 1960$, B. Daily, 1 ( $(00169061)$ (SAMA). $17.5 \mathrm{~km} \mathrm{E} \mathrm{of}$ Stuart Hiway on Horseshoe Bend Rd, 25.16667 $\mathrm{S}$ $133.3223^{\circ} \mathrm{E}, 412 \mathrm{~m}, 29$ Oct 2001, Cassis, Schuh, Schwartz, Silveira, Wall, Dodonaea viscosa Jacq. subsp. angustissima (Sapindaceae), det. NSW staff NSW 658405, 1 ( $(00414717)$ (AMNH). 22 mi S of Alice Springs, $24.3^{\circ} \mathrm{S} 134.6^{\circ} \mathrm{E}, 15 \mathrm{Feb}$ 1966, E. Britton, $10^{\top}$ (00168875), 1 (0) (00168876) (ANIC). $26.8 \mathrm{~km}$ W of Tanami Rd on Mt Wedge Station Rd, $22.50001^{\circ} \mathrm{S} 132.179^{\circ} \mathrm{E}, 589 \mathrm{~m}, 23 \mathrm{Oct}$ 2001, Cassis, Schuh, Schwartz, Silveira, Wall, 1 우 (00274401) (AM). $39 \mathrm{~km}$ E of Alice Springs, $23.68333^{\circ} \mathrm{S} 134.25^{\circ} \mathrm{E}, 26 \mathrm{Sep} 1978$, M.S. Upton, 1 우 (00110765) (ANIC). $45.3 \mathrm{~km} \mathrm{NW}$ of Bond Springs on Tanami Rd, $23.51668^{\circ} \mathrm{S} 133.4626^{\circ} \mathrm{E}$, 695 m, 21 Oct 2001, Cassis, Schuh, Schwartz, Silveira, Wall, 1 ㅇ (00274399) (AM). $62 \mathrm{~km} \mathrm{SW}$ by S of Alice Springs, $24.11^{\circ} \mathrm{S} 133.3^{\circ} \mathrm{E}, 16$ May 1978 ,

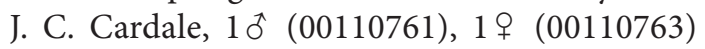
(ANIC). $74.8 \mathrm{~km}$ E of Yuendumu on Mt Denison-Coniston $\mathrm{Rd}, 22.1^{\circ} \mathrm{S} 132.4231^{\circ} \mathrm{E}, 646 \mathrm{~m}, 24$ Oct 2001, Cassis, Schuh, Schwartz, Silveira, Wall, 1 (00274400) (AM). $184 \mathrm{~km} \mathrm{~W} \mathrm{of} \mathrm{Stuart} \mathrm{Hiway}$ on Lasseter Hiway, $25.24417^{\circ} \mathrm{S} 131.57028^{\circ} \mathrm{E}, 510$ m, 31 Oct 2001, Cassis, Schuh, Schwartz, Silveira, Wall, $1+$ (00274398) (AM). Dingo Hole Dam, $30 \mathrm{~km} \mathrm{~N}$ of Ammaroo Stn, $21.483^{\circ} \mathrm{S}$ $135.233^{\circ} \mathrm{E}, 08$ Oct 1977, J.A. Forrest, 1 우 (00169110) (SAMA); 09 Oct 1977, G. F. Gross and J. A. Forrest, 1 đ (00169108) (SAMA). East of Arltunga Station, $23.36667^{\circ} \mathrm{S} 134.5971^{\circ} \mathrm{E}, 660$ m, 26 Oct 2001, Cassis, Schuh, Schwartz, Silveira, Wall, 1 ( $(00274402)(\mathrm{AM})$. W tip of Petermann Range, $25.07102^{\circ} \mathrm{S} 129.64253^{\circ} \mathrm{E}, 649$ m, 30 Oct 1963, P. Aitken and N.B. Tindale, $30^{\star}$ (00169094-00169096), 1 ㅇ (00169097) (SAMA). by Stuart Hiway, at turnoff to Orange Ck HS, $24.35774^{\circ} \mathrm{S} 133.42854^{\circ} \mathrm{E}, 474 \mathrm{~m}, 15$ Aug 1978, D. V. Lacis, $10^{\hat{~}}$ (00169109) (SAMA). Queensland: $91 \mathrm{~km}$ N of Quilpie, $25.99847^{\circ} \mathrm{S} 144.4098^{\circ} \mathrm{E}, 300$ m, 02 Nov 1998, Schuh, Cassis, Silveira, Amyema quandang (Lindley) Tieghem var. quandang (Loranthaceae), det. Royal Bot Gard. NSW 427341, 1 o (00110754), 1 우 (00110756) Hakea leucoptera R. Br. (Proteaceae) NSW 427661, 2 (00110757, 00110758) (AM), Hakea leucoptera R. Br. (Proteaceae) NSW 427661, 30 (00272789, 00272790, 00128979), 4 우 (00272791-00272793, 00128980) (AMNH). South Australia: $11.5 \mathrm{~km}$ $\mathrm{NE}$ of Wooltana Homestead, $30.33726^{\circ} \mathrm{S}$ 139.4934 ${ }^{\circ} \mathrm{E}, 180 \mathrm{~m}, 06 \mathrm{Nov}$ 1998, Schuh, Cassis, Silveira, 1 우 (00414715) (AMNH). $14.3 \mathrm{~km} \mathrm{~S}$ of Erudina Woolshed, $31.53334^{\circ} \mathrm{S} 139.5506^{\circ} \mathrm{E}, 86$ m, 09 Nov 2001, Cassis, Schuh, Schwartz, Silveira, 4 ㅈ(00274727-00274730), 3 우 (0027473200274734) (AM), 1 우 (00274735) (SAMA). 20 $\mathrm{km} \mathrm{W}$ of Nepabunna, Mt. Serle, $30.55365^{\circ} \mathrm{S}$ 138.8304 ${ }^{\circ} \mathrm{E}, 630 \mathrm{~m}, 07$ Nov 1998, Schuh, Cassis, Silveira, Acacia victoriae Benth. (Fabaceae), det. Royal Bot. Gard. NSW 427617, 1 đ (00110752) (AM), 1 ㅇ (00414716) (AMNH). $51 \mathrm{~km} \mathrm{NW}$ of Morgan, $33.58334^{\circ} \mathrm{S} 140^{\circ} \mathrm{E}, 150 \mathrm{~m}, 01$ Nov 1995 , Schuh, Cassis, and Gross, 10 (00110753) (AM). $139.2 \mathrm{~km}$ SE of William Creek, Finnis Springs (63 km NW of Maree), $29.60001^{\circ} \mathrm{S} 137.4175^{\circ} \mathrm{E}$, $21 \mathrm{~m}, 07$ Nov 2001, Cassis, Schuh, and Schwartz, 5 đ (00274736, 00274737, 00274739-00274741), 5 우 (00274743-00274747), 1 추 (00274691), 1 우 (00274692) (AM), 1 † (00274742), 1 ㅇ (00274748) (UNSW). Everard Park, $26.9966^{\circ} \mathrm{S}$ $132.69586^{\circ} \mathrm{E}, 516 \mathrm{~m}, 30$ Oct 1970, E. G. Matthews, $10^{\circ}$ (00169270) (SAMA). Great Vic. Desert, $21 \mathrm{~km} \mathrm{~W}$ of Vokes Hill, $28.56667^{\circ} \mathrm{S}$ $130.46667^{\circ} \mathrm{E}, 22$ Aug 1980, J. Forrest and G. Baker, 1 ㅇ (00169101) (SAMA). Koonamore Stn., $32.06355^{\circ} \mathrm{S} 139.38365^{\circ} \mathrm{E}, 03$ Apr 1979, J. A. For- 
rest, $10^{\star}$ (00169092) (SAMA). Lewiston Reserve, nr. Two Wells, $34.58372^{\circ} \mathrm{S} 138.5769^{\circ} \mathrm{E}, 04$ May 1967, N. McFarland, Callitris preissii Miq. (Cupressaceae), 1 (00169104) (SAMA). Marryat Creek, $48 \mathrm{~km} \mathrm{~S}$ of Cavenagh Downs, $26.318^{\circ} \mathrm{S} 133.095^{\circ} \mathrm{E}, 28$ Oct 1963 , P. Aitken and N. B. Tindale, 3 ㅇ (00169098-00169100) (SAMA). S of Connor Well, $22.57^{\circ} \mathrm{S} 133.32^{\circ} \mathrm{E}, 05$ Apr 1981, M. Malipatil and J. Hawkins, Melaleuca sp. (Myrtaceae), 1 (00178083) (WAMP). Warradale, $35.00451^{\circ} \mathrm{S} 138.5385^{\circ} \mathrm{E}, 18 \mathrm{~m}$, Feb 1974, P. B. McQuillan, 1 đo (00169067) (SAMA). near Victory Well, Everard Pk. Stn, 27.054 ${ }^{\circ} \mathrm{S}$ $132.506^{\circ} \mathrm{E}, 03$ Nov 1970, G. Gross, $30^{\Uparrow}$ (00169102, 00169268, 00169269), $1+$ (00169103) (SAMA). nr Muloorina HS, $29.23896^{\circ} \mathrm{S} 137.90103^{\circ} \mathrm{E}, 6 \mathrm{~m}$, 10 Mar 1965, A. N. McFarland, $10^{\dagger}$ (00169093) (SAMA). Victoria: Wyperfeld National Park, Moonah Track, $35.46302^{\circ} \mathrm{S} 142.0464^{\circ} \mathrm{E}, 65 \mathrm{~m}, 04$ Nov 2002, Cassis, Schuh, Schwartz, Silveira, Acacia brachybotrya Benth. (Fabaceae), det. NSW staff NSW 658103, 1 ơ (00414714) (AMNH). Western Australia: Pilbara Co.: $83 \mathrm{~km} \mathrm{~W}$ of Tom Price on Nanutarra Rd, $22.97922^{\circ} \mathrm{S}$ 117.23177º 360 m, 28 Aug 2005, G. Cassis, S. Lassau, S. and G. Carter, Acacia aneura F.Muell. ex Benth. var. pilbarana (Fabaceae), det. Perth staff PERTH 7273320, 2 9 (00110759, 00110760) (AM). $175 \mathrm{~km} \mathrm{~W}$ of Tom Price on Nanutarra Rd, $22.72841^{\circ} \mathrm{S} 116.435^{\circ} \mathrm{E}, 224 \mathrm{~m}, 28$ Aug 2005, G. Cassis, S. Lassau, S. and G. Carter, Senna artemisioides (Gaudich. ex DC.) Randell subsp. oligophylla (Fabaceae), det. Perth staff PERTH

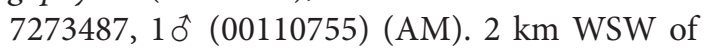
Muggan RH, $156 \mathrm{~km} \mathrm{SW}$ of Warburton, $27^{\circ} \mathrm{S}$ $125.31667^{\circ} \mathrm{E}, 13$ Sep 1982 - 14 Sep 1982, B. Hanich and T. F. Houston, $10^{\text {t }}$ (00178075) (WAMP). $4.5 \mathrm{~km}$ NW of jct of Blowholes Rd and North West Coastal Hiway, N of Carnarvon, $24.72267^{\circ} \mathrm{S} 113.7158^{\circ} \mathrm{E}, 28 \mathrm{~m}, 27$ Oct 2004 , Cassis, Wall, Weirauch, Tatarnic, Symonds, $10^{\widehat{T}}$ (00128694), 1 ㅇ (00128695) (AMNH). $7 \mathrm{~km} \mathrm{~N}$ of Billiluna, $19.51083^{\circ} \mathrm{S} 127.66306^{\circ} \mathrm{E}, 05$ May 1998 , J.D. Oswald, 2 ㅇ (00370682, 00370683) (TAMU). $16 \mathrm{mi} \mathrm{SE}$ by $\mathrm{S}$ of Carnarvon, $25.05247^{\circ} \mathrm{S}$ $113.79981^{\circ} \mathrm{E}, 11 \mathrm{~m}, 16$ Oct 1970 , D. H. Colless,
3 수 (00168871-00168873), 1 우 (00168874) (ANIC). $24 \mathrm{~km} \mathrm{SE} \mathrm{of} \mathrm{jct} \mathrm{of} \mathrm{Manga} \mathrm{Rd} \mathrm{and} \mathrm{Shark}$ Bay Rd, Shark Bay World Heritage Area, $26.39014^{\circ} \mathrm{S} 114.0094^{\circ} \mathrm{E}, 60 \mathrm{~m}, 26$ Oct 2004, Cassis, Wall, Weirauch, Symonds, Acacia tetragonophylla F. Muell. (Fabaceae), det. PERTH staff PERTH 6989802, 1 đ (00128696), 1 ㅇ (00128697) (AMNH). 32 km SE of Paynes Find toward BeaCon, $29.48558^{\circ} \mathrm{S} 117.7836^{\circ} \mathrm{E}, 250 \mathrm{~m}, 12 \mathrm{Dec} 1997$, Schuh, Brailovsky, Grevillea nematophylla F. Muell. (Proteaceae), det. PERTH staff PERTH 05879108, 16 đ (00272183-00272197, 00272203),

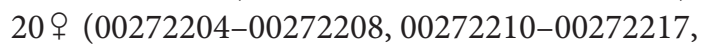
00272219, 00272221, 00272223, 00272225, 00272227-00272229) (AMNH), 1 ○ (00272201), 1 우 (00272224) (CNC) 1 đ (00272199), 1 ㅇ (00272222) (UCR), 1 ๙ิ (00272200), 1 우 (00272220) (USNM), 1 के (00272202), 1 ㅇ (00272226) (WAMP), 1 के (00272198), 1 ㅇ (00272218) (ZISP). $41 \mathrm{~km} \mathrm{E} \mathrm{of} \mathrm{Perenjori,}$ $29.54146^{\circ} \mathrm{S} 116.7039^{\circ} \mathrm{E}, 155 \mathrm{~m}, 11 \mathrm{Dec} 1997$, Schuh, Brailovsky, Dodonaea viscosa Jacq. subsp. angustissima (Sapindaceae), det. PERTH staff PERTH 05879124, 60 (00272230-00272235), 5 우 (00272237-00272241) (AMNH). Billy Well Creek, $20 \mathrm{~km} \mathrm{NE}$ of Mt Sandiman HS, $24.28306^{\circ} \mathrm{S}$ $115.5024^{\circ} \mathrm{E}, 231 \mathrm{~m}, 11$ May 1981 - 13 May 1981, B. Hanich and T. F. Houston, $2 \overbrace{}^{\star}$ (00178076, 00178077), 1 우 (00178078) (WAMP). Boorabbin Rock, $31.2^{\circ} \mathrm{S} 120.28333^{\circ} \mathrm{E}, 20$ Jan 1982 - 21 Jan 1982, B. Hanich and T. F. Houston, Thryptomene tuberculata E. Pritz. (Myrtaceae), 19 (00178081) (WAMP). Bungabiddy Rockhole Walter James RA., $24.65^{\circ} \mathrm{S} 128.75^{\circ} \mathrm{E}, 15$ Jan 1990 , T. F. Houston and M. S. Harvey, 2 ô (00178079, 00178080) (WAMP). Gill Pinnacle, [Schwerin] Mural Crescent, $24.88387^{\circ} \mathrm{S} 128.78239^{\circ} \mathrm{E}, 03$ Nov $1963, \mathrm{P}$. Aitken and N. B. Tindale, $20^{\text {( }}$ (00169105, 00169106) (SAMA); 05 Nov 1963, P. Aitken and N. B. Tindale, 1 đิ (00169107) (SAMA); $10 \mathrm{Nov}$ 1963, P. Aitken and N. B. Tindale, 1 (00178084) (WAMP). Koonong Pool Ashburton R, 11 km E of Ashburton Downs HS, $23.43825^{\circ} \mathrm{S}$ $117.16157^{\circ} \mathrm{E}, 247 \mathrm{~m}$, Dec 1982, H. Esler, 1 ㅇ (00178082) (WAMP). North West Coastal Hiway $45.8 \mathrm{~km}$ NE of jct with Blowholes Rd, $24.40709^{\circ} \mathrm{S}$ 


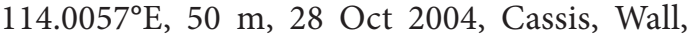
Weirauch, Tatarnic, Symonds, Acacia ramulosa W. Fitzg. var. linophylla (Fabaceae), det. PERTH staff PERTH 6987672, 1 (00196021) Senna artemisioides (Gaudich. ex DC.) Randell subsp. helmsii (Fabaceae), det. PERTH staff PERTH6987532, 10 (00196020) (AMNH).

Additional Specimens Examined: AUSTRALIA: Queensland: $4 \mathrm{~km}$ E of Camooweal, $19.56^{\circ} \mathrm{S} 138.09^{\circ} \mathrm{E}, 12$ May 1973 , M. S. Upton, $1 q$ (00168877) (ANIC). Western Australia: $41 \mathrm{~km}$ E of Perenjori, $29.54146^{\circ} \mathrm{S} 116.7039^{\circ} \mathrm{E}$, 155 m, 11 Dec 1997, Schuh, Brailovsky, Dodonaea viscosa Jacq. subsp. angustissima (Sapindaceae), det. PERTH staff PERTH 05879124, 1 nymph (00272236) (AMNH). Pilbara region, $23 \mathrm{~km}$ along Weano Gorge Rd from Karijini Drive turnoff, $22.424^{\circ} \mathrm{S} 118.23366^{\circ} \mathrm{E}, 29$ May 2004, M. Bulbert, N. Tatarnic and D. Britton, Acacia sp. (Fabaceae), 1 adult unknown sex (00090958) (AM).

\section{Xiphoidellus Weirauch and Schuh}

Xiphoidellus Weirauch and Schuh, 2011: 484 (new genus).

Discussion: Description of the following new species and new host and locality data increase knowledge of morphological diversity in Xiphoidellus and expands the known distribution of the genus.

\section{Xiphoidellus dumosus Weirauch and Schuh}

Xiphoidellus dumosus Weirauch and Schuh, 2011: 490 (new species).

Discussion: We have examined specimens of Xiphoidellus dumosus from a collecting event not included in the original description (Weirauch and Schuh, 2011). The range of this species, taken on a known host plant, is extended approximately $500 \mathrm{~km}$ further east to near Cape Arid National Park, close to the easternmost record of X. furvus Weirauch and Schuh, 2011. The majority of $X$. dumosus specimens, or $94 \%$ were taken on myrtaceous host plants in the tribe Leptospermeae; this host-plant specialization was not highlighted in the original description of Xiphoidellus due to the greater diversity of plant-family utilization of congeners. The new specimen and locality information are: AUSTRALIA: Western Australia: $7.5 \mathrm{~km}$ E of Balladonia Road on Fisheries Road, $33.74644^{\circ} \mathrm{S} 123.1687^{\circ} \mathrm{E}, 120 \mathrm{~m}, 25$ Nov 1999 , R.T. Schuh, G. Cassis, and R. Silveira, ex Taxandria parviceps (Schauer) J.R. Wheeler and N.G. Marchant (as Agonis) (Myrtaceae: Leptospermeae), det. PERTH staff PERTH 05095301, 3 ô (0039083400390836), 4 우 (00390830-00390833), 2 nymphs (00390828, 00390829) (AM).

\section{Xiphoidellus eucalyptae, new species}

Figure 20, map 5, plates 5, 33, table 1

Diagnosis: Distinguished from all congeners by short anteocular portion of head, large eyes in male, somewhat dull, slightly rugose head and pronotum (fig. 20), coloration pattern of dark castaneous head, pronotum, base and distal portion of hemelytron, most of cuneus, and metafemora contrasting with pale proximal portion of clavus, apex of embolium margin, base of cuneus, and remainder of appendages, as well as conspicuous orange-red mesoscutum and scutellum.

Description: Male: Macropterous, body moderately elongate, parallel sided; mean total length 3.01, mean pronotum width 0.98 . COLORATION (pl. 5): Castaneous brown on head, pronotum, embolium, base and distal one-half of hemelytron, base of coxae and metafemora, except apex, and ventral portion of thorax and abdomen contrasting with pale on middle of clavus, corium along cuneal fracture, base of cuneus, and reminder of legs, antennal segment 1 and base of segment 2 variable dusky white to pale brown; mesoscutum and scutellum orange red; tibia without dark spots at bases of pale spines. SURFACE AND VESTITURE (fig. 20, pl. 5): Head and pronotum subshining, faintly rugose, with flattened circular discs (fig. 20B), 

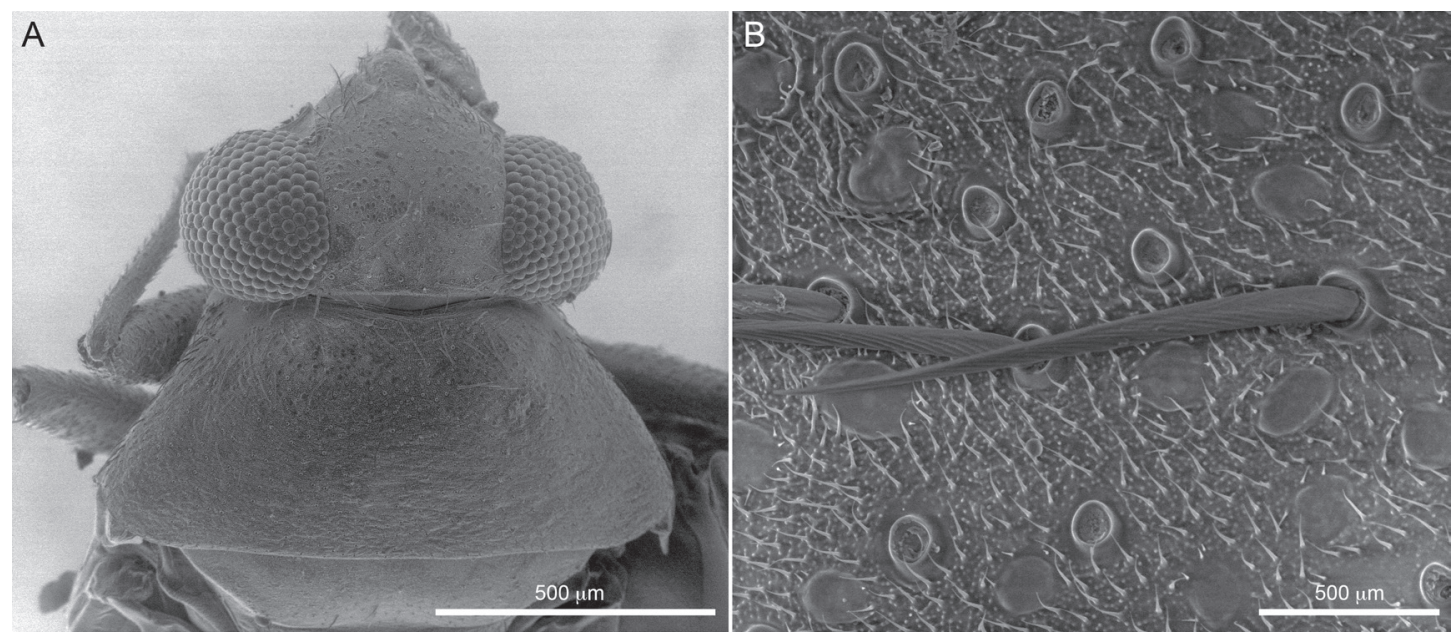

FIG. 20. Xiphoidellus eucalyptae, AMNH_PBI 00274800. Scanning electron micrographs. A. Head and pronotum, dorsal view. B. Detail of pronotal setae and sculpturation, dorsal view.

vestiture of moderately distributed, recumbent silvery and golden, shining simple setae (pl. 5). STRUCTURE: Head (fig. 20A, pl. 5): Short, transverse, removed from anterior margin of pronotum, posterior margins of eyes bowed posteriad; frons in lateral view surpassing anterior margin of eyes by one-half width of eye; eye occupying $95 \%$ height of head; ventral margin of eye extending beyond fossa by $2 \times$ diameter of fossa; eyes large, weakly bulging, deeply emarginate near fossa; interocular space narrow; antennal segment 2 subequal to width of pronotum; labium reaching to base of abdomen. Tho$\operatorname{rax}$ (fig. 20A, pl. 5): Pronotum relatively short, triangular lateral margins straight, calli weakly raised, posterior lobe flat, posterior margin broadly concave; mesoscutum broadly exposed. Pretarsus: Claws small, delicate, short, base of claw somewhat expanded; parempodia narrow fleshy (based on broken structure); pulvilli apparently absent. Hemelytron: Costal margin straight. GENITALIA (pl. 33A-H): Pygophore: Posteroventral surface of pygophore laterally compressed, bowlike, covered with short, pointed spicules (pl. 33H), caudal surface produced posteriad of posterior margin of aperture in lateral view; left side of aperture without patch of bristles. Endosoma: Strongly sigmoid with one com- plete coil, formed by two straps confluent until ventral strap terminates midway between basal bend in endosoma and secondary gonopore; dorsal strap extending beyond secondary gonopore with gradually attenuate, distal portion $4 \times$ length of secondary gonopore, terminating in narrow pointed spine. Secondary gonopore: Well sclerotized; gonopore sclerite emanating from proximal edge, reaching to proximal of bend in endosoma; distal edge with prominent flat, fingerlike protuberance with wide rounded apex projecting caudally. Phallotheca: Elongate, narrow apically, aperture located on ventral surface; basal portion strongly sclerotized on surface adhering pygophore. Parameres: Left paramere: Posterior process approximately $2 \times$ as long as anterior process, base of posterior process without distinct shoulder; region between processes not produced posteriad. Right paramere: Body moderately large with abruptly attenuate, narrow and short apex.

Female (pl. 5): Coloration as in male; differing from male with smaller eyes, antennal segment 2 more slender, and costal margin slightly more distinctly convex; mean total length 3.15, mean pronotum width 1.06. GENITALIA (pl. 33I-K): Posterior margin of sternite 7: With shield-shaped medial projection. Vestibular 
sclerites: Relatively large, coiled tube on right side, in dorsal view reaching to even with lateral corner of right sclerotized ring and just beyond anterior margin of dorsal labiate plate. First gonapophyses: Pair of medial sclerites attached to base of vestibulum. Ventral labiate plate: Paramedial anteroventral extension moderately large, right-side sclerite much larger than leftside sclerite; basomedial right-side extension covering anterior surface of basal structures. Dorsal labiate plate: Moderately large, subrectangular, long and with undulating lateral margin. Sclerotized rings: Large, subovoid, separated by width of a ring, relatively thick walled; lateral margin of ring with narrow piece reaching lateral margin of dorsal labiate plate. Posteromedial region: Undivided, sunken, medial microspiculate membrane, located anteroventrad of lateral oviducts and spermathecal gland. Anterolateral region: Portion anterior to rings with small patch of microspicules. Intersegmental membrane: Membranous fold. Posterior wall: Simple, entire, mostly sclerotized, anterior surface barely produced into genital chamber. Interramal sclerites: Sclerite spanning interramal region as broad dorsoposterior sclerotized transverse band, ventrolaterally with pair of strongly sclerotized narrowed plates, ventromedially membranous. Interramal lobes: Entire posterodorsal portion of posterior wall weakly microspiculate on anterior surface.

EтумоLOGY: Named for its occurrence on the genus Eucalyptus, which by botanical tradition is considered feminine.

Host: Recorded from Eucalyptus camaldulensis (Myrtaceae: Eucalypteae).

Distribution (map 5, table 4): Known only from the type locality-Cadelga Homesteadin northeastern South Australia, located in the middle of the eastern desert phytogeographic subregion.

Discussion: We place our new species in Xiphoidellus aware that not all features listed in the diagnosis of the genus (Weirauch and Schuh, 2011) are present in X. eucalyptae. Conforming to the diagnosis are: tibial spines without dark spots at bases, vestiture consisting of simple setae only, ventral (i.e., secondary) strap of endosoma reaching midway to secondary gonopore from major bend in endosoma, secondary gonopore with proximal sclerite, aperture seen laterally, fingerlike protuberance at distal margin, female with posterior margin of posterior wall reflexed dorsally, and right vestibular sclerite larger and more strongly elongated than left sclerite. Features of $X$. eucalyptae that differ from the diagnosis are: posterior process of left paramere about $2 \times$ as long as anterior process (not slightly longer), right paramere with short nonserrate apical process rather than long and serrate as in other species. The large eyes and relatively narrow vertex, head and pronotum with woolly surface texture and patterned dorsal coloration of the male are currently apomorphic for the genus. Xiphoidellus eucalyptae is the second species of the genus known from South Australia and the first collected in the interior of Australia (table 4).

Almost all collection records for $X$. dumosus (Weirauch and Schuh, 2011) indicate that this species predominately utilizes myrtaceous plant hosts in the tribe Leptospermeae (Taxandria spp. and Kunzea sp.). Two other Xiphoidellus spp. (X. aureus, $X$. unicolor) found on a wide variety of host-plant families, were also taken in small numbers on genera of Chamelaucieae and Melaleuceae. Based on the few known collection records, perhaps $X$. eucalyptae is the sole member of Xiphoidellus to utilize Eucalypteae.

Holotype: AUSTRALIA: South Australia: Cadelga Homestead, $26.08949^{\circ} \mathrm{S} 140.4106^{\circ} \mathrm{E}, 150$ m, 04 Nov 1998, Schuh, Cassis, Silveira, MV light, 10 (AMNH_PBI 00087348) (SAMA).

Paratypes: AUSTRALIA: South Australia: Cadelga Homestead, $26.08949^{\circ} \mathrm{S} 140.4106^{\circ} \mathrm{E}, 150$ m, 04 Nov 1998, Schuh, Cassis, Silveira, Eucalyptus camaldulensis Dehnh. (Myrtaceae), det. Royal

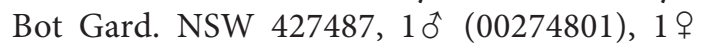
(00274798) (AM), $1 \delta^{\star} \quad(00274803), 1+$ (00274800) (AMNH), 10 (00274802), 1 ㅇ (00274799) (SAMA), MV light, 19 (00390320) (AM), 19 (00371751) (AMNH), $3 q$ (00390318, 00390319, 00087349) (SAMA). 


\section{Xiphoides Eyles and Schuh}

Xiphoides Eyles and Schuh, 2003: 305 (new genus).

Discussion: Previous to our research the species of Xiphoides were restricted to New Zealand. Character documentation for the following two new species augments the generic diagnosis of Xiphoides and expands the known distribution. Both new species have morphology that allows them to be placed in Xiphoides, including: the ovoid body with male slightly more elongate than female; pale tibial spines; vestiture of mixed white scalelike and black simple setae; coiled endosoma with two narrow confluent straps; very large vestibulum strongly extending to right side of bursa copulatrix; posterior wall without extensive structure, but microspicules present on posterolateral margin. On the other hand, their morphology varies modestly from the New Zealand species and therefore alters the diagnosis of the genus as prepared by Eyles and Schuh (2003). Notably, the apical portion of the right paramere is moderately long, but the posterior surface lacks serration; the phallotheca is elongate and narrow, but the anterior surface lacks a narrow spine; and the endosoma lacks spines on the dorsal strap basad of secondary gonopore. Likewise, neither species runs to completion in the key of Eyles and Schuh (2003).

The recognition of Xiphoides from Australia, more particularly Tasmania and South Australia (table 4), fills a geographic gap that bolsters the argument for transantarctic connections in the Phylinae as made by Weirauch and Schuh (2011), in this case completing the connection between New Zealand and Australia in the genus Xiphoides.

\section{Xiphoides anangu, new species}

\section{Map 5, plates 5, 34, table 1}

DiAgnosis: Recognized by the moderately large ovoid body, subshining dorsum, somewhat drab coloration, mixed, dense, white scalelike setae and black simple setae, coiled endosoma with two obvious straps, and needlelike ventral strap conspicuously separated from dorsal strap at midpoint of endosoma. Overall appearance very similar to that of Hypseloecus spp. (Pilophorini).

Description: Male: Macropterous, body ovoid; mean total length 3.83 , mean pronotum width 1.51. COLORATION (pl. 5): Dull yellowish gray brown with large areas of darker grayish mahogany brown on head, pronotum, scutellum, endocorium, apices of embolium and cuneus, and venter; hemelytral membrane fumose with sparse dark gray speckles; antennal segment 1 dark mahogany brown, remainder of antenna gray brown; maxillary plate and metepisternal scent gland auricle reddish brown; apices of femora (with increasing intensity from pro- to metafemora) with dark spots or blotches; tibiae pale with dark brown spots at bases of pale spines. SURFACE AND VESTITURE (pl. 5): Subshining; vestiture a mixture of dense appressed, apically truncate, white scalelike and reclining black simple setae; scalelike setae also present on ventral aspect of thorax pleuron and abdomen. STRUCTURE: Head (pl. 5): Short, transverse, conforming to anterior margin of pronotum; in lateral view frons surpassing anterior margin of eyes by approximately width of eye, eyes occupying nearly entire height of head; antennal fossa even with ventral margin of eye; eyes large, deeply emarginate near fossa; antennal segment $287 \%$ of pronotum width; labium reaching to base of metacoxa. Thorax (pl. 5): Pronotum shield shaped, lateral margins curved, calli confluent, weakly raised, posterior lobe flat, posterior margin straight; mesoscutum moderately exposed, scutellum transversely winkled. Pretarsus: Claw medium sized, curved; parempodia long, straight, setiform; pulvilli apparently absent. Hemelytron: Costal margin slightly convex. GENITALIA (pl. 34A-N): Pygophore: Large, broadly conical, posterior surface somewhat broad and slightly compressed laterally; large field of bristles lateral of left paramere insertion; posterior edge of aperture with flanged 
margin. Endosoma: Sigmoid, coiled, consisting of two straps, dorsal strap larger and reaching apex of endosoma as pointed spine; ventral strap separated from dorsal strap at distal end of first curve of coil, continuing distally as very narrow sclerite until end of second coil, separated from dorsal strap by membrane, then bifurcate proximal of secondary gonopore, one spine terminating at secondary gonopore other side rejoining apex of dorsal strap at apex of endosoma; dorsal strap without spines basad of secondary gonopore. Secondary gonopore: Well formed, ovoid, subapical, placed approximately $4 \times$ length of secondary gonopore from apex of endosoma. Phallotheca: Long, extending beyond pygophore aperture one-half length of apical portion, evenly narrow with rounded apex; surface without flanges; aperture long, narrow, situated on ventral margin; basal portion with long strut on entire right side and strongly sclerotized posterior plate. Parameres: Left paramere: Elongate, posterior process of moderate length, straight; anterior process elongate triangular in lateral view, horn shaped in dorsal view, well sclerotized, with spine about one-half length of process; orientation of spine either directed caudad (pl. 34G, I) or dorsad (pl. 34H, J). Right paramere: Elongate, lanceolate, as long as left paramere, smooth distally with long narrow apical spine; middle of paramere concave, sometimes apical one-quarter slightly curved away from body of paramere in dorsal view (pl. 34L).

Female (pl. 5): Coloration as in male; differing from male by smaller eyes, antennal segment 2 more slender, costal margin more strongly convex; mean total length 3.71 , mean pronotum width 1.63. GENITALIA (pl. 34O-R): Posterior margin of sternite 7: With a short, broadly triangular medial projection. Vestibular sclerites: Very large, fan shaped anteriorly, then as coiled tube posteriad; in dorsal view-sclerite reaching beyond right side of dorsal labiate plate by width of sclerotized ring; reaching to medial side of left sclerotized ring; anteriormost portion extending anteriad of dorsal labiate plate by length of plate. First gonapophyses: Pair of relatively large irregu- larly quadrate medial sclerites attached to vestibulum. Ventral labiate plate: Paramedial anteroventral extension moderately large, right-side sclerite larger than left-side sclerite; basomedial right-side extension sclerotized, covering anterior surface of basal structures; ventral surface sclerotized. Dorsal labiate plate: Large, shield shaped, lateral margin short, convex. Sclerotized rings: Moderately large ovoid, lateral angle rounded, medial margin with dorsally directed edge; rings separated by width of a ring, thick walled; lateral margin of ring almost reaching lateral margin of dorsal labiate plate. Posteromedial region: Undivided, sunken, medial sclerotized plate, located ventrad of lateral oviducts and spermathecal gland. Anterolateral region: Strongly microspiculate anterior to rings. Intersegmental structure: Thin, membranous, not extending to margins of posterior wall. Posterior wall: Relatively simple, not divided on midline or projecting anteriad into genital chamber. Interramal sclerites: Sclerotized, spanning interramal space with wide dorsoposterior sclerotized band and confluent on ventrolateral region with pair of wide sclerotized plates; ventromedially membranous. Interramal lobes: Dorsoposterior edge with pair of wide lateral microspiculate fields.

Eтүмоlogy: Named for the Pitjantjatjara, an indigenous people of the Central Australian desert, who refer to themselves as Anangu.

Host: Unknown.

Distribution (map 5): Known from two collecting events in the central Australian desert of northwest South Australia and one locality 340 $\mathrm{km}$ northwest in Western Australia placed in the western desert and eastern desert phytogeographic subregions, respectively.

Discussion: Currently only $X$. anangu is known to have a small variable spine on the left paramere dorsad of the anterior process ( $\mathrm{pl}$. $34 \mathrm{G}-\mathrm{J})$. This is the first species of the genus recorded from central Australia; its host plant remains to be discovered.

HоLотуре: AUSTRALIA: Western Australia: Gill Pinnacle, [Schwerin] Mural Crescent, $24.88387^{\circ} \mathrm{S}$ $128.78239^{\circ} \mathrm{E}, 07$ Nov 1963, P. Aitken and N. B. Tindale, 10 (AMNH_PBI 00110767) (SAMA). 

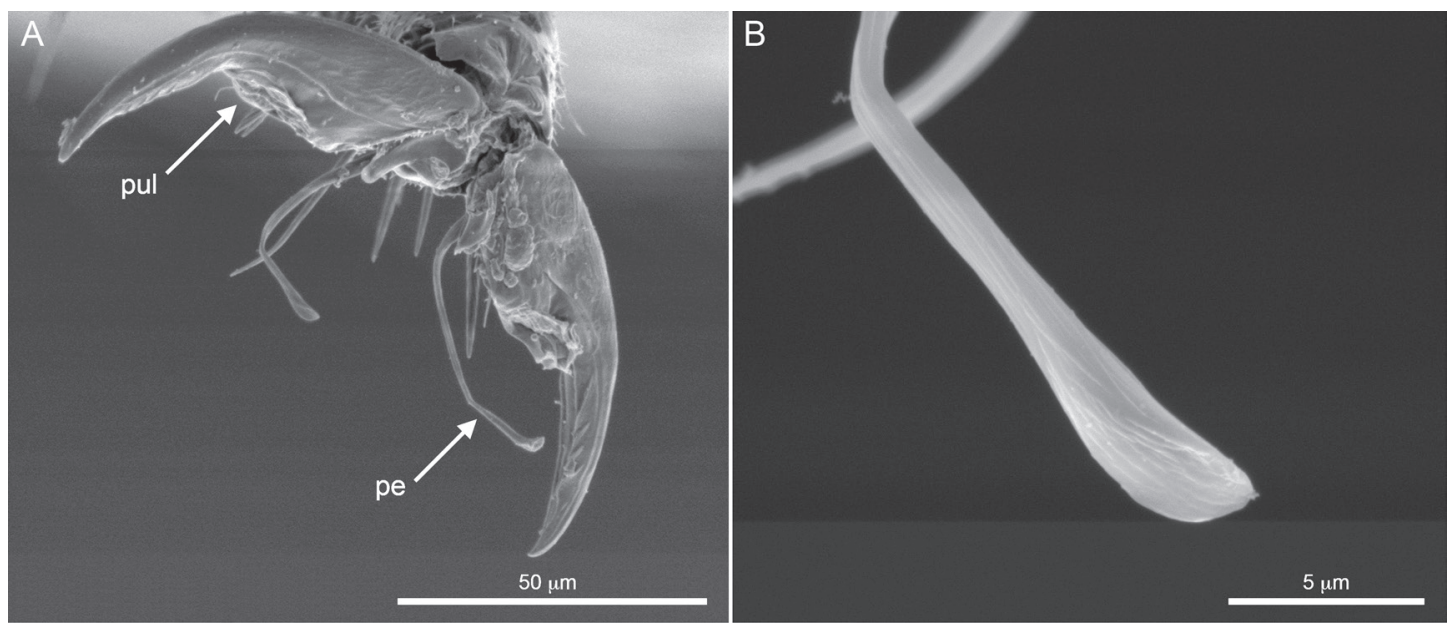

FIG. 21. Xiphoides tasmanensis, AMNH_PBI 00414858. Scanning electron micrographs. A. Pretarsus, frontal view. B. Detail of parempodia, dorsal view. Abbreviations: pe, parempodium; pul, pulvillus.

Paratypes: AUSTRALIA: South Australia: Musgrave Ra. NG01 10 km NNE of Mt Woodroffe, $26.24861^{\circ} \mathrm{S} 131.79333^{\circ} \mathrm{E}, 13$ Oct 1994 , Pitjantjatjara Lands Survey, 2 ㅇ (00110768, 00110769) (SAMA). Musgrave Ra. NG03, 7 km $\mathrm{NE}$ of Mt Woodroffe, $26.27833^{\circ} \mathrm{S} 131.79555^{\circ} \mathrm{E}$, 15 Oct 1994, Pitjantjatjara Lands Survey, $10^{\star}$ (00110766) (SAMA).

Xiphoides tasmanensis, new species

Figure 21, map 5, plates 5, 35, table 1

Diagnosis: Recognized by the small, ovoid, completely shining black body with dusky pale color on apex of scutellum, antennal segment 1 , most of segment 2, and apex of femora; pale tibial spines with diffuse, darkened basal marking; relatively sparse, long, shining, golden simple dorsal vestiture; and male genitalia with thin endosoma, absence of anterior spine on phallotheca and right paramere with short apical process. Similar in appearance to dark-colored Xiphoidellus spp.

Description: Male: Macropterous, subovoid; mean total length 2.74 , mean pronotum width 1.01. COLORATION (pl. 5): Uniformly black with dusky pale yellow on mandibular and maxillary plates, antennal segment 1 and basal four-fifths of segment 2, apex of scutellum, apex of femora and tibia; bases of pale tibial spines diffusely dark. SURFACE AND VESTITURE (pl. 5): Shining; vestiture of relatively sparse, long, suberect, shining golden simple setae. STRUCTURE: Head (pl. 5): Short, transverse, confluent with anterior margin of pronotum; in lateral view frons surpassing anterior margin of eyes by one-half width of eye, eyes occupying $84 \%$ height of head; antennal fossa even with ventral margin of eye, shallowly emarginate near at fossa; antennal segment 2 $62 \%$ of pronotum width; labium reaching to apex of metacoxa. Thorax (pl. 5): Pronotum relatively short, subquadrate, lateral margins curved, calli confluent, weakly raised, posterior lobe flat, posterior margin straight; mesoscutum moderately exposed. Pretarsus: Claw relatively large, slightly curved; parempodia somewhat lamelliform, rather long, curved, apices flattened, paddlelike; pulvilli short, moderately wide, proximad of angle of claw (figs. 21A, B). Hemelytron: Costal margin slightly convex. GENitAliA (pl. 35A-G): Pygophore: Small, broadly conical; left side of aperture without clump of bristles or tubercle; caudal surface with approximately eight transverse ridges. 
Endosoma: Sigmoid, consisting of two straps, ventral strap terminating approximately in middle of endosoma, dorsal strap continuing to terminate as thin spine with thin apex and smooth membrane on ventral surface; dorsal strap without spines basad of secondary gonopore. Secondary gonopore: Very faint, subapical, situated within distal membrane about the $5 \times$ length of secondary gonopore from apex of dorsal sclerotized strap. Phallotheca: Narrow, gently tapered to pointed apex; surface without flanges; small ovate aperture located terminally. Parameres: Left paramere: Short anterior process and narrow posterior process, body of paramere smoothly rounded in dorsal view, posterior shoulder not projecting. Right paramere: Relatively elongate, posterior margin gently rounded, small beveled apex with serrate edge.

Female (pl. 5): Coloration as in male; body more strongly ovoid than in male, smaller eyes, antennal segment 2 more slender; mean total length 2.84, mean pronotum width 1.07. GENITALIA (pl. 35H-K): Posterior margin of sternite 7: With elongate triangular medial projection. Vestibular sclerites: Moderately large, coiled tube on right side, in dorsal view reaching to even with medial corner of right sclerotized ring and even with anterior margin of dorsal labiate plate. First gonapophyses: Vestibulum attached ventrally to pair of small triangular medial sclerites at base of first gonapophyses. Ventral labiate plate: Paramedial anteroventral extension moderately large, right-side sclerite larger than left; basomedial right-side extension weakly sclerotized but covering anterior surface of basal structures; surface of ventral labiate plate ventral to sclerotized rings microspiculate. Dorsal labiate plate: Moderately large, shield shaped, short lateral to ring, lateral margin convex. Sclerotized rings: Moderately large, separated by width of a ring, teardrop shaped, lateral angle attenuate, thick walled; lateral margin of ring not reaching lateral margin of dorsal labiate plate. Posteromedial region: Undivided, sunken, medial microspiculate membrane located anteroventrad of lateral oviducts and spermathecal gland. Anterolateral region: Region anterior of rings without microspicules. Posterior wall: Simple, entire, membranous. Intersegmental membrane: Narrow, weakly spiculate, small transverse fringe adjacent to dorsoposterior margin of interramal sclerite. Interramal sclerites: Membranous spanning interramal region, ventrolaterally with pair of very weakly sclerotized narrowed plates; anterior surface barely produced into genital chamber. Interramal lobes: Absent.

EтyмоLogy: Named for its occurrence in the Australian state of Tasmania.

Hosts (tables 2, 3): Recorded from Leptospermum rupestre, L. scoparium (pl. 38H, I) (Myrtaceae: Leptospermeae), and Arthrotaxis cupressoides (Taxodiacae). The presence of X. tasmanensis on the last plant species is presumed to be a sitting record as the likely host, L. lanigerum (Aiton) Sm., occurred at the same locality.

Distribution (map 5, table 4): Known from Mount Wellington Park west of Hobart and Cradle Mountain, Lake Saint Clair National Park, Tasmania, in temperate forest of the Tasmanian phytogeographic subregion.

Discussion: Xiphoides tasmanensis is the first species of the genus recorded from the island state of Tasmania. Of the six original species assigned to Xiphoides only $X$. regis Eyles and Schuh, 2003, was taken on Myrtaceae; its host, Kunzea ericoides Thompson, J., also belongs to the Leptospermeae.

Holotype: AUSTRALIA: Tasmania: $4.1 \mathrm{~km}$ $\mathrm{N}$ of Huon Hwy and Pilliger Ave intersection, Mt. Wellington, The Springs, $42.91707^{\circ} \mathrm{S}$ 147.25546 E, $684 \mathrm{~m}, 15$ Jan 2004, M.D. Schwartz and P.P. Tinerella, Leptospermum scoparium J.R. Forst. \& G. Forst. (Myrtaceae), det. NSW staff NSW 658210, 1 đ (AMNH_PBI 00414867) (TMAG).

Paratypes: AUSTRAliA: Tasmania: 4.1 $\mathrm{km} \mathrm{N}$ of Huon Hwy and Pilliger Ave intersection, Mt. Wellington, The Springs, $42.91707^{\circ} \mathrm{S}$ $147.25546^{\circ} \mathrm{E}, 684 \mathrm{~m}, 15 \mathrm{Jan} 2004$, M.D. Schwartz and P.P. Tinerella, Leptospermum scoparium J.R. Forst. \& G. Forst. (Myrtaceae), det. NSW staff NSW 658210, 4 ㅇ (00414842, 00414843, 00414863, 00414865), 1 † (00414866) (AM), 
4 우 (00414853-00414856), 2 주 (00414857, 00414858) (AMNH), 2 ㅇ (00414841, 00414864), 1 đo (00414868) (TMAG). Cradle Mountain Lake Saint Clair National Park, Visitor Centre, Cradle Mountain, $41.59618^{\circ} \mathrm{S} 145.9308^{\circ} \mathrm{E}, 823$ m, 25 Jan 2004, M.D. Schwartz and P.P. Tinerella, Leptospermum rupestre Hook. f. (Myrtaceae), det. NSW staff NSW 658260, 10 (00414848), 1 ㅇ (00414862) (AMNH). Cradle Mountain - Lake St Clair Nat Park, Ronny Creek carpark and Little Kate House vicinity, $41.63579^{\circ} \mathrm{S} 145.94963^{\circ} \mathrm{E}, 868 \mathrm{~m}, 26$ Jan 2004 , M.D. Schwartz and P.P. Tinerella, Athrotaxis cupressoides D. Don (Taxodiaceae), det. NSW staff NSW 658261, 2 o (00414844, 00414846), 5 우 (00414849-00414852, 00414859) (AM), 2 중 (00414845, 00414847), 2 ㅇ (00414860, 00414861) (AMNH).

\section{Subtribe Semiina}

Discussion: Leon and Weirauch (2016) placed their newly recognized genus Restiophylus in the Semiina, primarily on the basis of male genitalic structure. We concur with that placement and expand the known distribution of the Semiina within Australia to also include the east coast of the continent (see map 6, table 4).

\section{Restiophylus orientalis, new species}

Map 5, plates 5, 36, table 1

Diagnosis: Similar to Restiophylus lyginiae Leon and Weirauch, 2016, in mixed vestiture consisting of black simple and silvery sericeous setae, pronotum with one medial and a pair of lateral cream-colored longitudinal lines, and head with elongate anteocular region. Distinguished from $R$. lyginiae by the concolorous pale embolium and exocorium, endosoma without apical process, base of anterior process of left paramere with obvious prominence, and apex of right paramere narrow and relatively long.

Description: MALE: Macropterous, body elongate oval; mean total length 3.97, mean pronotum width 1.03. COLORATION (pl. 5): Reddish brown; head, pronotum, mesoscutum, and scutellum with cream-colored longitudinal median line, pronotum with cream-colored lateral line on each side of midline and on lateral margins; apex of scutellum white; hemelytron predominately pale with variable-sized patches of reddish brown on clavus medial to claval vein, surrounding cubitus distally, and on cuneus distally; tibia without spots at bases of black spines. SURFACE AND VESTITURE (pl. 5): Shining; dorsum with suberect black simple setae intermixed with shining, subappressed, sericeous setae on head, pronotum, and claval commissure. STRUCTURE: Head (pl. 5): Elongate, projecting anteriorly, triangular in dorsal view, posterior margin adjacent to anterior margin of pronotum; in lateral view frons surpassing anterior margin of eyes by $1.5 \times$ width of eye, eyes occupying $80 \%$ height of head, and antenna fossa with ventral margin slightly dorsal to ventral margin of eye; eyes medium sized, slightly emarginate near fossa; interocular space wide; antennal segment 2 longer than width of pronotum by $8 \%$ of segment length; labium reaching to middle of abdomen. Thorax (pl. 5): Pronotum rectangular, calli weakly raised, posterior lobe flat, anterior margin concave, lateral and posterior margins straight; mesoscutum broadly exposed. Pretarsus: Claws moderately large; parempodia setiform; puvillus large covering entire ventral surface of claw. Hemelytron: Elongate, costal weakly convex. GENITALIA (pl. 36A-G): Pygophore: With a few stout bristles on ventroposterior surface. Endosoma: J-shaped, single strap, with apical process absent. Secondary gonopore: Apical, of relatively slender structure, aperture on ventral surface of endosoma. Phallotheca: Narrow, apical portion relatively short and beaklike, aperture located at apex, base of apical portion with short, flattened pointed flange on right anterior side, basal portion elongate, nearly parallel sided. Parameres: Left paramere: Expanded prominence on base of anterior process; anterior process shorter than posterior process, distal portion of poste- 
rior process bent downward, apex chiseled; distal portion of anterior process moderately produced and bent upward. Right paramere: Moderately elongate apical region relatively short, pointed.

Female: Coloration as in male; differing from male in smaller eyes, antennal segment 2 more slender, costal margin slightly more convex (pl. 5); mean total length 3.98, mean pronotum width 1.11. GENITALIA (pl. $36 \mathrm{H}-\mathrm{K}$ ): Posterior margin of sternite 7: With narrow medial projection. Vestibular sclerites: Relatively small, weakly sclerotized; formed by practically symmetrical medial plates, situated greatly anteriad of anterior margin of dorsal labiate plate in dorsal view. First gonapophyses: Flat plates attached ventrally to pair of small, narrow medial sclerites at base of first gonapophyses. Ventral labiate plate: Weakly sclerotized anteroventral extension short. Dorsal labiate plate: Medium sized, weakly sclerotized, subovoid, shifted greatly posteriad of orientation typical of phylines in dorsal view; short with concave margin laterally. Sclerotized rings: Small, subovoid, elongate, oriented in longitudinal axis of body separated by approximately $2 \times$ length of ring, thick walled; anterior angle with narrow spine reaching anterior margin of dorsal labiate plate. Posteromedial region: Divided, sunken, membranous, apparently without microspiculate, located ventrad of lateral oviducts and spermathecal gland. Anterolateral region: Small, apparently without microspicules. Intersegmental structure: Narrow, without microspicules, present only as a fold. Posterior wall: Strongly oriented in anteriorposterior plane, simple, not divided medially, membranous medially and posteriorly, without anteriorly or posteriorly directed prominence. Interramal sclerites: Pair of strongly sclerotized anterolateral plates occupying majority of interramal space. Interramal lobes: Absent.

Etymology: Named for its occurrence in eastern Australia, in contrast to the other known species of Restiophylus; from the Latin, orientalis, "eastern."
Host: The host labels on all specimens of this taxon indicate they were collected on the genus Leptospermum (Myrtaceae). We strongly question the accuracy of this host association, because the four other members of Restiophylus are well documented as occurring on various genera of Restionaceae; further fieldwork would be required to determine if the species are host specific. Although we have no explanation for the apparent error in labeling, deduction suggests that among the several possibilities, the actual host may well be Leptocarpus tenax (Restionaceae), which is known to occur in the vicinity of the type locality. Although currently unverified, $R$. orientalis, n. sp., may have been collected at the UNSW Smiths Lake field station, south of Hat Head where L. tenax occurs in abundance (G. Cassis, personal commun.). In Western Australia L. tenax is the primary host plant of R. leptocarpi Leon and Weirauch, 2016; $R$. meeboldinae Leon and Weirauch, 2015, was also taken on the same host. Leon and Weirauch (2015), considering the wider distribution of Leptocarpus spp. across southern Australia, posited that specimens of Restiophylus would eventually be collected beyond southwestern Western Australia. Documentation of R. orientalis from New South Wales supports this hypothesis.

Schuh and Schwartz (2016: 176) discussed specimens here placed in Restiophylus under their generic discussion of their new genus Pulvillophylus (Phylinae: Cremnorrhinini: Cremnorrhinina), because of the apparent similarity of appearance to Pulvillophylus angustatus Schuh and Schwartz, 2016. Our eventual dissection of the male genitalia makes clear the fallacy of that comparison and the correct treatment of this taxon as a member of Restiophylus (Schwartz and Schuh, 2016: 4), the description of which was published during the period that the paper by Schuh and Schwartz (2016) was in proof.

Distribution (map 5): Known only from the type locality in Hat Head National Park, east of Kempsey, New South Wales, in the southeastern phytogeographic subregion. 


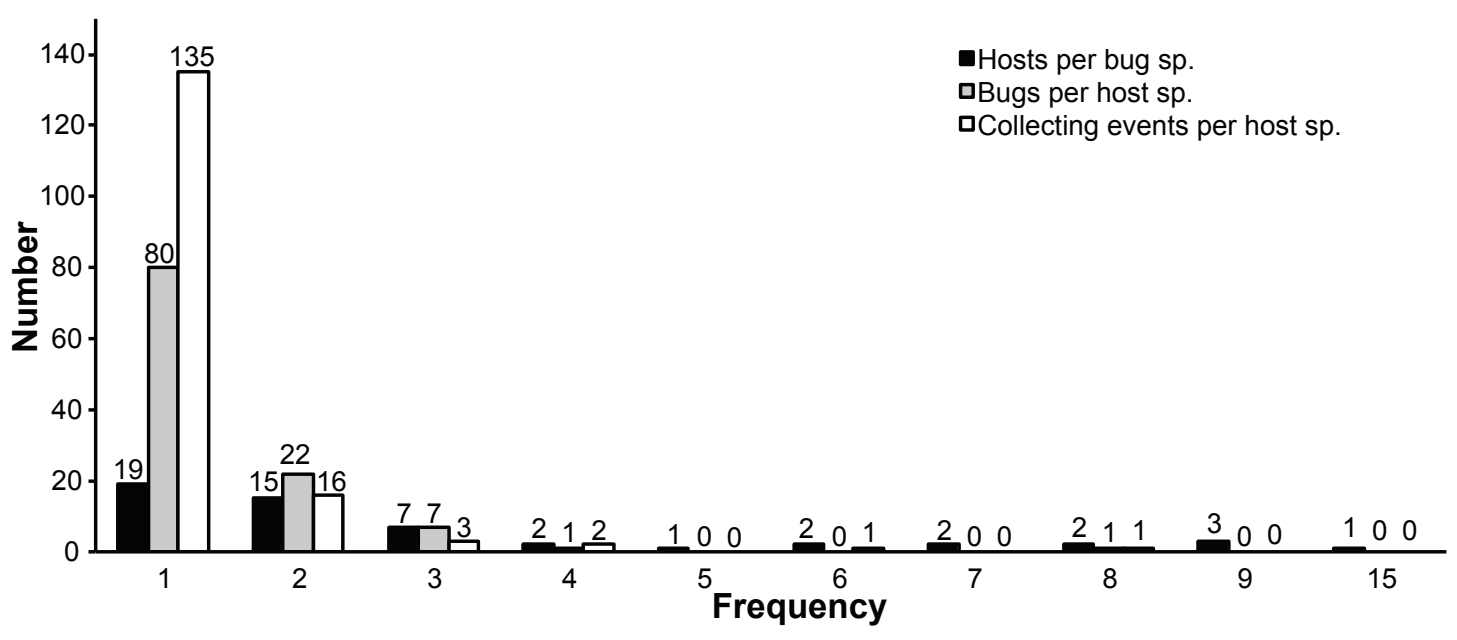

FIG. 22. Frequency of association of all Australian Phylinae with Myrtaceae host plants.

Discussion: Currently $R$. orientalis is the only species of the genus distributed in eastern Australia. The characters of the male genitalia noted in the Diagnosis are not found in congeners.

Holotype: AUSTRALIA: New South Wales: Hat Head National Park near Kempsey, $31.06667^{\circ} \mathrm{S} 153.03333^{\circ} \mathrm{E}, 5 \mathrm{~m}, 22$ Oct 1995 , Schuh and Cassis, Leptospermum sp. (Myrtaceae), det. NSW staff NSW 658210, $10^{\star}$ (AMNH_PBI 00132198) (AM).

Paratypes: AUSTRAliA: New South Wales: Hat Head National Park near Kempsey, $31.06667^{\circ} \mathrm{S} 153.03333^{\circ} \mathrm{E}, 5 \mathrm{~m}, 22$ Oct 1995 , Schuh and Cassis, Leptospermum sp. (Myrtaceae), $10^{\text {Tे }}$ (00132197) Leptospermum sp. (Myrtaceae), det. NSW staff NSW 658210, 10 (00132199), 6 ㅇ (00132206-00132209, 00132212, 00132213) (AM), Leptospermum sp. (Myrtaceae), det. NSW staff NSW 658210, 2 के $(00132200,00132201), 4$ 우 (00132204, 00132205, 00132210, 00132211) Leptospermum sp. (Myrtaceae), 1 đิ (00136149) (AMNH).

Additional Specimens Examined: AUSTRALIA: New South Wales: Hat Head National Park near Kempsey, $31.06667^{\circ} \mathrm{S} 153.03333^{\circ} \mathrm{E}, 5$ m, 22 Oct 1995, Schuh and Cassis, Leptospermum sp. (Myrtaceae), det. NSW staff NSW 658210, 2 nymphs $(00132202,00132203)(A M)$.

\section{DISCUSSION}

Cognizant that our newly emerging knowledge of the Australian plant bug fauna is limited by available collections of specimens and host data, we present a few observations on the utilization of Myrtaceae tribes by suprageneric groups of the Australian Phylinae. In terms of specimens for all myrtaceous-feeding species described herein (see tables 2, 3), the tribal utilization is in the following proportions: Exaeretini-Chamelaucieae 2\%, Eucalypteae $22 \%$, Leptospermeae $4 \%$, Melaleuceae $72 \%$ and Exocarpocorina-Chamelaucieae 11\%, Eucalypteae $1 \%$, Leptospermeae $72 \%$, and Melaleuceae $17 \%$. The tribal breakdown for all myrtaceousfeeding specimens of Australian Exocarpocorina, including the newly described species herein and 30 spp. of Harpagophylus, Melaleucoides, Myrtophylus, Scholtzicoris, Thryptomenomiris, and Xiphoidellus gleaned from the Arthropod Easy Capture database (based on 102 collection events, 3012 specimens, 17 plant genera, 47 host spp.) reports Chamelaucieae 50\%, Eucalypteae 0\%, Leptospermeae 21\%, and Melaleuceae 29\%. It appears that Exaeretini represented by species of Eucalyptophylus and Melaleucaphylus have stronger host associations with the Eucalypteae and Melaleuceae respectively than the species 
TABLE 2

New Plant Bug spp. (except Restiophylus and Teddus) Organized by Host Plant Family and Tribe, with State, Collecting Event and Number of Specimens

\begin{tabular}{|c|c|c|c|c|c|c|}
\hline Plant family & Myrtaceae tribe & Plant species & Insect species & $\begin{array}{l}\text { State or } \\
\text { territory }\end{array}$ & $\begin{array}{l}\text { Insect } \\
\text { coll. } \\
\text { events }\end{array}$ & $\begin{array}{l}\text { Insect } \\
\text { speci- } \\
\text { mens }\end{array}$ \\
\hline \multirow{2}{*}{\multicolumn{2}{|c|}{ CASUARINACEAE }} & $\begin{array}{l}\text { Allocasuarina campestris } \\
\text { (Diels) L.A.S. Johnson }\end{array}$ & Melaleucaphylus omnivorus & WA & 1 & 1 \\
\hline & & $\begin{array}{l}\text { Allocasuarina corniculata } \\
\text { (F. Muell.) L.A.S. Johnson }\end{array}$ & Melaleucaphylus vimineae & WA & 1 & 2 \\
\hline \multicolumn{2}{|l|}{ FABACEAE } & Acacia sp. & Melaleucaphylus nodosae & NSW & 1 & 17 \\
\hline \multirow[t]{23}{*}{ MYRTACEAE } & CHAMELAUCIEAE & Baeckea crispiflora F. Muell. & Melaleucaphylus omnivorus & WA & 1 & 6 \\
\hline & & Baeckea uncinella Benth. & Melaleucaphylus omnivorus & WA & 1 & 4 \\
\hline & & & Melaleucaphylus polyphagus & WA & 1 & 4 \\
\hline & & $\begin{array}{l}\text { Calytrix amethystina Cra- } \\
\text { ven }\end{array}$ & Calytriphylus menzies & WA & 1 & 9 \\
\hline & & Calytrix angulata Lindl. & Calytriphylus menzies & WA & 1 & 7 \\
\hline & & & Leptospermia cassisi & WA & 1 & 41 \\
\hline & & Calytrix glutinosa Lindl. & Melaleucaphylus omnivorus & WA & 1 & 1 \\
\hline & & Calytrix strigosa A. Cunn. & Leptospermia cassisi & WA & 1 & 3 \\
\hline & & $\begin{array}{l}\text { Micromyrtus obovata } \\
\text { (Turcz.) J.W. Green }\end{array}$ & Leptospermia cassisi & WA & 1 & 6 \\
\hline & & $\begin{array}{l}\text { Pileanthus vernicosus } \\
\text { F. Muell. }\end{array}$ & $\begin{array}{l}\text { Melaleucaphylus phymato- } \\
\text { carpi }\end{array}$ & WA & 1 & 1 \\
\hline & & $\begin{array}{l}\text { Scholtzia drummondii } \\
\text { Benth. }\end{array}$ & Melaleucaphylus omnivorus & WA & 1 & 3 \\
\hline & & Verticordia densiflora Lindl. & Leptospermia cassisi & WA & 1 & 6 \\
\hline & & Verticordia picta Endl. & Leptospermia cassisi & WA & 1 & 3 \\
\hline & & $\begin{array}{l}\text { Verticordia polytricha } \\
\text { Benth. }\end{array}$ & Melaleucaphylus vimineae & WA & 1 & 27 \\
\hline & EUCALYPTEAE & $\begin{array}{l}\text { Eucalyptus camaldulensis } \\
\text { Dehnh. }\end{array}$ & Eucalyptophylus polyphagus & SA & 1 & 31 \\
\hline & & & Xiphoidellus eucalyptae & SA & 1 & 6 \\
\hline & & $\begin{array}{l}\text { Eucalyptus gamophylla } \\
\text { F. Muell. }\end{array}$ & Eucalyptophylus polyphagus & NT & 1 & 15 \\
\hline & & $\begin{array}{l}\text { Eucalyptus macrocarpa } \\
\text { subsp. elachanta Brooker \& } \\
\text { Hopper }\end{array}$ & Eucalyptophylus macrocarpae & WA & 1 & 48 \\
\hline & & $\begin{array}{l}\text { Eucalyptus macrocarpa } \\
\text { Hook. }\end{array}$ & Eucalyptophylus macrocarpae & WA & 1 & 148 \\
\hline & & & Eucalyptophylus polyphagus & WA & 1 & 2 \\
\hline & & $\begin{array}{l}\text { Eucalyptus pleurocarpa } \\
\text { Schauer }\end{array}$ & Eucalyptophylus polyphagus & WA & 8 & 207 \\
\hline & & Eucalyptus sp. & Eucalyptophylus polyphagus & WA & 2 & 16 \\
\hline & & $\begin{array}{l}\text { Eucalyptus tetragona } \\
\text { (R. Br.) F. Muell. }\end{array}$ & Eucalyptophylus polyphagus & WA & 1 & 6 \\
\hline
\end{tabular}


TABLE 2 Continued

\begin{tabular}{|c|c|c|c|c|c|c|}
\hline Plant family & Myrtaceae tribe & Plant species & Insect species & $\begin{array}{l}\text { State or } \\
\text { territory }\end{array}$ & $\begin{array}{r}\text { Insect } \\
\text { coll. } \\
\text { events }\end{array}$ & $\begin{array}{l}\text { Insect } \\
\text { speci- } \\
\text { mens }\end{array}$ \\
\hline & \multirow[t]{10}{*}{ LEPTOSPERMEAE } & $\begin{array}{l}\text { Kunzea ambigua }(\mathrm{Sm} .) \\
\text { Druce }\end{array}$ & Melaleucaphylus kunzeae & NSW & 4 & 83 \\
\hline & & $\begin{array}{l}\text { Leptospermum brevipes } \\
\text { F. Muell. }\end{array}$ & Leptospermia anatoles & NSW & 1 & 28 \\
\hline & & $\begin{array}{l}\text { Leptospermum coriaceum } \\
\text { (F. Muell. ex Miq.) Cheel }\end{array}$ & Leptospermia anatoles & SA & 2 & 79 \\
\hline & & $\begin{array}{l}\text { Leptospermum crassipes } \\
\text { Lehm. }\end{array}$ & Leptospermia cassisi & WA & 1 & 35 \\
\hline & & $\begin{array}{l}\text { Leptospermum fastigiatum } \\
\text { S. Moore }\end{array}$ & Leptospermia cassisi & WA & 2 & 209 \\
\hline & & $\begin{array}{l}\text { Leptospermum rupestre } \\
\text { Hook. f. }\end{array}$ & Xiphoides tasmanensis & TAS & 1 & 2 \\
\hline & & $\begin{array}{l}\text { Leptospermum scoparium } \\
\text { J.R. Forst. \& G. Forst. }\end{array}$ & Xiphoides tasmanensis & TAS & 1 & 15 \\
\hline & & Leptospermum sp. & Leptospermia cassisi & WA & 1 & 42 \\
\hline & & & Melaleucaphylus nodosae & NSW & 1 & 3 \\
\hline & & $\begin{array}{l}\text { Pericalymma ellipticum var. } \\
\text { ellipticum (Endl.) Schauer }\end{array}$ & Leptospermia cassisi & WA & 1 & 94 \\
\hline & \multirow[t]{16}{*}{ MELALEUCEAE } & Beaufortia elegans Schauer & Melaleucaphylus beaufortiae & WA & 2 & 9 \\
\hline & & $\begin{array}{l}\text { Beaufortia micrantha } \\
\text { Schauer }\end{array}$ & Melaleucaphylus micranthae & WA & 1 & 18 \\
\hline & & $\begin{array}{l}\text { Beaufortia schaueri } \\
\text { L. Preiss }\end{array}$ & Melaleucaphylus micranthae & WA & 1 & 5 \\
\hline & & & Melaleucaphylus omnivorus & WA & 1 & 2 \\
\hline & & $\begin{array}{l}\text { Beaufortia sprengelioides } \\
\text { (DC.) Craven }\end{array}$ & Melaleucaphylus beaufortiae & WA & 1 & 2 \\
\hline & & $\begin{array}{l}\text { Eremaea beaufortioides var. } \\
\text { beaufortioides Benth. }\end{array}$ & Melaleucaphylus eremaeae & WA & 1 & 10 \\
\hline & & & Melaleucaphylus omnivorus & WA & 1 & 2 \\
\hline & & $\begin{array}{l}\text { Eremaea pauciflora } \\
\text { (Endl.) Druce }\end{array}$ & Melaleucaphylus phymatocarpi & WA & 1 & 1 \\
\hline & & $\begin{array}{l}\text { Melaleuca brevifolia } \\
\text { Turcz. }\end{array}$ & Melaleucaphylus polyphagus & SA & 1 & 22 \\
\hline & & Melaleuca cucullata Turcz. & Melaleucaphylus polyphagus & WA & 1 & 5 \\
\hline & & Melaleuca filifolia F. Muell. & Melaleucaphylus vimineae & WA & 1 & 6 \\
\hline & & $\begin{array}{l}\text { Melaleuca glomerata } \\
\text { F. Muell. }\end{array}$ & Melaleucacoris glomeratae & NT & 1 & 115 \\
\hline & & & Melaleucaphylus glomeratae & NT & 1 & 44 \\
\hline & & & Melaleucaphylus vimineae & NT & 1 & 1 \\
\hline & & $\begin{array}{l}\text { Melaleuca halmaturorum } \mathrm{F} \text {. } \\
\text { Muell. ex Miq. }\end{array}$ & Melaleucaphylus halmaturorum & VIC & 1 & 136 \\
\hline & & & Melaleucaphylus polyphagus & VIC & 1 & 1 \\
\hline
\end{tabular}


TABLE 2 Continued

\begin{tabular}{|c|c|c|c|c|c|c|}
\hline Plant family & Myrtaceae tribe & Plant species & Insect species & $\begin{array}{l}\text { State or } \\
\text { territory }\end{array}$ & $\begin{array}{r}\text { Insect } \\
\text { coll. } \\
\text { events }\end{array}$ & $\begin{array}{l}\text { Insect } \\
\text { speci- } \\
\text { mens }\end{array}$ \\
\hline & & Melaleuca hamulosa Turcz. & Melaleucaphylus polyphagus & WA & 1 & 63 \\
\hline & & Melaleuca laetifica Craven & Melaleucaphylus omnivorus & WA & 1 & 60 \\
\hline & & Melaleuca lanceolata Otto & Ancoraphylus victoriensis & VIC & 1 & 4 \\
\hline & & $\begin{array}{l}\text { Melaleuca megacephala } \\
\text { F. Muell. }\end{array}$ & Melaleucaphylus vimineae & WA & 1 & 30 \\
\hline & & $\begin{array}{l}\text { Melaleuca nodosa } \\
\text { (Sol. ex Gaertn.) Sm. }\end{array}$ & Melaleucaphylus nodosae & NSW & 2 & 130 \\
\hline & & $\begin{array}{l}\text { Melaleuca pauperiflora } \\
\text { subsp. pauperiflora } \\
\text { F. Muell. }\end{array}$ & Melaleucaphylus pauperiflorae & WA & 1 & 1 \\
\hline & & $\begin{array}{l}\text { Melaleuca rhaphiophylla } \\
\text { Schauer }\end{array}$ & Melaleucaphylus rhaphiophyllae & WA & 1 & 171 \\
\hline & & $\begin{array}{l}\text { Melaleuca sheathiana } \\
\text { W. Fitzg. }\end{array}$ & Melaleucaphylus sheathianae & WA & 2 & 390 \\
\hline & & Melaleuca sp. & Melaleucaphylus nodosae & NSW & 1 & 3 \\
\hline & & & Melaleucaphylus omnivorus & WA & 1 & 4 \\
\hline & & & Melaleucaphylus vimineae & WA & 2 & 30 \\
\hline & & $\begin{array}{l}\text { Melaleuca systena } \\
\text { (Schauer) Craven }\end{array}$ & Melaleucaphylus vimineae & WA & 1 & 1 \\
\hline & & $\begin{array}{l}\text { Melaleuca teuthidoides } \\
\text { Barlow }\end{array}$ & Melaleucaphylus sheathianae & WA & 1 & 46 \\
\hline & & & Melaleucaphylus vimineae & WA & 1 & 3 \\
\hline & & Melaleuca uncinata R. Br. & Melaleucaphylus vimineae & WA & 2 & 49 \\
\hline & & Melaleuca viminea Lindl. & Melaleucaphylus vimineae & WA & 2 & 50 \\
\hline & & $\begin{array}{l}\text { Melaleuca viridiflora Sol. ex } \\
\text { Gaertn. }\end{array}$ & Melaleucaphylus viridiflorae & NT & 1 & 32 \\
\hline & & Melaleuca wilsonii F. Muell. & Melaleucaphylus polyphagus & VIC & 4 & 155 \\
\hline & & $\begin{array}{l}\text { Phymatocarpus porphyro- } \\
\text { cephalus F. Muell. }\end{array}$ & $\begin{array}{l}\text { Melaleucaphylus phymato- } \\
\text { carpi }\end{array}$ & WA & 1 & 72 \\
\hline OLEACEAE & & Notelaea microcarpa R. Br. & Melaleucaphylus dubiosus & NSW & 1 & 3 \\
\hline \multirow[t]{3}{*}{ PROTEACEAE } & & Grevillea armigera Meisn. & Leptospermia cassisi & WA & 1 & 2 \\
\hline & & $\begin{array}{l}\text { Grevillea hookeriana subsp. } \\
\text { apiciloba (F. Muell.) R.O. } \\
\text { Makinson }\end{array}$ & Melaleucaphylus vimineae & WA & 1 & 3 \\
\hline & & Hakea cygna Lamont & Melaleucaphylus omnivorus & WA & 1 & 1 \\
\hline TAXODIACEAE & & $\begin{array}{l}\text { Athrotaxis cupressoides } \\
\text { D. Don }\end{array}$ & Xiphoides tasmanensis & TAS & 1 & 11 \\
\hline
\end{tabular}


TABLE 3

New Plant Bug spp. (except Restiophylus) Organized by Plant Bug, Host Plant Family and Tribe, with State, Collecting Event and Number of Specimens

\begin{tabular}{|c|c|c|c|c|c|c|}
\hline Insect species & Plant family & Plant tribe & Plant species & $\begin{array}{l}\text { State or } \\
\text { territory }\end{array}$ & $\begin{array}{c}\text { Insect } \\
\text { coll. } \\
\text { events }\end{array}$ & $\begin{array}{l}\text { Insect } \\
\text { speci- } \\
\text { mens }\end{array}$ \\
\hline Ancoraphylus victoriensis & MYRTACEAE & Melaleuceae & Melaleuca lanceolata & VIC & 1 & 4 \\
\hline \multirow[t]{2}{*}{ Calytriphylus menzies } & MYRTACEAE & Chamelaucieae & Calytrix amethystina & WA & 1 & 9 \\
\hline & & & Calytrix angulata & WA & 1 & 7 \\
\hline \multirow[t]{2}{*}{ Eucalyptophylus macrocarpae } & MYRTACEAE & Eucalypteae & $\begin{array}{l}\text { Eucalyptus macrocarpa } \\
\text { subsp. elachanta }\end{array}$ & WA & 1 & 48 \\
\hline & & & Eucalyptus macrocarpa & WA & 1 & 148 \\
\hline \multirow[t]{6}{*}{ Eucalyptophylus polyphagus } & MYRTACEAE & Eucalypteae & Eucalyptus camaldulensis & SA & 1 & 31 \\
\hline & & & Eucalyptus gamophylla & NT & 1 & 15 \\
\hline & & & Eucalyptus macrocarpa & WA & 1 & 2 \\
\hline & & & Eucalyptus pleurocarpa & WA & 8 & 207 \\
\hline & & & Eucalyptus sp. & WA & 2 & 16 \\
\hline & & & Eucalyptus tetragona & WA & 1 & 6 \\
\hline \multirow[t]{2}{*}{ Leptospermia anatoles } & MYRTACEAE & Leptospermeae & Leptospermum brevipes & NSW & 1 & 28 \\
\hline & & & Leptospermum coriaceum & SA & 2 & 79 \\
\hline \multirow[t]{10}{*}{ Leptospermia cassisi } & MYRTACEAE & Chamelaucieae & Calytrix angulata & WA & 1 & 41 \\
\hline & & & Calytrix strigosa & WA & 1 & 3 \\
\hline & & & Micromyrtus obovata & WA & 1 & 6 \\
\hline & & & Verticordia densiflora & WA & 1 & 6 \\
\hline & & & Verticordia picta & WA & 1 & 3 \\
\hline & & Leptospermeae & Leptospermum crassipes & WA & 1 & 35 \\
\hline & & & Leptospermum fastigiatum & WA & 2 & 209 \\
\hline & & & Leptospermum sp. & WA & 1 & 42 \\
\hline & & & $\begin{array}{l}\text { Pericalymma ellipticum } \\
\text { var. ellipticum }\end{array}$ & WA & 1 & 94 \\
\hline & Proteaceae & & Grevillea armigera & WA & 1 & 2 \\
\hline Melaleucacoris glomeratae & MYRTACEAE & Melaleuceae & Melaleuca glomerata & NT & 1 & 115 \\
\hline \multirow[t]{2}{*}{ Melaleucaphylus beaufortiae } & MYRTACEAE & Melaleuceae & Beaufortia elegans & WA & 2 & 9 \\
\hline & & & Beaufortia sprengelioides & WA & 1 & 2 \\
\hline Melaleucaphylus dubiosus & Oleaceae & & Notelaea microcarpa & NSW & 1 & 3 \\
\hline Melaleucaphylus eremaeae & MYRTACEAE & Melaleuceae & $\begin{array}{l}\text { Eremaea beaufortioides } \\
\text { var. beaufortioides }\end{array}$ & WA & 1 & 10 \\
\hline Melaleucaphylus glomeratae & MYRTACEAE & Melaleuceae & Melaleuca glomerata & NT & 1 & 44 \\
\hline $\begin{array}{l}\text { Melaleucaphylus } \\
\text { halmaturorum }\end{array}$ & MYRTACEAE & Melaleuceae & Melaleuca halmaturorum & VIC & 1 & 136 \\
\hline Melaleucaphylus kunzeae & MYRTACEAE & Leptospermeae & Kunzea ambigua & NSW & 4 & 83 \\
\hline \multirow[t]{2}{*}{ Melaleucaphylus micranthae } & MYRTACEAE & Melaleuceae & Beaufortia micrantha & WA & 1 & 18 \\
\hline & & & Beaufortia schaueri & WA & 1 & 5 \\
\hline
\end{tabular}


TABLE 3 Continued

\begin{tabular}{|c|c|c|c|c|c|c|}
\hline Insect species & Plant family & Plant tribe & Plant species & $\begin{array}{l}\text { State or } \\
\text { territory }\end{array}$ & $\begin{array}{l}\text { Insect } \\
\text { coll. } \\
\text { events }\end{array}$ & $\begin{array}{l}\text { Insect } \\
\text { speci- } \\
\text { mens }\end{array}$ \\
\hline \multirow[t]{4}{*}{ Melaleucaphylus nodosae } & Fabaceae & & Acacia sp. & NSW & 1 & 17 \\
\hline & MYRTACEAE & Leptospermeae & Leptospermum sp. & NSW & 1 & 3 \\
\hline & & Melaleuceae & Melaleuca nodosa & NSW & 2 & 130 \\
\hline & & & Melaleuca sp. & NSW & 1 & 3 \\
\hline \multirow[t]{10}{*}{ Melaleucaphylus omnivorus } & Casuarinaceae & & Allocasuarina campestris & WA & 1 & 1 \\
\hline & MYRTACEAE & Chamelaucieae & Baeckea crispiflora & WA & 1 & 6 \\
\hline & & & Baeckea uncinella & WA & 1 & 4 \\
\hline & & & Calytrix glutinosa & WA & 1 & 1 \\
\hline & & & Scholtzia drummondii & WA & 1 & 3 \\
\hline & & Melaleuceae & Beaufortia schaueri & WA & 1 & 2 \\
\hline & & & $\begin{array}{l}\text { Eremaea beaufortioides } \\
\text { var. beaufortioides }\end{array}$ & WA & 1 & 2 \\
\hline & & & Melaleuca laetifica & WA & 1 & 60 \\
\hline & & & Melaleuca sp. & WA & 1 & 4 \\
\hline & Proteaceae & & Hakea cygna & WA & 1 & 1 \\
\hline Melaleucaphylus pauperiflorae & MYRTACEAE & Melaleuceae & $\begin{array}{l}\text { Melaleuca pauperiflora } \\
\text { subsp. pauperiflora }\end{array}$ & WA & 1 & 1 \\
\hline \multirow[t]{3}{*}{ Melaleucaphylus phymatocarpi } & MYRTACEAE & Chamelaucieae & Pileanthus vernicosus & WA & 1 & 1 \\
\hline & MYRTACEAE & Melaleuceae & Eremaea pauciflora & WA & 1 & 1 \\
\hline & & & $\begin{array}{l}\text { Phymatocarpus } \\
\text { porphyrocephalus }\end{array}$ & WA & 1 & 72 \\
\hline \multirow[t]{6}{*}{ Melaleucaphylus polyphagus } & MYRTACEAE & Chamelaucieae & Baeckea uncinella & WA & 1 & 4 \\
\hline & MYRTACEAE & Melaleuceae & Melaleuca brevifolia & SA & 1 & 22 \\
\hline & & & Melaleuca cucullata & WA & 1 & 5 \\
\hline & & & Melaleuca halmaturorum & VIC & 1 & 1 \\
\hline & & & Melaleuca hamulosa & WA & 1 & 63 \\
\hline & & & Melaleuca wilsonii & VIC & 4 & 155 \\
\hline Melaleucaphylus rhaphiophyllae & MYRTACEAE & Melaleuceae & Melaleuca rhaphiophylla & WA & 1 & 171 \\
\hline \multirow[t]{2}{*}{ Melaleucaphylus sheathianae } & MYRTACEAE & Melaleuceae & Melaleuca sheathiana & WA & 2 & 390 \\
\hline & & & Melaleuca teuthidoides & WA & 1 & 46 \\
\hline \multirow[t]{4}{*}{ Melaleucaphylus vimineae } & Casuarinaceae & & Allocasuarina corniculata & WA & 1 & 2 \\
\hline & MYRTACEAE & Chamelaucieae & Verticordia polytricha & WA & 1 & 27 \\
\hline & & Melaleuceae & Melaleuca filifolia & WA & 1 & 6 \\
\hline & & & Melaleuca glomerata & NT & 1 & 1 \\
\hline \multirow[t]{4}{*}{ Melaleucaphylus vimineae } & MYRTACEAE & Melaleuceae & Melaleuca megacephala & WA & 1 & 30 \\
\hline & & & Melaleuca sp. & WA & 1 & 30 \\
\hline & & & Melaleuca systena & WA & 1 & 1 \\
\hline & & & Melaleuca teuthidoides & WA & 1 & 3 \\
\hline
\end{tabular}


TABLE 3 Continued

\begin{tabular}{|c|c|c|c|c|c|c|}
\hline Insect species & Plant family & Plant tribe & Plant species & $\begin{array}{l}\text { State or } \\
\text { territory }\end{array}$ & $\begin{array}{c}\text { Insect } \\
\text { coll. } \\
\text { events }\end{array}$ & $\begin{array}{l}\text { Insect } \\
\text { speci- } \\
\text { mens }\end{array}$ \\
\hline & & & Melaleuca uncinata & WA & 2 & 49 \\
\hline & & & Melaleuca viminea & WA & 2 & 50 \\
\hline & Proteaceae & & $\begin{array}{l}\text { Grevillea hookeriana } \\
\text { subsp. apiciloba }\end{array}$ & WA & 1 & 3 \\
\hline Melaleucaphylus viridiflorae & MYRTACEAE & Melaleuceae & Melaleuca viridiflora & NT & 1 & 32 \\
\hline \multirow[t]{17}{*}{ Teddus katrinae } & Cupressaceae & & Callitris preissii & SA & 1 & 1 \\
\hline & Fabaceae & & $\begin{array}{l}\text { Acacia aneura var. } \\
\text { pilbarana }\end{array}$ & WA & 1 & 2 \\
\hline & & & Acacia aneura & NT & 1 & 1 \\
\hline & & & Acacia brachybotya & VIC & 1 & 1 \\
\hline & & & Acacia pendula & NSW & 1 & 4 \\
\hline & & & $\begin{array}{l}\text { Acacia ramulosa var. } \\
\text { linophylla }\end{array}$ & WA & 1 & 1 \\
\hline & & & Acacia sp. & WA & 1 & 1 \\
\hline & & & Acacia tetragonophylla & WA & 1 & 2 \\
\hline & & & Acacia victoriae & SA & 1 & 1 \\
\hline & & & $\begin{array}{l}\text { Senna artemisioides } \\
\text { subsp. helmsii }\end{array}$ & WA & 1 & 1 \\
\hline & & & $\begin{array}{l}\text { Senna artemisioides } \\
\text { subsp. oligophylla }\end{array}$ & WA & 1 & 1 \\
\hline & Loranthaceae & & $\begin{array}{l}\text { Amyema quandang var. } \\
\text { quandang }\end{array}$ & QLD & 1 & 2 \\
\hline & Myrtaceae & Chamelaucieae & Thryptomene tuberculata & WA & 1 & 1 \\
\hline & Myrtaceae & Melaleuceae & Melaleuca sp. & SA & 1 & 1 \\
\hline & Proteaceae & & Grevillea nematophylla & WA & 1 & 46 \\
\hline & & & Hakea leucoptera & QLD & 1 & 9 \\
\hline & Sapindaceae & & $\begin{array}{l}\text { Dodonaea viscosa subsp. } \\
\text { angustissima }\end{array}$ & WA & 1 & 13 \\
\hline Xiphoidellus eucalyptae & MYRTACEAE & Eucalypteae & Eucalyptus camaldulensis & SA & 1 & 6 \\
\hline \multirow[t]{3}{*}{ Xiphoides tasmanensis } & MYRTACEAE & Leptospermeae & Leptospermum rupestre & TAS & 1 & 2 \\
\hline & & & Leptospermum scoparium & TAS & 1 & 15 \\
\hline & Taxodiaceae & & Athrotaxis cupressoides & TAS & 1 & 11 \\
\hline
\end{tabular}


TABLE 4

New Spp.: Distribution of States, Phytogeographical Subzones, Number of Collection Events and Specimens

\begin{tabular}{|c|c|c|c|c|}
\hline Species & State & Phytogeographic subregion ${ }^{\mathrm{a}}$ & \# coll. events & \# specimens \\
\hline Ancoraphylus victoriensis & VIC & Eastern Desert & 1 & 4 \\
\hline Calytriphylus menzies & WA & Western Desert & 1 & 12 \\
\hline Eucalyptophylus macrocarpae & WA & Southwestern & 2 & 196 \\
\hline \multirow[t]{4}{*}{ Eucalyptophylus polyphagus } & NT & Eastern Desert & 1 & 15 \\
\hline & SA & Eastern Desert & 1 & 31 \\
\hline & WA & Pilbara & 1 & 6 \\
\hline & WA & Southwestern & 11 & 225 \\
\hline \multirow[t]{2}{*}{ Leptospermia anatoles } & NSW & Southeastern & 1 & 28 \\
\hline & SA & Adelaide & 2 & 79 \\
\hline \multirow[t]{3}{*}{ Leptospermia cassisi } & WA & Southwest Interzone & 1 & 6 \\
\hline & WA & Southwestern & 7 & 197 \\
\hline & WA & Western Desert & 1 & 239 \\
\hline Melaleucacoris glomeratae & NT & Eastern Desert & 1 & 115 \\
\hline Melaleucaphylus beaufortiae & WA & Southwestern & 2 & 11 \\
\hline Melaleucaphylus dubiosus & NSW & Southeastern & 1 & 3 \\
\hline Melaleucaphylus eremaeae & WA & Southwestern & 1 & 10 \\
\hline Melaleucaphylus glomeratae & NT & Eastern Desert & 2 & 91 \\
\hline Melaleucaphylus halmaturorum & VIC & Eastern Desert & 1 & 136 \\
\hline Melaleucaphylus kaputar & NSW & Eastern Desert & 1 & 7 \\
\hline Melaleucaphylus kunzeae & NSW & Southeastern & 4 & 83 \\
\hline Melaleucaphylus micranthae & WA & Southwestern & 2 & 23 \\
\hline Melaleucaphylus ngarkat & SA & Adelaide & 1 & 2 \\
\hline Melaleucaphylus nodosae & NSW & Southeastern & 7 & 190 \\
\hline \multirow[t]{2}{*}{ Melaleucaphylus omnivorus } & WA & Southwest Interzone & 1 & 4 \\
\hline & WA & Southwestern & 6 & 80 \\
\hline Melaleucaphylus pauperiflorae & WA & Southwestern & 1 & 1 \\
\hline Melaleucaphylus phymatocarpi & WA & Southwestern & 3 & 76 \\
\hline \multirow[t]{4}{*}{ Melaleucaphylus polyphagus } & SA & Adelaide & 1 & 22 \\
\hline & VIC & Adelaide & 5 & 156 \\
\hline & WA & Southwest Interzone & 1 & 4 \\
\hline & WA & Southwestern & 3 & 106 \\
\hline Melaleucaphylus rhaphiophyllae & WA & Southwestern & 1 & 171 \\
\hline Melaleucaphylus sheathianae & WA & Southwest Interzone & 3 & 445 \\
\hline \multirow[t]{5}{*}{ Melaleucaphylus vimineae } & NT & Eastern Desert & 2 & 2 \\
\hline & WA & Eastern Desert & 1 & 1 \\
\hline & WA & Southwest Interzone & 5 & 52 \\
\hline & WA & Southwestern & 5 & 108 \\
\hline & WA & Western Desert & 2 & 41 \\
\hline
\end{tabular}


TABLE 4 Continued

\begin{tabular}{|c|c|c|c|c|}
\hline Species & State & Phytogeographic subregion $^{a}$ & \# coll. events & \# specimens \\
\hline Melaleucaphylus viridiflorae & NT & Armhen Land & 1 & 32 \\
\hline Restiophylus orientalis & NSW & Southeastern & 1 & 18 \\
\hline \multirow[t]{13}{*}{ Teddus katrinae } & NSW & Eastern Desert & 2 & 6 \\
\hline & NT & Eastern Desert & 12 & 15 \\
\hline & NT & Western Desert & 3 & 6 \\
\hline & QLD & Central Desert & 1 & 1 \\
\hline & QLD & Eastern Desert & 1 & 11 \\
\hline & SA & Adelaide & 4 & 4 \\
\hline & SA & Eastern Desert & 10 & 37 \\
\hline & VIC & Eastern Desert & 1 & 1 \\
\hline & WA & Central Desert & 1 & 2 \\
\hline & WA & Pilbara & 4 & 5 \\
\hline & WA & Southwest Interzone & 1 & 1 \\
\hline & WA & Southwestern & 2 & 14 \\
\hline & WA & Western Desert & 8 & 64 \\
\hline Xiphoidellus eucalyptae & SA & Eastern Desert & 1 & 12 \\
\hline \multirow[t]{2}{*}{ Xiphoides anangu } & SA & Eastern Desert & 1 & 3 \\
\hline & WA & Western Desert & 1 & 1 \\
\hline Xiphoides tasmanensis & TAS & Tasmania & 3 & 28 \\
\hline TOTAL & & & 151 & 3239 \\
\hline
\end{tabular}

${ }^{a}$ Terrestrial phytogeographial subregions (Ebach et al., 2015).

of Exocarpocorina. As a caveat, collections on Eucalypteae were not as intensive as on the other Myrtaceae tribes (G. Cassis, personal commun.).

Schuh and Schwartz (2016) presented a histogram illustrating the host-frequency associations of the Australian Cremnorrhinina in terms of the number of hosts utilized by individual bug species, number of bugs occupying individual hosts, and the strength of data upon which these parameters were based. We document with the bar graph in figure 22 that the host associations of myrtaceous-feeding Australian Phylinae are very similar to those of the Cremnorrhinina-that the preponderance of known host associations are documented by single collecting events, most plant species are occupied by a single bug species, and a majority of bug species show high host specificity. The gray bars present data that most known hosts are occupied by a single species ( 80 hosts) whereas a much smaller number of hosts are occupied by 2, 3, 4, or 8 phyline species. The solid black bars report data showing the degree of fidelity of bug species to plant species. Most Australian Myrtaceae feeders occupy one (19) or two (15) individual hosts, with three hosts having onehalf that number of occurrences of individual bug species and even fewer bug species utilizing higher numbers of individual known hosts, to a maximum number of known hosts for a single bug species being 15. Confidence in knowledge of host associations can be judged by the number of times (collecting events) a given bug species has been taken on a given plant species coupled with the number of specimens collected on that plant species. The white bars in figure 22 show 135 individual host associations are documented by a 
TABLE 5

Myrtaceae Host Plants Shared between Melaleucaphylus and Melaleucoides spp.

\begin{tabular}{|c|c|c|c|}
\hline Tribe & Host plant spp. & Melaleucaphylus spp. & Melaleucoides spp. \\
\hline \multirow[t]{2}{*}{ Melaleuceae } & Beaufortia micrantha & Melaleucaphylus micranthae & Melaleucoides beaufortiae \\
\hline & & & Melaleucoides micranthae \\
\hline \multirow{13}{*}{ Melaleuceae } & Melaleuca brevifolia & Melaleucaphylus polyphagus & Melaleucoides brevifoliae \\
\hline & Melaleuca laetifica & Melaleucaphylus omnivorus & Melaleucoides systenae \\
\hline & Melaleuca megacephala & Melaleucaphylus vimineae & Melaleucoides verticordiae \\
\hline & Melaleuca rhaphiophylla & Melaleucaphylus rhaphiophyllae & Melaleucoides rhaphiophyllae \\
\hline & & & Melaleucoides uncinatae \\
\hline & Melaleuca sheathiana & Melaleucaphylus sheathianae & Melaleucoides annae \\
\hline & & & Melaleucoides sheathianae \\
\hline & Melaleuca teuthidoides & Melaleucaphylus sheathianae & Melaleucoides sheathianae \\
\hline & & Melaleucaphylus vimineae & \\
\hline & Melaleuca uncinata & Melaleucaphylus vimineae & Melaleucoides cassisi \\
\hline & & & Melaleucoides uncinatae \\
\hline & Melaleuca viminea & Melaleucaphylus vimineae & Melaleucoides leuropomae \\
\hline & & & Melaleucoides systenae \\
\hline \multirow{2}{*}{ Melaleuceae } & Phymatocarpus porphyrocephalus & Melaleucaphylus phymatocarpi & Melaleucoides leuropomae \\
\hline & & & Melaleucoides systenae \\
\hline Chamelaucieae & Verticordia polytricha & Melaleucaphylus vimineae & Melaleucoides verticordiae \\
\hline
\end{tabular}

single collecting event, 16 by two collecting events, to a maximum of eight collecting events for a single host association.

\section{Host-Association Comparison BETWEEN SPECIES OF}

MELALEUCAPHYLUS AND MELALEUCOIDES

Eleven host plant species support bugs of both genera (see table 5) and usually these individual bug species are found on a wide range host plants utilizing several to many other additionally plants. Melaleuca laetifica, M. megacephala, M. viminea, Phymatocarpus prophyrocephalus (Melaleuceae), and Verticordia polytricha (Chamelaucieae) are hosts for one or more of the following bug species: Melaleucaphylus omnivorus, M. vimineae; Melaleucoides leuropomae, M. systenae, M. verticordiae, as well as Harpagophylus verticordii and Leptospermia cassisi, two other myrtaceous feeding phylines with a wide host range.

Bug species that utilize only one plant species can also share that same host with a bug species from the other genus. Beaufortia micrantha is almost exclusively the host of Melaleucaphylus micranthae and Melaleucoides micranthae while Melaleuca rhaphiophylla is the only host for Melaleucaphylus rhaphiophyllae and Melaleucoides rhaphiophyllae, as well as Scholtzicoris linnavuorii, all from the same collecting event. We note that in both above examples the habitus coloration of the plant-bug species pairs (and $S$. linnavuorii) is dissimilar.

\section{ACKNOWLEDGMENTS}

We thank Gerasimos Cassis for his contributions to the fieldwork that brought together most of the specimens on which this study is based. 
Without his efforts to secure funding, organize logistics, and search out specimens in the field, our knowledge of Australian Miridae would pale in comparison to what we know today. We thank the Australian Museum, the American Museum of Natural History, and the United States National Science Foundation (NSF) for support of field trips contributing specimens to this project. Initial work on genitalic dissection and establishment of generic diagnoses was conducted by C.W. with support from the NSF Planetary Biodiversity Inventories award DEB 0316495, R.T.S. and Gerasimos Cassis, principal investigators. Our thanks to staff members of the Western Australian Herbarium (WAH), Perth, and the Royal Botanic Gardens, Sydney, for identifying host-plant specimens, and to the WAH and the New York Botanical Garden for vouchering those specimens. We thank the relevant authorities in various Australian states for the issuance of collecting permits that allowed for the assembly of the collections-both insect and plant-on which this study is based.

Ruth Salas, AMNH, prepared the specimen measurements, captured the preponderance of the specimen data, prepared most of the scanning electron micrographs, and reexamined many specimens during the process of selecting depositories and revising a previous version of the manuscript. Steve Thurston, AMNH, prepared the habitus photos and assembled all of the artwork for this project in its published form. To both of them we offer our sincere thanks for helping to bring this project to fruition. Jean Francois Landry and Vazrick Nazari, AAFC, provided the Nikon Eclipse E800 photomicrographic system and assisted with its use during preparation of images of the genitalia. Keith Hubbard, AAFC, prepared additional scanning electron micrographs. Marina Cheng, UNSW, provided additional photographs of host plants and Frank Hennings, UNSW, verified the identity of voucher specimens of Melaleuca viridiflora; a photograph of flowers of the same species was posted by Summerdrought, CC BY-SA 4.0 (https://commons.wikimedia.org/w/index. php?curid=48902329). South Australia Seed Con- servation Centre posted the habitus photograph of Leptospermum coriaceum (http://saseedbank. com.au/species_information.php?rid=2640). G. Cassis (UNSW) and Katrina L. Menard, University of Oklahoma, provided valuable discussions and reviews to improve the final version of the manuscript. We also thank Mary Knight, editor, AMNH Scientific Publications, for her scholarly advice and suggestions on the formation of scientific names derived from classical languages.

\section{REFERENCES}

Carvalho, J.C.M. 1981. Mirídeos neotropicais, CCXXIV: Descrições de dois gêneros e cinco espécies novas (Hemiptera). Revista Brasileira de Biologia 41: $11-18$.

Carvalho, J.C.M. 1984. Mirídeos neotropicais, CCLII: Descriçoes de novos gêneros e espécies da tribo Phylini Douglas \& Scott (Hemiptera). Boletim do Museu Paraense Emilio Goeldi, Zoologia 1: 143206.

Cassis, G. 2008. The Lattinova complex of the austromirine plant bugs (Hemiptera: Heteroptera: Miridae: Orthotylinae). Proceedings of the Entomological Society of Washington 110: 845-939.

Cassis, G., and C. Symonds. 2008. Systematics, biogeography and host associations of the lace bug genus Inoma (Hemiptera: Heteroptera: Tingidae). Acta Entomologica Musei Nationalis Pragae 48 (2): 433484.

Cassis, G., and C. Symonds. 2011. Systematics, biogeography and host plant associations of the lace bug genus Lasiacantha Stål in Australia (Insecta: Hemiptera: Heteroptera: Tingidae). Zootaxa 2818: $1-63$

Cassis, G., and C. Symonds. 2014. Systematics and host plant associations of a new genus of Acacia-inhabiting plant bugs from arid Australia (Insecta: Hemiptera: Heteroptera: Miridae: Orthotylinae). Invertebrate Systematics 28 (5): 522-554.

Cassis, G., P. Koenig, C. Symonds, and R. Shofner. 2017. Systematics and host plant associations of the Australian lace bug genus Nethersia (Insecta: Heteroptera: Tingidae), including the description of 18 new species. Insect Systematics \& Evolution 48: 1-95.

Cheng, M., A. Mututantri, and G. Cassis 2012. Myrtlemiris, a new genus and new species of Australian 
plant bugs (Insecta: Heteroptera: Miridae): systematics, phylogeny and host associations. Systematic Entomology $37 \quad(2)$ : 305-331. [doi: 10.1111/j.1365-3113.2012.00621.x]

Ebach, M.C., C.E. Gonzalez-Orozco, J.T. Miller, and D.J. Murphy. 2015. A revised area taxonomy of phytogeographical regions within the Australian bioregionalisation atlas. Phytotaxa 208 (4) 261-277. [doi: 10.11646/phytotaxa.208.4.2]

Eyles, A.C., and R.T. Schuh. 2003. Revision of New Zealand Bryocorinae and Phylinae (Insecta: Hemiptera: Miridae). New Zealand Journal of Zoology 30: 263325.

González-Orozco, C.E., et al. 2014. Quantifying phytogeographical regions of Australia using geospatial turnover in species composition PLoS One 9 (3): e92558. [doi: 10.1371/journal.pone.0092558]

Knight, H.H. 1968. Taxonomic review: Miridae of the Nevada test site and the western United States. Brigham Young University Science Bulletin, Biological Series 9: 282 pp.

Kozub, D., V. Khmelik, J. Shapoval, V. Chentsov, and S. Yatsenko. 2008. Helicon Focus Pro. Kharkov, Ukraine: Helicon Soft Ltd.

Leon, S., and C. Weirauch. 2016. Restiid-feeding Semiini (Hemiptera: Miridae: Phylinae) from Western Australia: Description and phylogenetic analysis of the new plant bug genus Restiophylus, n. gen. Annals of the Entomological Society of America 109 (1): 145-157. [doi.org/10.1093/aesa/sav105]

Malipatil, M.B. 1992. Revision of Australian Campylomma Reuter (Hemiptera: Miridae: Phylinae). Australian Journal of Entomology 31(4): 357-368. [doi. org/10.1111/j.1440-6055.1992.tb00526.x]

Menard, K.L., and R.T. Schuh, 2011. Revision of Leucophoropterini: diagnoses, key to genera, redescription of the Australian fauna, and descriptions of new Indo-Pacific genera and species (Insecta: Hemiptera: Miridae). Bulletin of the American Museum of Natural History 361: 1-159.

Menard, K.L., R.T. Schuh, and J. Woolley. 2013. Total evidence phylogenetic analysis and reclassification of the Phylinae (Insecta: Heteroptera: Miridae), with the recognition of new tribes and subtribes and a redefinition of Phylini. Cladistics. 30: 391-427.

Reuter, O.M. 1904. Ad cognitionem Capsidarum Australiae. Öfversigt af Finska Vetenskaps SocietetensFörhandlingar 47 (5): 1-16+1 pl. [in Latin]

Russell, K., and C. Weirauch. 2017. 'Toothbrush' plant bugs and allies: Protemiris gen. nov., a new genus and five new species of Proteaceae-associated Aus- tralian Phylinae (Hemiptera: Miridae). Austral Entomology 56: 75-93.

Schuh, R.T. 1984. Revision of the Phylinae (Hemiptera, Miridae) of the Indo-Pacific. Bulletin of the American Museum of Natural History 177 (1): 1-476.

Schuh, R.T. 2006. Revision, phylogenetic, biogeographic, and host analysis of the endemic western North American Phymatopsallus group, with the description of 9 new genera and 15 new species (Insecta: Hemiptera: Miridae: Phylinae). Bulletin of the American Museum of Natural History 301: 1-115.

Schuh, R.T. 2016. Scholtzicoris linnavuorii, new genus and new species of Myrtaceae-feeding plant bug from Western Australia (Hemiptera: Heteroptera: Miridae: Phylinae: Semiini: Exocarpocorina). Entomologica Americana 122(1-2): 156-163.

Schuh, R.T., and K.L. Menard, 2011. Santalalean-feeding plant bugs: ten new species in the genus Hypseloecus Reuter from Australia and South Africa (Heteroptera: Miridae: Phylinae): their hosts and placement in the Pilophorini. Australian Journal of Entomology 50: 365-392.

Schuh, R.T., and K.L. Menard. 2013. A revised classification of the Phylinae (Insecta: Heteroptera: Miridae): arguments for the placement of genera. American Museum Novitates 3785: 1-72.

Schuh, R.T., and P. Pedraza. 2010. Wallabicoris, new genus (Hemiptera: Miridae: Phylinae: Phylini) from Australia, with the description of 37 new species and an analysis of host associations. Bulletin of the American Museum of Natural History 338: 1-118.

Schuh, R.T., and M.D. Schwartz. 2016. Nineteen new genera and 82 new species of Cremnorrhinina from Australia, including analyses of host relationships and distributions (Insecta: Hemiptera: Miridae: Phylinae: Cremnorrhinini). Bulletin of the American Museum of Natural History 401: 1-279.

Schuh, R.T., and C. Weirauch. 2010. Myrtaceae-feeding Phylinae (Hemiptera: Miridae) from Australia: description and analysis of phylogenetic and host relationships for a monophyletic assemblage of three new genera. Bulletin of the American Museum of Natural History 344: 1-95.

Schuh, R.T., C. Weirauch, and K.L. Menard. 2014. Resolving the identities of Phylinae (Heteroptera: Miridae) described by O.M. Reuter from Australia in 1904. Entomologica Americana 120(1): 4-6.

Schwartz, M.D., and R.T. Schuh. 2016. Two new species of Pulvillophylus from Western Australia (Insecta: Hemiptera: Miridae: Phylinae: Cremnorrhinini). American Museum Novitates 3860: 1-12. 
Soto, D. and C. Weirauch. 2009. Description of the Australian plant bug genus Jiwarli, n. gen. (Heteroptera: Miridae: Phylinae). American Museum Novitates 3653: 14 pp.

Symonds, S., and G. Cassis. 2018. Systematics and analysis of the radiation of Orthotylini plant bugs associated with callitroid conifers in Australia: description of five new genera and 32 new species (Heteroptera: Miridae: Orthotylinae). Bulletin of the American Museum of Natural History 422: $1-226$.

Weirauch, C. 2007. Revision and cladistic analysis of the Polyozus group of Australian Phylini (Heteroptera: Miridae: Phylinae). American Museum Novitates 3590: 1-60.

Weirauch, C., and R.T. Schuh. 2011 (“2010”). Southern hemisphere distributional patterns in plants bugs (Hemiptera: Miridae: Phylinae): Xiphoidellus, gen. nov. from Australia and Ampimpacoris, gen. nov. from Argentina, show transantarctic relationships. Invertebrate Systematics 24: 473508.

Weirauch, C., et al. 2017. Areas of endemism in the Nearctic: a case study of 1339 species of Miridae (Insecta: Hemiptera) and their plant hosts. Cladistics 33: 279-294.

Wilson, P.G. 2011. Myrtaceae. In K. Kubitzki (editor), The families and genera of vascular plants. Vol. 10, Sapindales, Cucurbitales, Myrtaceae: 212-271. Heidelberg: Springer-Verlag.
Wilson, P.G., M.M. O’Brien, P.A. Gadek, and C.J. Quinn. 2001. Myrtaceae revisited: a reassessment of infrafamilial groups. American Journal of Botany 88 (11): 2013-2025.

Wilson, P.G., M.M. O’Brien, M.M. Heslewood, and C.J. Quinn. 2005. Relationships within Myrtaceae sensu lato based on a matK phylogeny. Plant Systematics and Evolution 251: 3-19.

Yasunaga, T. 2010. Plant bugs of the tribe Phylini in Thailand (Heteroptera: Miridae: Phylinae), with descriptions of six new species from additional areas in tropical and subtropical Asia. Entomologica Americana 116 (3/4): 50-92. [doi: 10.1664/10-RA-006.1]

Yasunaga, T. 2016. A review of the plant bug genus Campylomma Reuter from Indochina (Heteroptera: Miridae: Phylinae: Nasocorini), with description of a new species cryptically inhabiting Macaranga bracts (Euphorbiaceae) in Thailand. Journal of Asia-Pacific Entomology. 19: 459-465. [doi. org/10.1016/j.aspen.2016.04.007]

Yasunaga, T., and R.K. Duwal. 2015. Further records and descriptions of the plant bug subfamily Phylinae (Hemiptera: Heteroptera: Miridae) from Thailand. Zootaxa 3981 (2): 193-219. [doi: 10.11646/ zootaxa.3981.2.3]

Yasunaga, T., R.T. Schuh, and R.K. Duwal. 2015. Taxonomic review of the plant bug genus Campylomma Reuter from Japan (Heteroptera: Miridae: Phylinae: Nasocorini), with descriptions of two new species. Tijdschrift voor Entomologie 158: 49-69. 


\section{PLATES AND MAPS}





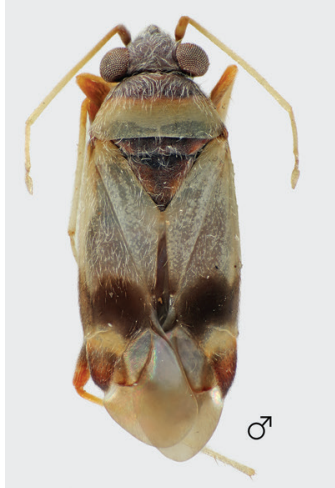

Eucalyptophylus macrocarpae 00390295

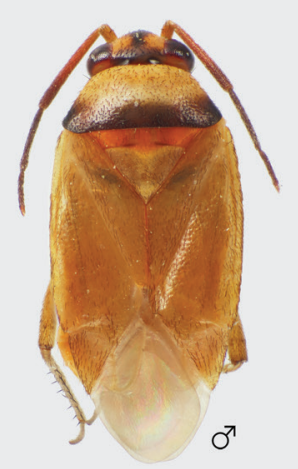

Melaleucaphylus beaufortiae 00087287

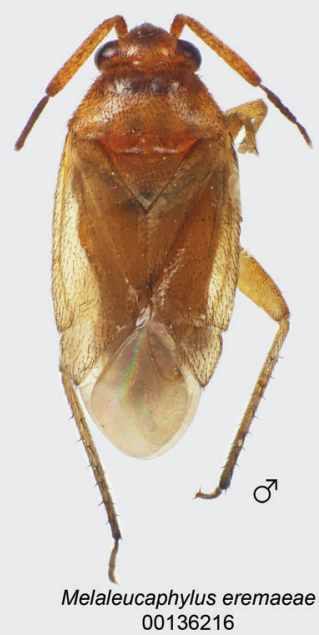

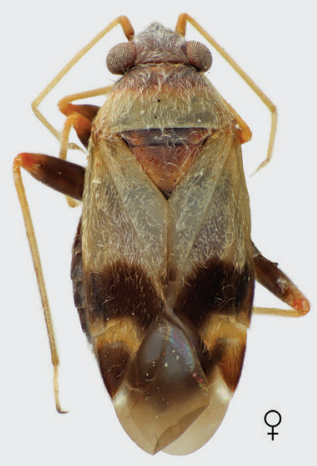

Eucalyptophylus macrocarpae 00390260

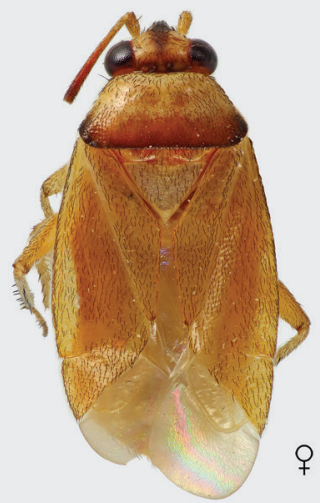

Melaleucaphylus beaufortiae 00372148

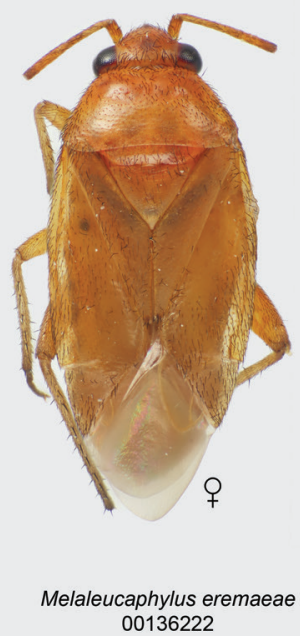

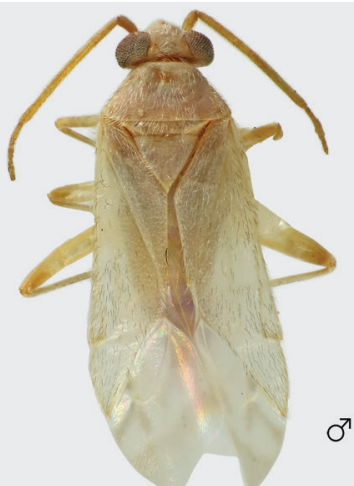

Eucalyptophylus polyphagus 00131377

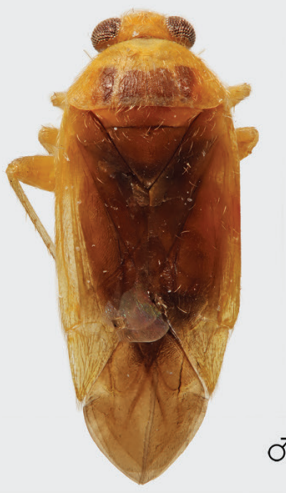

Melaleucaphylus dubiosus 00087293

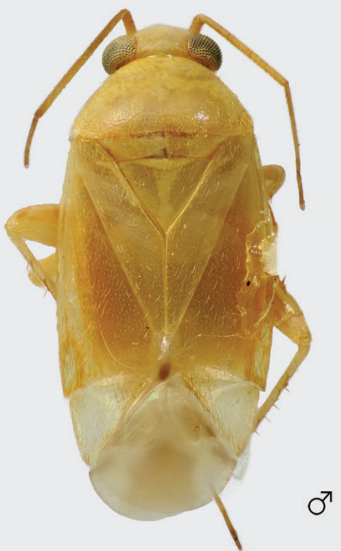

Melaleucaphylus glomeratae 00418698

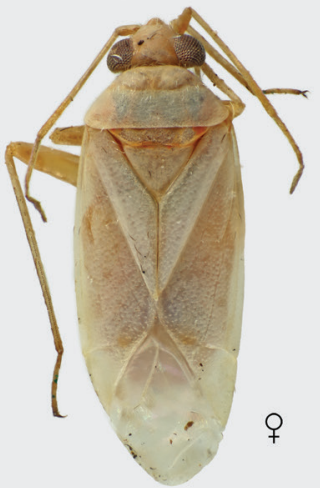

Eucalyptophylus polyphagus 00130907

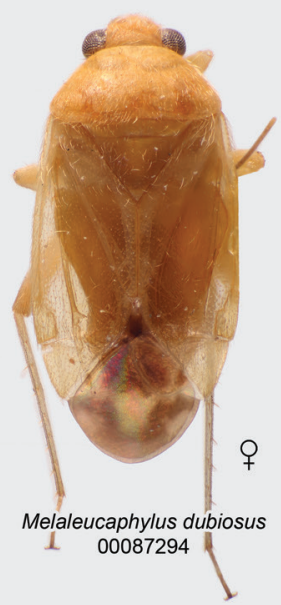

PLATE 1. Digital dorsal habitus images of Eucalyptophylus spp., Melaleucaphylus beaufortiae-M. glomeratae. 


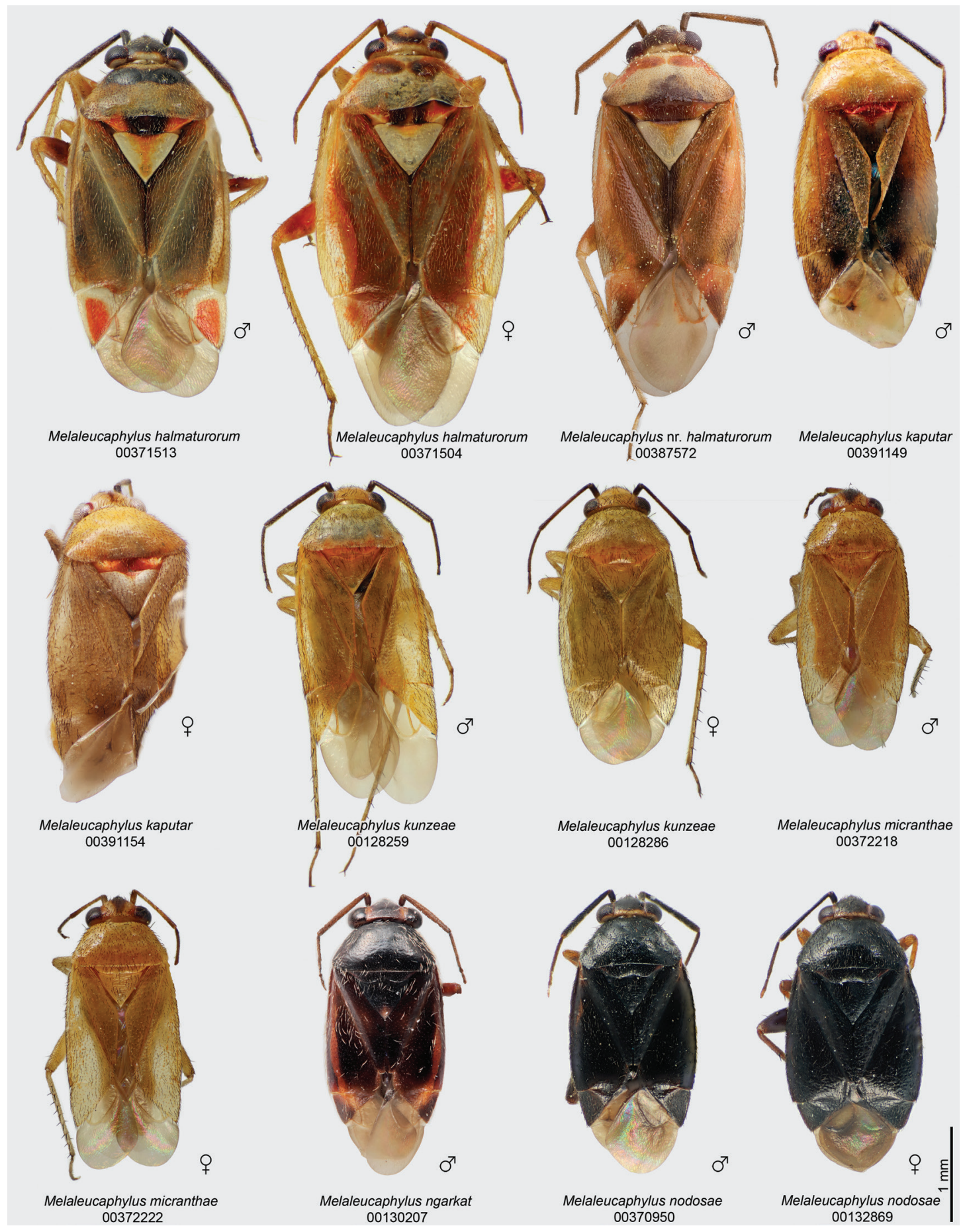

PLATE 2. Digital dorsal habitus images of Melaleucaphylus halmaturorum-M. nodosae. 


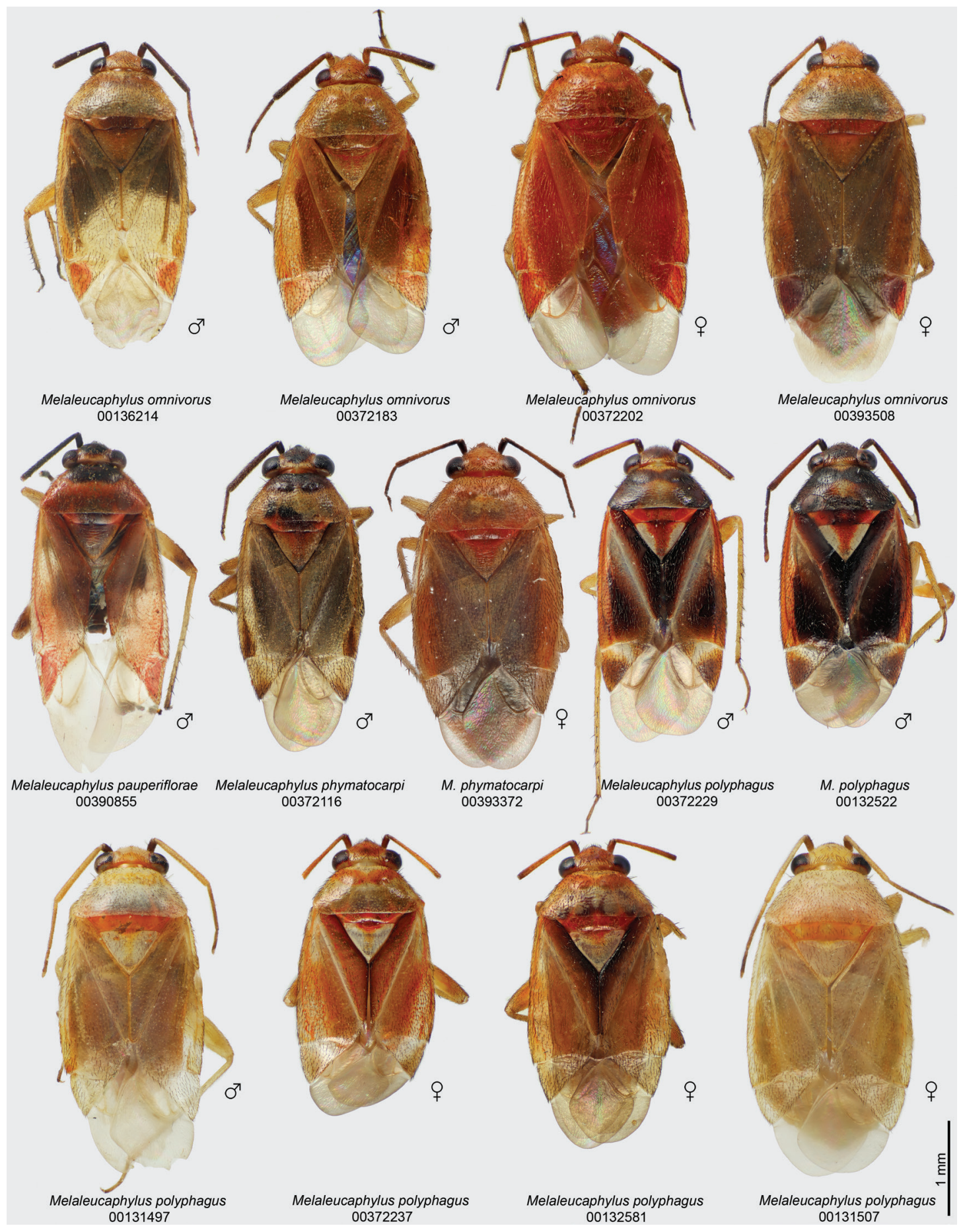

PLATE 3. Digital dorsal habitus images of Melaleucaphylus omnivorus-M. polyphagus. 




PLATE 4. Digital dorsal habitus images of Melaleucaphylus rhaphiophyllae-M. viridiflorae, Acoraphylus victoriensis, Calytriphylus menzies, Leptospermia anatoles. 


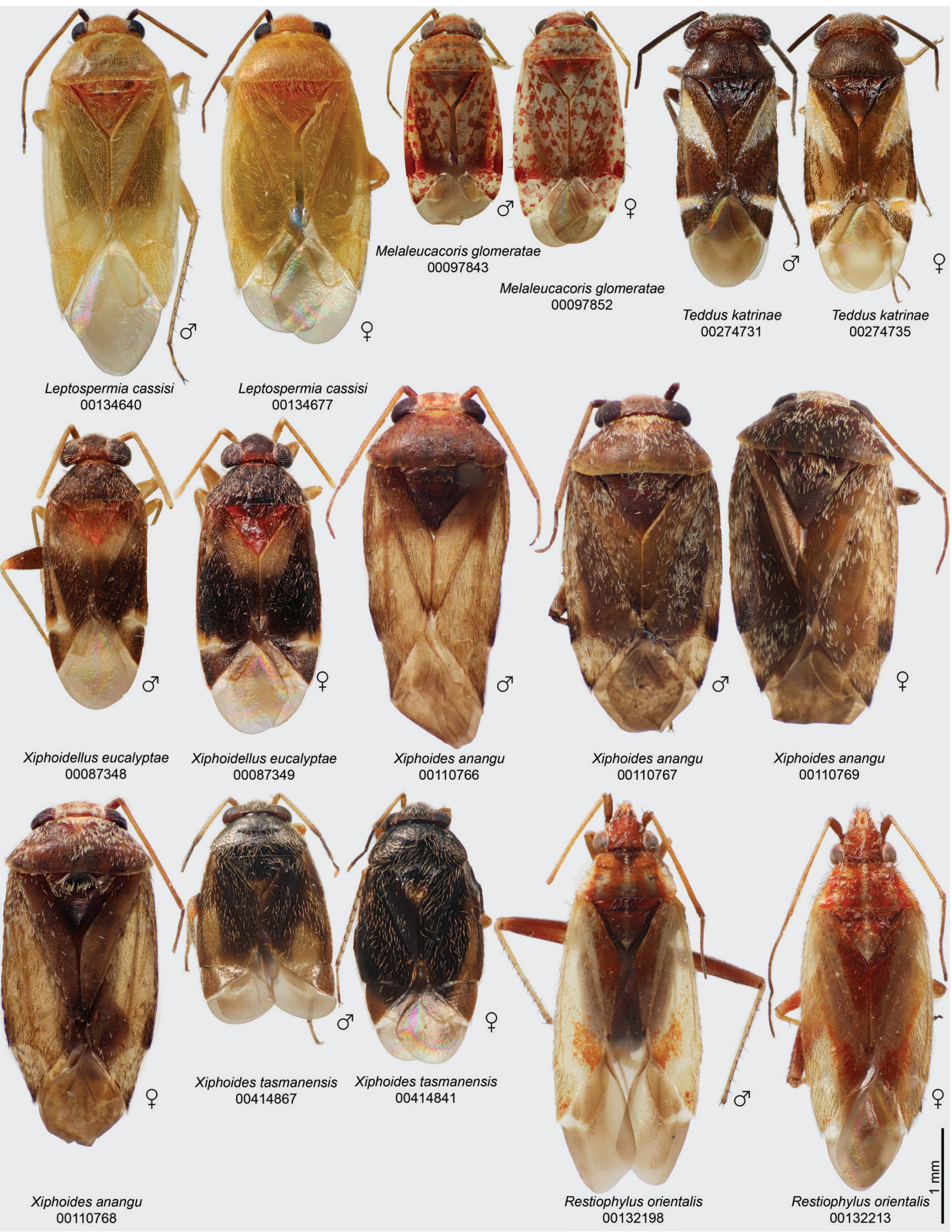

PLATE 5. Digital dorsal habitus images of Leptospermia cassisi, Melaleucacoris glomeratae, Eucalyptophylus spp., Teddus katrinae, Xiphoidellus eucalyptae, Xiphoides spp., Restiophylus orientalis. 


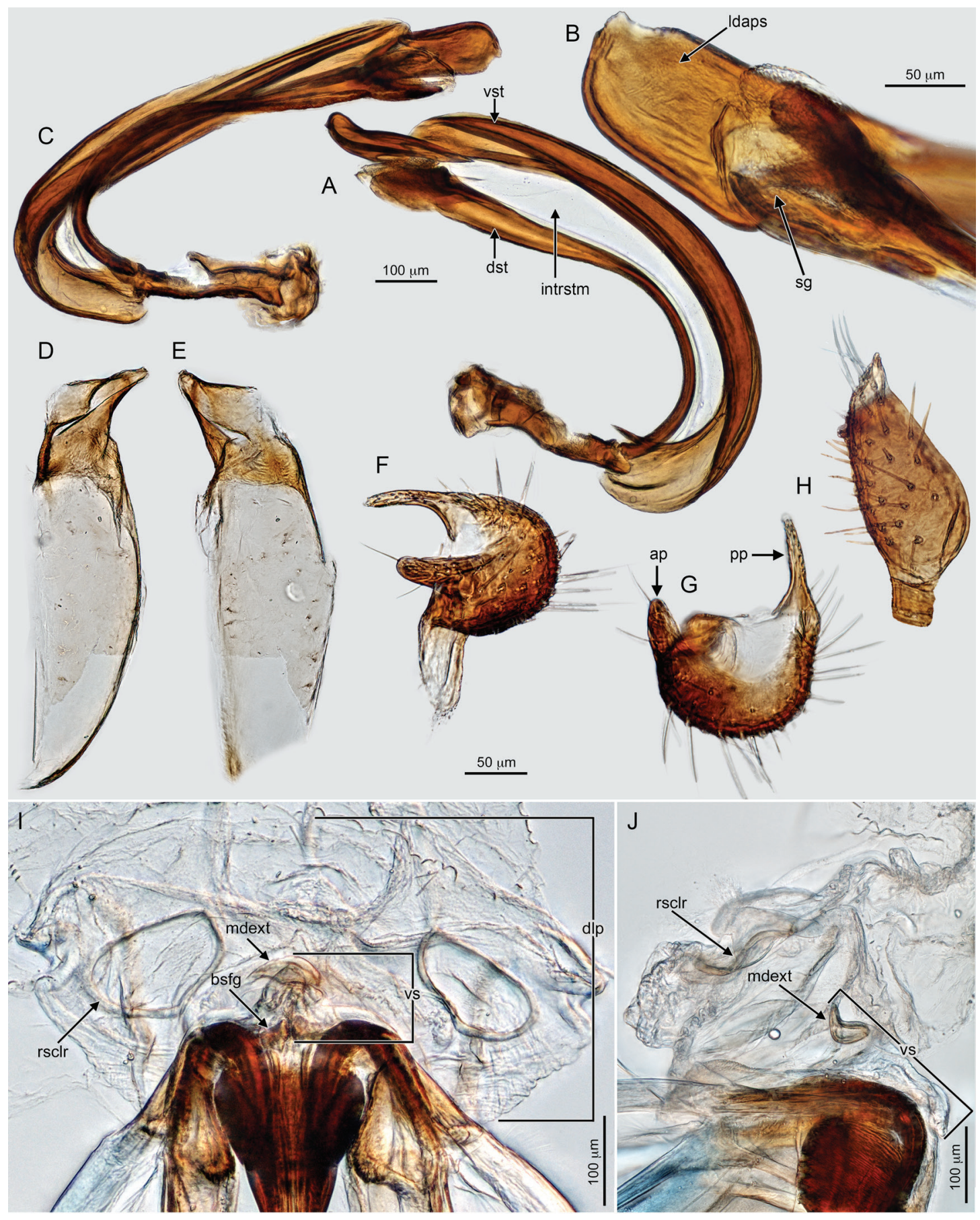

PLATE 6. Eucalyptophylus macrocarpae. Digital genitalic images. Male, AMNH_PBI 00414189: A-H. A-C: Endosoma. A. Left lateral view. B. Detail of secondary gonopore, dorsoapical view. C. Right lateral view. D, E: Phallotheca. D. Anterior view. E. Posterior view. F, G: Left paramere. F. Anterior view. G. Dorsal view. H. Right paramere, lateral view. Female, Bursa copulatrix, AMNH_PBI 00414197: I. Ventral view. J. Right lateral view. 

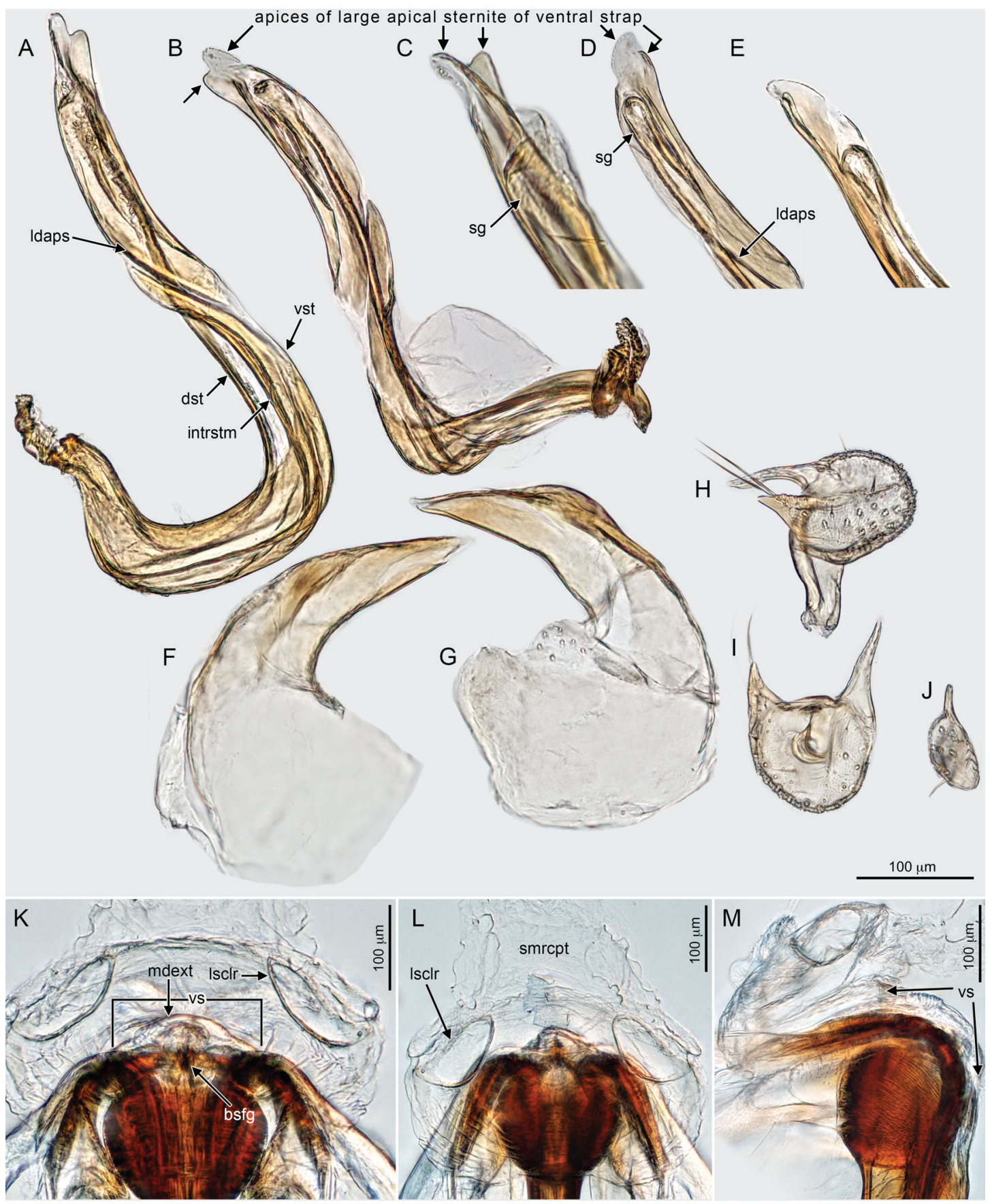

PLATE 7. Eucalyptophylus polyphagus. Digital genitalic images. Male. A-E: Endosoma. A. Left lateral view. B. Right lateral view. C, D: Detail of secondary gonopore and discrete apical sternite of ventral strap. C. Dorsal view. D. Ventral view. E. Left lateral view. F, G: Phallotheca. F. Anterior view. G. Posterior view. H, I: Left paramere. H. Anterior view. I. Dorsal view. H. Right paramere, lateral view. AMNH_PBI 00087439: A. AMNH_PBI 00130903: B-D, F-J. AMNH_PBI 00414686: E. Female, Bursa copulatrix, AMNH_PBI 00390403: K. Ventral view. L. Dorsal view. M. Right lateral view. 

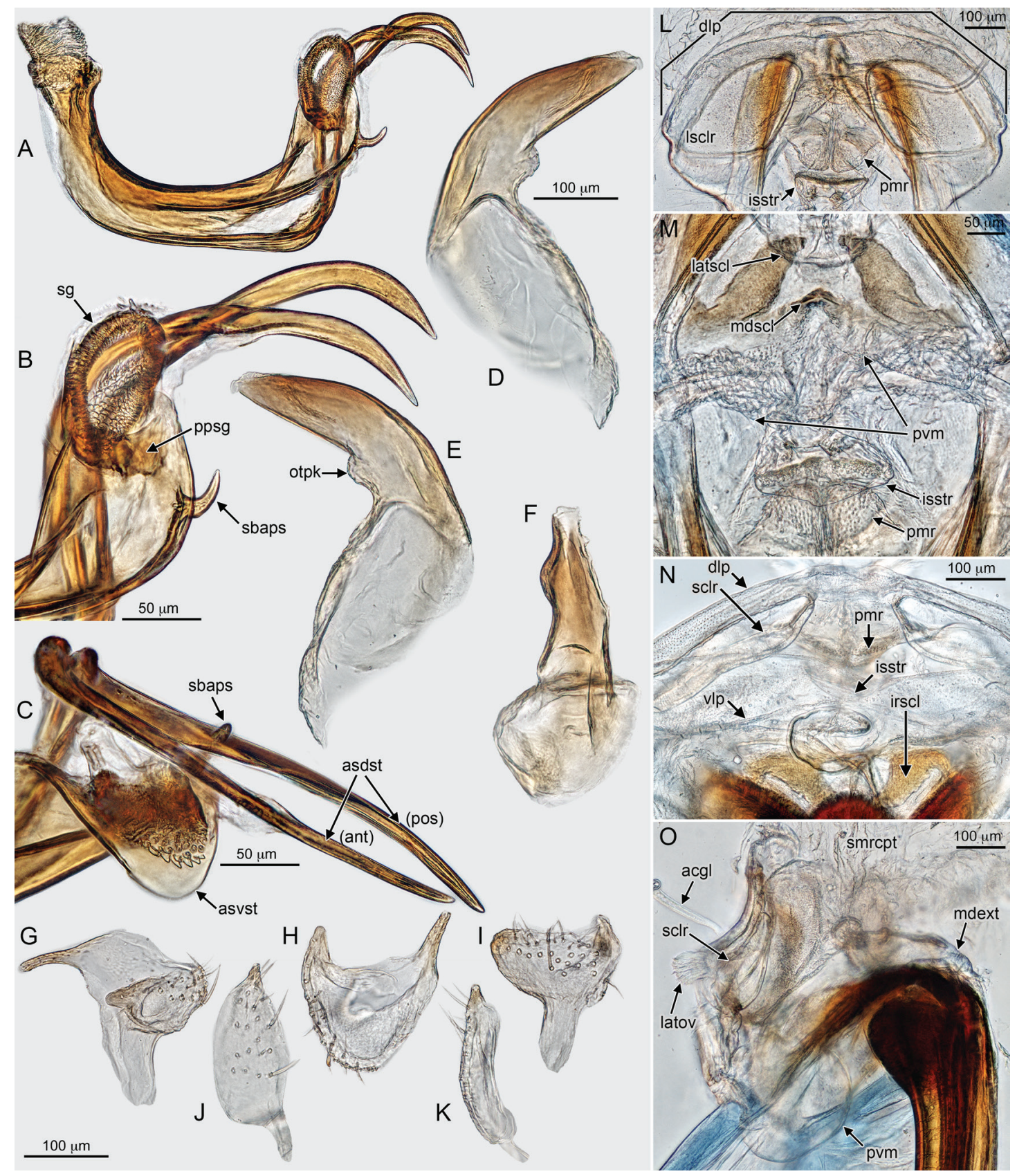

PLATE 8. Melaleucaphylus beaufortiae. Digital genitalic images. Male. A-C: Endosoma. A. Left lateral view. B, C: Detail of secondary gonopore and apical spines. B. Left lateral view. C. Dorsal view. D-F: Phallotheca. D. Anterior view. E. Posterior view. F. Caudal view. G-I: Left paramere. G. Anterior view. H. Dorsal view. I. Posterior view. J, K: Right paramere. J. Lateral view. K. Dorsal view. AMNH_PBI 00087491: B, C. AMNH_PBI 00372146: A, D-K. Female. L. Bursa copulatrix, dorsal view. M. Genital chamber, anteroventral view. N. Genital chamber, anterior view. O. Bursa copulatrix, right lateral view. AMNH_PBI 00372150: N, O. AMNH_ PBI 00412913: L, M. 


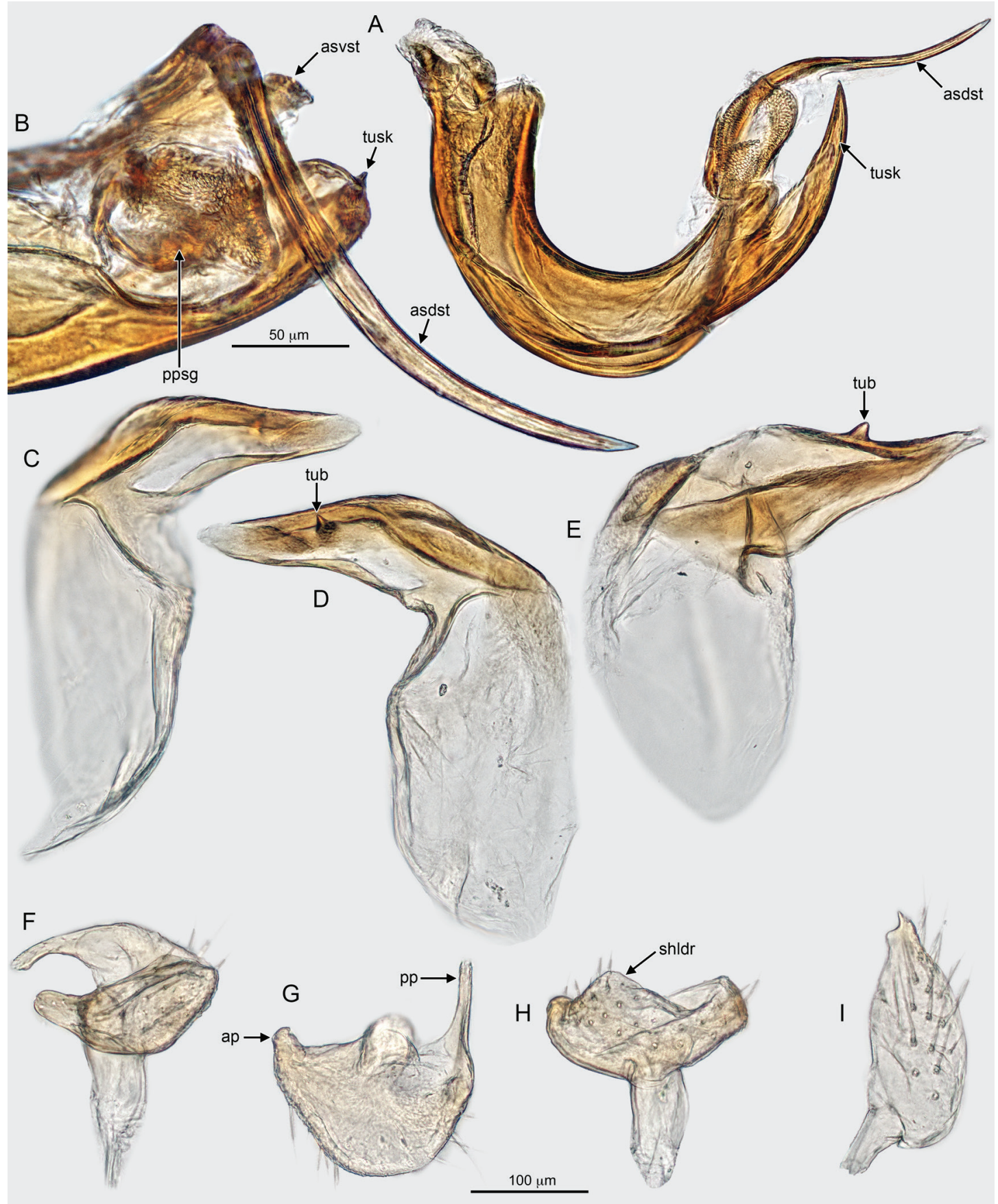

PLATE 9. Melaleucaphylus dubiosus. Digital genitalic images. Male, AMNH_PBI 00087494. A, B: Endosoma. A. Left lateral view. B. Detail of apical spine and secondary gonopore, dorsal view. C-E: Phallotheca. C. Anterior view. D. Posterior view. E. Anterodorsal, view. F-G: Left paramere. F. Anterior view. G. Dorsal view. H. Posterior view. I. Right paramere, lateral view. 


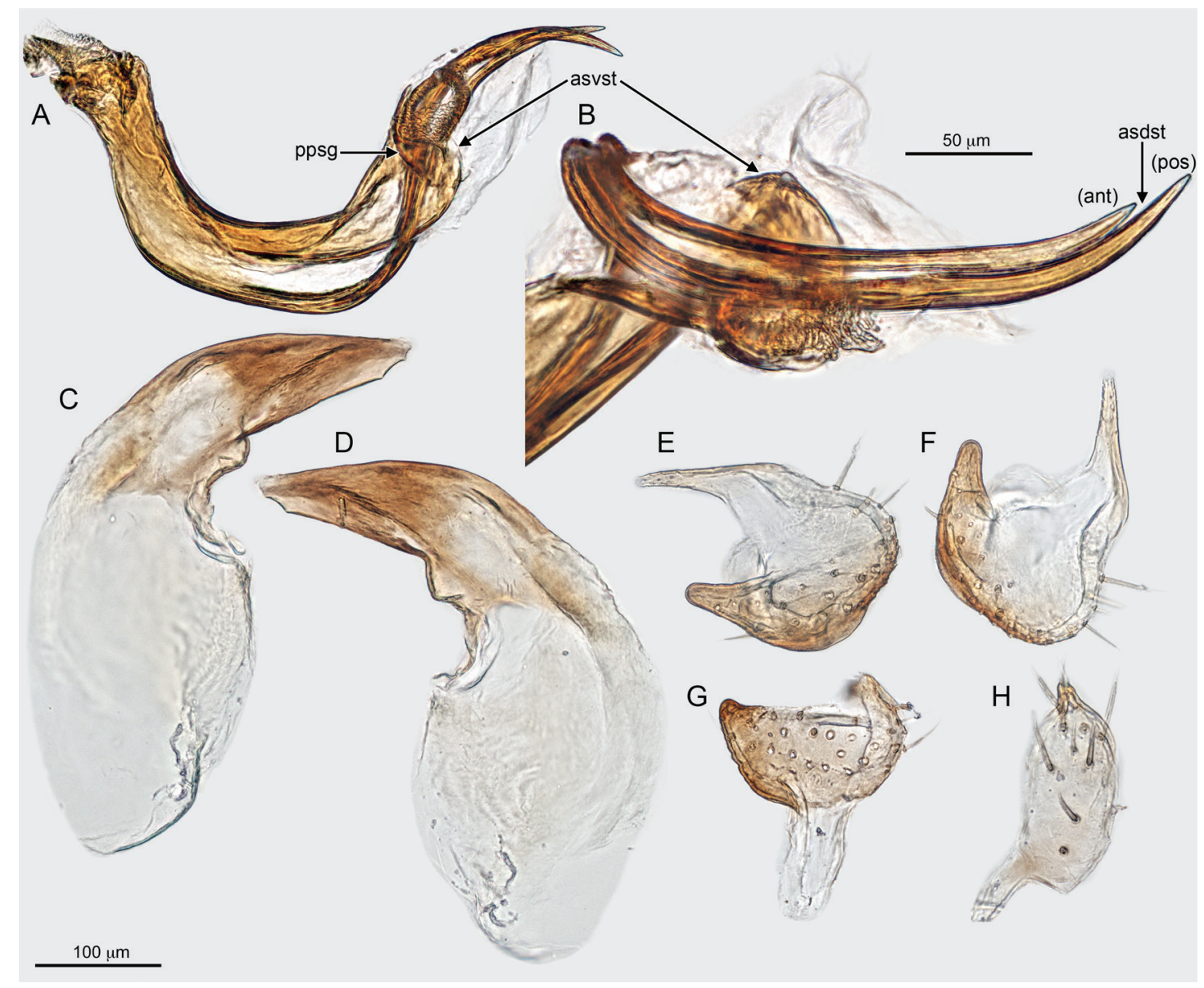

PLATE 10. Melaleucaphylus eremaeae. Digital genitalic images. Male, AMNH_PBI 00136213. A, B: Endosoma A. Left lateral view. B. Detail of apical spines and secondary gonopore, dorsal view. C, D: Phallotheca. C. Anterior view. D. Posterior view. E-G: Left paramere. E. Anterior view. F. Dorsal view. G. Posterior view. H. Right paramere, lateral view. 


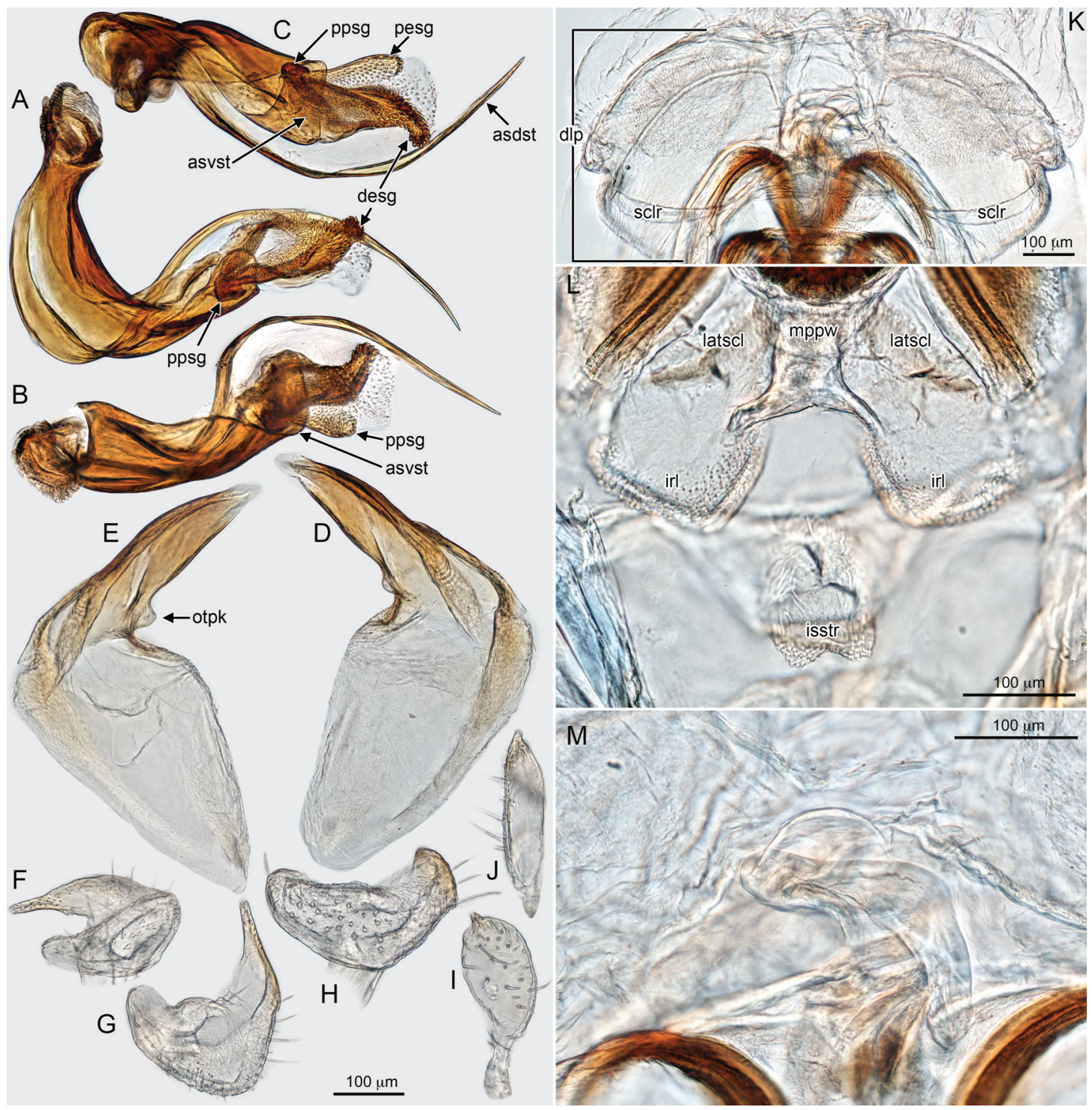

PLATE 11. Melaleucaphylus glomeratae. Digital genitalic images. Male, AMNH_PBI 00418694. A-C: Endosoma A. Left lateral view. B. Dorsal view. C. Caudal view. D, E: Phallotheca. D. Anterior view. E. Posterior view. F-H: Left paramere. F. Anterior view. G. Dorsal view. H. Posterior view. I, J: Right paramere. I. Lateral view. J. Dorsal view. Female, AMNH_PBI 00418728. K. Bursa copulatrix, dorsal view. L. Genital chamber, anteroventral view. $\mathbf{M}$. Vestibular sclerites, anterior view. 

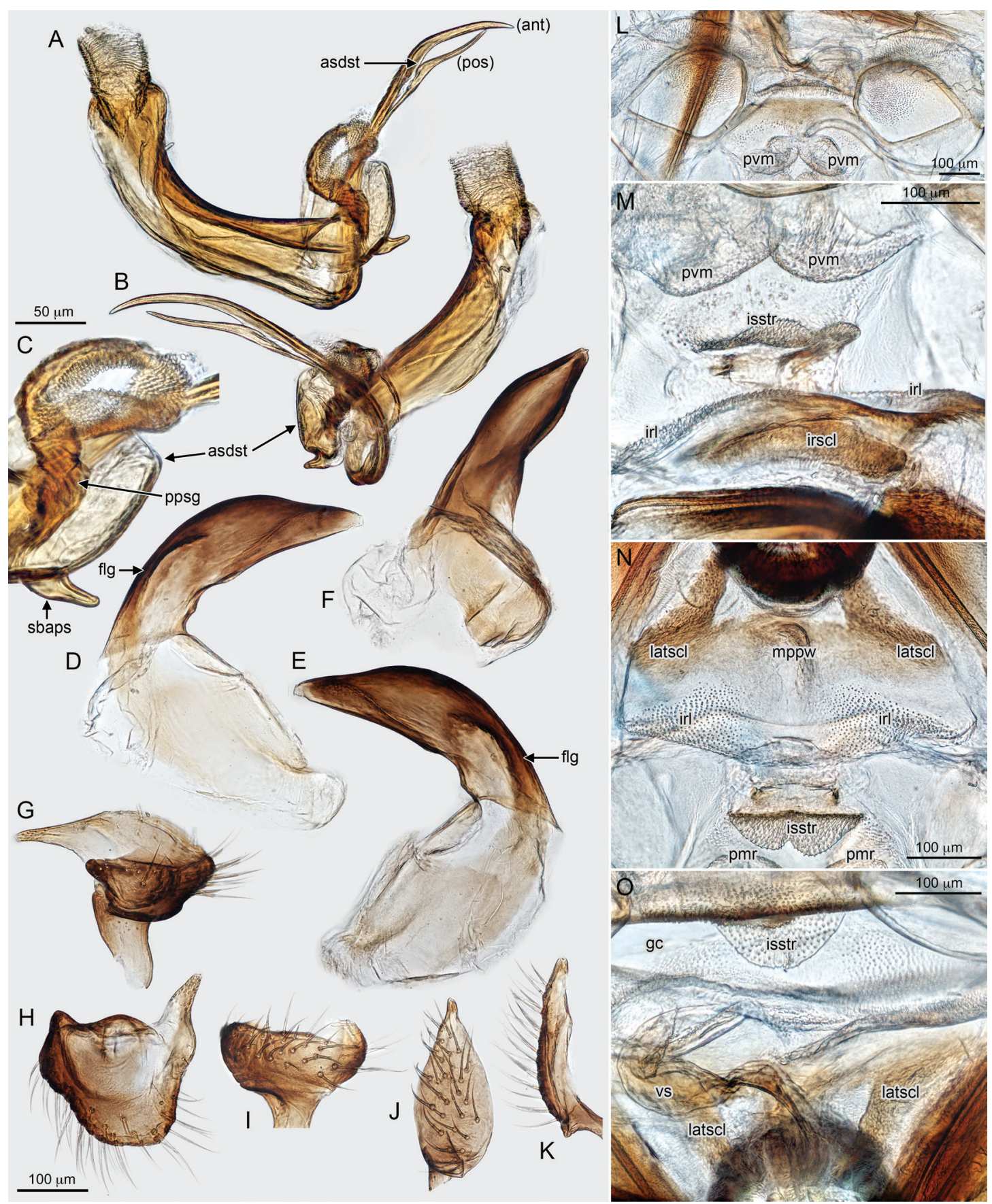

PLATE 12. Melaleucaphylus halmaturorum. Digital genitalic images. Male, AMNH_PBI 00371450. A-C: Endosoma A. Left lateral view. B. Dorsal view. C. Detail of secondary gonopore and subapical spine, left lateral view. D-F: Phallotheca. D. Posterior view. E. Anterior view. F. Ventral view. G-I: Left paramere. G. Anterior view. H. Dorsal view. I. Posterior view. J, K: Right paramere. J. Lateral view. K. Dorsal view. Female, AMNH_ PBI 00059065. L. Bursa copulatrix, dorsal view. M, N: Genital chamber. M. Right lateral view. N. Anteroventral view. $\mathbf{O}$. Vestibular sclerites, anterior view. 


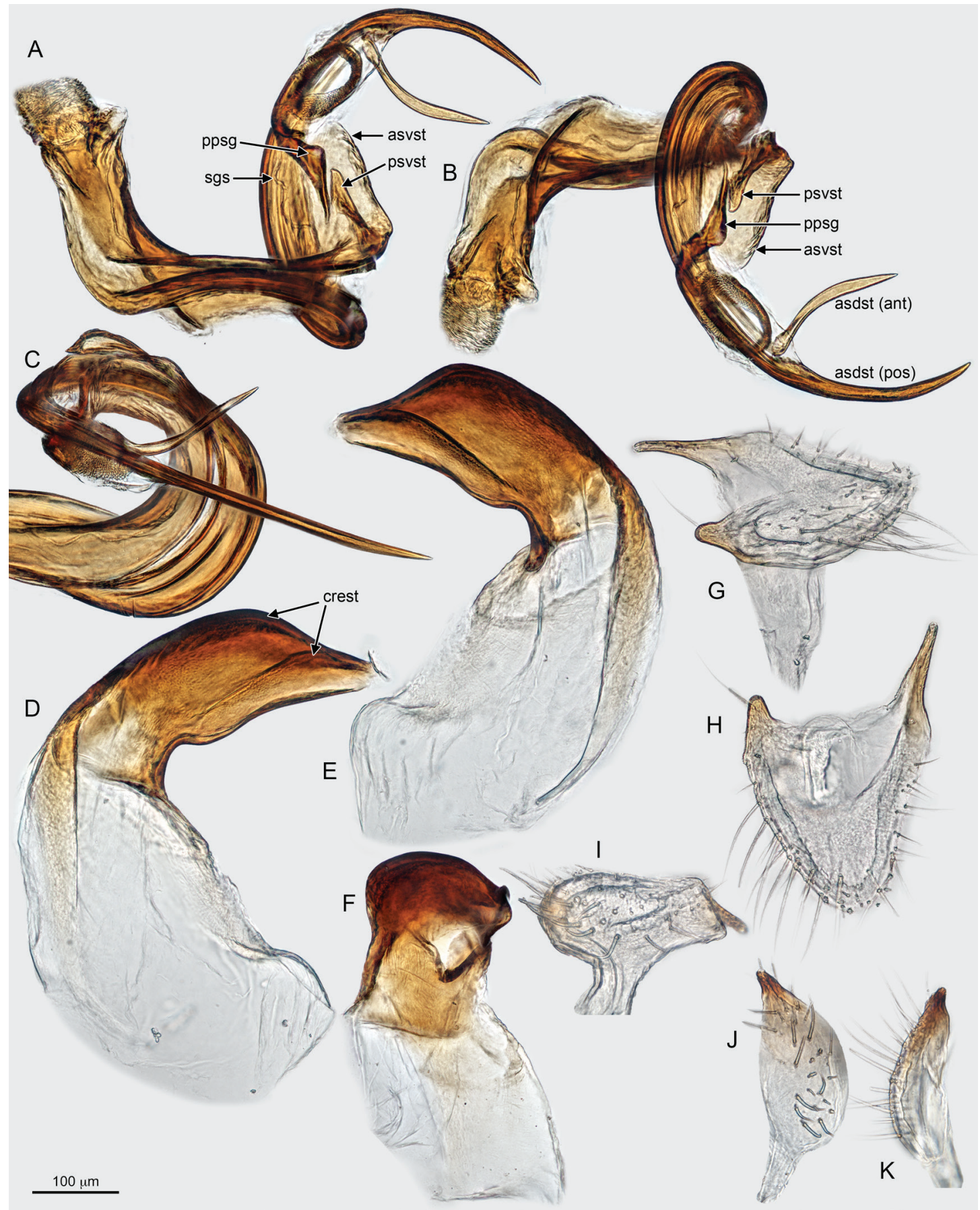

PLATE 13. Melaleucaphylus kaputar. Digital genitalic images. Male, AMNH_PBI 00391148. A-C: Endosoma. A. Left lateral view. B. Right lateral view. C. Detail of apical spines and secondary gonopore, dorsal view. D-F: Phallotheca. D. Anterior view. E. Posterior view. F. Caudal view. G-I: Left paramere. G. Anterior view. H. Dorsal view. I. Posterior view. J, K: Right paramere. J. Lateral view. K. Dorsal view. 


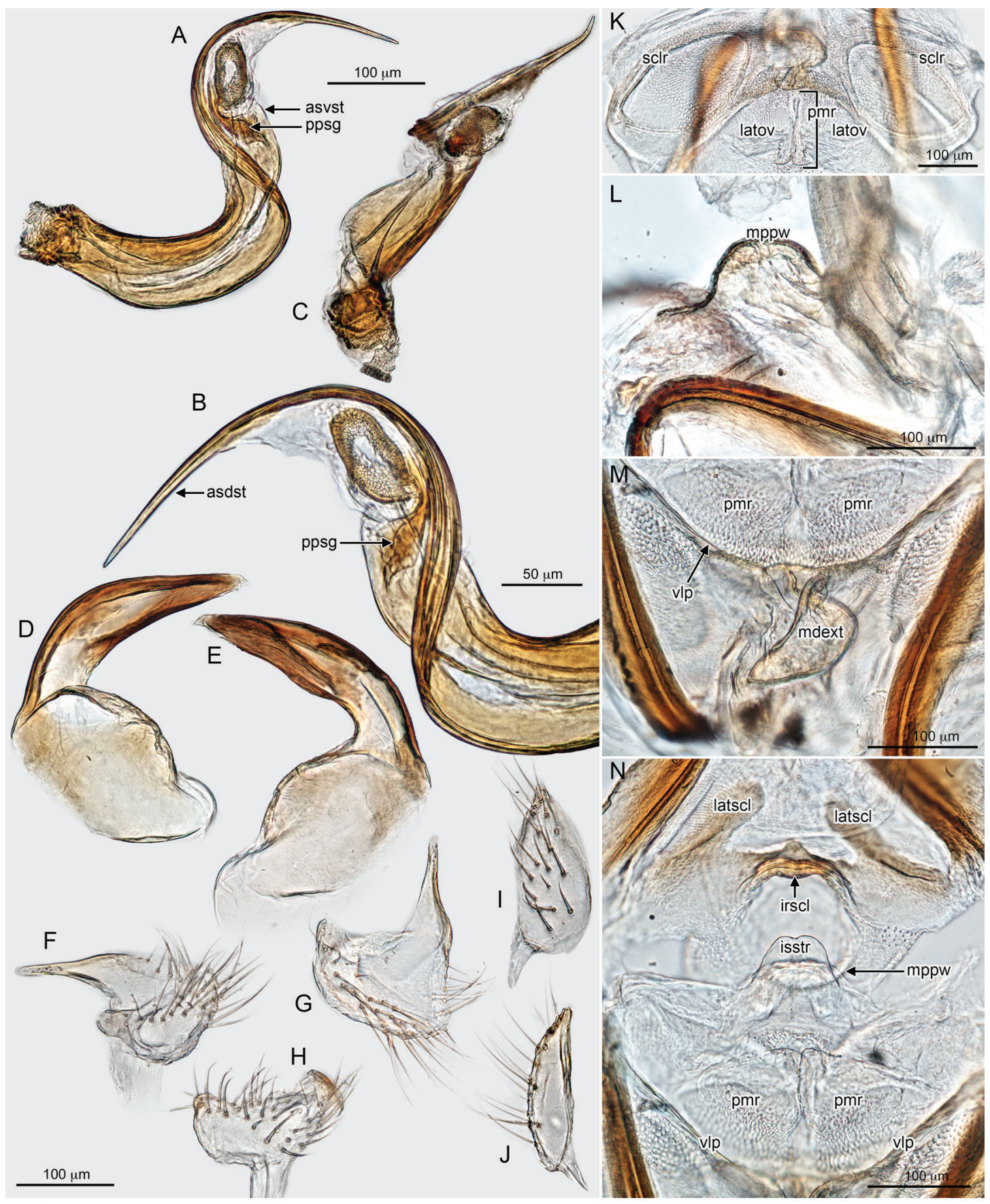

PLATE 14. Melaleucaphylus kunzeae. Digital genitalic images. Male. A-C: Endosoma. A. Left lateral view. B. Detail of secondary gonopore and gonopore process, right lateral view. C. Dorsal view. D, E: Phallotheca. D. Anterior view. E. Posterior view. F-H: Left paramere. F. Anterior view. G. Dorsal view. H. Posterior view. I, J: Right paramere. I. Lateral view. J. Dorsal view. AMNH_PBI 00058633: A-C. AMNH_PBI 00414838: D-J. Female, AMNH_PBI 00128236. K, L: Bursa copulatrix. K. Dorsal view. L. Left lateral view. M. Vestibular sclerites, anterior view. N. Genital chamber, anteroventral view. 

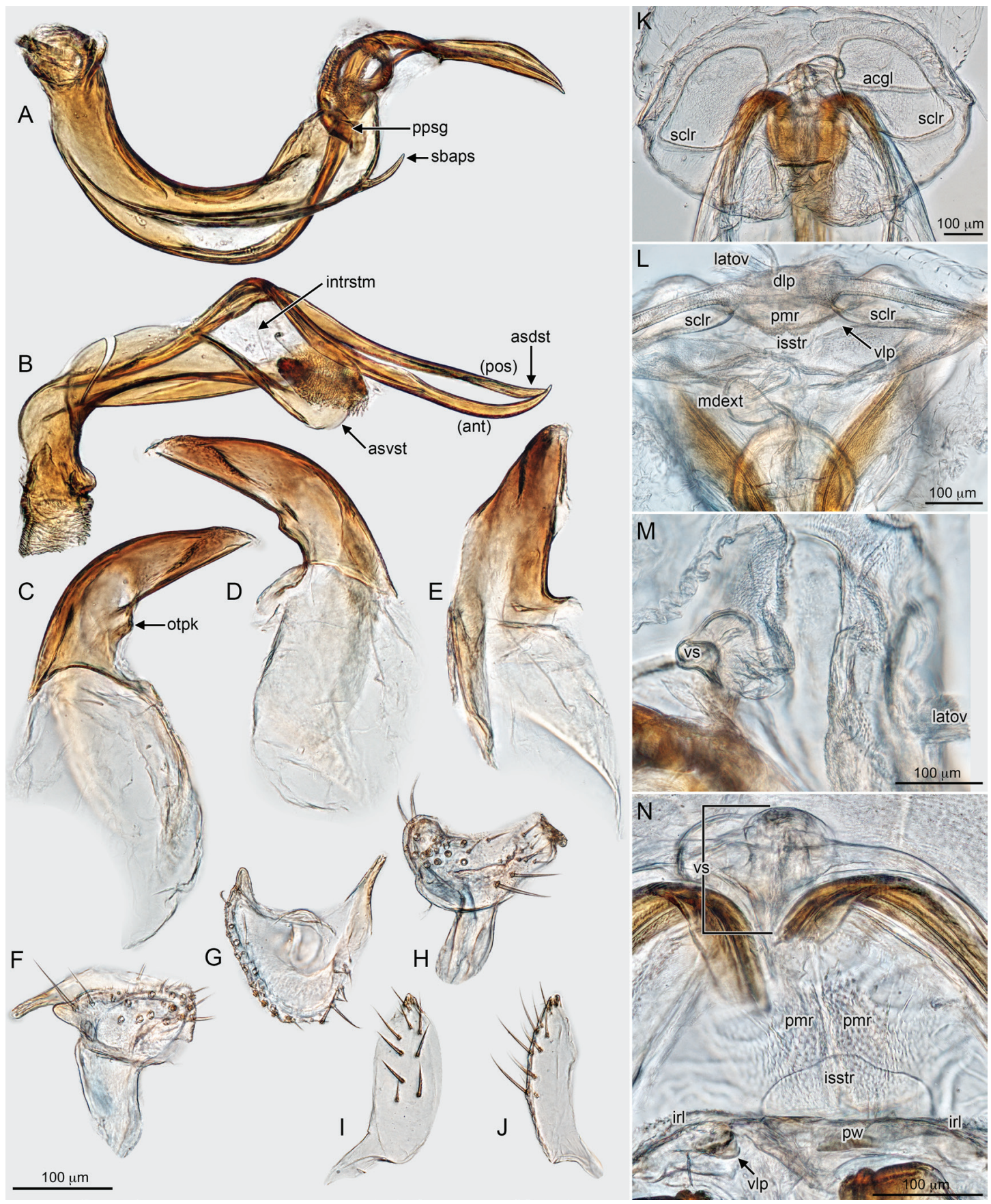

PLATE 15. Melaleucaphylus micranthae. Digital genitalic images. Male, AMNH_PBI 00131447. A, B: Endosoma. A. Left lateral view. B. Dorsal view. C-E: Phallotheca. C. Anterior view. D. Posterior view. E. Dorsal view. F-H: Left paramere. F. Anterior view. G. Dorsal view. H. Posterior view. I, J. Right paramere. I. Lateral view. J. Dorsal view. Female, AMNH_PBI 00131451. K. Bursa copulatrix, dorsal view. L. Vestibular sclerites and genital chamber, anterior view. M. Vestibular sclerites, left lateral view. N. Genital chamber, ventral view. 


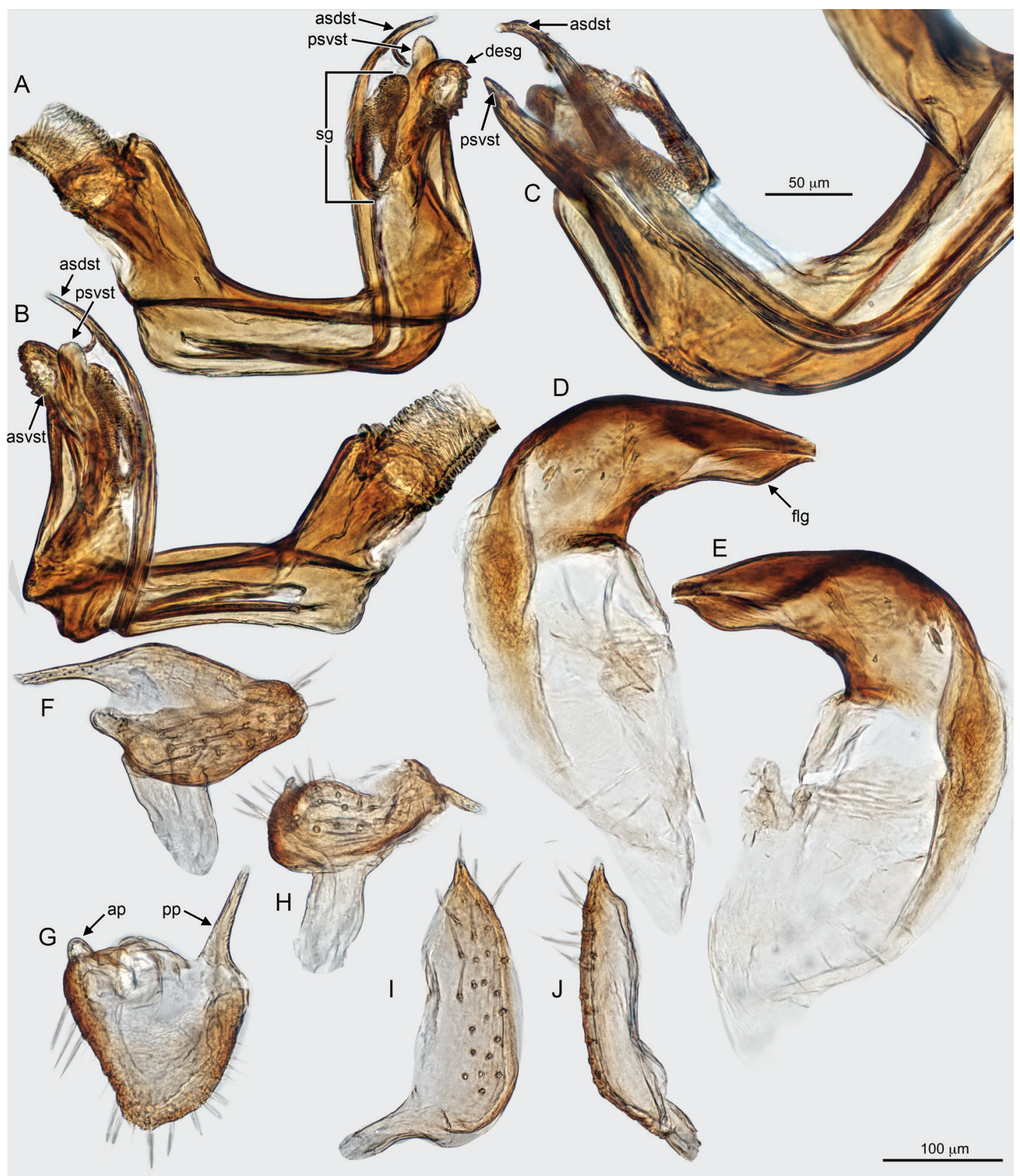

PLATE 16. Melaleucaphylus ngarkat. Digital genitalic images. Male, AMNH_PBI 00130208. A-C: Endosoma. A. Left lateral view. B. Right lateral view. C. Detail of apical spines and secondary gonopore, dorsal view. D, E: Phallotheca. D. Anterior view. E. Posterior view. F-H: Left paramere.F. Anterior view. G. Dorsal view. H. Posterior view. I, J: Right paramere. I. Lateral view. J. Dorsal view. 

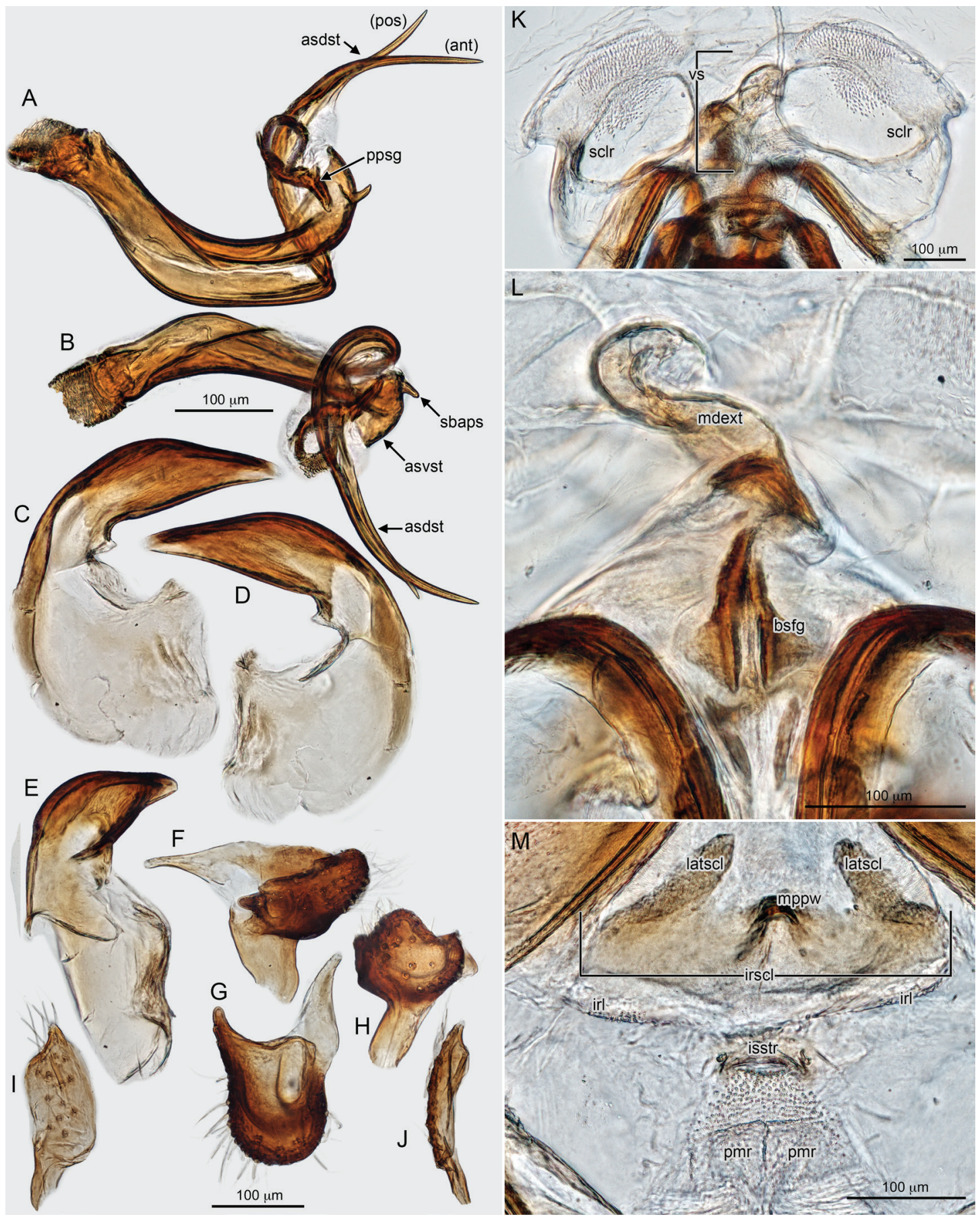

PLATE 17. Melaleucaphylus nodosae. Digital genitalic images. Male, AMNH_PBI 00087444. A, B: Endosoma. A. Left lateral view. B. Dorsal view. C-E: Phallotheca. C. Anterior view. D. Posterior view. E. Caudal view. F-H: Left paramere. F. Anterior view. G. Dorsal view. H. Posterior view. I, J: Right paramere. I. Lateral view. J. Dorsal view. Female, AMNH_PBI 00132884. K. Bursa copulatrix, dorsal view. L. Vestibular sclerites, anterior view. M. Posterior wall, anteroventral view. 


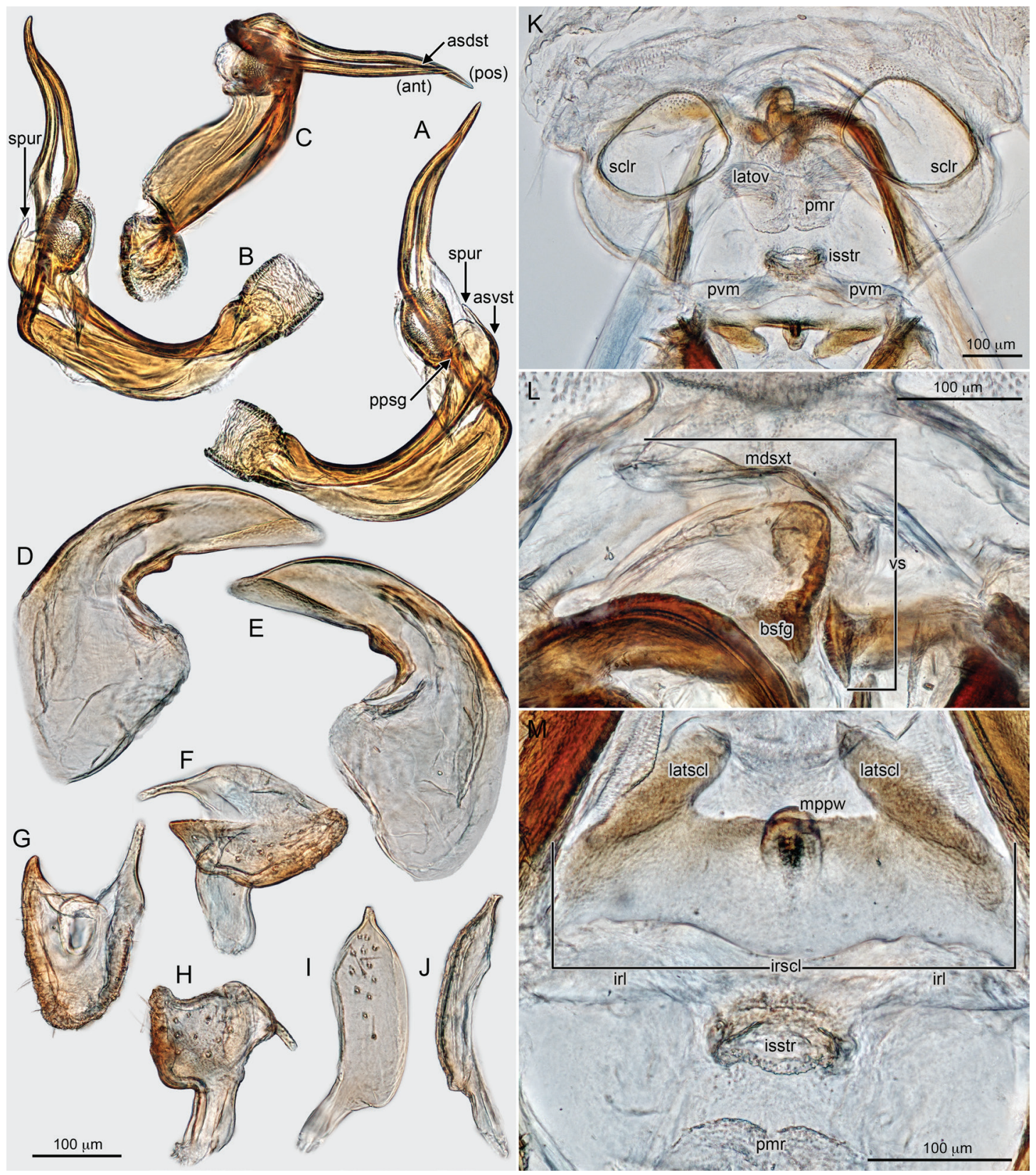

PLATE 18. Melaleucaphylus omnivorus. Digital genitalic images. Male, AMNH_PBI 00087579. A-C: Endosoma. A. Left lateral view. B. Right lateral view. C. Dorsal view. D, E: Phallotheca. D. Anterior view. E. Posterior view. F-H: Left paramere. F. Anterior view. G. Dorsal view. H. Posterior view. I, J: Right paramere. I. Lateral view. J. Dorsal view. Female, AMNH_PBI 00393463. K. Bursa copulatrix, dorsal view. L. Vestibular sclerites, anterior view. M. Genital chamber with posterior wall, anteroventral view. 


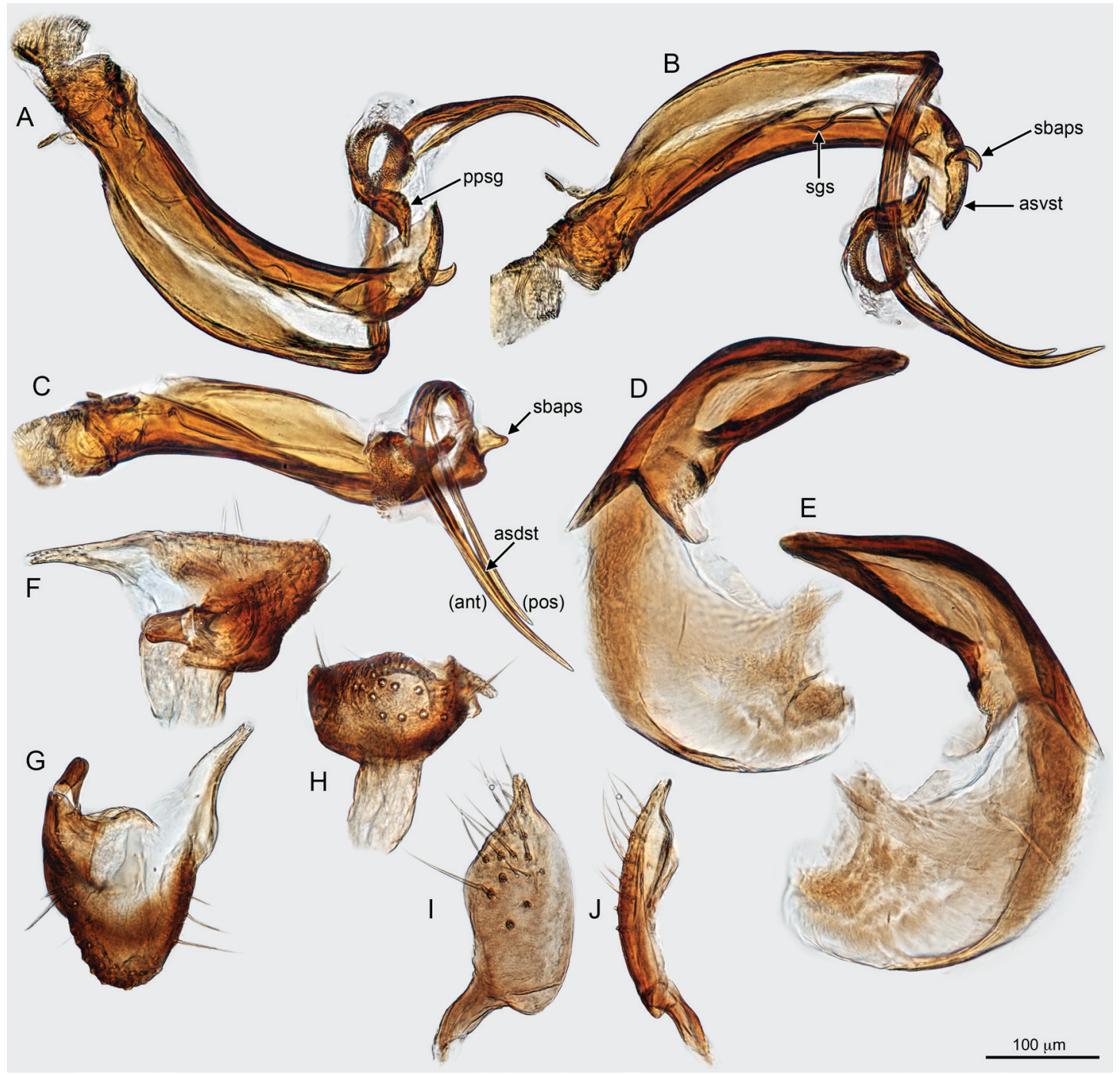

PLATE 19. Melaleucaphylus pauperiflorae. Digital genitalic images. Male, AMNH_PBI 00390855. A-C: Endosoma. A. Left lateral view. B. Right lateral view. C. Detail of apical spines and secondary gonopore, dorsal view. D, E: Phallotheca. D. Anterior view. E. Posterior view. F-H: Left paramere. F. Anterior view. G. Dorsal view. H. Posterior view. I, J: Right paramere. I. Lateral view. J. Dorsal view. 

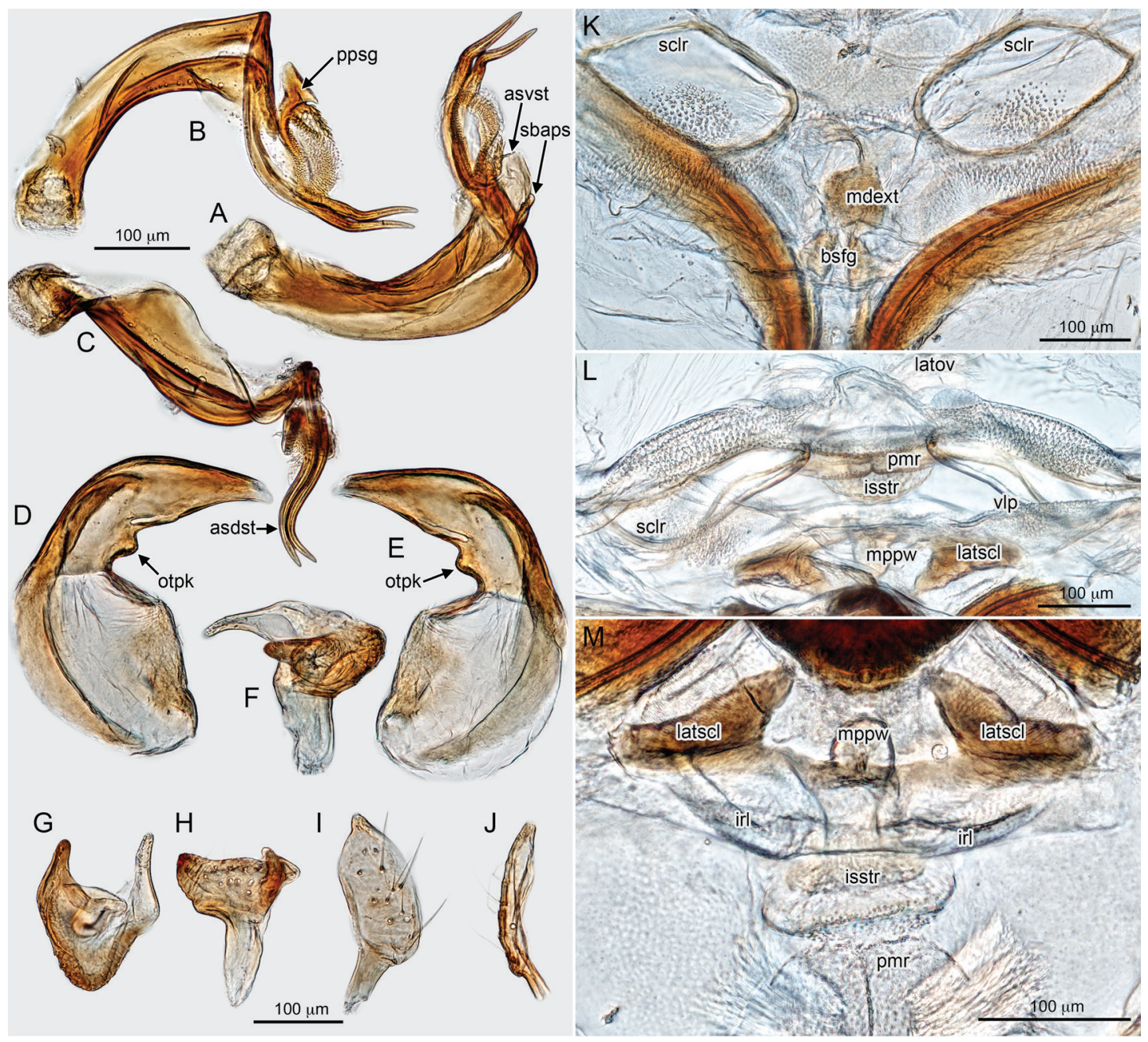

PLATE 20. Melaleucaphylus phymatocarpi. Digital genitalic images. Male. A-C: Endosoma. A. Left lateral view. B. Right lateral view. C. Dorsal view. D, E: Phallotheca. D. Anterior view. E. Posterior view. F-H: Left paramere. F. Anterior view. G. Dorsal view. H. Posterior view. I, J: Right paramere. I. Lateral view. J. Dorsal view. AMNH_PBI 00136643: B, C-J. AMNH_PBI 00368519: A. Female, AMNH_PBI 00136663. K. Bursa copulatrix and vestibular sclerites, anteroventral view. L. Genital chamber, anterior view. M. Posterior wall, anteroventral view. 

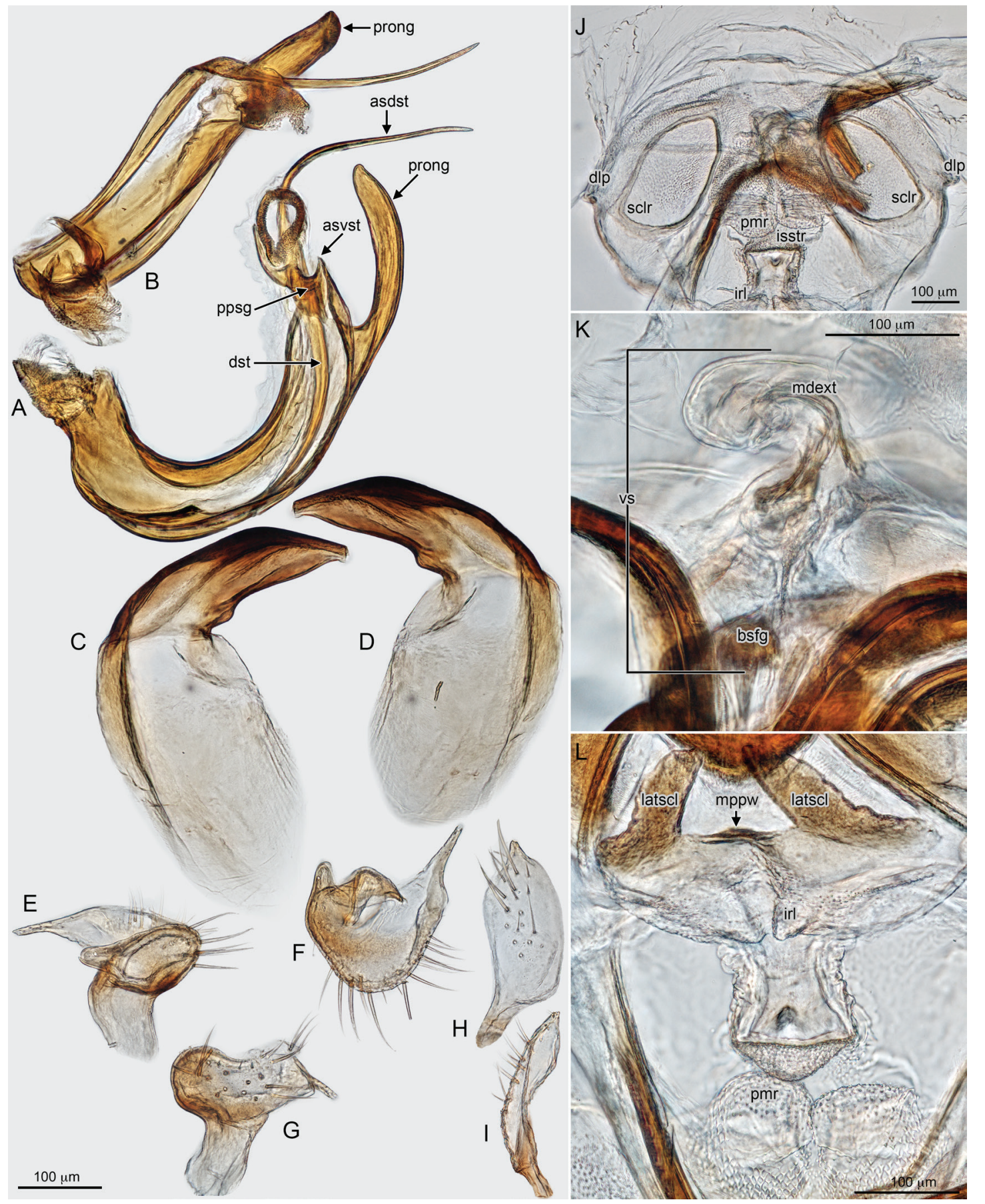

PLATE 21. Melaleucaphylus polyphagus. Digital genitalic images. Male, AMNH_PBI 00391145. A, B: Endosoma. A. Left lateral view. B. Dorsal view. C, D: Phallotheca. C. Anterior view. D. Posterior view. E-G: Left paramere. E. Anterior view. F. Dorsal view. G. Posterior view. H, I: Right paramere. H. Lateral view. I. Dorsal view. Female, AMNH_PBI 00132597. J. Bursa copulatrix, dorsal view. K. Vestibular sclerites, anterior view. L. Genital chamber with posterior wall, anteroventral view. 


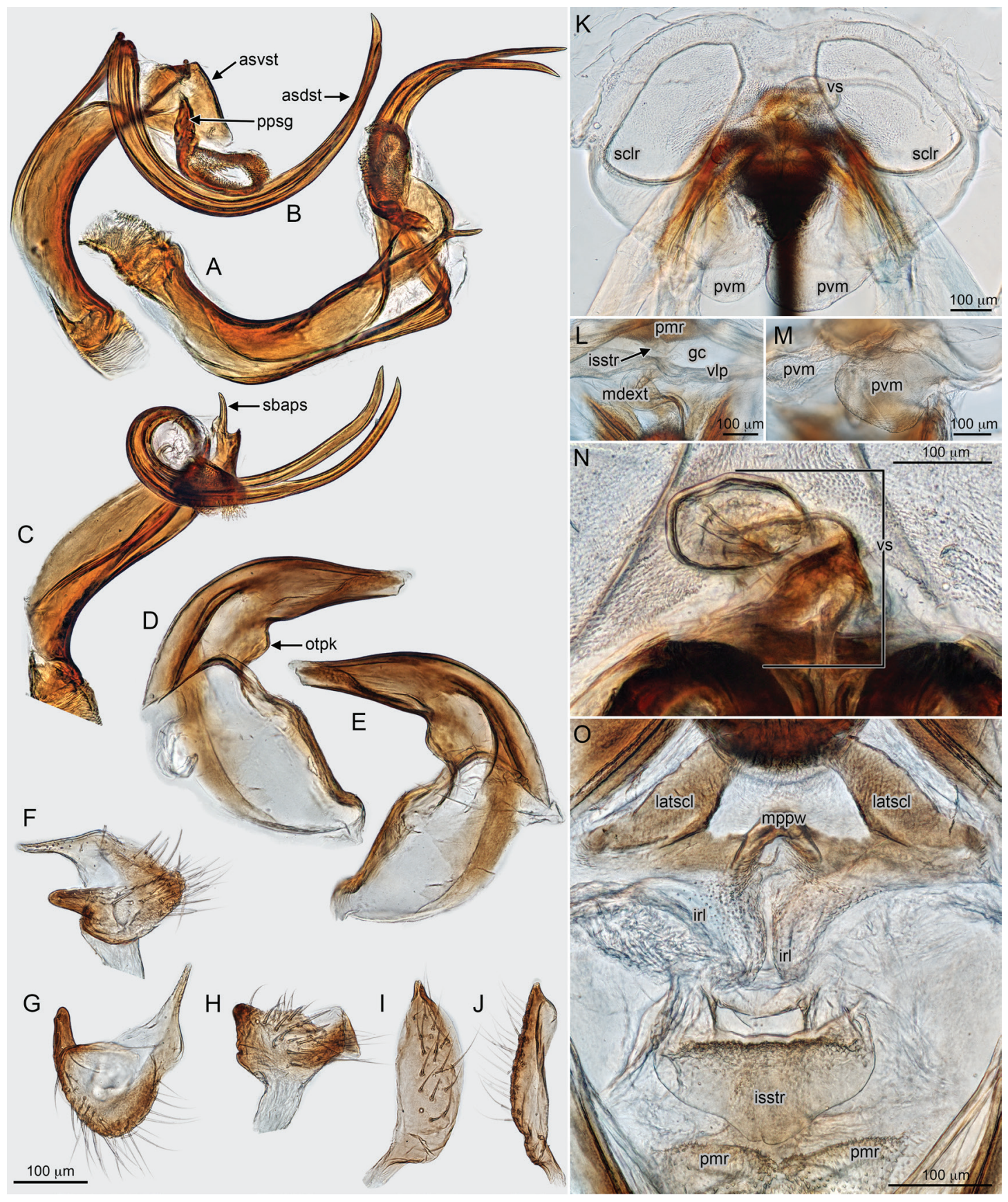

PLATE 22. Melaleucaphylus rhaphiophyllae. Digital genitalic images. Male, AMNH_PBI 00393330. A-C: Endosoma. A. Left lateral view. B. Right lateral view. C. Dorsal view. D, E: Phallotheca. D. Anterior view. E. Posterior view. F-H: Left paramere. F. Anterior view. G. Dorsal view. H. Posterior view. I, J: Right paramere. I. Lateral view. J. Dorsal view. Female. K. Bursa copulatrix, dorsal view. L. Vestibular sclerites and genital chamber, anterior view. M. Dorsal labiate plate, posterior view. N. Vestibular sclerites, ventral view. O. Genital chamber with posterior wall, anteroventral view. AMNH_PBI 003691161: L, M, O. AMNH_PBI 00414836: K, N. 


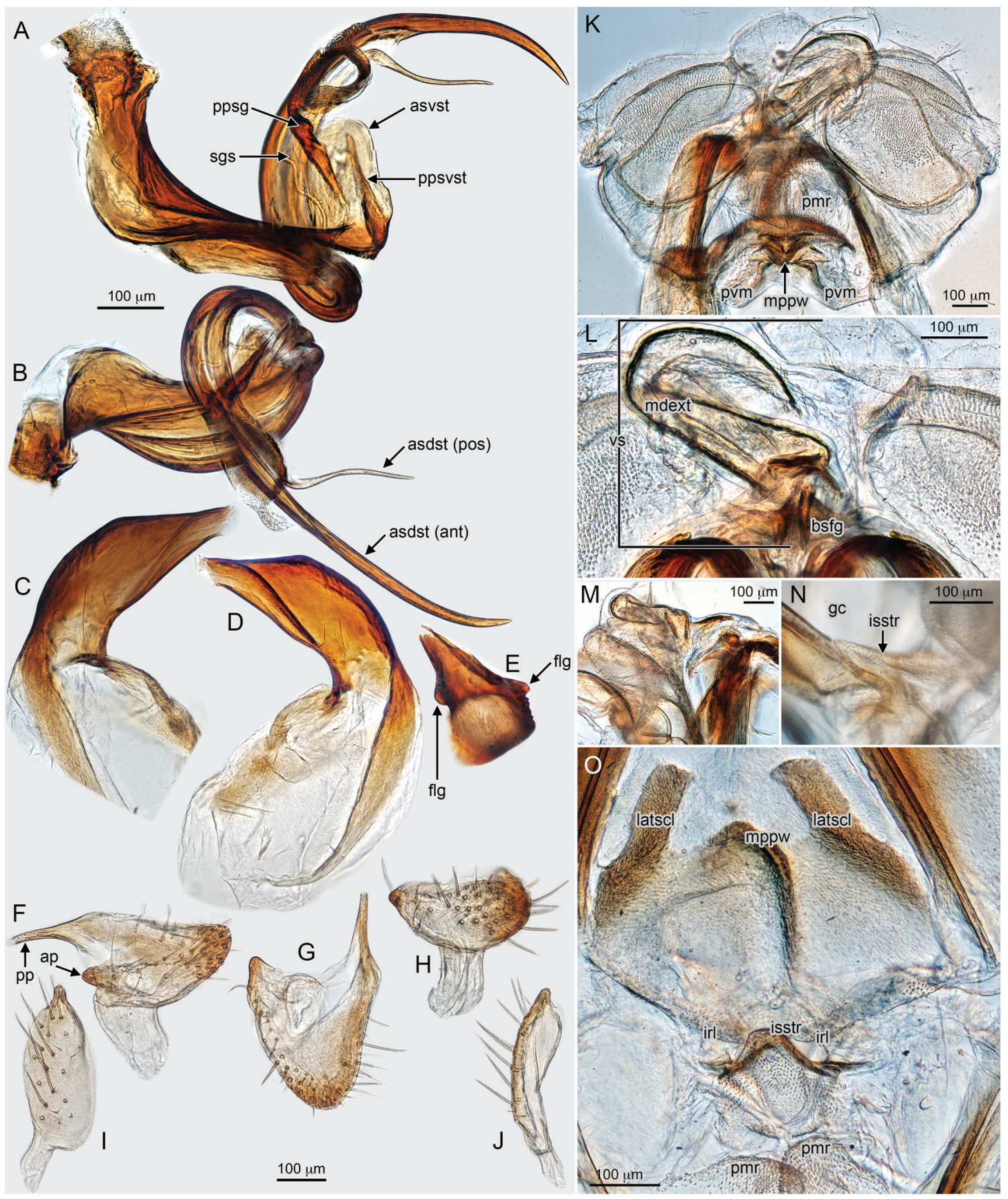

PLATE 23. Melaleucaphylus sheathianae. Digital genitalic images. Male, AMNH_PBI 00370822. A, B: Endosoma. A. Left lateral view. B. Dorsal view. C-E: Phallotheca. C. Anterior view. D. Posterior view. E. Caudal view. F-H: Left paramere. F. Anterior view. G. Dorsal view. H. Posterior view. I, J: Right paramere. I. Lateral view. J. Dorsal view. Female. K. Bursa copulatrix, dorsal view. L. Vestibular sclerites, ventral view. M. Vestibular sclerites, right lateral view. N. Intersegmental process, right lateral view. $\mathbf{O}$. Genital chamber with posterior wall, anteroventral view. AMNH_PBI 00087109: K-M. AMNH_PBI 00091687: N, O. 


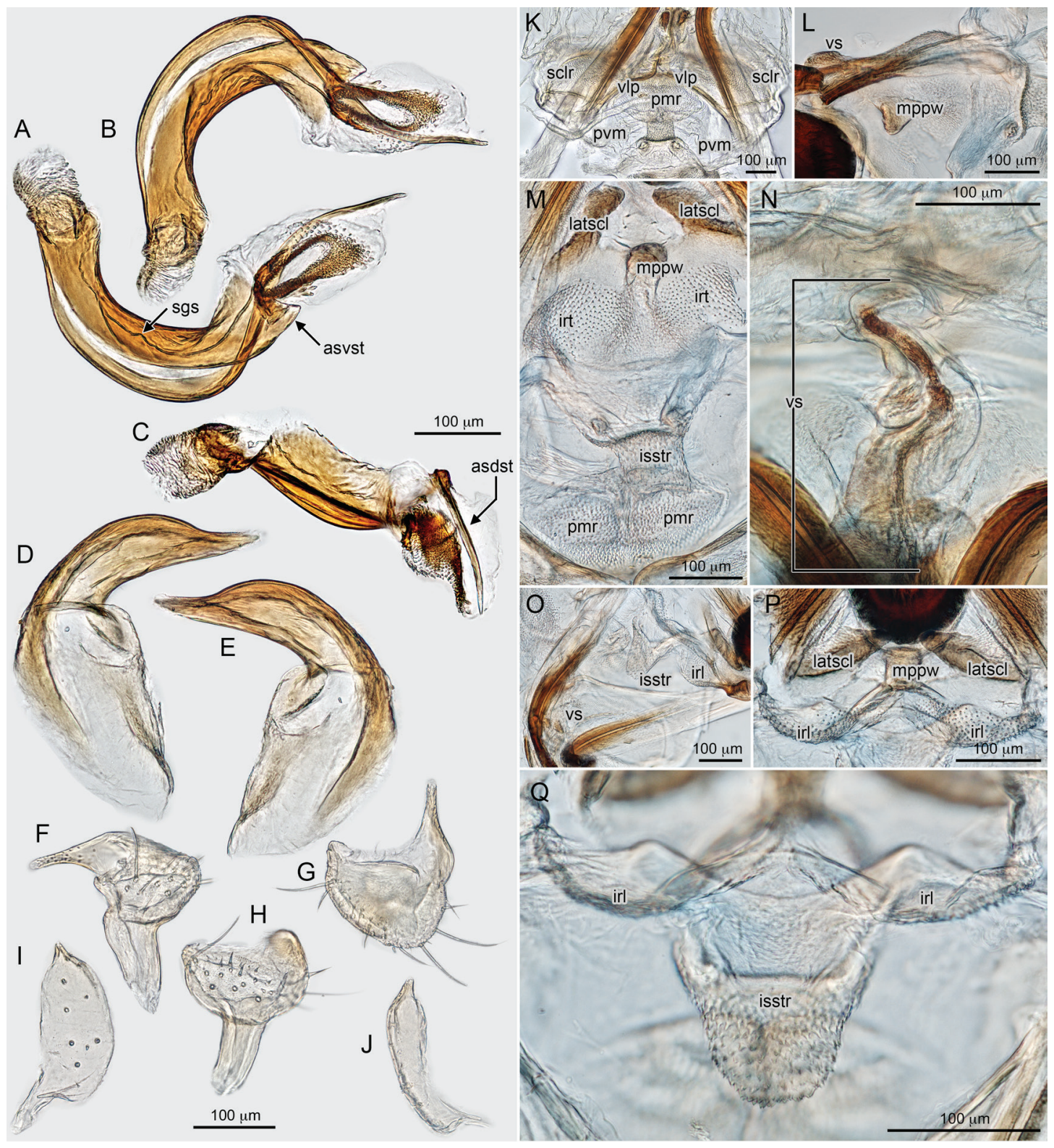

PLATE 24. Melaleucaphylus vimineae. Digital genitalic images. Male, AMNH_PBI 00393540. A-C: Endosoma. A. Left lateral view. B. Right lateral view. C. Dorsal view. D, E: Phallotheca. D. Anterior view. E. Posterior view. F-H: Left paramere. F. Anterior view. G. Dorsal view. H. Posterior view. I, J: Right paramere. I. Lateral view. J. Dorsal view. Female. K. Bursa copulatrix, ventral view. L. Genital chamber with midline structure of posterior wall, left dorsolateral view. M. Genital chamber, ventral view. N. Vestibular sclerites, posterior view. O. Genital chamber with intersegmental process left lateral view. P. Posterior wall, ventral view. Q. Intersegmental process, ventral view. AMNH_PBI 00128711: K-M. AMNH_PBI 00130650: N-Q. 

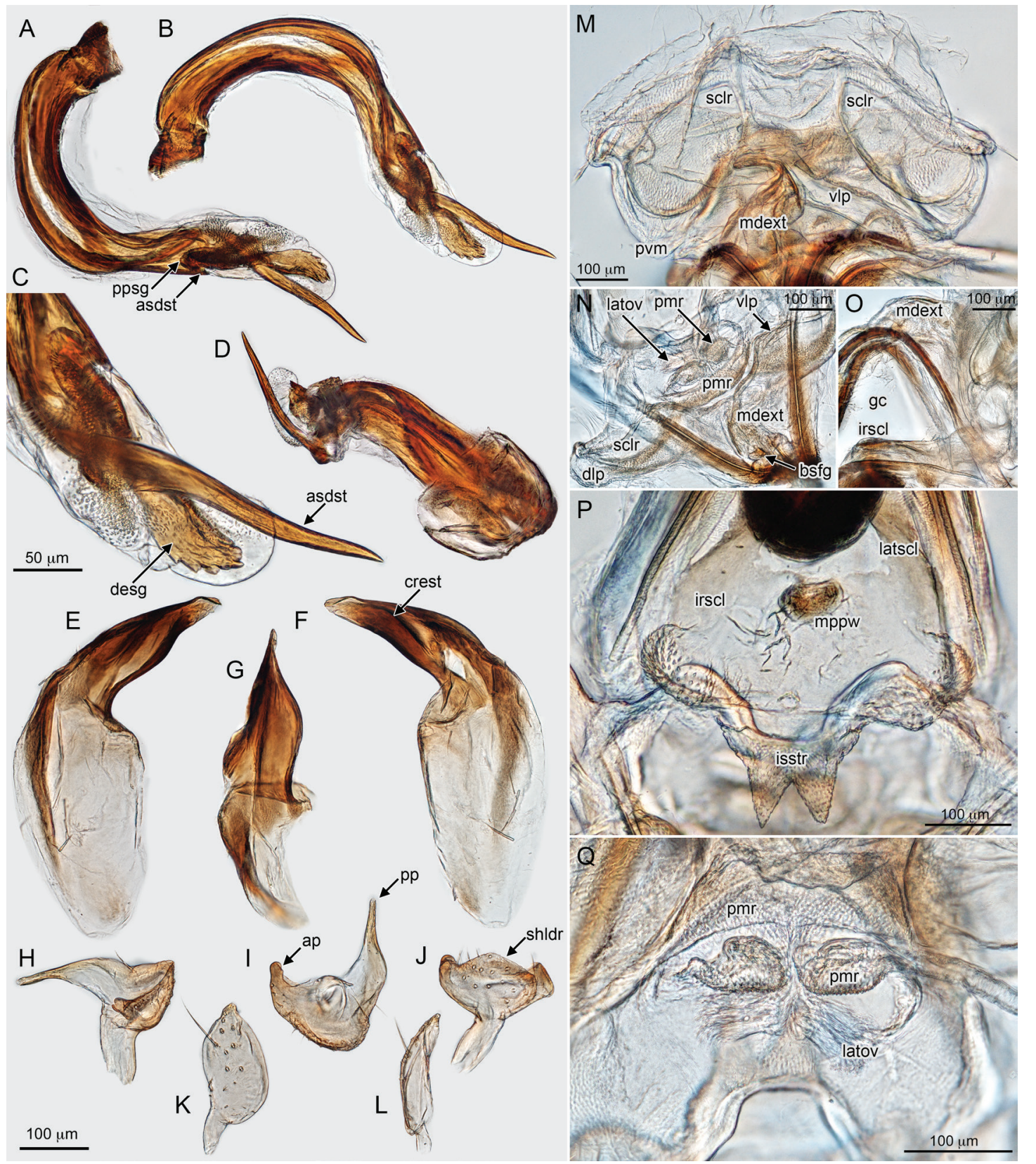

PLATE 25. Melaleucaphylus viridiflorae. Digital genitalic images. Male, UNSW_PBI 00025507. A-D: Endosoma. A. Left lateral view. B. Right lateral view. C. Detail of secondary gonopore and apical spines, right lateral view. D. Dorsal view. E-G: Phallotheca. E. Anterior view. F. Posterior view. G. Dorsal view. H-J: Left paramere. H. Anterior view. I. Dorsal view. J. Posterior view. K, L: Right paramere. K. Lateral view. L. Dorsal view. Female, UNSW_PBI 0002550. M. Bursa copulatrix (sclerotized rings, vestibular sclerites), anteroventral view. N. Vestibular sclerites, anterior view. O. Bursa copulatrix, genital chamber (vestibular sclerites, posterior wall), left lateral view. P. Posterior wall and intersegmental process, anteroventral view. Q. Dorsal labiate plate with medial plates, dorsal view. 


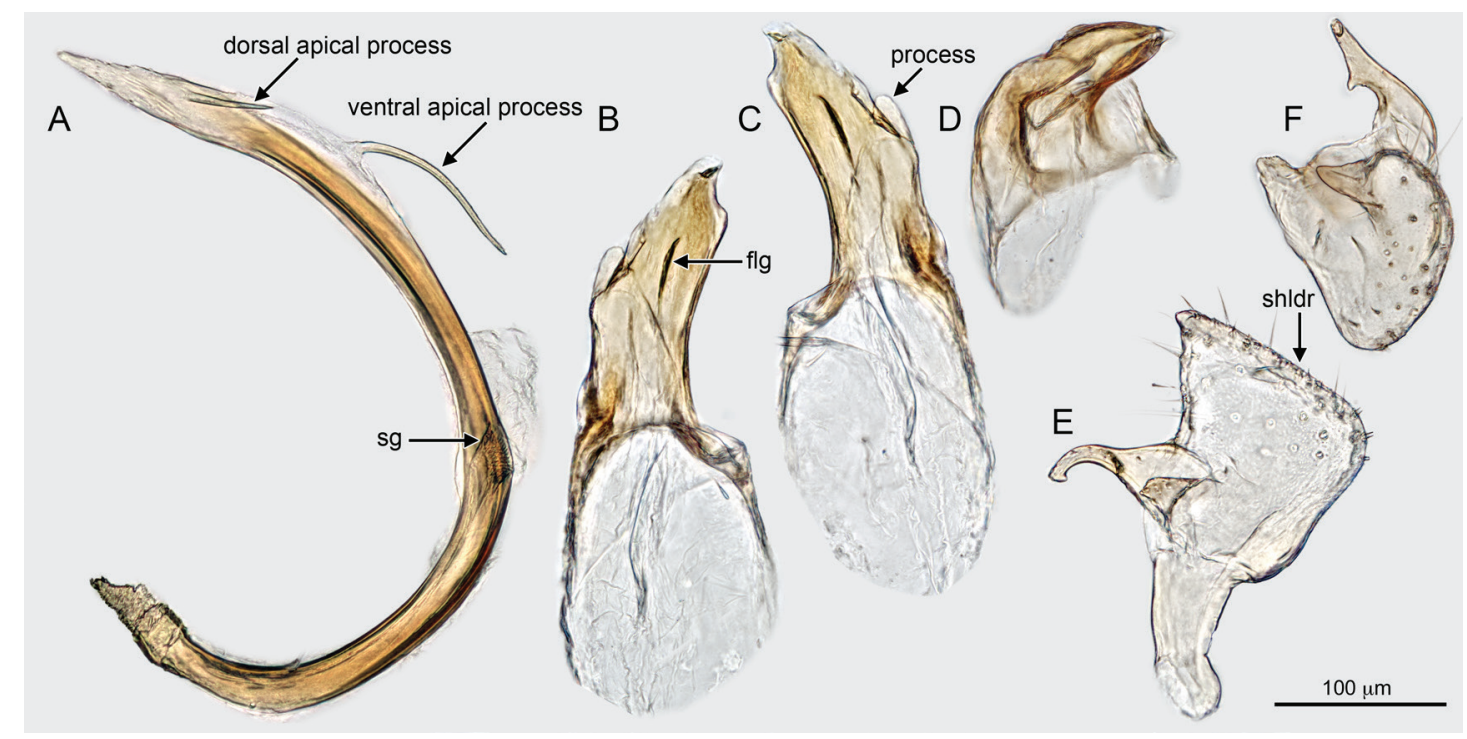

PLATE 26. Ancoraphylus victoriensis. Digital genitalic images. Male, AMNH_PBI 00414830. A. Endosoma, left lateral view. B-D: Phallotheca. B. Anterior view. C. Posterior view. D. Caudal, view. E, F: Left paramere. E. Anterior view. F. Dorsal view. 


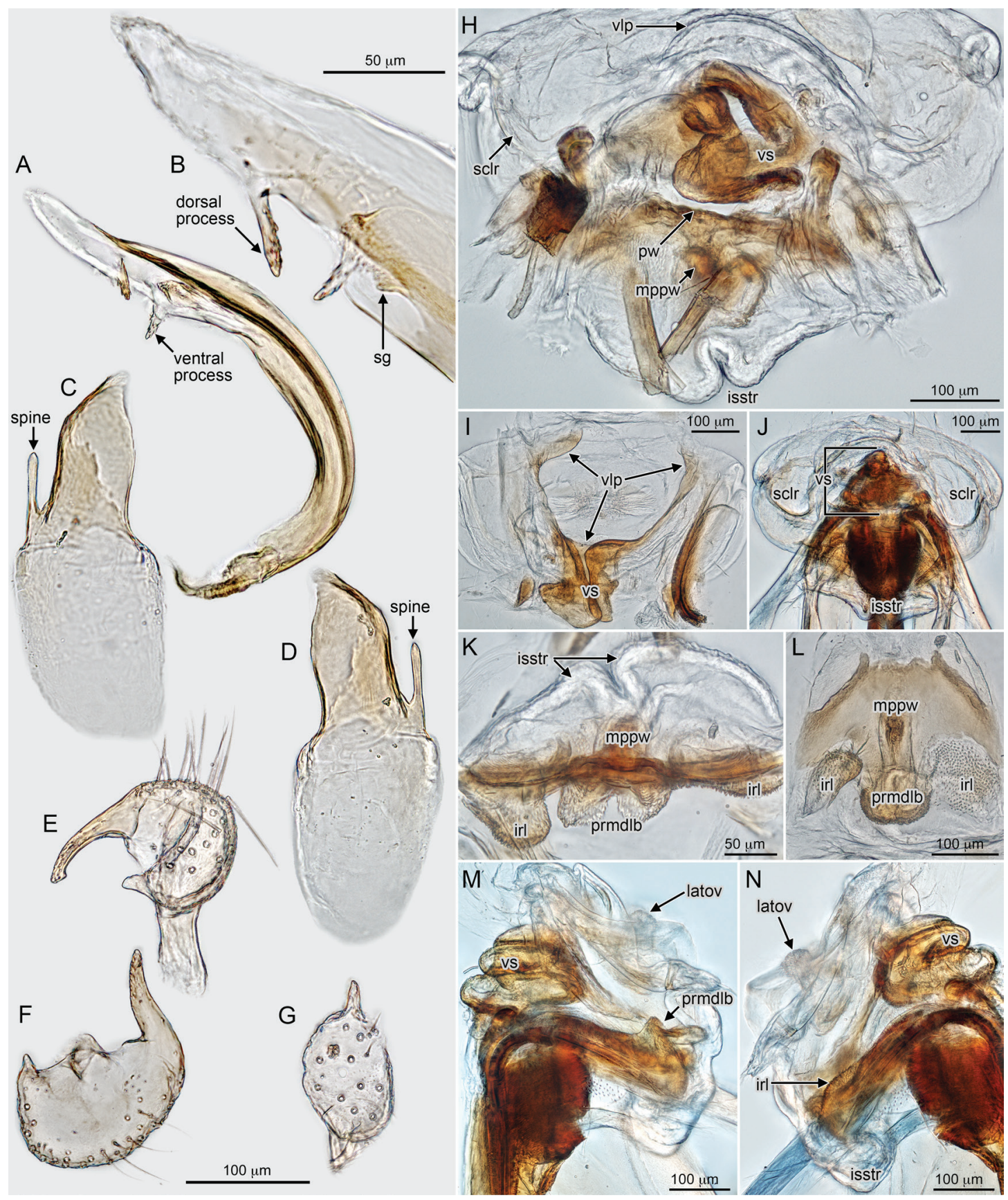

PLATE 27. Calytriphylus menzies. Digital genitalic images. Male, AMNH_PBI 00128941. A, B: Endosoma. A. Left lateral view. B. Detail of secondary gonopore and apical spines, left lateral view. C, D: Phallotheca. C. Anterior view. D. Posterior view. E, F: Left paramere. E. Anterior view. F. Dorsal view. G. Right paramere. Female, AMNH_PBI 00087224. H. Bursa copulatrix with vestibular sclerites, anteroventral view. I. Vestibular sclerites, ventral view. J. Bursa copulatrix with sclerotized rings, dorsal view. K, L: Posterior wall. K. Ventral view. L. Anterior view. M, N: Bursa copulatrix, vestibular sclerites. M. Left lateral view. N. Right lateral view. 


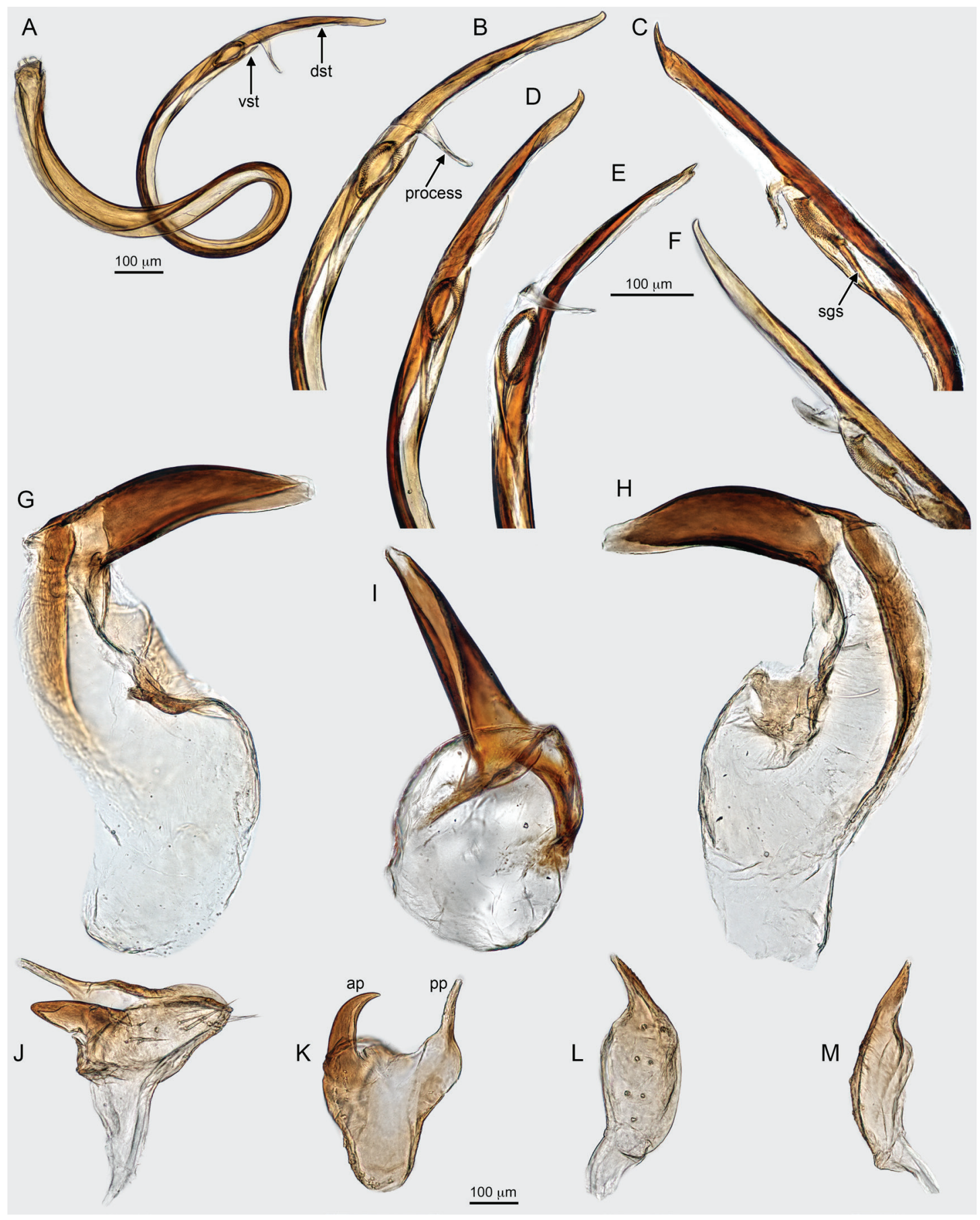

PLATE 28. Leptospermia anatoles. Digital genitalic images. Male. A-F: Endosoma. A, B. Left lateral view. C, F. Ventral view. D. Left ventral view. E. Left lateral view. G-I: Phallotheca. G. Anterior view. H. Posterior view. I. Ventral view. J, K: Left paramere. J. Anterior view. K. Dorsal view. L, M: Right paramere. L. Lateral view. M. Dorsal view. AMNH_PBI 00088863: C, D, F-M. AMNH_PBI 00132889: A, B. AMNH_PBI 00393415: E. 


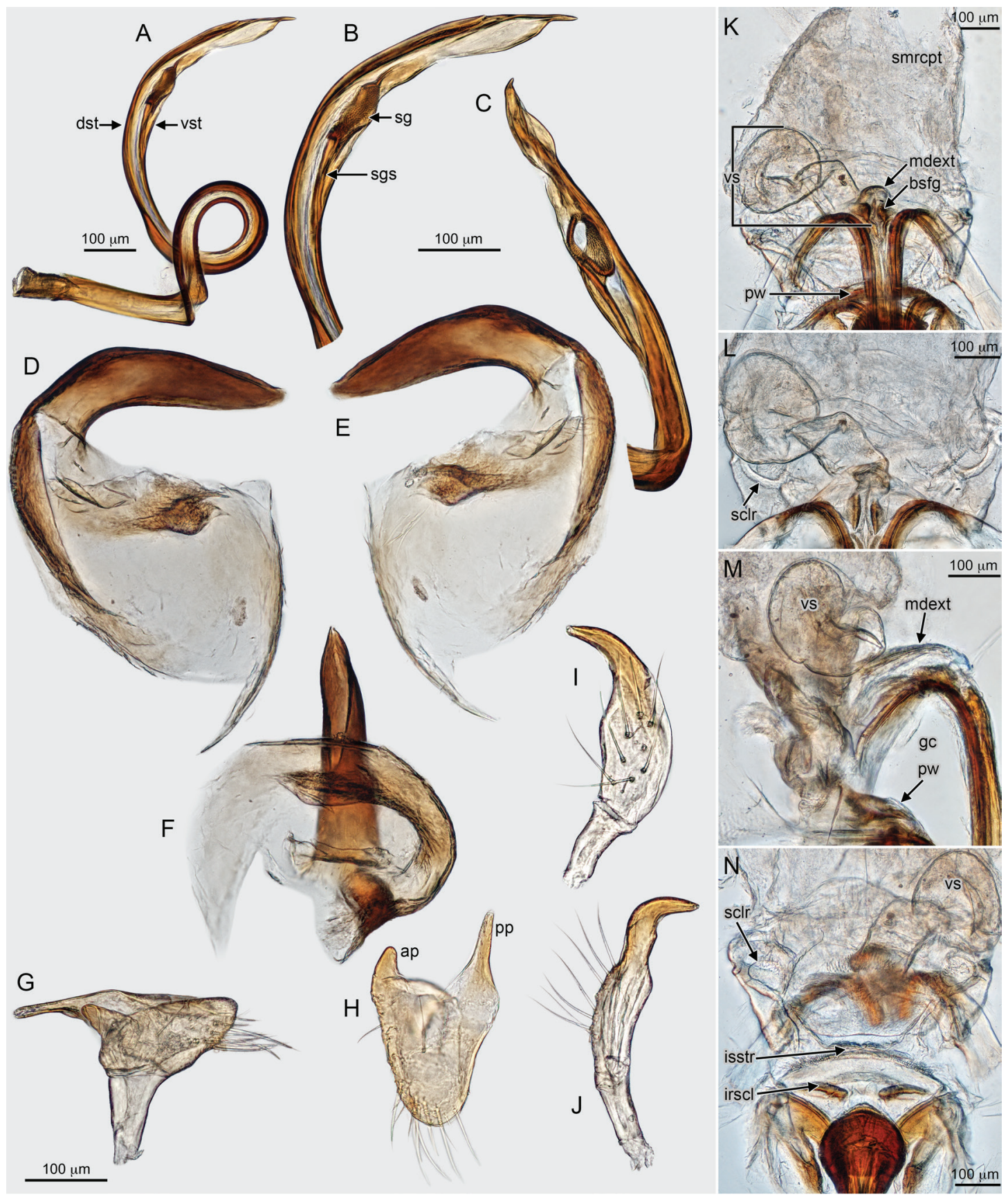

PLATE 29. Leptospermia cassisi. Digital genitalic images. Male, AMNH_PBI 00136831. A-C: Endosoma. A. Left lateral view. B, C: Detail of secondary gonopore and apical spine. B. Left lateral view. C. Ventral view. D-F: Phallotheca. D. Anterior view. E. Posterior view. F. Ventral view. G, H: Left paramere. G. Anterior view. H. Dorsal view. I, J: Right paramere. I. Lateral view. J. Dorsal view. Female, AMNH_PBI 00412994. K-N: Bursa copulatrix. K. Seminal depository and vestibular sclerites, ventral view. L. Dorsal labiate plate and vestibular sclerites, ventral view. M. Vestibular sclerites and posterior wall, right lateral view. N. Genital chamber and posterior wall, dorsal view. 

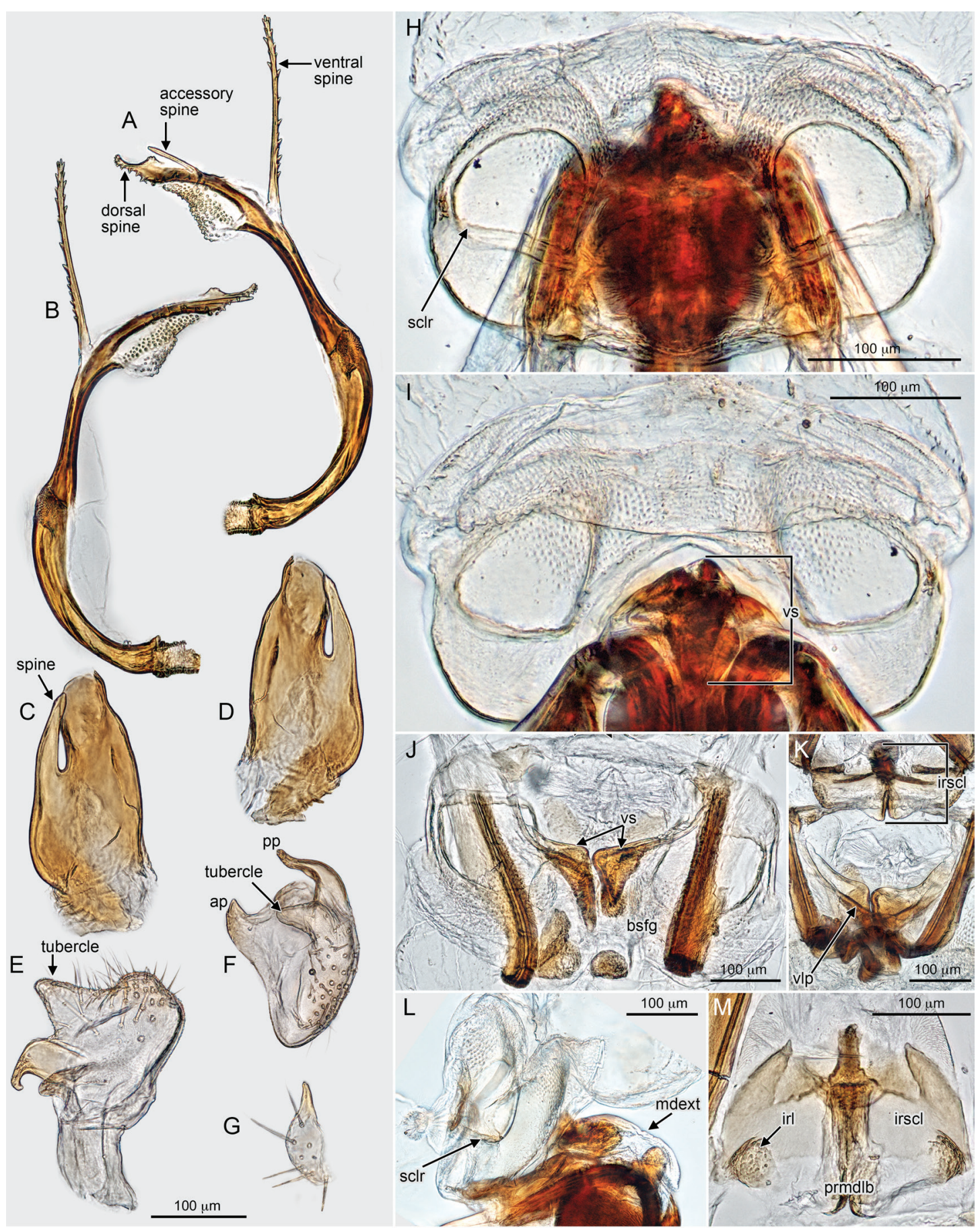


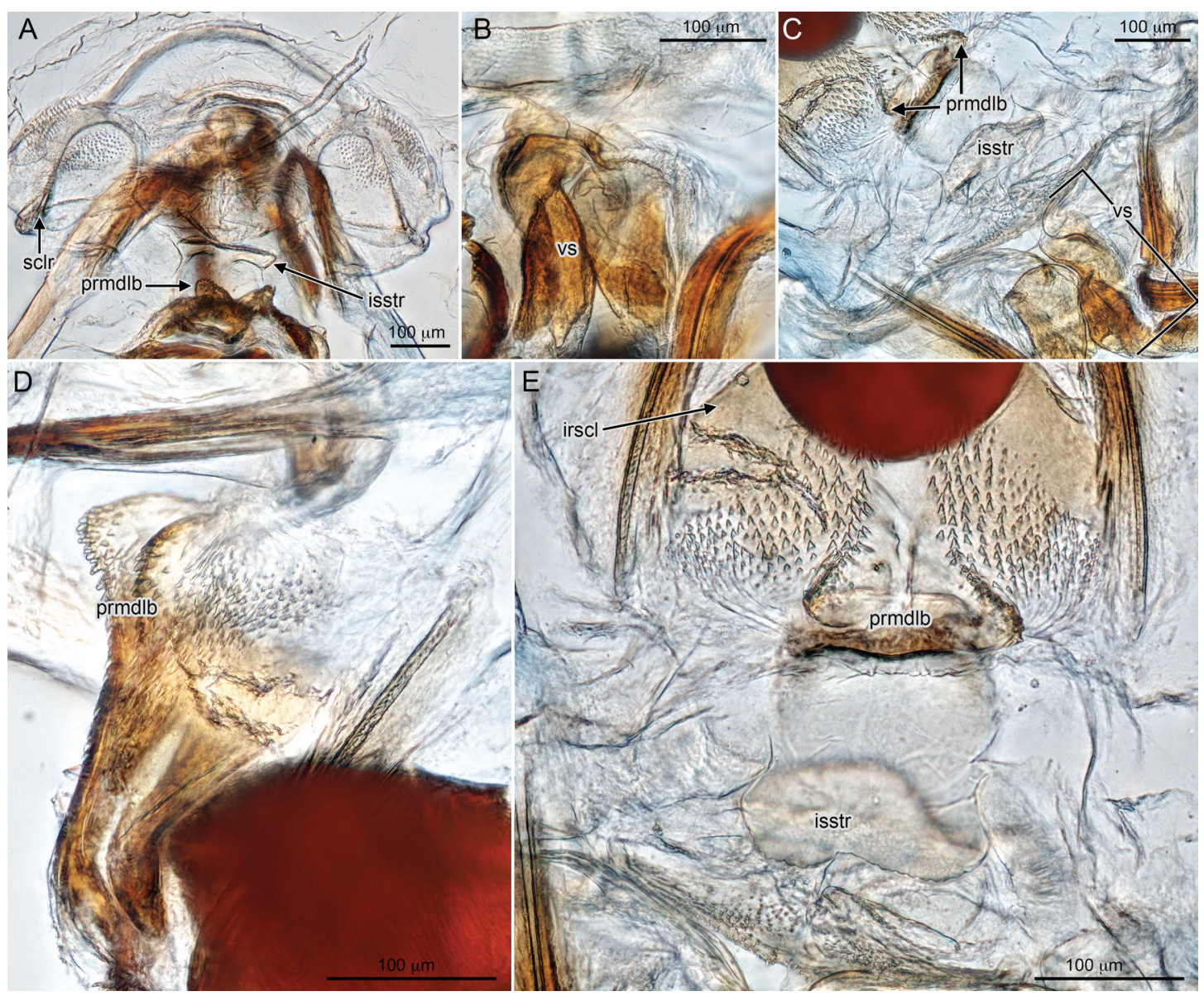

PLATE 31. Scholtzicoris linnavuorii. Digital genitalic images. Female, AMNH_PBI 00414777. A. Bursa copulatrix, dorsal view. B. Vestibular sclerites, anterior view. C. Genital chamber, ventral view. D. Posterior wall, left lateral view. E. Posterior wall and intersegmental process, anteroventral view.

PLATE 30. Melaleucacoris glomeratae. Digital genitalic images. Male, AMNH_PBI 00097916. A, B: Endosoma. A. Left lateral view. B. Right lateral view. C, D: Phallotheca. C. Anterior view. D. Posterior view. E, F: Left paramere. E. Anterior view. F. Dorsal view. G. Right paramere, lateral view. Female. H, I: Bursa copulatrix. H. Dorsal view. I. Ventral view. J. Vestibular sclerites, ventral view. K. Genital chamber, ventral view. L. Bursa copulatrix and vestibular sclerites, right lateral view. M. Posterior wall, anterior view. AMNH_PBI 00097814: K. AMNH_PBI 00097923: J, M. AMNH_PBI 00097927: H, I, L. 


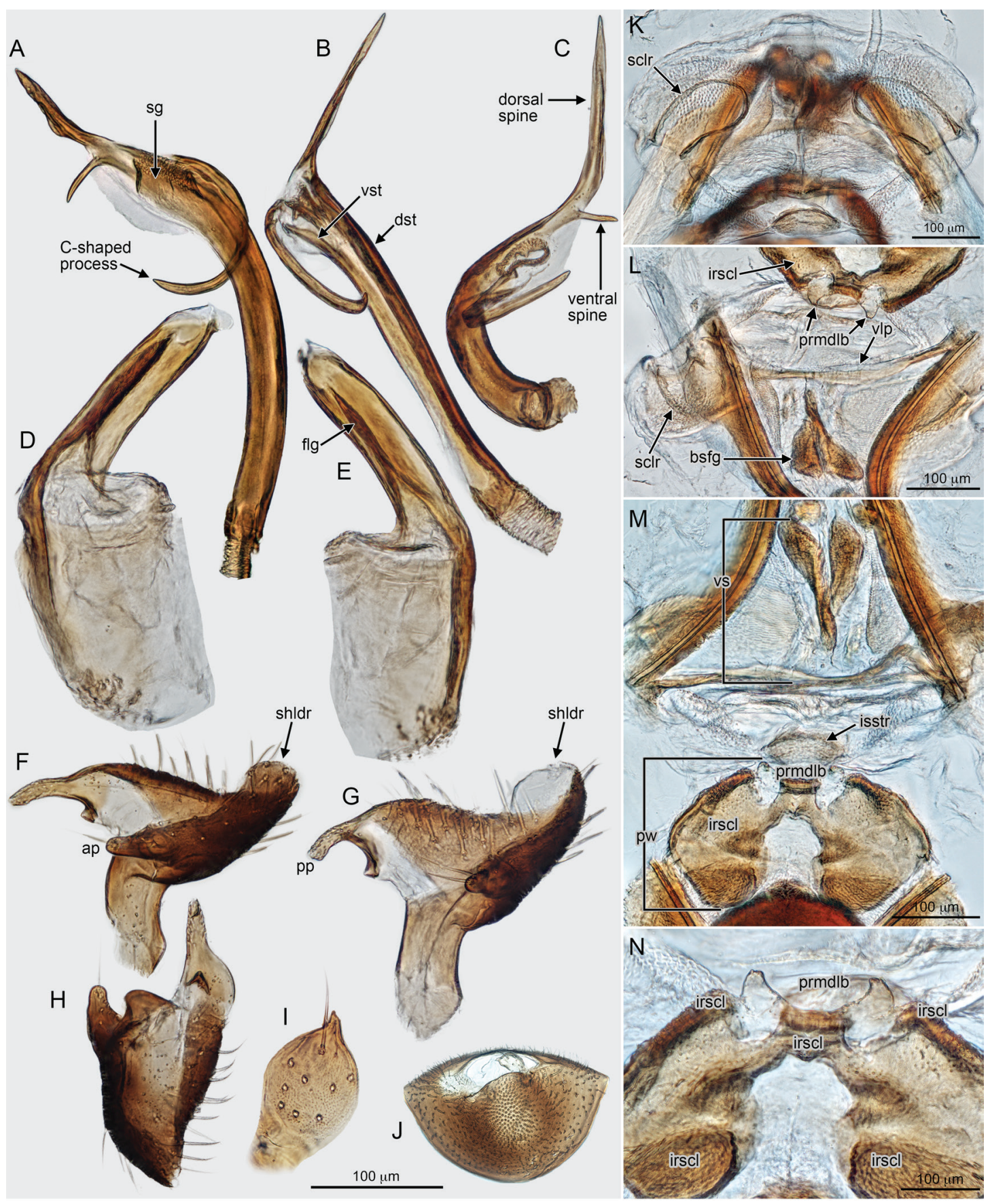

PLATE 32. Teddus katrinae. Digital genitalic images. Male. A-C: Endosoma. A. Left lateral view. B. Dorsal view. C. Caudal view. D, E: Phallotheca. D. Anterior view. E. Posterior view. F-H: Left paramere. F. Anterior view. G. Anteromedial view. H. Dorsal view. I. Right paramere, lateral view. J. Pygophore, caudal view. AMNH_PBI 00110762: D-J. AMNH_PBI 00274691: A-C. Female, AMNH_PBI 00110765. K. Bursa copulatrix, dorsal view. L. Vestibular sclerites, anterior view. M. Genital chamber, anteroventral view. N. Posterior wall, anterior view. 

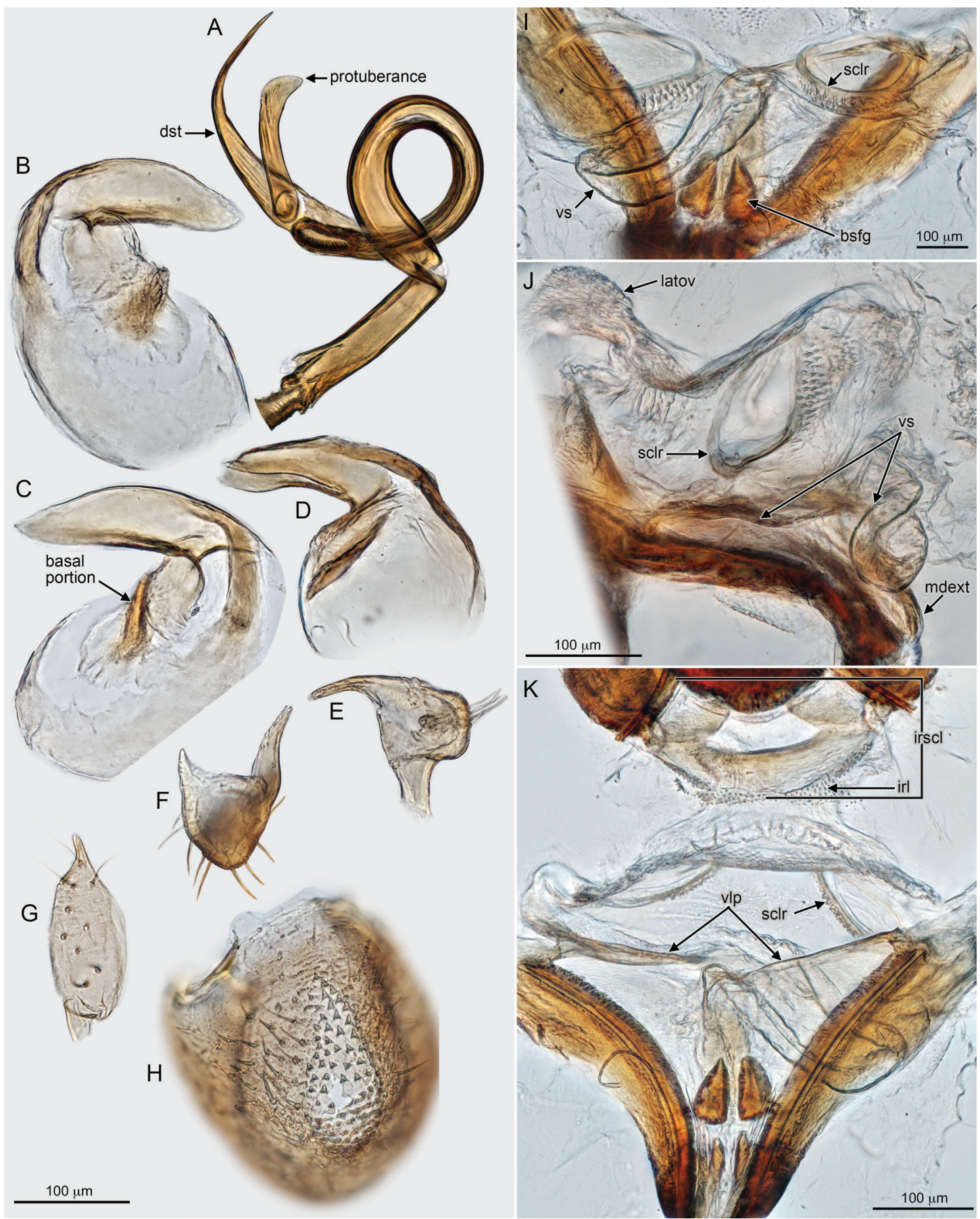

PLATE 33. Xiphoidellus eucalyptae. Digital genitalic images. Male, AMNH_PBI 00274802. A. Endosoma. B-D: Phallotheca. B. Anterior view. C. Posterior view. D. Ventral view. E, F: Left paramere. E. Anterior view. F. Dorsal view. G. Right paramere, lateral view. H. Pygophore, caudal view. Female, AMNH_PBI 00274800. I, J. Bursa copulatrix. I. Dorsal view. J. Right, lateral view. K. Genital chamber, anteroventral view. 

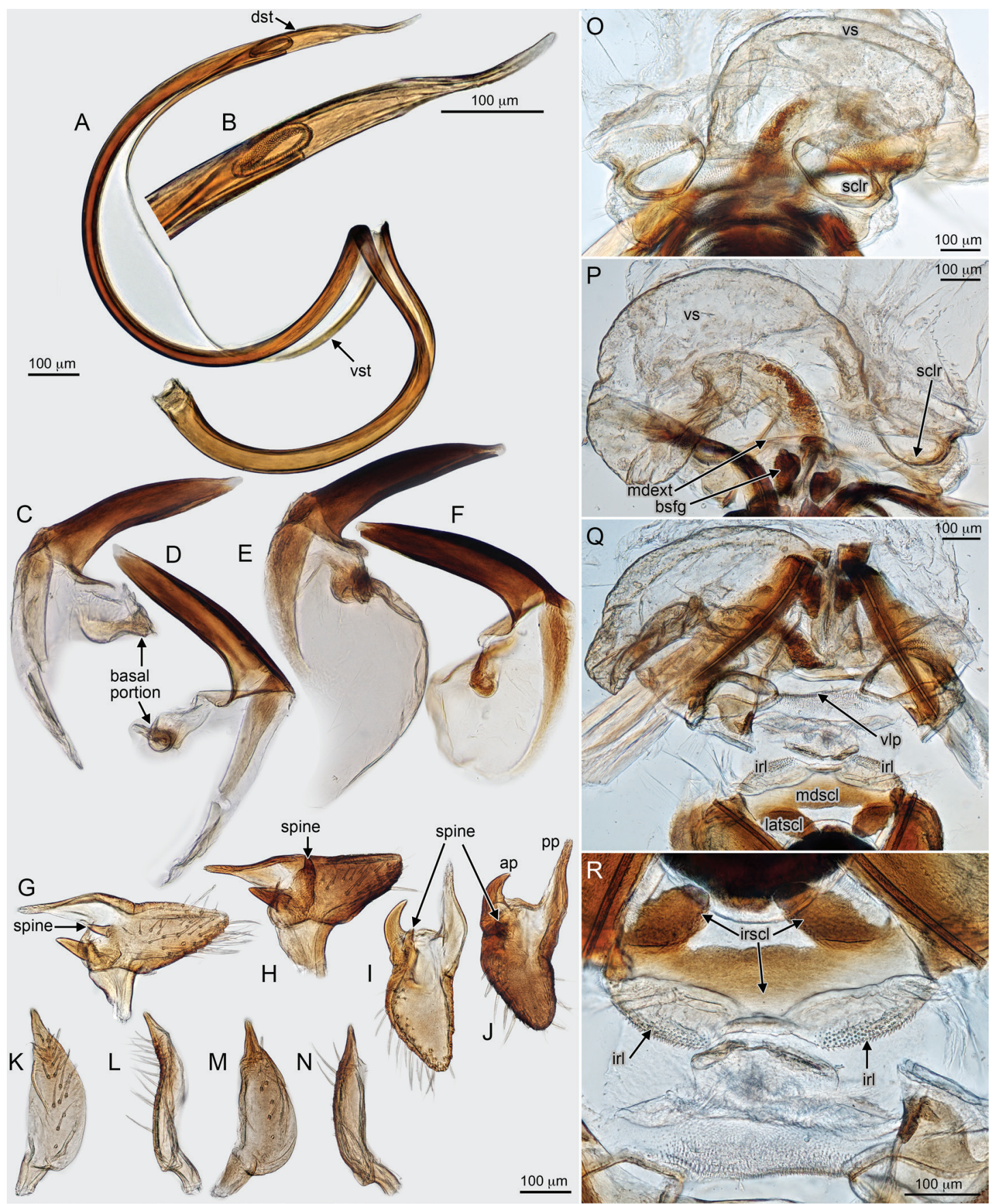

PLATE 34. Xiphoides anangu. Digital genitalic images. Male. A, B. Endosoma. A. Left lateral view. B. Detail of secondary gonopore and apical spine. C-F. Phallotheca. C, E. Anterior view. D, F. Posterior view. G-J. Left paramere. G, H. Anterior view. I, J. Dorsal view. K-N. Right paramere. K, L. Lateral view. M, N. Dorsal view. AMNH_PBI 00110766: A-D, G, I, K, M. AMNH_PBI 00110767: E, F, H, J, L, N. Female, AMNH_PBI 00110769. O, P. Bursa copulatrix. O. Dorsal view. P. Ventral view. Q, R. Genital chamber, anteroventral view. Q. Vestibular sclerites. R. Detail of posterior wall. 

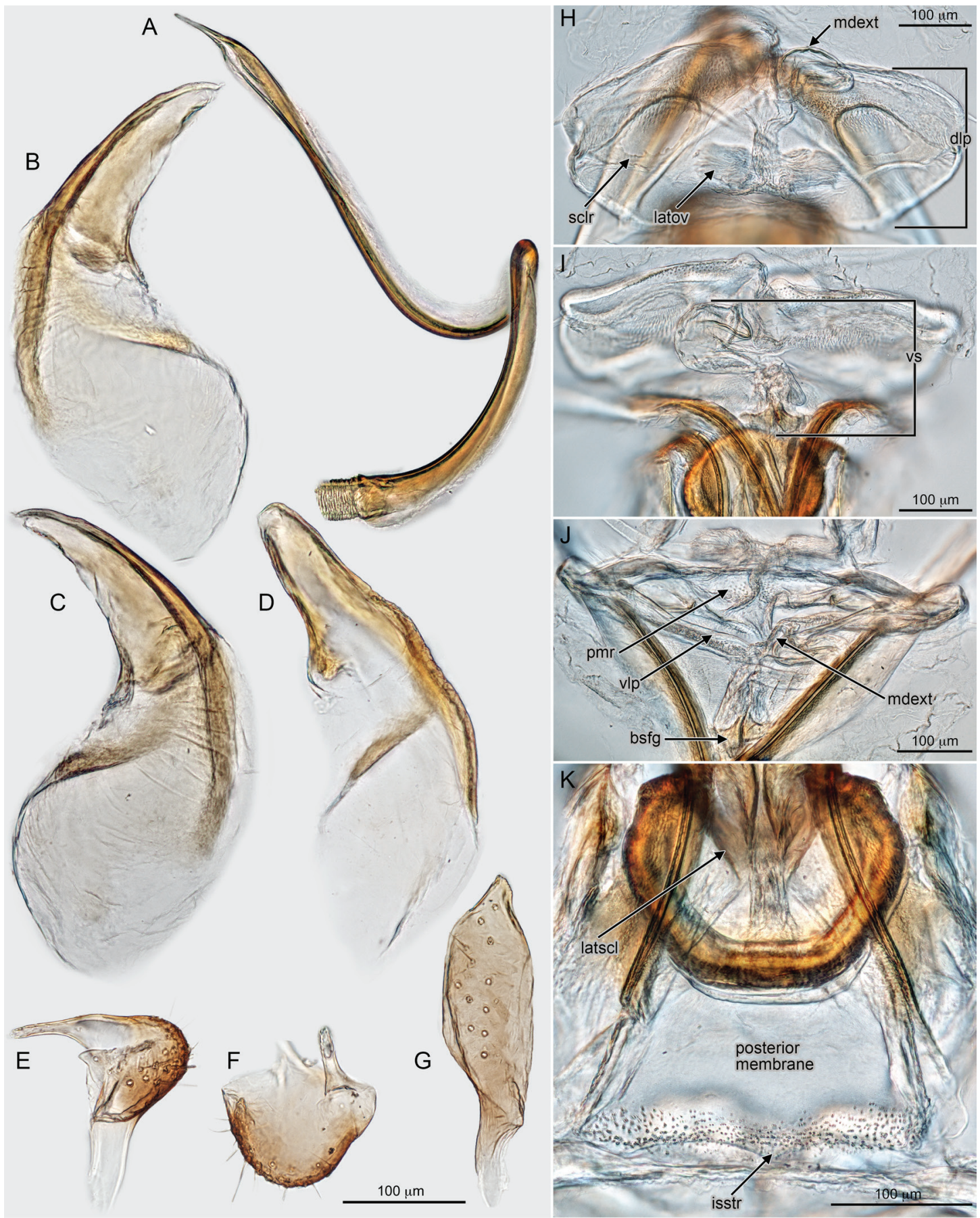

PLATE 35. Xiphoides tasmanensis. Digital genitalic images. Male, AMNH_PBI 00414858. A. Endosoma. B-D: Phallotheca. B. Anterior view. C. Posterior view. D. Ventral view. E, F: Left paramere. E. Anterior view. F. Dorsal view. G. Right paramere, lateral view. Female, AMNH_PBI 00414856. H, I. Bursa copulatrix. H. Dorsal view. I. Ventral view. J, K. Genital chamber. J. Anterior view. K. Detail of posterior wall, anteroventral view. 


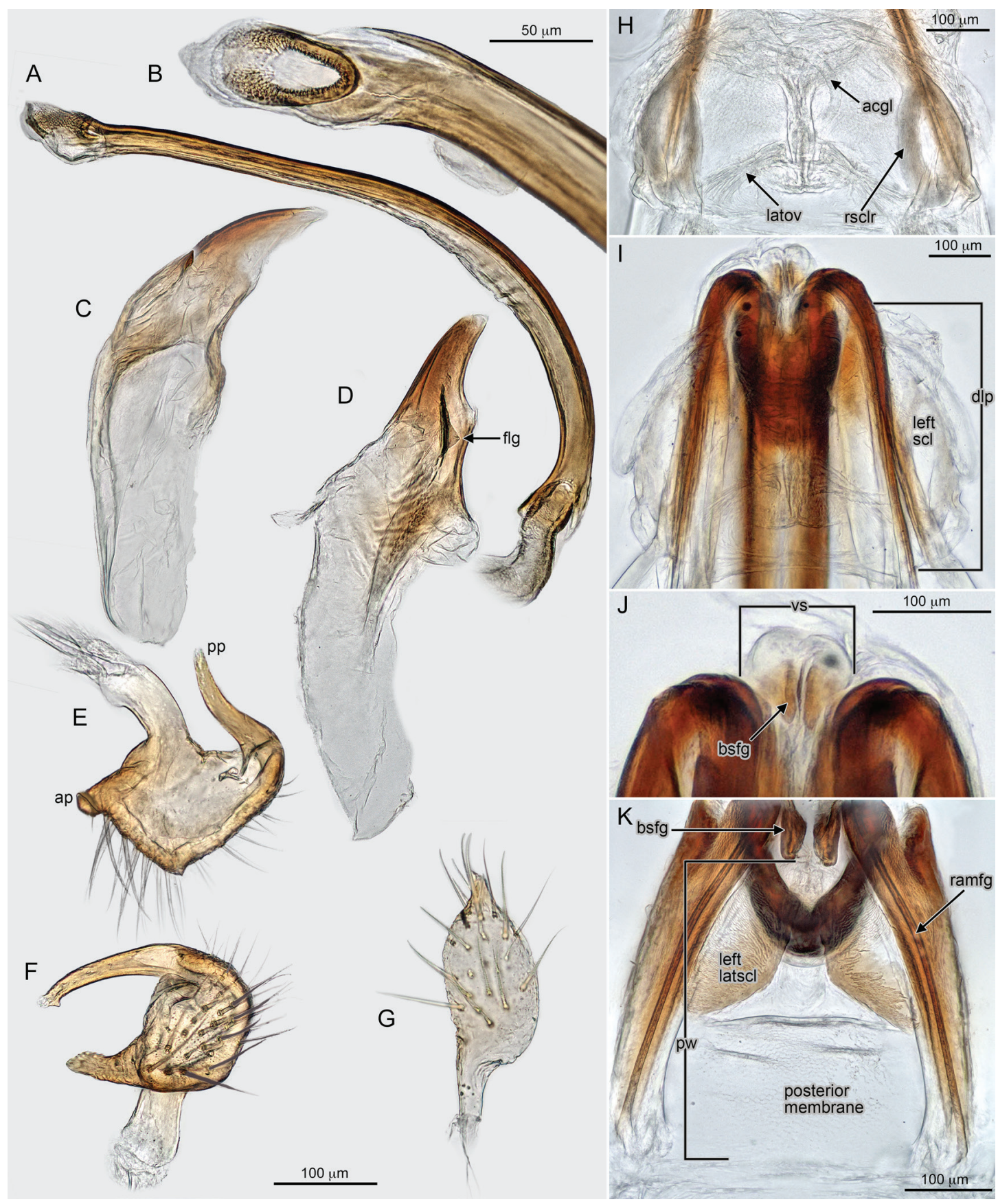

PLATE 36. Restiophylus orientalis. Digital genitalic images. Male, AMNH_PBI 00132197. A. Endosoma, left lateral view. B. Detail of secondary gonopore, ventral view. C, D: Phallotheca. C. Anterior view. D. Posterior view. E, F: Left paramere. E. Anterior view. F. Dorsal view. G. Right paramere, lateral view. Female, AMNH_ PBI 00132205. H, I: Bursa copulatrix. H. Dorsal view. I. Ventral view. J. Vestibular sclerites, ventral view. K. Posterior wall, anterior view. 

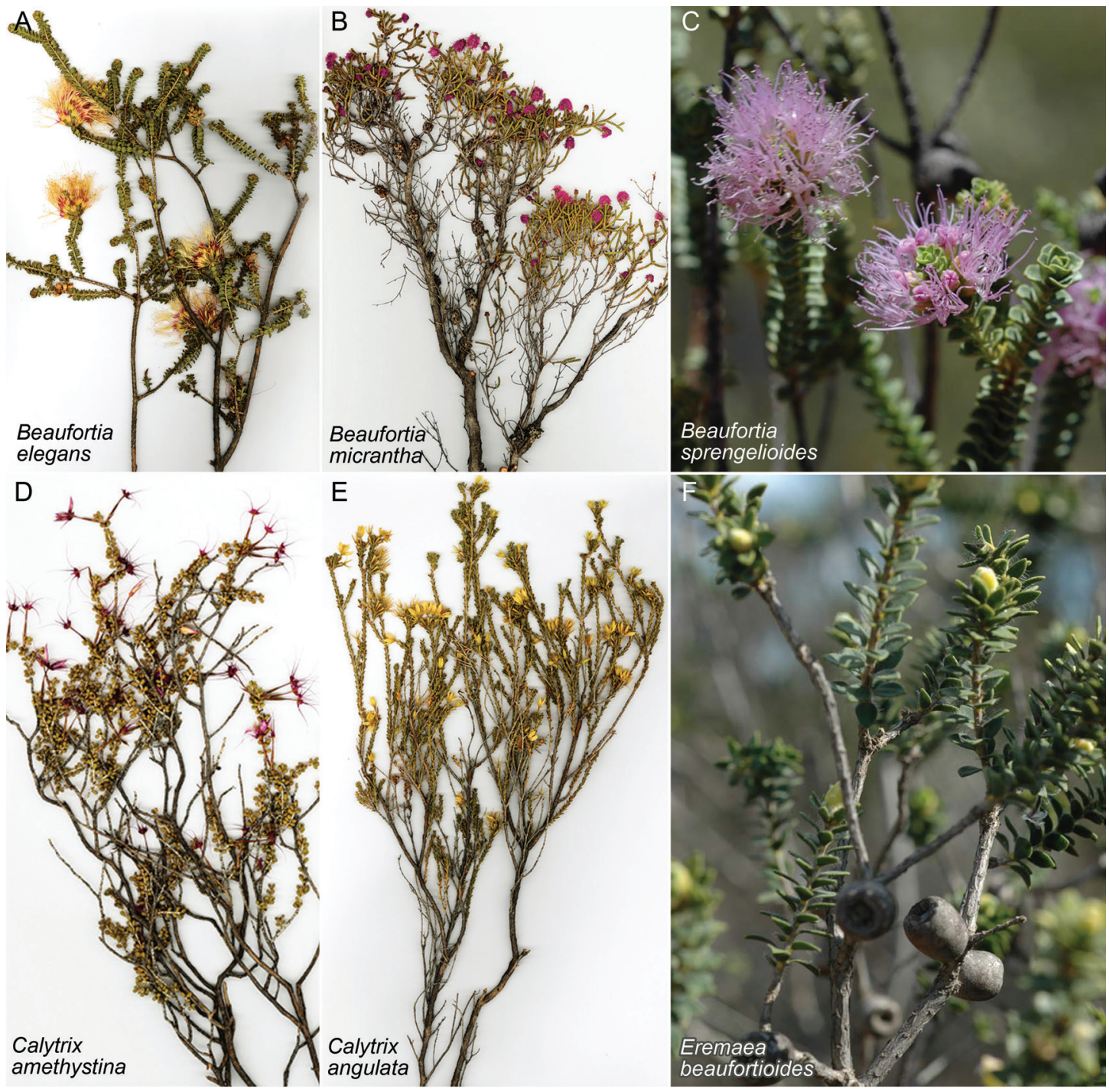

PLATE 37. Myrtaceae hosts of Phylinae spp. A. Beaufortia elegans: WA: Kalbarri National Park, Z-Bend Road. B. Beaufortia micrantha: WA: Fitzgerald River National Park, Hammersley Road. C. Beaufortia sprengelioides: WA: Useless Loop Rd ca. $20 \mathrm{~km} \mathrm{~W}$ of jct with Shark Bay Rd. D. Calytrix amethystina: WA: $28 \mathrm{~km}$ S of Menzies (3.5 km E of Hiway). E. Calytrix angulata: WA: $28 \mathrm{~km} \mathrm{~S}$ of Menzies (3.5 km E of Hiway). F. Eremaea beaufortioides: WA: $11 \mathrm{~km}$ S of Eneabba on Brand Hiway, Eneabba Reserve. 


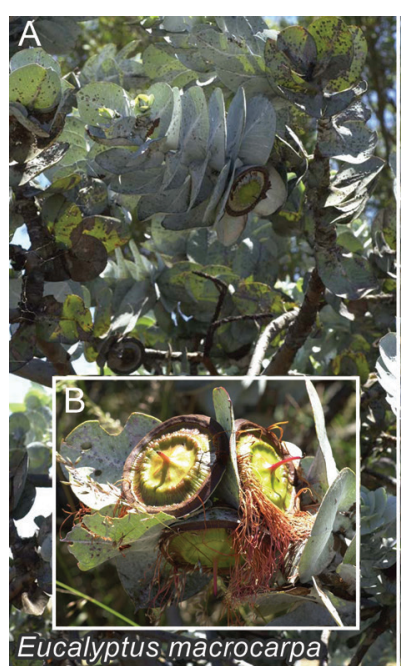

$\mathrm{F}$

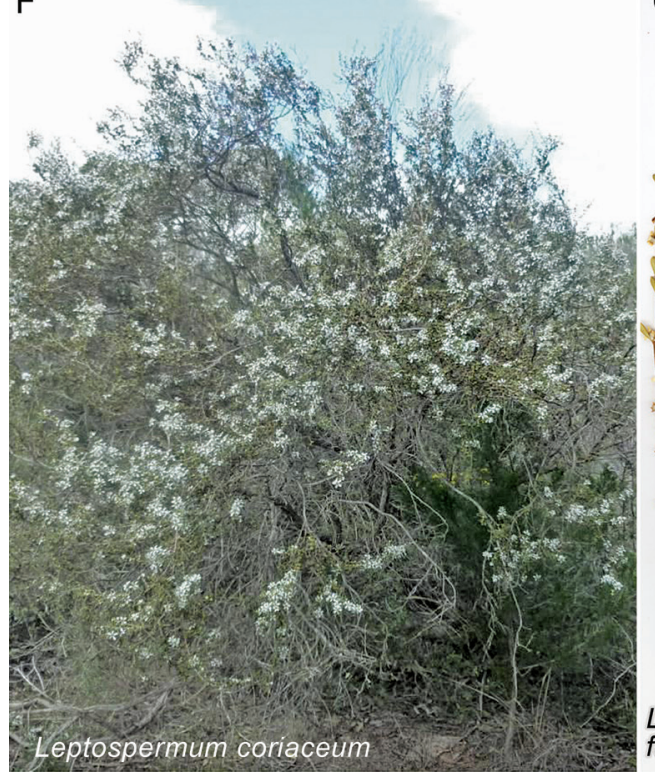

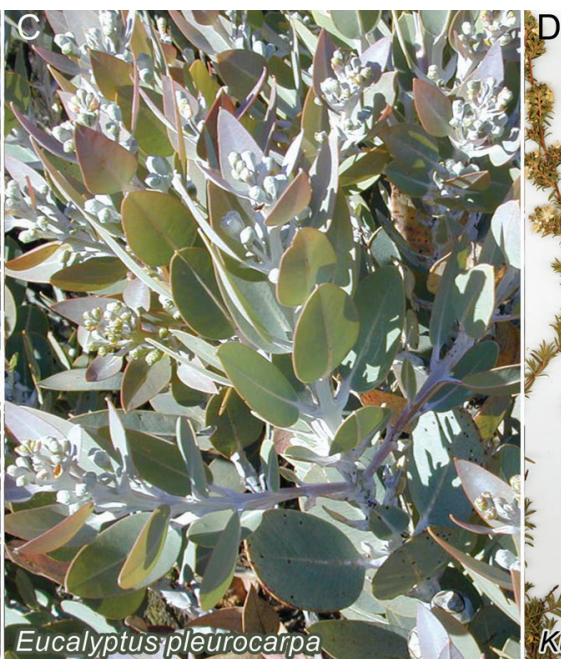

$\mathrm{G}$

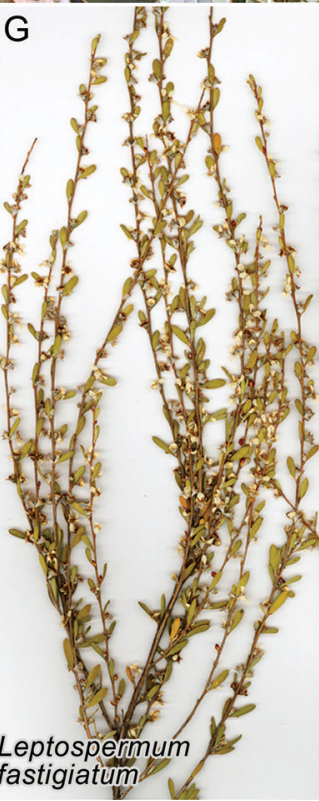

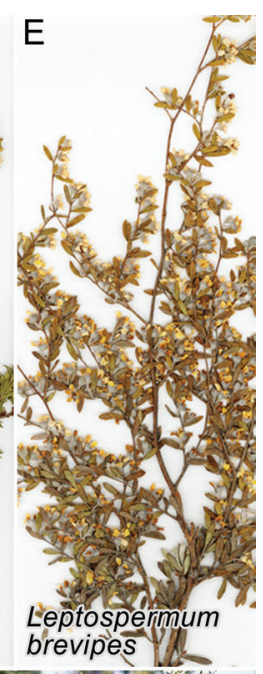

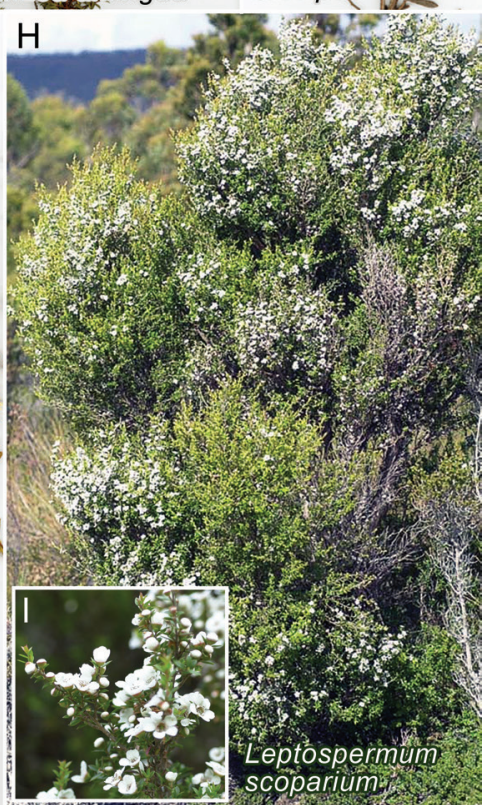

PLATE 38. Myrtaceae hosts of Phylinae spp. A. Eucalyptus macrocarpa subsp. elachanta: WA: Brand Hiway $18.8 \mathrm{~km} \mathrm{~S}$ of jct with Cervantes Rd. B. Detail of flower and fruit: same locality. C. Eucalyptus pleurocarpa: WA: $39 \mathrm{~km}$ E of Lake King. D. Kunzea ambigua: NSW: $65 \mathrm{~km}$ N of Sydney on Pacific Hiway. E. Leptospermum brevipes: NSW: $20 \mathrm{~km}$ E of Retreat (W. of Uralla). F. Leptospermum coriaceum: SA: Eyre Peninsula, photo c/o South Australia Seed Conservation Centre. G. Leptospermum fastigiatum: WA: $28 \mathrm{~km} \mathrm{~S}$ of Menzies (3.5 km E of Hiway). H. Leptospermum scoparium: TAS: $3.6 \mathrm{~km}$ NE of Southwest National Park (Maydena access): Gordon River Rd. I. Detail of flowers: TAS: Mt. Wellington, the Springs. 



6 halmaturorum
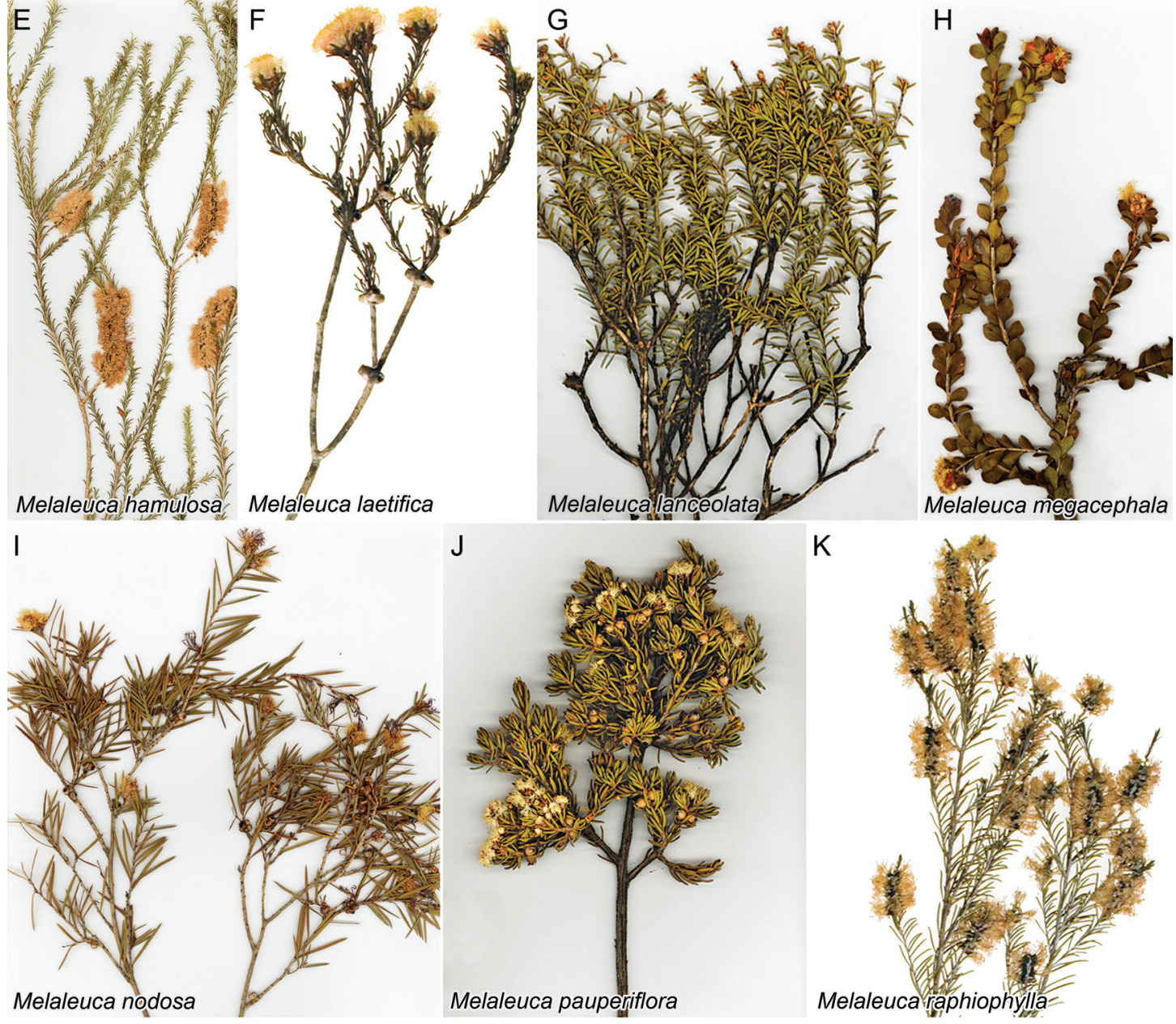

PLATE 39. Myrtaceae hosts of Phylinae spp. A. Melaleuca brevifolia: WA: $4.2 \mathrm{~km}$ SE of Esperance, Lake Mullet Nature Reserve. B. Melaleuca glomerata: NT: Finke Gorge National Park, Palm Valley. C. Melaleuca halmaturorum: VIC: Jeparit Environmental Park. D. Detail of flowers: same locality. E. Melaleuca hamulosa: WA: Lake Magenta Road, 4 km N of South Coast Hiway. F. Melaleuca laetifica: WA: Kalbarri National Park, 37.7 km E Kalbarri. G. Melaleuca lanceolata: VIC: Nullabor National Park on Eyre Hiway. H. Melaleuca megacephala: WA: Kalbarri National Park, Loop Road. I. Melaleuca nodosa: NSW: Myall Lakes National Park, 10.3 km S Seal Rocks Rd on Hawks Nest Rd. J. Melaleuca pauperiflora: WA: Frank Hann National Park, Lillian Stoke Rock. K. Melaleuca rhaphiophylla: WA: Brand Hiway $8.2 \mathrm{~km} \mathrm{~N}$ of Eneabba. 

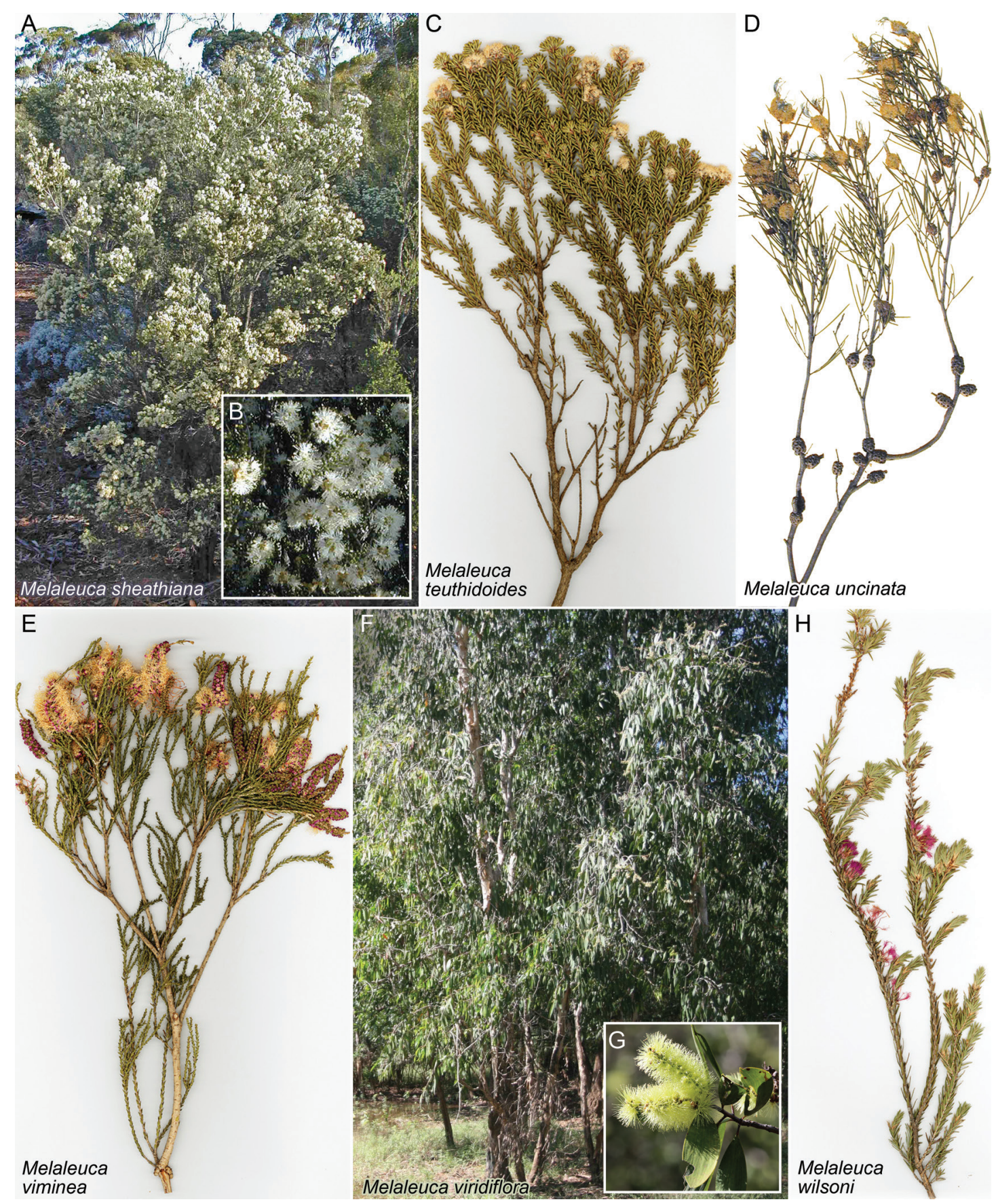

PLATE 40. Myrtaceae hosts of Phylinae spp. A. Melaleuca sheathiana: WA: $11 \mathrm{~km} \mathrm{~N}$ of Coolgardie-Esperance Hiway on Kambalda Road. C. Melaleuca teuthidoides: $91.4 \mathrm{~km}$ SE of Southern Cross. D. Melaleuca uncinata: WA: $56.6 \mathrm{~km} \mathrm{~W}$ of Yalgoo. E. Melaleuca viminea: WA: Cervantes. F. Melaleuca viridiflora: NT: Fish River Station, Site B3. G. Detail of flowers: QLD: Davies Creek National Park, photo c/o Summerdrought. H. Melaleuca wilsonii: VIC: Little Desert National Park, 5-6 km W of McDonald Hiway. 


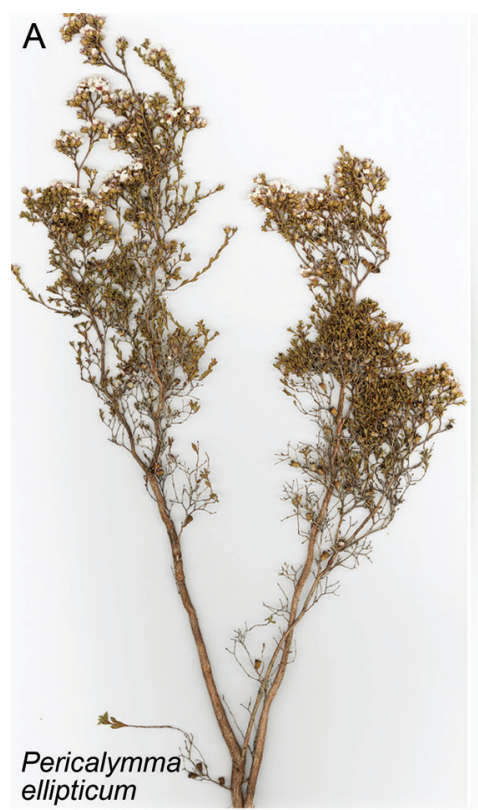

B

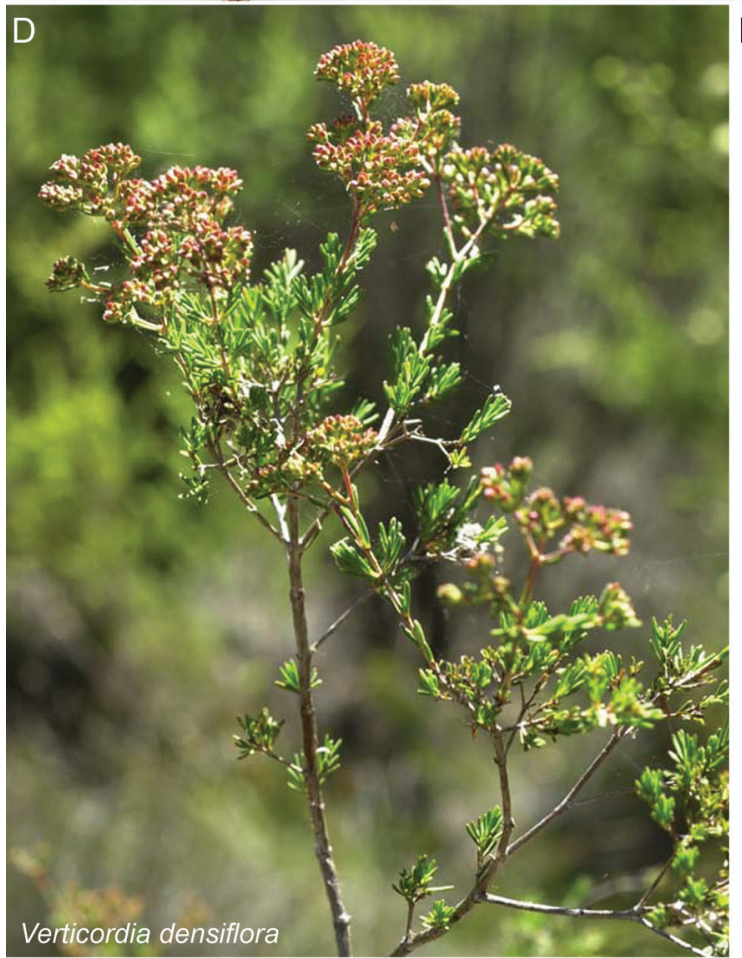

Phymatocarpus porphyrocephalus

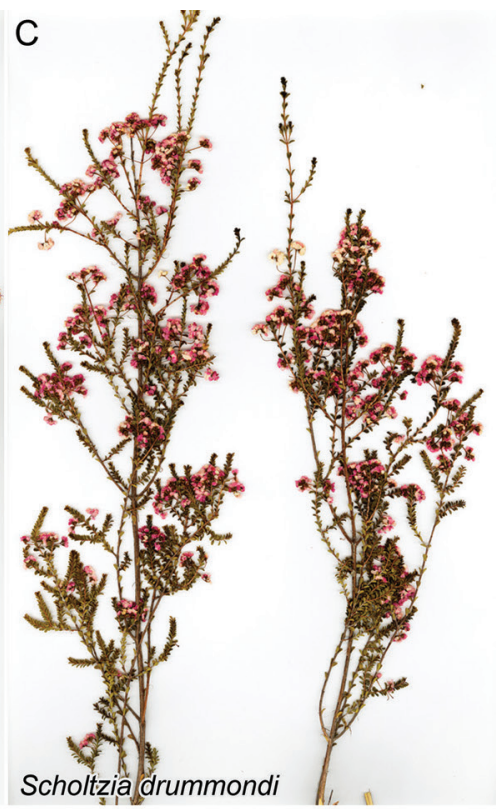

E

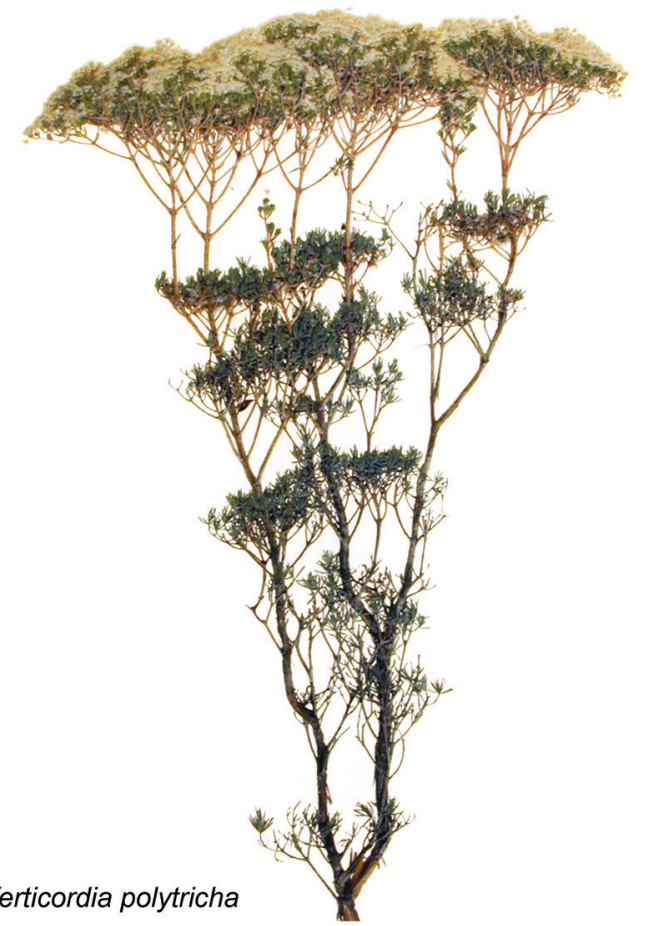

PLATE 41. Myrtaceae hosts of Phylinae spp. A. Pericalymma ellipticum: WA: $17 \mathrm{~km} \mathrm{~N}$ of Albany, Simpson Road at Chester Pass Hiway. B. Phymatocarpus porphyrocephalus: WA: Kalbarri National Park, Loop Road. C. Scholtzia drummondii: WA: Brand Hiway, $55.9 \mathrm{~km}$ S of Dongarra Road. D. Verticordia densiflora: $5 \mathrm{~km} \mathrm{~N}$ of Badgingerra. E. Verticordia polytricha: WA: Kalbarri National Park, Loop Road. 


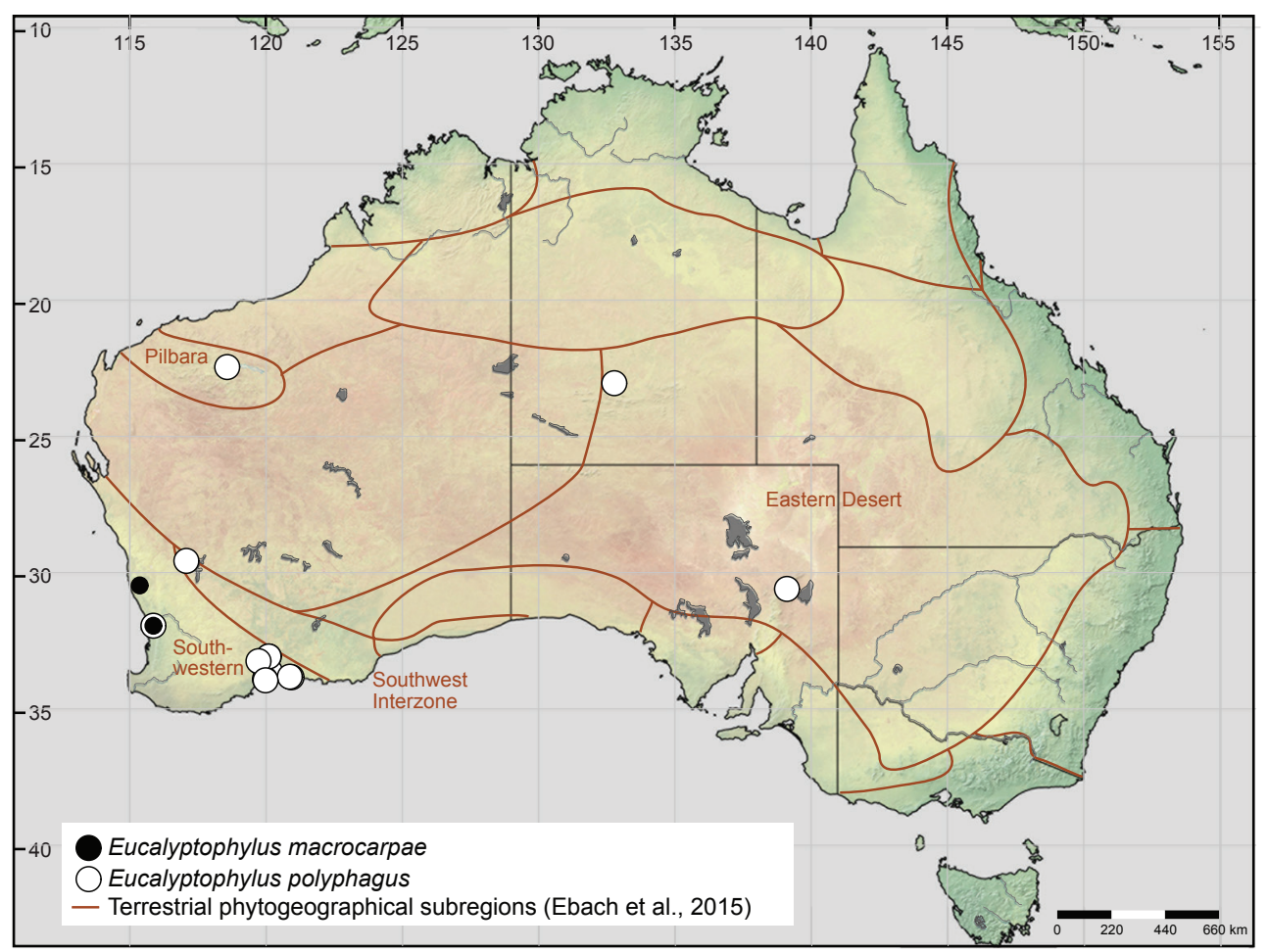

MAP 1. Distribution of Eucalyptophylus spp. 


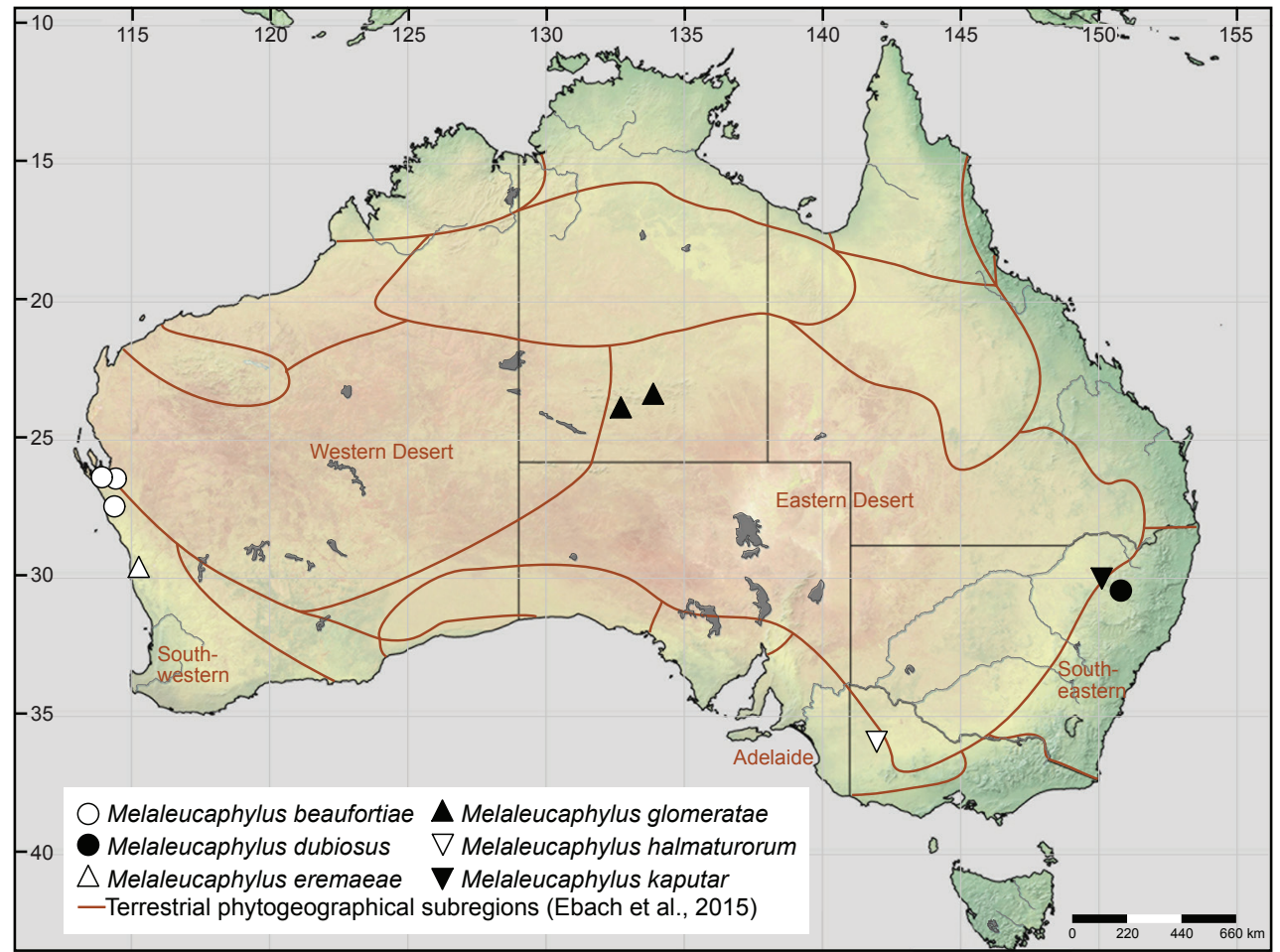

MAP 2. Distribution of Melaleucaphylus beaufortiae-M. kaputar. 


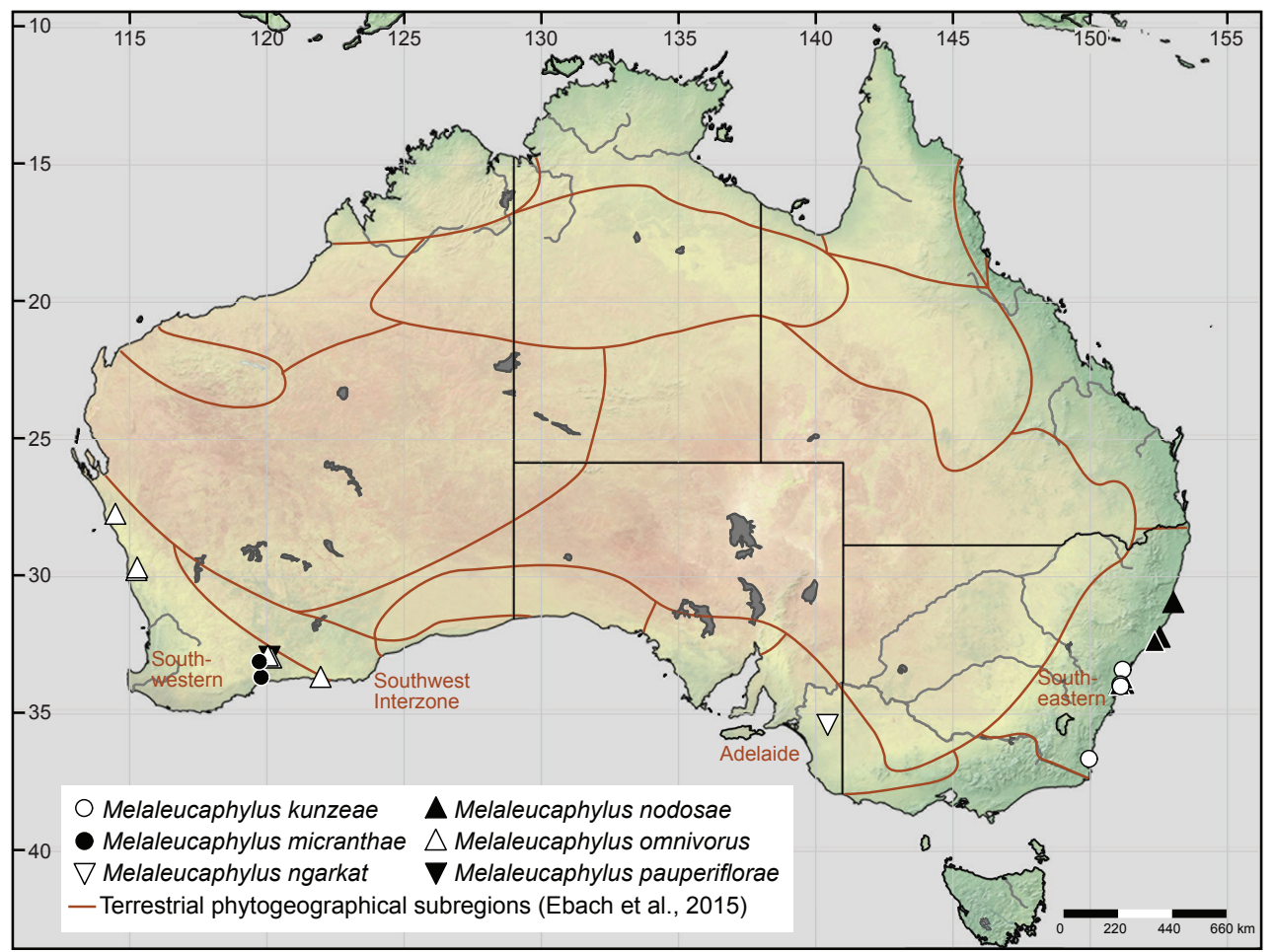

MAP 3. Distribution of Melaleucaphylus kunzeae-M. pauperiflorae. 


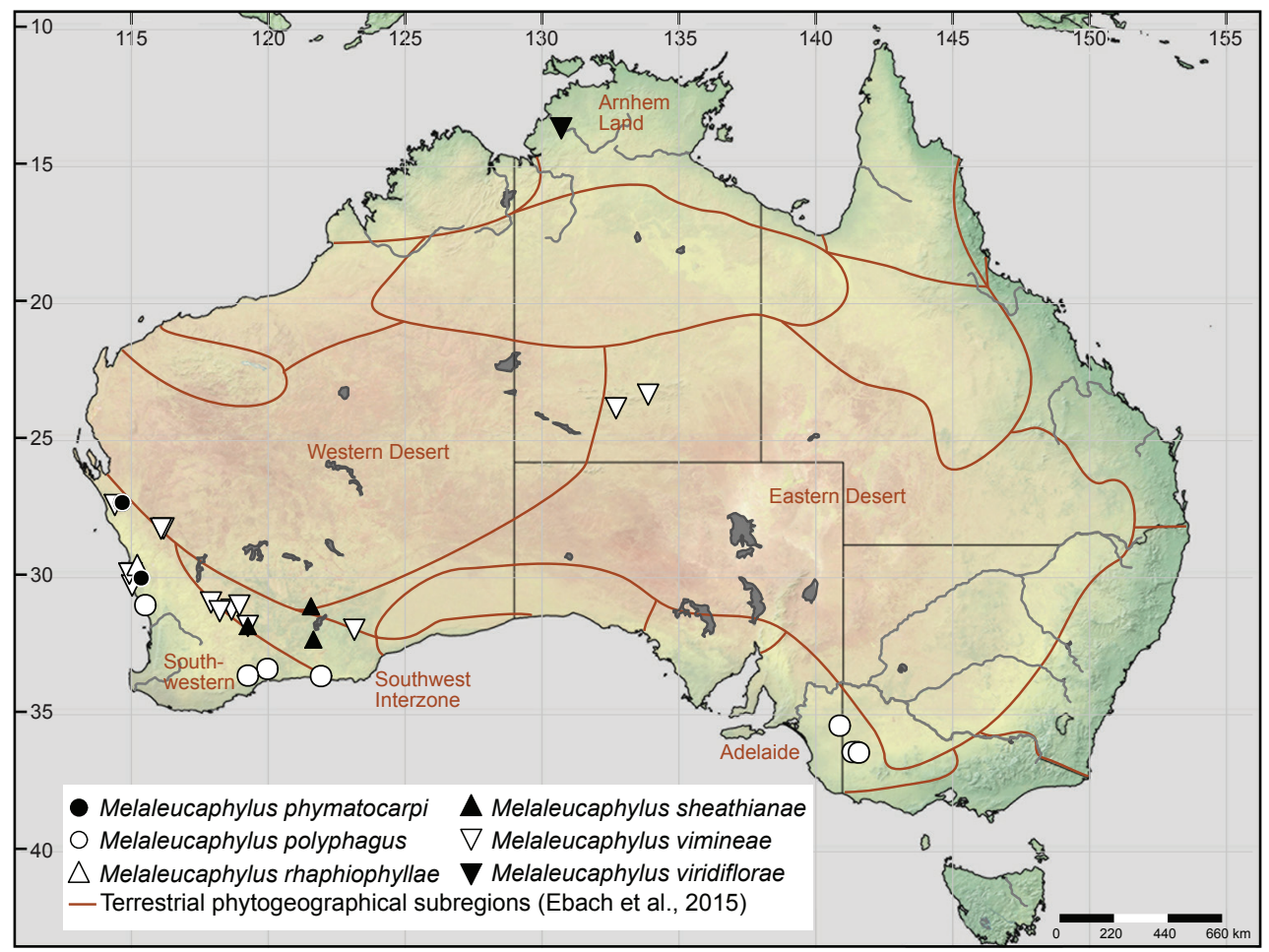

MAP 4. Distribution of Melaleucaphylus phymatocarpi-M. viridiflorae. 


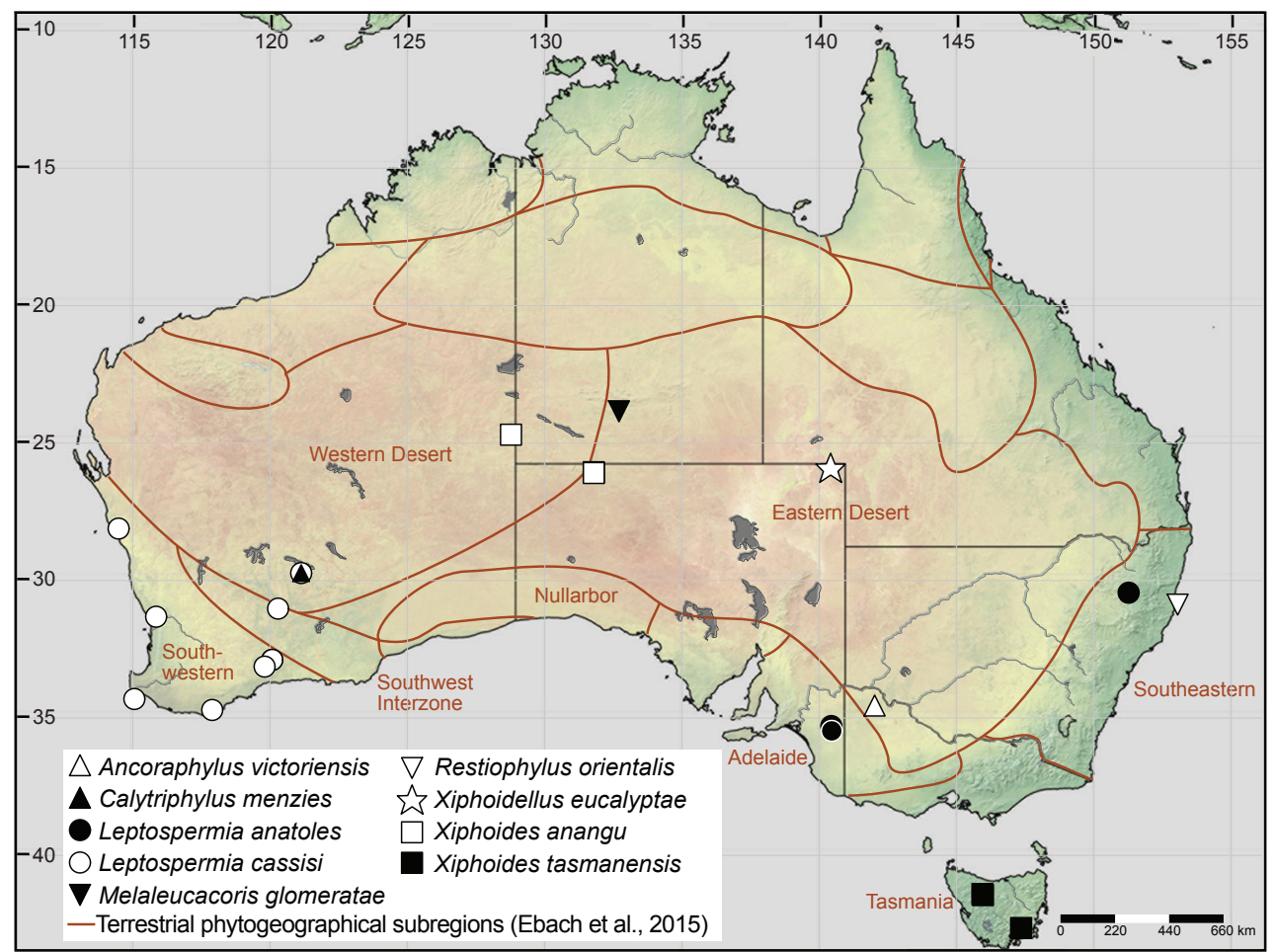

MAP 5. Distribution of Ancoraphylus victoriensis, Calytriphylus menzies, Leptospermia spp., Melaleucacoris glomeratae, Restiophylus orientalis, Xiphoidellus eucalyptae, and Xiphoides spp. 


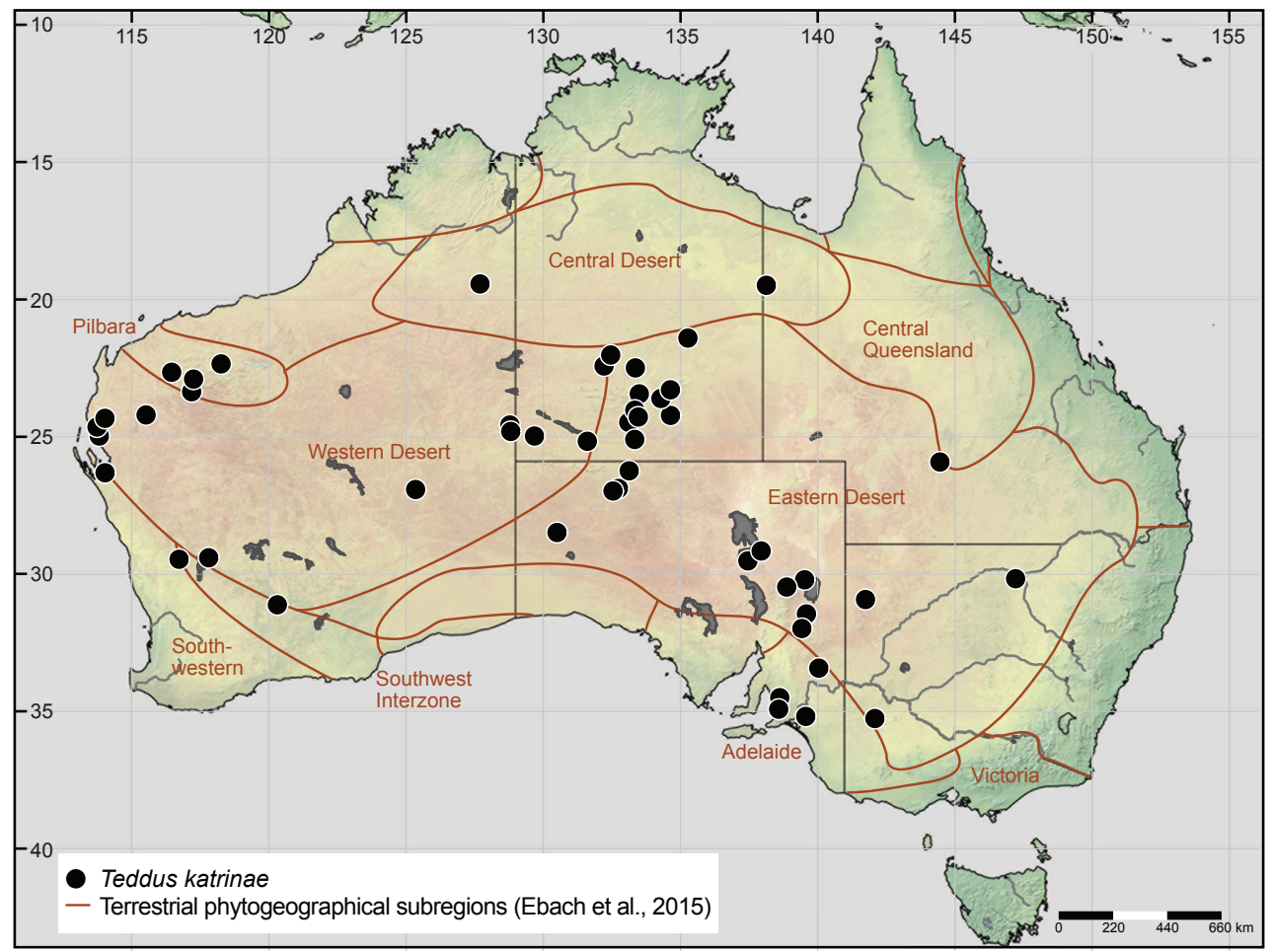

MAP 6. Distribution of Teddus katrinae. 





\title{
Scientific Publications of the American Museum of Natural History
}

AMERICAN MUSEUM NOVITATES

Bulletin of the American Museum of Natural history

Anthropological Papers of the American Museum of Natural History

\author{
Publications Committee \\ ROBERT S. VOSS, CHAIR \\ BOARD OF EDITORS \\ Jin Meng, Paleontology \\ LORENZO PRENDINI, INVERTEBRATE ZOOLOGY \\ Robert S. Voss, Vertebrate Zoology \\ Peter M. Whiteley, Anthropology \\ MANAGING EDITOR \\ MARY KNIGHT
}

Submission procedures can be found at http://research.amnh.org/scipubs

All issues of Novitates and Bulletin are available on the web (http://digitallibrary.amnh.

org/dspace). Order printed copies on the web from:

http://shop.amnh.org/a701/shop-by-category/books/scientific-publications.html

or via standard mail from:

American Museum of Natural History—Scientific Publications

Central Park West at 79th Street

New York, NY 10024

(@) This paper meets the requirements of ANSI/NISO Z39.48-1992 (permanence of paper).

ON THE COVER: (CLOCKWise FROM TOP) Floral LANDSCAPE 3.5 km E of Lillian Stoke Rock, Washington, male MelaleucacoRIS GLOMERATAE, ENDOSOMA OF EUCALYPTOPHYLUS MACROCARPAE, Vestibular sCLERItes of MELALEUCAPHYLUS NODOSAE, AND MALE E. MACROCARPAE. 